\title{
Understanding Selected Critical Corrosion and Electrochemical Factors for the Improvement of Sacrificial Mg-Based Anodes for the Cathodic Protection of an Mg-Al-Zn Alloy
}

A Dissertation
Presented to
the Faculty of the School of Engineering and Applied Science
University of Virginia
In Partial Fulfillment
Of the Requirements for the Degree of
Boctor of Philosophy in Materials Science and Engineering
Taylor W. Cain
November, 2017




\section{APPROVAL SHEET}

This dissertation

is submitted in partial fulfillment of the requirements

for the degree of

Doctor of Philosophy (Materials Science and Engineering)

Taylor W. Cain

(Author)

The Dissertation has been read and approved by the examining committee:

\begin{tabular}{c}
\hline John R. Scully \\
(Dissertation Advisor) \\
\hline $\begin{array}{c}\text { James M. Fitz-Gerald } \\
\text { (Dissertation Chairman) }\end{array}$ \\
\hline $\begin{array}{c}\text { Sean R. Agnew } \\
\text { (Committee Member) }\end{array}$ \\
\hline $\begin{array}{c}\text { Gary M Koenig } \\
\text { (Committee Member) }\end{array}$ \\
\hline $\begin{array}{c}\text { Nick Birbilis } \\
\text { (Committee Member) }\end{array}$
\end{tabular}

Accepted for the School of Engineering and Applied Science:

Craig H. Benson, Dean, School of Engineering and Applied Science November, 2017 


\section{Understanding Selected Critical Corrosion and Electrochemical Factors for the Improvement of Sacrificial Mg-Based Anodes for the Cathodic Protection of an Mg-Al-Zn Alloy}

\section{i. Abstract}

Research on magnesium (Mg) alloys has become widely popular in recent times for use in structures as a lightweight substitutional metal, as an anode material for batteries and fuel cells, as well as biodegradable implants amongst other applications. While research on $\mathrm{Mg}$ alloys has never been greater, the broader use of $\mathrm{Mg}$ has been limited in part by its poor intrinsic corrosion resistance and insufficient protection strategies which currently consist of primarily barrier type coatings.

The overall goal of this research is to produce a multifunctional metallic coating for $\mathrm{Mg}$ alloys which will act as (1) a corrosion barrier, (2) provide sacrificial anodic based cathodic protection in the event of a scratch or defect in the coating, and (3) provide ionic inhibitor release from the coating to heal the scratch. An ideal coating for this application must possess a low intrinsic corrosion rate, be able to supply a large amount of cathodic polarization to the metal to be protected, be non-polarizable to resist detrimental positive changes in galvanic couple potential, and contain a reservoir of inhibiting ions for storage and environmentally triggered release. Achieving a Mg-based coating with these characteristics is difficult primarily due to the limited number of alloying elements which can produce a negative electrochemical potential with respect to the substrate, manifestation of the negative difference effect (NDE) and anodically enhanced cathodic kinetics which complicate an understanding of the $\mathrm{Mg}$ corrosion mechanisms with respect to traditional electrochemical theory, as well as the limited number of elements which can provide inhibition of $\mathrm{Mg}$ while maintaining an anodic corrosion potential. This dissertation seeks to 
provide an understanding of selected factors which predominantly govern the performance of $\mathrm{Mg}$ based anodes and how these factors can be manipulated to produce optimized cathodic protection of Mg alloys via a tunable alloy system.

As a first step, the range of cathodic potentials (i.e., the minimum level of cathodic polarization) necessary to achieve practical cathodic protection of Mg alloy AZ31B-H24 (Mg3Al-1Zn) was explored. Cathodic potentiostatic polarization of AZ31B-H24 was performed over a range of potentials in various environments and the AZ31B-H24 dissolution rate was characterized by gravimetric mass loss measurements and analysis of the dissolved species in solution via inductively coupled plasma optical emission spectroscopy (ICP-OES). The results indicate that a one order of magnitude or greater reduction in the dissolution rate by cathodic protection of AZ31B-H24 is difficult to achieve at cathodic overpotentials of less than $100 \mathrm{mV}$ below the open circuit potential (OCP). This was attributed to the persistence of self-corrosion of $\mathrm{Mg}$ alloys related to the negative difference effect. As such the origins and manifestation of the negative difference effect of $\mathrm{Mg}$ was explored for methods to minimize this detrimental effect which is an impediment to realization of cathodic protection.

The negative difference effect is distinguished by an anomalous increase in hydrogen evolution reaction (HER) rate with increasing anodic polarization. The NDE was studied by anodic potentiostatic polarization of high purity $\mathrm{Mg}$ in solutions of $0.6 \mathrm{M} \mathrm{NaCl}, 0.6 \mathrm{M} \mathrm{NaCl}$ saturated with $\mathrm{Mg}(\mathrm{OH})_{2}, 0.1 \mathrm{M} \mathrm{MgCl}_{2}, 0.1 \mathrm{M} \mathrm{Na}_{2} \mathrm{SO}_{4}$, and $0.1 \mathrm{M}$ TRIS. These solutions provide a wide range of electrolytes and $\mathrm{pH}$ to enable the study of dissolving $\mathrm{Mg}$ anodes under a range of conditions. The dissolution behavior was characterized by combined gravimetric mass loss measurements, hydrogen evolution gas capture, charge measured by the potentiostat, and solution analysis ICP-OES. The fate of $\mathrm{Mg}$ and other impurity elements was elucidated through 
characterization of elemental enrichment on dissolving Mg surfaces by Particle Induced X-ray Emission (PIXE) and Rutherford Backscattering Spectroscopy (RBS) while dissolution films were characterized by Raman spectroscopy. The results indicate that the NDE is a strong function of noble element enrichment and the nature and stability of the dissolution film which forms. Thus, alloying elements which can stabilize the dissolution film and decrease cathodic kinetics such as Sn should be explored for a sacrificial coating.

Next, the behavior of simulated sacrificial cathodic protection was performed by galvanic couple testing via zero resistance ammeter testing of AZ31B-H24 coupled to commercial Mg alloy WE43 $(\mathrm{Mg}-4 \mathrm{Y}-3 \mathrm{RE}, \mathrm{RE}=\mathrm{Nd}, \mathrm{La})$ and commercially pure Mg. The results were characterized by gravimetric mass loss measurements, the galvanic couple potential, galvanic couple current density, and enhanced cathodic kinetics. These studies revealed that the most effective sacrificial anode based protection of AZ31B-H24 was achieved with WE43 which was attributed to this alloy being able to resist anodically enhanced cathodic kinetics and its lower fraction of self-corrosion during galvanic corrosion relative to $\mathrm{CP} \mathrm{Mg}$ coupled to AZ31B-H24. This validated the conclusions of the first task. With this knowledge, the choice of alloying elements for production of a tunable sacrificial coating was explored.

$\mathrm{La}^{3+}$ and $\mathrm{Gd}^{3+}$ were investigated to inhibit corrosion of AZ31B-H24 through simulated release from a coating enabled by seeding solutions with $\mathrm{LaCl}_{3}$ or $\mathrm{GdCl}_{3}$. These elements possess corrosion potentials at or below that of high purity Mg which suggests that they may be able to provide and sustain a negative corrosion potential with respect to AZ31B-H24 when these elements are alloyed with $\mathrm{Mg}$. The concentration of $\mathrm{La}$ and $\mathrm{Gd}$ inhibitor ions were varied between $10^{-4} \mathrm{M}$ to $0.2 \mathrm{M}$ while maintaining a total $\left[\mathrm{Cl}^{-}\right]$of $0.6 \mathrm{M}$ via compounding additions of $\mathrm{NaCl}$. The results characterized by gravimetric mass loss indicate that almost a $2 \mathrm{x}$ decrease in corrosion 
occurred when the inhibitor ion concentration was below $10^{-2} \mathrm{M}$ but the corrosion rate increased rapidly at with increasing inhibitor ion concentration at or beyond this level. Furthermore, both the anodic and cathodic kinetics increased as a function of inhibitor ion concentration which suggests a limited concentration of inhibitor in $\mathrm{Mg}$ would be beneficial to corrosion resistance. The dissolution trajectory of dissolving $\mathrm{Mg}$ as a function of $\mathrm{pH}$ was accurately calculated using a novel method to produce and analyze chemical stability diagrams. These analyses were successful in providing a scientific explanation for the solution inhibitor concentration effect.

The final chapter of this dissertation investigated the effect of Sn concentration of solid solution $\mathrm{Mg}-\mathrm{Sn}$ alloys on the intrinsic corrosion resistance and sacrificial cathodic protection of AZ31B-H24. The corrosion resistance of Mg-Sn alloys was demonstrated to increase with increasing Sn concentration due to reductions of the hydrogen evolution reaction (HER) rate on the dissolving Mg surface which is speculated to occur via the low exchange current density for HER of Sn and the enrichment of Sn on the dissolving Mg surface which reduces the fraction of sites available for fast HER. ZRA testing revealed more than an order of magnitude decrease in dissolution rate of AZ31B-H24 with Mg-Sn sacrificial anodes. The final ranking of new improved sacrificial anode materials compared to $\mathrm{CP} \mathrm{Mg}$ and WE43 follows the trend $\mathrm{Mg}-5 \mathrm{Sn}>\mathrm{Mg}-1 \mathrm{Sn}>$ Mg-10Sn > WE43 > CP Mg where Mg-5Sn produced the lowest dissolution rate and greatest degree of protection of AZ31B-H24 when galvanically coupled. This is attributed to the low intrinsic corrosion rate of $\mathrm{Mg}-\mathrm{Sn}$ alloys and the reduced cathodic reaction rate on the $\mathrm{Mg}-\mathrm{Sn}$ alloys surface.

The synthesis of the dissertation has provided, for the first time, a framework for improving sacrificial anode based cathodic protection of Mg alloys based on a comprehensive understanding of selected critical factors which govern the behavior of $\mathrm{Mg}$ corrosion. Furthermore, the novel use 
of RBS and PIXE to analyze the composition of corroding Mg surfaces was successful and presents an opportunity for implementation in the field of corrosion research. Technologically, a new coating alloy concept for sacrificial anodic protection of a commercial Mg alloy was identified. 


\section{ii. Acknowledgments}

First and foremost, I would like to thank my advisor Prof. John R. Scully for his guidance and professional advices. I have gained valuable and irreplaceable knowledge that I will carry with me throughout my career. I would also like to thank my committee members Prof. James M FitzGerald, Prof. Sean R. Agnew, Prof. Gary M. Koenig, and especially Prof. Nick Birbilis who has provided much inspiration and valuable experiences over the years.

I would like to thank all those in the MSE department and within CESE who have made this journey enjoyable. I would particularly like to thank Prof. Gary Shiflet, Mike M., Mike H., Jay, RJ, Ian, Andrew, and Sam for helpful research discussions and collaborations in the lab. I would also like to thank Rob, Ryan, Chris, Derek, Rebecca, Balaji, Veronica, Katie, Matt M., Leslie, Kat, Angela, Kate, Marybeth, Piyush, Lindsey, Matt S., Lucas, and Collin for their friendship over the years. Outside of UVA, I would like to thank Prof. Henry J. Rack and Dr. Herbert Boeckels for inspiring me to pursue a Ph.D.

Finally, I would like to thank my family for their never-ending support and Eleanor who helped make the last year wonderful. 


\section{iii. Publications}

The Publications that resulted/will result from this dissertation are listed below:

1. T. Cain, L.G. Bland, N. Birbilis, and J.R. Scully, "A Compilation of Corrosion Potentials for Magnesium Alloys," CORROSION, 2014. 70(10): p. 1043-1051.

2. T. Cain, S.B. Madden, N. Birbilis, and J.R. Scully, "Evidence of the Enrichment of Transition Metal Elements on Corroding Magnesium Surfaces Using Rutherford Backscattering Spectrometry," Journal of the Electrochemical Society 2015. 162(6): p. C228-C237.

3. T.W. Cain, M.A. Melia, J.M. Fitz-Gerald, and J.R. Scully, "Evaluation of the Potential Range for Sacrificial Mg Anodes for the Cathodic Protection of Mg Alloy AZ31B-H24," CORROSION, 2017. 73(5): p. 544-562.

4. T.W. Cain, I. Gonzalez-Afanador, N. Birbilis, and J.R. Scully, "The Role of Surface Films and Dissolution Products on the Negative Difference Effect for Magnesium: Comparison of $\mathrm{Cl}^{-}$versus $\mathrm{Cl}^{-}$Free Solutions," Journal of the Electrochemical Society 2017. 164(6): p. C300C311.

5. T.W. Cain, J.S. Laird, N. Birbilis, and J.R. Scully, "Investigation of the Enrichment of Dissolving Mg Anodes in Various Environments by Nuclear Microprobe Analysis," manuscript in progress.

6. T.W. Cain and J.R. Scully, "Development of Mg-Sn Based Anodes for the Improved Sacrificial Cathodic Protection of Mg-Al-Zn Alloy AZ31B-H24," manuscript in progress 


\section{iv. Table of Contents}

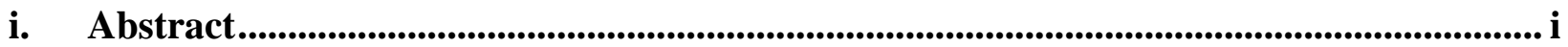

ii. Acknowledgments ................................................................................................................ vi

iii. Publications ........................................................................................................ vii

iv. Table of Contents ...................................................................................................... viii

v. List of Figures............................................................................................................................... xiii

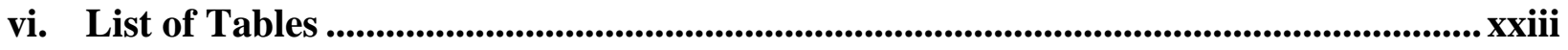

1. Introduction ................................................................................................................................. 1

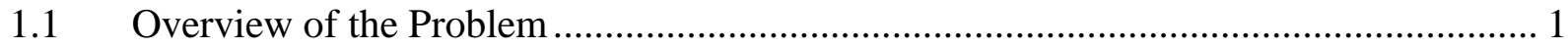

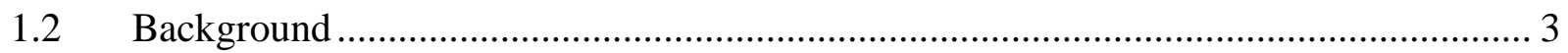

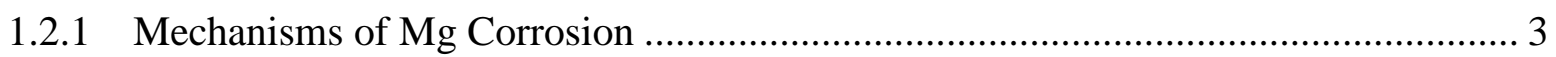

1.2.2 Thermodynamic Protection vs. Kinetic Prevention of $\mathrm{Mg}$........................................ 6

1.2.3 Principles of Sacrificial Cathodic Protection ........................................................... 7

1.2.3.1 Mixed Potential Theory of Galvanic Corrosion for Sacrificial Protection ......... 7

1.2.3.2 Criteria for Ideal Sacrificial Cathodic Protection .............................................. 9

1.2.3.3 Specification for Sacrificial Cathodic Protection of Mg Alloys ....................... 10

1.2.4 The Negative Difference Effect and Anodically Induced Cathodic Activation ....... 10

1.2.5 Potential for Sacrificial Cathodic Protection of Mg via Mg Alloy Coatings............ 16

1.2.5.1 Studies of Sacrificial Cathodic Protection of Mg to Date.................................. 16

1.2.5.2 Target Alloying Elements for Tunable Sacrificial Anodic Mg Coatings ......... 17

1.2.6 Critical Assessment of Current Protection Strategies ................................................ 21

1.2.7 Benefits of Multifunctional Electrochemically Tunable Alloys for Scratch Protection 23

$1.3 \quad$ Critical Unresolved Issues .................................................................................... 25

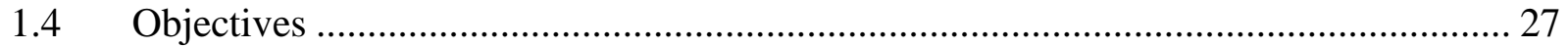

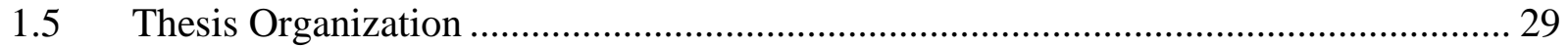

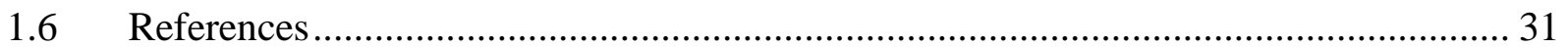

2. Range of Potentials for Kinetic Immunity of HP Mg and AZ31B-H24 ........................... 37

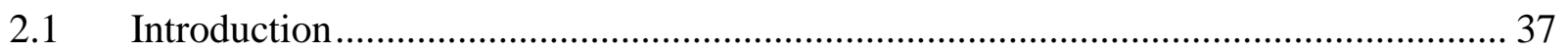

2.2 Experimental Procedures ………………………................................................... 38

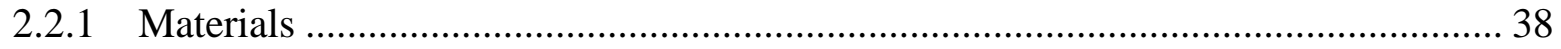

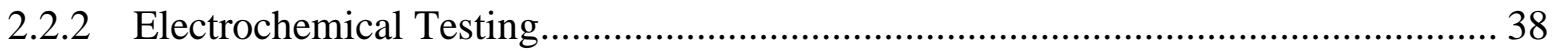


2.2.3 Inductively Coupled Plasma-Optical Emission Spectroscopy.................................. 40

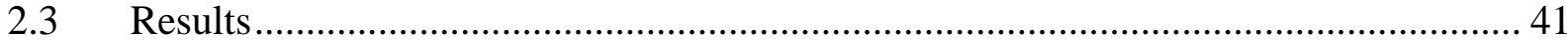

2.3.1 Mass Loss Measurements During Potentiostatic Polarization.................................... 41

2.3.2 Change in $\mathrm{pH}$ with Potentiostatic Polarization ...................................................... 46

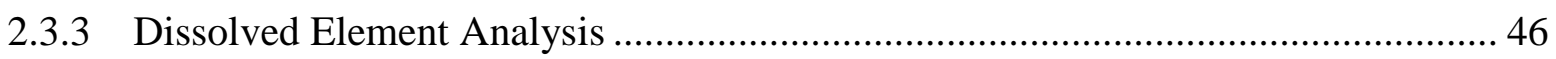

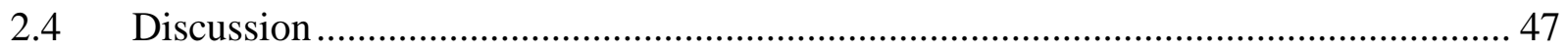

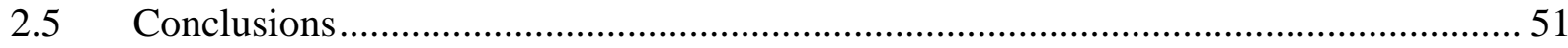

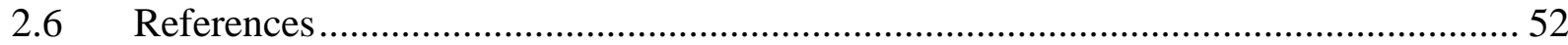

2.7 Appendix - Calculating IR corrected Anodic Tafel Slopes .......................................... 53

3. Factors Controlling the Enhanced Cathodic Activity of HP Mg: The Role of Dissolution Films and Impurity Enrichment .................................................................................. 57

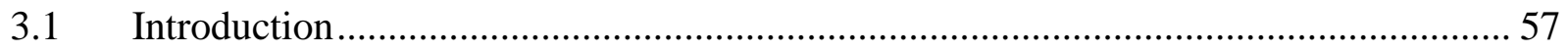

$3.2 \quad$ Experimental Procedures ………………………............................................... 58

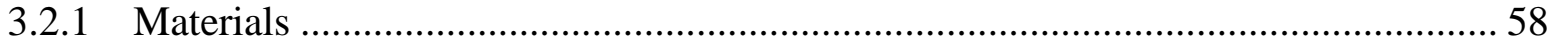

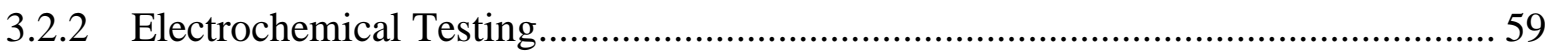

3.2.3 Inductively Coupled Plasma - Optical Emission Spectroscopy (ICP-OES) ............. 63

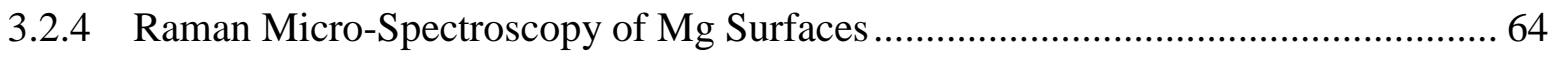

3.2.5 Rutherford Backscattering Spectroscopy Corroded Mg Surfaces ............................. 64

3.2.6 Micro Particle Induced X-ray Emission of Corroded Mg Surfaces........................... 66

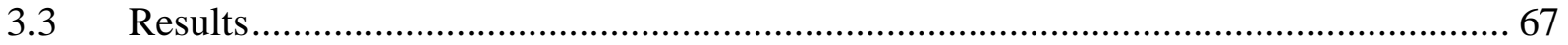

3.3.1 Anodic Potentiostatic Polarization of HP Mg............................................................ 67

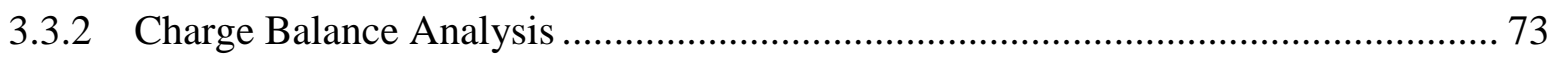

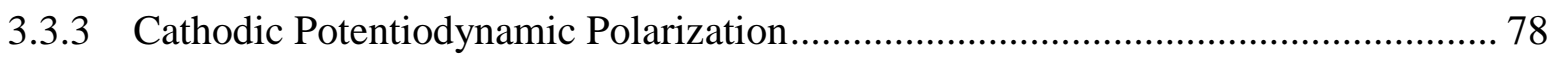

3.3.4 Inductively Coupled Plasma - Optical Emission Spectroscopy ............................... 79

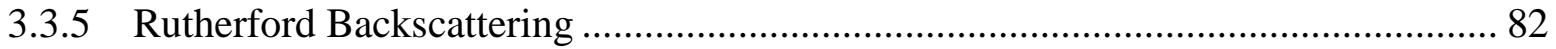

3.3.6 Micro Particle Induced X-ray Emission of Corroded Mg Surfaces .......................... 85

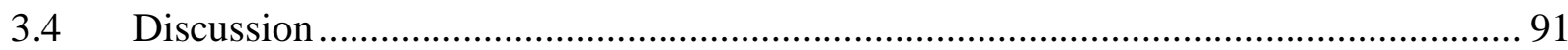

3.4.1 Role of Electrolyte and $\mathrm{Mg}(\mathrm{OH})_{2}$ Film Formation on the NDE............................. 91

3.4.2 Role of Impurities and Anodic Sites ....................................................................... 94

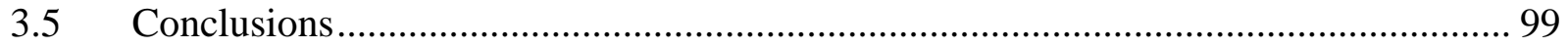

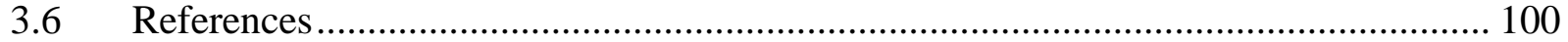

4. Evaluation of the Commercial Mg Alloy Anodes for Sacrificial Cathodic Protection of Mg Alloy AZ31B-H24 .................................................................................................................................. 102 


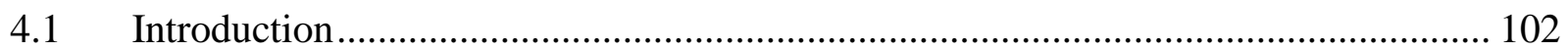

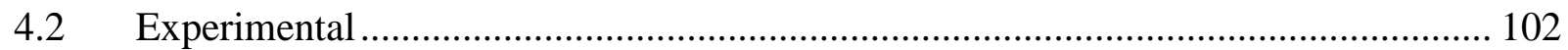

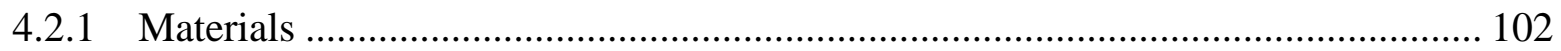

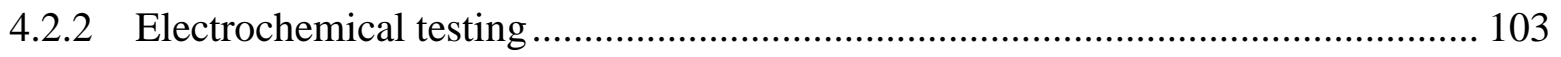

4.2.3 Optical and Scanning Electron Microscopy ………............................................ 104

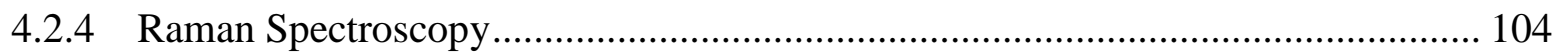

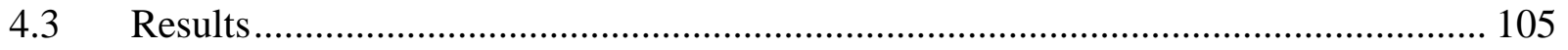

4.3.1 Evaluation of the Sacrificial Cathodic Protection of AZ31B-H24 with CP Mg and

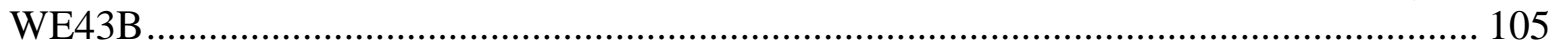

4.3.1.1 Potentiodynamic Polarization of AZ31B-H24, CP Mg, and WE43B ........... 105

4.3.1.2 ZRA tests of AZ31B-H24 to CP Mg and WE43B in 0.6 M NaCl ................ 105

4.3.1.3 ZRA tests of AZ31B-H24 to CP Mg and WE43B in $0.1 \mathrm{M} \mathrm{MgCl}_{2} \ldots \ldots \ldots \ldots . . . .108$

4.3.1.4 ZRA tests of AZ31B-H24 to CP Mg and WE43B in 0.1 M TRIS ................ 110

4.3.2 Evaluation of Anodically Induced Cathodic Activation ........................................... 112

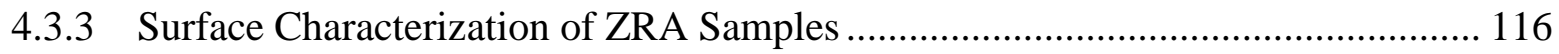

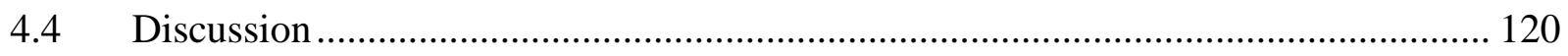

4.4.1 Range of Potentials for Sacrificial Cathodic Protection of AZ31B-H24 and Implications on Design of Sacrificial Mg-Based Alloys ................................................... 120

4.4.2 The Effects of Anodically Induced Cathodic Activation and Trends in ZRA

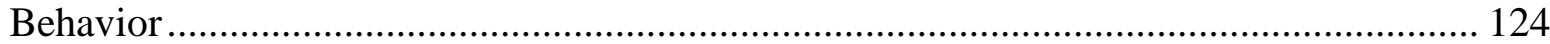

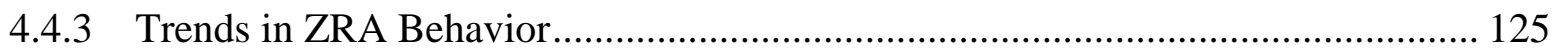

4.4.4 Effects of Polarity Reversal: Application to Laser Surface Modified AZ31B

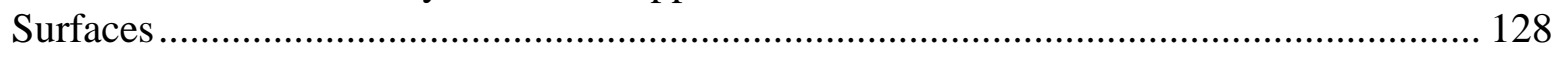

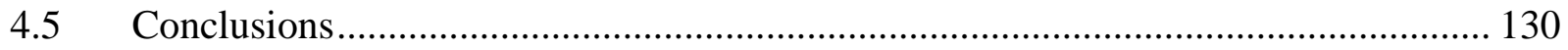

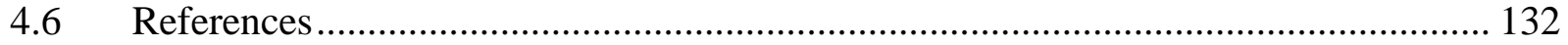

4.7 Appendix- List of Symbols Used for Galvanic Couples ......................................... 134

\section{Evaluation of Rare Earth Ions for the Inhibition of AZ31B in Chloride Environments 135}

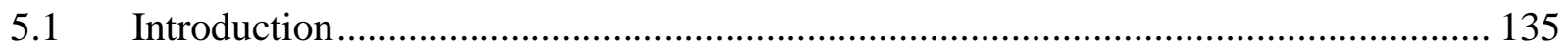

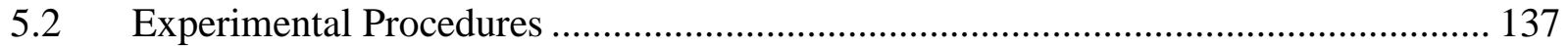

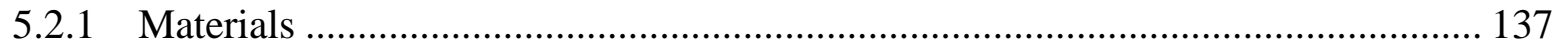

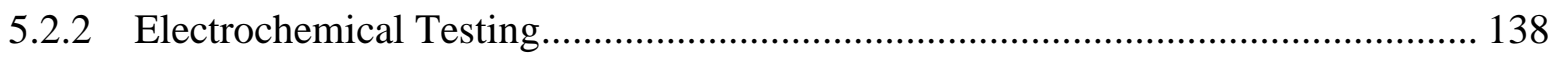

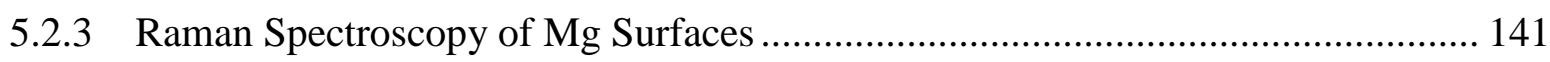

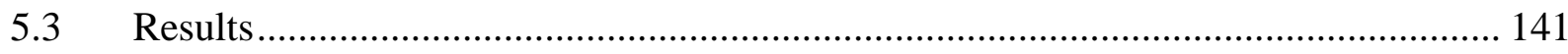




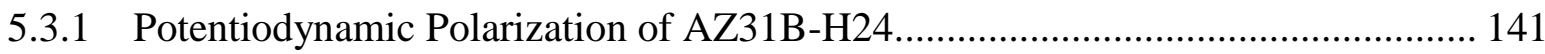

5.3.2 Gravimetric Mass Loss Measurements as a Function of $\mathrm{RE}^{3+}$ Concentration........ 146

5.3.3 Galvanostatic-Potentiostatic Cycle Testing .......................................................... 150

5.3.4 EIS Testing after Varying Anodic Galvanostatic Polarization .............................. 156

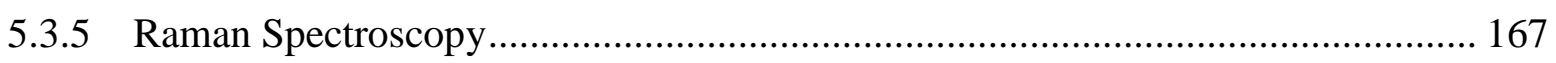

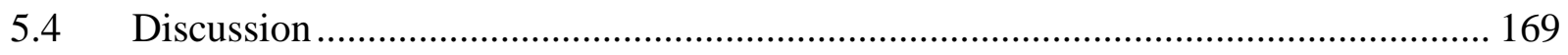

5.4.1 Role of Inhibitor on AZ31B-H24 Corrosion Kinetics ............................................ 169

5.4.2 Influence of $\mathrm{pH}$ on Dissolution Film Formation and Polarization Resistance ....... 170

5.4.3 Implications on Design Multifunctional Coatings for AZ31B-H24 …….............. 175

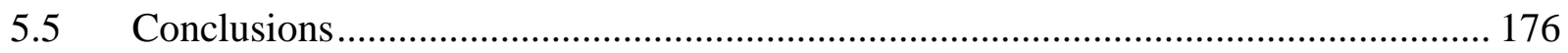

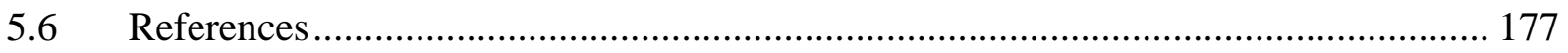

5.7 Appendix- Construction of Chemical Stability Diagrams and Mg Dissolution

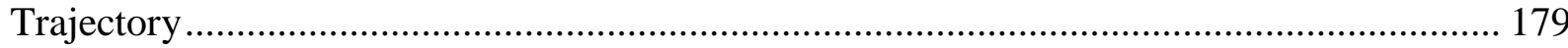

5.7.1 Plotting Equilibrium Stability Boundaries .......................................................... 179

5.7.2 Plotting the Mg Dissolution Trajectory ........................................................... 179

6. Assessment of Mg-Sn Surface Alloys for the Sacrificial Cathodic Protection of Mg Alloy AZ31B .................................................................................................................................. 183

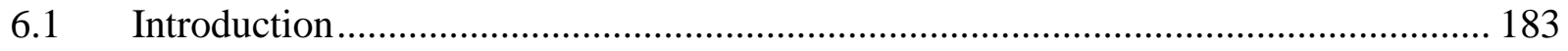

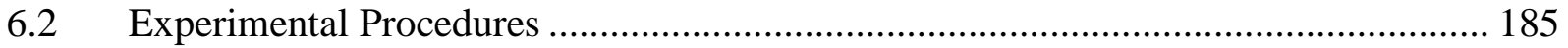

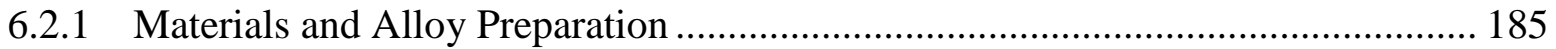

6.2.2 Pulsed Laser Deposition of Mg-Sn Alloys on AZ31B ........................................ 186

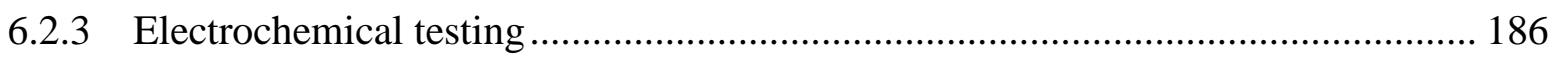

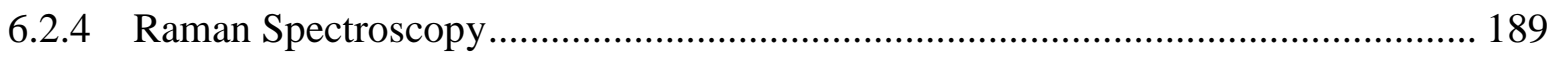

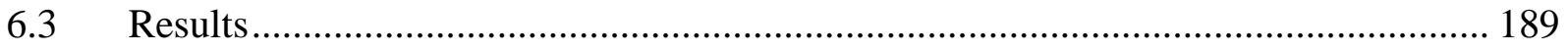

6.3.1 As Quenched Microstructure of Mg-Sn Alloys ...................................................... 189

6.3.2 Polarization and Corrosion Behavior of Bulk Mg-Sn Alloys at OCP .................... 191

6.3.3 Galvanostatic-Potentiostatic Cycle Testing ......................................................... 199

6.3.4 ZRA testing of Bulk Mg-Sn Alloys with AZ31B ………….............................. 202

6.3.5 Characterization and ZRA Testing of Mg-Sn Alloys Deposited on AZ31B .......... 208

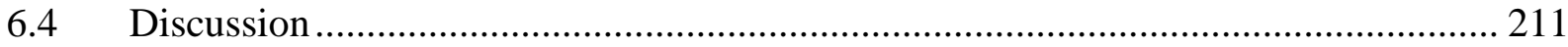

6.4.1 Improved Corrosion Resistance of Mg-Sn Alloys................................................... 211

6.4.2 Performance of Mg-Sn Alloys for Sacrificial Protection of AZ31B-H24 .............. 215

6.4.3 Effect of Polarity Reversal on Sacrificial Cathodic Protection ............................. 216 
6.4.4 Future Prospects of Mg-Sn Metallic Coatings for Sacrificial Cathodic Protection of

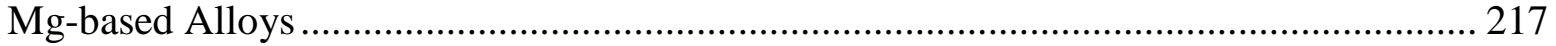

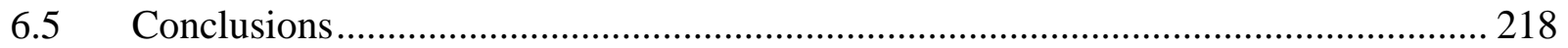

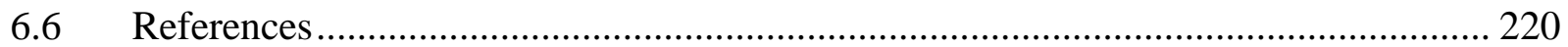

7. Synthesis of Findings and Suggestions for Future Research .................................... 222

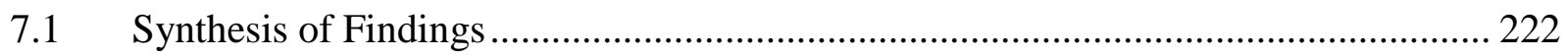

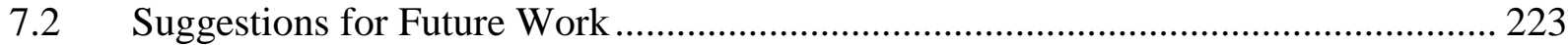




\section{v. List of Figures}

Figure 1.1. E-pH diagram for the stability of $\mathrm{Mg}$ in water. (a) is the equilibrium line for the HER.

Figure 1.2. E-pH diagram of $\mathrm{Mg}$ in reference to SCE showing the range of kinetic immunity for Mg. (a) is the equilibrium line for the HER. 7

Figure 1.3. Schematic E-log I plot for a conventional galvanic couple exhibiting Tafel behavior. The reversible potentials of each half-cell reaction are omitted for simplicity thus illustrating the case of cathodic prevention.

Figure 1.4. Summary of AZ alloy corrosion potentials $\left(E_{\text {corr }}\right) V_{S C E}$ measured in quiescent $0.1 \mathrm{M}$ $\mathrm{NaCl}$. Note: all alloying additions to AZ91E are in wt\%. Data from [95,96].

Figure 1.5. Summary of corrosion potentials $\left(\mathrm{E}_{\mathrm{corr}}\right)$ versus a saturated calomel electrode measured in quiescent $0.1 \mathrm{M} \mathrm{NaCl}$ for rare earth additions to $\mathrm{Mg}$. Note: Alloying additions to $\mathrm{Mg}$ are in wt\%. Data from [5,35,96-101].

Figure 1.6. Summary of corrosion potentials $\left(\mathrm{E}_{\mathrm{corr}}\right)$ versus a saturated calomel electrode measured in quiescent $0.1 \mathrm{M} \mathrm{NaCl}$ in the case of alternative alloying additions. Data from $[5,35,99,100,102-104]$

Figure 1.7. Schematic E vs log I plot showing how an increase in anodic kinetics or decrease in cathodic kinetics leads to a decrease in the OCP of an electrode.

Figure 1.8. Predicted values of the OCP for amorphous Al-Co-Ce alloys over a range of Co and

Ce concentrations in at\% utilizing a Scheffé regression model [19]. 25

Figure 2.1. Representative curves for the net current density vs. time for AZ31B-H24 in (a) 0.6 $\mathrm{M} \mathrm{NaCl}$, (c) $0.1 \mathrm{M} \mathrm{MgCl}_{2}$, and (e) $0.1 \mathrm{M}$ TRIS. The average equivalent charge density after 24 hours by mass loss at each potential are shown in (b) $0.6 \mathrm{M} \mathrm{NaCl}$, (d) $0.1 \mathrm{M} \mathrm{MgCl}_{2}$, and (f) $0.1 \mathrm{M}$ TRIS. At least three measurements were taken at each potential with the error bars being one standard deviation except where deviations are too small to be seen. 42

Figure 2.2. Optical images of the typical $\mathrm{CrO}_{3}$ cleaned surfaces revealing dissolution damage on the surface of AZ31B-H24 after 24-hour potentiostatic polarization in $0.6 \mathrm{M} \mathrm{NaCl}$ at the indicated potential. The sample area is $1 \mathrm{~cm}^{2}$

Figure 2.3. Optical images of the typical $\mathrm{CrO}_{3}$ cleaned surfaces revealing dissolution damage on the surface of AZ31B-H24 after 24-hour potentiostatic polarization in $0.1 \mathrm{M} \mathrm{MgCl}_{2}$ at the indicated potential. The sample area is $1 \mathrm{~cm}^{2}$. 
Figure 2.4. Typical optical images of AZ31B-H24 surfaces revealing dissolution damage after 24-hour potentiostatic polarization in 0.1 M TRIS at the indicated potential. The sample area is $1 \mathrm{~cm}^{2}$. Samples were not $\mathrm{CrO}_{3}$ cleaned due to lack of a film.

Figure 2.5. The change in bulk solution $\mathrm{pH}$ after 24-hour potentiostatic polarization of AZ31B$\mathrm{H} 24$ in $0.6 \mathrm{M} \mathrm{NaCl}, 0.1 \mathrm{M} \mathrm{MgCl}_{2}$, and $0.1 \mathrm{M}$ TRIS at the indicated potentials. 46

Figure 2.6. The anodic dissolution charge density measured by mass loss and ICP-OES converted to current density assuming a fixed rate of corrosion over the entire test period and plotted as a function of applied potential forAZ31B-H24 in (a) $0.6 \mathrm{M} \mathrm{NaCl}$, (b) $0.1 \mathrm{M}$ $\mathrm{MgCl}_{2}$, and (c) $0.1 \mathrm{M}$ TRIS. The green rectangle outlines a region where the dissolution rate is an order of magnitude or less than the OCP dissolution rate and is not susceptible to polarity reversal, the orange region outlines a region where the dissolution rate is an order of magnitude or less than the OCP dissolution rate and is susceptible to polarity reversal, the yellow region outlines potentials where the dissolution rate is less than an order of magnitude decrease in OCP dissolution rate and it susceptible to polarity reversal. The red and black lines indicate the anodic Tafel slope corrected for the ohmic resistance in each solution as described in Section 2.7.

Figure 2.7. E vs. log i plots of the deviation between theoretical true Tafel slopes and apparent Tafel slopes experiencing IR drop in solution. The true anodic Tafel slope is $27 \mathrm{mV} / \mathrm{dec}$ in (a) and $112.5 \mathrm{mV} / \mathrm{dec}$ in (b). The solid black and red lines are the respective true anodic and cathodic Tafel slope while the dashed lines are the apparent Tafel slope. ........................ 56

Figure 3.1. Schematic of the electrochemical testing procedure used in this study.................. 60 Figure 3.2. The Effect of scan rate on measurements of the cathodic kinetics of HP Mg in $0.6 \mathrm{M}$ $\mathrm{NaCl}$. Scans were performed after the OCP was allowed to stabilize for 10 minutes. Schematic activation controlled and diffusion controlled regions are shown by the arrows.60 Figure 3.3. The effect of $\mathrm{CrO}_{3}$ acid treatment according to ASTM G1 [10] on the cathodic kinetics of $\mathrm{HP} \mathrm{Mg}$ in $0.6 \mathrm{M} \mathrm{NaCl}$ after stabilizing at OCP for one minute. Each sample was prepared to 1200 grit $\mathrm{SiC}$ finish. ' $\mathrm{Cr}$ ' runs represents $\mathrm{CrO}_{3}$ treated samples and 'Fresh' runs have not been $\mathrm{CrO}_{3}$ treated. The scan rate was $2,500 \mathrm{mV} / \mathrm{s}$.

Figure 3.4. Potentiostat recorded net current density as a function of time for $99.9 \%$ pure $\mathrm{Mg}$ in solution for 24 hours at the designated potentials in quiescent (a) $0.6 \mathrm{M} \mathrm{NaCl}$, (b) $0.6 \mathrm{M}$ 
$\mathrm{NaCl}$ saturated with $\mathrm{Mg}(\mathrm{OH})_{2}$, (c) $0.1 \mathrm{M} \mathrm{MgCl}_{2}$, (d) $0.1 \mathrm{M} \mathrm{Na}_{2} \mathrm{SO}_{4}$, and (e) $0.1 \mathrm{M}$ TRIS buffer solution. The change in measured $\mathrm{pH}$ before and after testing is shown in (f). 70

Figure 3.5. Raman spectra of sample surfaces after corrosion in each electrolyte. Standard spectra for Brucite $\left(\mathrm{Mg}(\mathrm{OH})_{2}\right.$, RRUFF ID: R040077) and Epsomite $\left(\mathrm{MgSO}_{4} \cdot 7 \mathrm{H}_{2} 0\right.$, RRUFF ID: R150060) are from the RRUFFTM database [13]. The peak at $1075 \mathrm{~cm}^{-1}$ is likely to be related to $\mathrm{CO}_{3}{ }^{2-}$ species. Instrument artifacts were subtracted from each spectrum.

Figure 3.6. Optical micrographs of the surface morphology of corroded Mg samples after cleaning with $\mathrm{CrO}_{3}$. 0.1 M TRIS samples were not cleaned due to the absence of surface films.

Figure 3.7. The charge calculated from mass loss compared to the charge calculated from captured hydrogen plus the charge measured by the potentiostat as a function of applied potential for $\mathrm{HP} \mathrm{Mg}$ in (a) $0.6 \mathrm{M} \mathrm{NaCl}$, (b) $0.6 \mathrm{M} \mathrm{NaCl}$ saturated with $\mathrm{Mg}(\mathrm{OH})_{2}$, (c) $0.1 \mathrm{M}$ $\mathrm{MgCl}_{2}$, (d) $0.1 \mathrm{M} \mathrm{Na}_{2} \mathrm{SO}_{4}$, and (e) 0.1 M TRIS buffer solution. Error bars are one standard deviation from the mean.

Figure 3.8. (a) The NDE as a function of applied potential and (b) the ratio of charge measured by the potentiostat to the charge consumed by mass loss. Error bars are one standard deviation from the mean.

Figure 3.9. Cathodic potentiodynamic polarization scans with the corrosion films intact compared to film free condition after removing corrosion products with $\mathrm{CrO}_{3}$ for (a) $0.6 \mathrm{M}$ $\mathrm{NaCl}$, (b) $0.6 \mathrm{M} \mathrm{NaCl}$ saturated with $\mathrm{Mg}(\mathrm{OH})_{2}$, (c) $0.1 \mathrm{M} \mathrm{MgCl}_{2}$, (d) $0.1 \mathrm{M} \mathrm{Na}_{2} \mathrm{SO}_{4}$, and (e) 0.1 M TRIS. The average cathodic current density at $-2 \mathrm{~V}_{\mathrm{SCE}}$ is summarized in (f). Scans were performed after $1 \mathrm{~min}$ at OCP either after completion of potentiostatic polarization or re-immersion into solution after cleaning. The potential scan rate was $2500 \mathrm{mV} / \mathrm{s}$. 80

Figure 3.10. (a) RBS scan of high purity Mg ground to a 1200-grit finish in ethanol with (b) the corresponding concentration vs. depth profile as determined by the SIMNRA 6.06 computer code. 83

Figure 3.11. (a) RBS scan of high purity Mg ground to a 1200-grit finish in ethanol followed by $\mathrm{CrO}_{3}$ cleaning with (b) the corresponding concentration vs. depth profile as determined by the SIMNRA 6.06 computer code.

Figure 3.12. (a) RBS scan of high purity after 24 hour potentiostatic polarization at $-1.625 \mathrm{~V}_{\mathrm{SCE}}$ with (b) the corresponding concentration vs. depth profile as determined by the SIMNRA 
6.06 computer code. Corrosion products were cleaned off using $\mathrm{CrO}_{3}$ solution. (c) shows the Fe:Mg ratio as a function of depth in the sample................................................. 86

Figure 3.13. Typical fit of PIXE data using the GeoPIXE program code. This is the case for HP $\mathrm{Mg}$ immersed in $0.6 \mathrm{M} \mathrm{NaCl}$ after an anodic pulse of $2 \mathrm{~mA} / \mathrm{cm}^{2}$ for 2 minutes with the dissolution film intact.

Figure 3.14. Processed PIXE data to reveal the change in surface composition of HP Mg due to increasing anodic dissolution in $0.6 \mathrm{M} \mathrm{NaCl}$ with (a) the dissolution film intact and (b) after $\mathrm{CrO}_{3}$ cleaning. 87

Figure 3.15. Processed PIXE data to reveal the change in surface composition of HP Mg due to increasing anodic dissolution in $0.6 \mathrm{M} \mathrm{NaCl}$ saturated with $\mathrm{Mg}(\mathrm{OH})$ with (a) the dissolution film intact and (b) after $\mathrm{CrO}_{3}$ cleaning. 88

Figure 3.16. Processed PIXE data to reveal the change in surface composition of HP Mg due to increasing anodic dissolution in $0.1 \mathrm{M} \mathrm{MgCl}_{2}$ with (a) the dissolution film intact and (b) after $\mathrm{CrO}_{3}$ cleaning 88

Figure 3.17. Processed PIXE data to reveal the change in surface composition of HP Mg due to increasing anodic dissolution in $0.1 \mathrm{M} \mathrm{Na}_{2} \mathrm{SO}_{4}$ with (a) the dissolution film intact and (b) after $\mathrm{CrO}_{3}$ cleaning

Figure 3.18. Processed PIXE data to reveal the change in surface composition of HP Mg due to increasing anodic dissolution in 0.1 M TRIS.

Figure 3.19. Spatially resolved elemental maps of HP Mg anodically dissolved in $0.6 \mathrm{M} \mathrm{NaCl}$ at $2 \mathrm{~mA} / \mathrm{cm}^{2}$ for 2 minutes with the dissolution film intact. 90

Figure 3.20. Spatially resolved elemental maps of HP Mg anodically dissolved in $0.6 \mathrm{M} \mathrm{NaCl}$ at $10 \mathrm{~mA} / \mathrm{cm}^{2}$ for 2 minutes with the dissolution film intact. 91

Figure 3.21. Schematic model of element enrichment showing impurity particles being trapped in the dissolution film and at the film/metal interface in addition to elemental enrichment (gold region) at the film/metal interface. 95

Figure 4.1. Potentiodynamic polarization scans at $1 \mathrm{mV} / \mathrm{s}$ for $\mathrm{AZ31B}, \mathrm{CP} \mathrm{Mg}$, and WE43B after resting at OCP for $10 \mathrm{~min}$ in (a) $0.6 \mathrm{M} \mathrm{NaCl}$, (b) $0.1 \mathrm{M} \mathrm{MgCl}_{2}$, and (c) $0.1 \mathrm{M}$ TRIS. ...... 106

Figure 4.2. Zero resistance ammeter measurements for couples of (a) AZ31B-H24 to CP Mg, (b) AZ31B-H24 to WE43B, and (c) the corresponding charge density measured by gravimetric 
mass loss and the couple current density in $0.6 \mathrm{M} \mathrm{NaCl}$. CP Mg and WE43B were chosen as the working electrodes. 108

Figure 4.3. Zero resistance ammeter measurements for couples of (a) AZ31B-H24 to CP Mg, (b) AZ31B-H24 to WE43B, and (c) the corresponding charge density measured by gravimetric mass loss and the couple current density in $0.1 \mathrm{M} \mathrm{MgCl}_{2}$. CP Mg and WE43B were chosen as the working electrodes.

Figure 4.4. Zero resistance ammeter measurements for couples of (a) AZ31B-H24 to CP Mg, (b) AZ31B-H24 to WE43B, and (c) the corresponding charge density measured by gravimetric mass loss and the couple current density in 0.1 M TRIS. CP Mg and WE43B were chosen as the working electrodes. 112

Figure 4.5. Cathodic polarization scans taken before and after ZRA measurements of AZ31B$\mathrm{H} 24$ coupled to $\mathrm{CP} \mathrm{Mg}$ in each environment. The scans were performed after resting at OCP for 10 minutes prior to and after ZRA measurements. (a-c) Used fresh solution for testing of post-ZRA cathodic polarization while (d) used the original solution for testing of post-ZRA cathodic polarization.

Figure 4.6. Cathodic polarization scans taken before and after ZRA measurements of AZ31BH24 coupled to WE43B in each environment. The scans were performed after resting at OCP for 10 minutes prior to and after ZRA measurements. (a-c) Used fresh solution for testing of post-ZRA cathodic polarization while (d) used the original solution for testing of post-ZRA cathodic polarization 114

Figure 4.7. Optical micrographs of sample surfaces after ZRA measurements. Corrosion products were not cleaned from sample surfaces.

Figure 4.8. Optical micrographs of cleaned AZ31B-H24 surfaces after showing corrosion damage incurred at OCP after 24 hours compared to that by ZRA testing. 117

Figure 4.9. (a) Bright field optical micrograph of corrosion film forming on AZ31B-H24 sample after ZRA test with WE43B in $0.1 \mathrm{M} \mathrm{MgCl}_{2}$. (b) Bright field optical micrographs of the AZ31B-H24 surface before and after cleaning with $\mathrm{CrO}_{3}$. (c) Secondary electron SEM image with EDS spot analysis of the film.....

Figure 4.10. Raman spectroscopy of ZRA sample surfaces in (a) $0.6 \mathrm{M} \mathrm{NaCl}$, (b) $0.1 \mathrm{M} \mathrm{MgCl}_{2}$, and (c) $0.1 \mathrm{M}$ TRIS. The material listed first (bold) is the material that the scan was performed on. 
Figure 4.11. Schematic E vs. I plots for (a) traditional galvanic couples exhibiting anodic and cathodic Tafel behavior and (b) Mg-Mg galvanic couples with increasing anodic hydrogen evolution reaction rates.

Figure 4.12. Cathodic potentiodynamic polarization curves performed after 24 hour potentiostatic polarization in $0.6 \mathrm{M} \mathrm{NaCl}$ at the indicated potentials. Scans were performed at $1 \mathrm{mV} / \mathrm{s}$.

Figure 4.13. ZRA measurement of AZ31B LSM samples coupled to AZ31B base plate in (a) 0.6 $\mathrm{M} \mathrm{NaCl}$, (b) $0.1 \mathrm{MgCl}_{2}$, (c) $0.1 \mathrm{M}$ TRIS

Figure 5.1. Predominance area diagrams for (a) Mg, (b) La, and (c) Gd systems. These were calculated using the MEDUSA software package.

Figure 5.2. Equivalent circuit used to fit EIS spectra in this investigation 140

Figure 5.3. OCP vs. time behavior of AZ31B-H24 immersed in (a) $\mathrm{LaCl}_{3}$ and (b) $\mathrm{GdCl}_{3}$ for 24 hours

Figure 5.4. E vs. $\log$ i plots for IR-corrected anodic polarization of AZ31B-H24 after immersion in varying concentrations of $\mathrm{La}^{3+}$ for (a) 10 minutes and (b) 24 hours; (c) and (d) display the respective behavior in varying concentrations of $\mathrm{Gd}^{3+}$ after 10 minutes and 24 hours respectively. The scan rate was $1 \mathrm{mV} / \mathrm{s}$. 144

Figure 5.5. E vs. log i plots for cathodic polarization of AZ31B-H24 after immersion in varying concentrations of $\mathrm{La}^{3+}$ for (a) 10 minutes and (b) 24 hours; (c) and (d) display the respective behavior in varying concentrations of $\mathrm{Gd}^{3+}$ after 10 minutes and 24 hours respectively. The scan rate was $2,500 \mathrm{mV} / \mathrm{s}$......

Figure 5.6. Gravimetric mass loss converted to anodic charge for AZ31B-H24 immersed in varying concentrations of (a) $\mathrm{La}^{3+}$ and (b) $\mathrm{Gd}^{3+}$ at OCP for 24 hours.

Figure 5.7. Optical macro images of AZ31B-H24 after 24 hour exposure to various concentrations of (a) $\mathrm{La}^{3+}$ and (b) $\mathrm{Gd}^{3+}$ revealing the corrosion films formed on the sample surface. The exposure area was $1 \mathrm{~cm}^{2}$. 148

Figure 5.8. Higher magnification image revealing the corrosion surface of AZ31B-H24 immersed in $0.1 \mathrm{M} \mathrm{GdCl}_{3}+0.3 \mathrm{M} \mathrm{NaCl}$ for 24 hours. 148

Figure 5.9. The average $\mathrm{pH}$ of the bulk solution for AZ31B-H24 freely corroding at OCP for 24 hours in varying concentrations of (a) $\mathrm{La}^{3+}$ and (b) $\mathrm{Gd}^{3+}$ compared to $0.6 \mathrm{M} \mathrm{NaCl}$. The chloride concentration was constant at $0.6 \mathrm{M} \mathrm{Cl}^{-}$. 
Figure 5.10. The typical data measured during galvanostatic-cycling test for AZ31B-H24 in varying concentrations of $\mathrm{La}^{3+}$ compared to $0.6 \mathrm{M} \mathrm{NaCl}$. (a) shows the potential vs. time and (b) shows the cathodic current vs. time for each respective galvanostatic and potentiostatic pulse

Figure 5.11. Summary of cycle testing in $\mathrm{LaCl}_{3}$. The average potential measured at the end of each anodic galvanostatic step is shown in by the solid symbols in (a) and compared to anodic potentiodynamic polarization curves. The average cathodic current density measured at the end of potentiostatic pulses at $-2 \mathrm{~V}_{\mathrm{SCE}}$ is shown in (b) where $\mathrm{i}_{\mathrm{a}}$ is the applied anodic current density and $i_{c}$ is the cathodic current density measured after the respective anodic pulse.

Figure 5.12. The typical data measured during galvanostatic-cycling test for AZ31B-H24 in varying concentrations of $\mathrm{Gd}^{3+}$ compared to $0.6 \mathrm{M} \mathrm{NaCl}$. (a) shows the potential vs. time and (b) shows the cathodic current vs. time for each respective galvanostatic and potentiostatic pulse

Figure 5.13. Summary of cycle testing in $\mathrm{GdCl}_{3}$. The average potential measured at the end of each anodic galvanostatic step is shown in by the solid symbols in (a) and compared to anodic potentiodynamic polarization curves. The average cathodic current density measured at the end of potentiostatic pulses at $-2 \mathrm{~V}_{\mathrm{SCE}}$ is shown in (b) where $\mathrm{i}_{\mathrm{a}}$ is the applied anodic current density and $i_{c}$ is the cathodic current density measured after the respective anodic pulse.

Figure 5.14. EIS measurements with varying $\left[\mathrm{La}^{3+}\right]$ at a constant total chloride concentration of $0.6 \mathrm{M}$ after anodic galvanostatic polarization at $0.1 \mathrm{~mA} / \mathrm{cm}^{2}$. (a) shows Bode magnitude plot, (b) shows the Bode phase plot, and (c) shows the Nyquist plot. 157

Figure 5.15. EIS measurements with varying $\left[\mathrm{La}^{3+}\right]$ at a constant total chloride concentration of $0.6 \mathrm{M}$ after anodic galvanostatic polarization at $1 \mathrm{~mA} / \mathrm{cm}^{2}$. (a) shows Bode magnitude plot, (b) shows the Bode phase plot, and (c) shows the Nyquist plot. 158

Figure 5.16. EIS measurements with varying $\left[\mathrm{La}^{3+}\right]$ at a constant total chloride concentration of $0.6 \mathrm{M}$ after anodic galvanostatic polarization at $10 \mathrm{~mA} / \mathrm{cm}^{2}$. (a) shows Bode magnitude plot, (b) shows the Bode phase plot, and (c) shows the Nyquist plot. 159 
Figure 5.17. (a) The change in average polarization resistance of AZ31B-H24 with varying $\left[\mathrm{La}^{3+}\right]$ as a function of applied anodic current density (b) the change in $\mathrm{pH}$ as a function of applied current density. The initial $\mathrm{pH}$ of each solution is plotted at $0.01 \mathrm{~mA} / \mathrm{cm}^{2}$. 160

Figure 5.18. EIS measurements with varying $\left[\mathrm{Gd}^{3+}\right]$ at a constant total chloride concentration of 0.6 $\mathrm{M}$ after anodic galvanostatic polarization at $0.1 \mathrm{~mA} / \mathrm{cm}^{2}$. (a) shows Bode magnitude plot, (b) shows the Bode phase plot, and (c) shows the Nyquist plot.

Figure 5.19. EIS measurements with varying $\left[\mathrm{Gd}^{3+}\right]$ at a constant total chloride concentration of 0.6 M after anodic galvanostatic polarization at $1 \mathrm{~mA} / \mathrm{cm}^{2}$. (a) shows Bode magnitude plot, (b) shows the Bode phase plot, and (c) shows the Nyquist plot. 162

Figure 5.20. EIS measurements with varying $\left[\mathrm{Gd}^{3+}\right]$ at a constant total chloride concentration of 0.6 M after anodic galvanostatic polarization at $10 \mathrm{~mA} / \mathrm{cm}^{2}$. (a) shows Bode magnitude plot, (b) shows the Bode phase plot, and (c) shows the Nyquist plot. 163

Figure 5.21. (a) The change in average polarization resistance of AZ31B-H24 with varying $\left[\mathrm{Gd}^{3+}\right]$ as a function of applied anodic current density and (b) the change in $\mathrm{pH}$ as a function of applied current density. The initial $\mathrm{pH}$ of each solution is plotted at $0.01 \mathrm{~mA} / \mathrm{cm}^{2}$. 164

Figure 5.22. Optical macro images of corroded AZ31B-H24 surfaces after different anodic galvanostatic pulses as a function with varying $\left[\mathrm{La}^{3+}\right]$. The sample exposure area was $1 \mathrm{~cm}^{2}$.

Figure 5.23. Optical macro images of corroded AZ31B-H24 surfaces after different anodic galvanostatic pulses as a function with varying $\left[\mathrm{Gd}^{3+}\right]$. The sample exposure area was 1 $\mathrm{cm}^{2}$. 166

Figure 5.24. Higher magnification optical image showing the dissolution surface of AZ31B-H24 after anodic polarization at $1 \mathrm{~mA} / \mathrm{cm}^{2}$ for 24 hours in in $10^{-2} \mathrm{M} \mathrm{GdCl}_{3}+0.57 \mathrm{M} \mathrm{NaCl}$.. 166 Figure 5.25. Raman spectra measured on AZ31B-H24 after 24 hour anodic galvanostatic polarization in each solution tested in Section 5.3.4. (a) shows the results for conditions with $\mathrm{La}^{3+}$ compared to $\mathrm{Mg}(\mathrm{OH})_{2}, \mathrm{La}(\mathrm{OH})_{3}$, and $\mathrm{La}(\mathrm{CO})_{3} \mathrm{OH}$ standards while (b) shows the results for $10^{-3} \mathrm{M} \mathrm{Gd}^{3+}$ and $10^{-2} \mathrm{M} \mathrm{Gd}^{3+}$ compared to $\mathrm{Mg}(\mathrm{OH})_{2}$ standard and (c) shows the results for $10^{-1} \mathrm{M} \mathrm{Gd}^{3+}$ compared to $\mathrm{Mg}(\mathrm{OH})_{2}$ standard and the standard for $\mathrm{La}(\mathrm{CO})_{3} \mathrm{OH}$ used as a proxy to $\mathrm{Gd}$ species as no standards for Gd were available. 168

Figure 5.26. Chemical stability diagram for (a) $\mathrm{La}^{3+}$ and (b) $\mathrm{Gd}^{3+}$ systems showing the dissolution trajectory of $\mathrm{Mg}$ during corrosion. The dissolution trajectories for different 
levels of $\mathrm{La}^{3+}$ or $\mathrm{Gd}^{3+}$ and the case of no inhibitor ion (blue) are shown by the dashed lines. The horizontal dotted lines indicate what the theoretical concentration of $\mathrm{Mg}^{2+}$ would be in solution at the end of each galvanostatic hold. The intersection of the dissolution trajectory with either the theoretical $\left[\mathrm{Mg}^{2+}\right]$ or the chemical stability lines are indicated by the grey dots and indicate the theoretical final $\mathrm{pH}$. The dots labelled 1 are after an applied current density of $0.1 \mathrm{~mA} / \mathrm{cm}^{2}$ for 24 hours, the dots labelled 2 for $1 \mathrm{~mA} / \mathrm{cm}^{2}$ and the dots labelled 3 for $10 \mathrm{~mA} / \mathrm{cm}^{2}$. 173

Figure 5.27. Comparison of the calculated final $\mathrm{pH}$ using the $\mathrm{Mg}$ dissolution trajectory and chemical stability diagram in Figure 5.26 compared to the measured final $\mathrm{pH}$ after anodic galvanostatic polarization experiments in Section 5.3.4 for (a) $\mathrm{LaCl}_{3}$ and (b) $\mathrm{GdCl}_{3}$. Excellent agreement between the calculated and measured values of $\mathrm{pH}$ is observed...... 174 Figure 6.1. Equilibrium binary phase diagram for the $\mathrm{Mg}-\mathrm{Sn}$ system [7].

Figure 6.2. Powder X-ray diffraction pattern for Mg-Sn alloys. (a) shows the measured intensity vs. $2 \theta$ with corresponding reference spectra. The black solid line reference lines correspond to $\mathrm{Mg}$ while the red dotted reference line correspond to $\mathrm{Mg}_{2} \mathrm{Sn}$. (b) shows the log of the intensity.

Figure 6.3. Backscattered SEM images showing a single phase for (a) Mg-1Sn, (b) Mg-5Sn, and (c) Mg-10Sn. Samples were polished to a $1 \mu \mathrm{m}$ diamond finish.

Figure 6.4. Plots of OCP vs. time with corresponding anodic (a,b) and cathodic (c,d) polarization scans taken after 10 minutes at OCP. Anodic scans were performed at $1 \mathrm{mV} / \mathrm{s}$ while cathodic scans were conducted at $2500 \mathrm{mV} / \mathrm{s}$. (e) Shows the anodic polarization curves after performing IR correction. Overcompensation is seen at high current densities due to additional ohmic resistance of anodic hydrogen evolution. 193

Figure 6.5. (a) OCP vs time behavior for $\mathrm{Mg}$-Sn alloys for 24 hours and (b) corresponding cathodic potentiodynamic polarization scans taken after 24 hours in $0.6 \mathrm{M} \mathrm{NaCl}$. The peaks present in (a) are breaks in the potential when EIS was performed. 195

Figure 6.6. Variation of polarization resistance of $\mathrm{Mg}-\mathrm{Sn}$ alloys with time immersed in $0.6 \mathrm{M}$ $\mathrm{NaCl}$ at $\mathrm{OCP}$ compared to $\mathrm{AZ31B}$ 196

Figure 6.7. In situ optical images of $\mathrm{Mg}-\mathrm{Sn}$ alloys compared to AZ31B under immersion in 0.6 $\mathrm{M} \mathrm{NaCl}$ at OCP at intervals when EIS was performed. The exposed sample area is $1 \mathrm{~cm}^{2}$. 
Figure 6.8. (a) Raman spectroscopy on the various corrosion films that formed during 24 hour immersion testing in $0.6 \mathrm{M} \mathrm{NaCl}$. Optical images of (b) $\mathrm{Mg}-1 \mathrm{Sn}$, (c) $\mathrm{Mg}-5 \mathrm{Sn}$, and (d) $\mathrm{Mg}$ 10Sn after immersion corresponding to the film areas probed by Raman Spectroscopy... 198

Figure 6.10. Summary of cycle testing. The average potential measured at the end of each anodic galvanostatic step is shown in by the solid symbols in (a) and compared to anodic potentiodynamic polarization curves. The average cathodic current density measured at the end of potentiostatic pulses at $-2 \mathrm{~V}_{\mathrm{SCE}}$ is shown in (b) where $\mathrm{i}_{\mathrm{a}}$ is the applied anodic current density and $i_{c}$ is the cathodic current density measured after the respective anodic pulse. 201

Figure 6.11. ZRA testing of Mg-1Sn with AZ31B in $0.6 \mathrm{M} \mathrm{NaCl}$. (a) Shows the change in couple potential with time while (b) shows the change in coupled current density with time. $\mathrm{Mg}$ 1Sn was placed as the working electrode with AZ31B-H24 being the counter electrode.. 203 Figure 6.13. ZRA testing of Mg-10Sn with AZ31B in $0.6 \mathrm{M} \mathrm{NaCl}$. (a) Shows the change in couple potential with time while (b) shows the change in coupled current density with time. $\mathrm{Mg}-10 \mathrm{Sn}$ was placed as the working electrode with AZ31B-H24 being the counter electrode. 204

Figure 6.14. Optical images of sample surfaces after ZRA testing are shown in (c) for $\mathrm{Mg}-1 \mathrm{Sn}$, (d) for Mg-5Sn, and (e) for Mg-10Sn. The exposed sample area is $1 \mathrm{~cm}^{2}$. 206

Figure 6.15. Charge accumulated due to mass loss and the galvanic couple current during ZRA testing for (a) Mg-Sn alloys coupled to AZ31B compared to (b) commercially pure $\mathrm{Mg}$ and WE43 coupled to AZ31B from a previous investigation...... 207

Figure 6.16. Backscattered SEM image of PLD coated Si wafers using (a) Mg-1Sn, (b) Mg-5Sn, and (c) Mg-10Sn targets. (d) shows the cross section of Mg-1Sn deposited on an Si wafer. The red circles indicate where point EDS analysis was performed. 209

Figure 6.17. ZRA testing of AZ31B coated with Mg-Sn alloys coupled to non-coated AZ31B for 24 hours in $0.6 \mathrm{M} \mathrm{NaCl}$. (a) shows the change in couple potential with time while (b) shows the couple current with time. 210

Figure 6.18. Optical images taken after ZRA testing are shown in (c) for Mg-1Sn coatings, (d) Mg-5Sn coatings, and (e) Mg-10Sn Coatings. The test area was $1 \mathrm{~cm}^{2}$ to provide a 1:1 anode to cathode ratio. 211

Figure 6.19. Predominance diagram for $\mathrm{Sn}^{2+}$ calculated using the Medusa software package. . 214 


\section{vi. List of Tables}

Table 1.1. The standard reversible electrochemical potentials in water at room temperature for elements relevant to $\mathrm{Mg}$ corrosion [21].

Table 1.2. Partial listing of RE-containing precursor solutions for conversion coatings illustrating

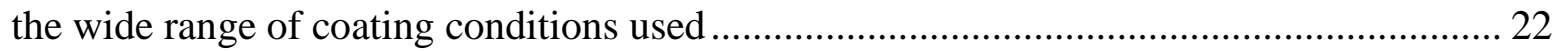

Table 2.1. Composition of AZ31B-H24 used in this study in wt\%. Compositional analysis was performed by QUANT (Quality Analysis and Testing Corporation), USA...................... 38

Table 2.2. Approximate elemental detection limits for the ICP-OES used in this investigation in $\operatorname{ppm}(\mathrm{mg} / \mathrm{L})$.

Table 2.3. Percent of dissolved elements in solution as a function of applied potential for AZ31B-H24 in $0.6 \mathrm{M} \mathrm{NaCl}$ for 24 hours.

Table 2.4. Percent of dissolved elements in solution as a function of applied potential for

AZ31B-H24 in $0.1 \mathrm{M}$ TRIS for 24 hours.

Table 3.1. Composition of high purity $\mathrm{Mg}$ used in this study in weight ppm $(\mu \mathrm{g} / \mathrm{g})$.

Compositional analysis was performed by QUANT (Quality Analysis and Testing Corporation), USA. 58

Table 3.2. Approximate elemental detection limits for the ICP-OES used in this investigation in $\operatorname{ppm}(\mathrm{mg} / \mathrm{L})$.

Table 3.3. The scattering factor $\mathrm{K}$ and energy $\mathrm{E}$ of ${ }^{4} \mathrm{He}$ projectiles after collision with the substrate under the conditions used in this experiment. 65

Table 3.4. Average element concentration from the raw data intensities in $0.6 \mathrm{M} \mathrm{NaCl}$ after 24hour potentiostatic polarization determined by ICP-OES. Solutions were acidified with $1 \mathrm{M}$ $\mathrm{HCl}$ to dissolve insoluble corrosion products. Grey cells are below the respective element detection limit.

Table 3.5. Average element concentration from the raw data intensities in $0.6 \mathrm{M} \mathrm{NaCl}$ saturated with $\mathrm{Mg}(\mathrm{OH})_{2}$ after 24-hour potentiostatic polarization determined by ICP-OES. Solutions were acidified with $1 \mathrm{M} \mathrm{HCl}$ to dissolve insoluble corrosion products. Grey cells are below the respective element detection limit.

Table 3.6. Average element concentration from the raw data intensities in $0.1 \mathrm{M} \mathrm{MgCl}_{2}$ after 24hour potentiostatic polarization determined by ICP-OES. Solutions were acidified with $1 \mathrm{M}$ 
$\mathrm{HCl}$ to dissolve insoluble corrosion products. Grey cells are below the respective element detection limit.

Table 3.7. Average element concentration from the raw data intensities in $0.1 \mathrm{M} \mathrm{Na}_{2} \mathrm{SO}_{4}$ after 24-hour potentiostatic polarization determined by ICP-OES. Solutions were acidified with 1 $\mathrm{M} \mathrm{HCl}$ to dissolve insoluble corrosion products. Grey cells are below the respective element detection limit. The Fe: $\mathrm{Mg}$ ratio is given in the last column.

Table 3.8. Average element concentration from the raw data intensities in 0.1 M TRIS after 24hour potentiostatic polarization determined by ICP-OES. Solutions were acidified with $1 \mathrm{M}$ $\mathrm{HCl}$ to dissolve insoluble corrosion products. The total concentration of $\mathrm{Fe}$ with respect to $\mathrm{Mg}$ is calculated in the final column in units of ppm. Grey cells are below the respective element detection limit. The Fe:Mg ratio is given in the last column. .................................. 82

Table 3.9. Common factors describing the negative difference effect ........................................ 92

Table 4.1. Composition of materials used in this investigation. Analysis performed by Quantitative Testing Corporation (QUANT) using ICP-OES. 103

Table 4.2. The average initial and final $\mathrm{pH}$ measured in solution for each couple tested in this investigation.

Table 4.3. The average self-corrosion fraction for anode materials CP Mg and WE43B during galvanic couples in each solution tested in this study from ZRA measurements.

Table 4.4. Dominating change in reaction kinetics due to variations in the couple potential and couple current. 126

Table 6.1. Composition (wt\%) of materials used in this investigation. Analysis of $\mathrm{HP} \mathrm{Mg}$ and AZ31B-H24 performed by Quantitative Testing Corporation (QUANT) using ICP-OES. $\mathrm{Mg}$-Sn alloys were quantified by X-ray fluorescence. 186 


\section{Introduction}

\subsection{Overview of the Problem}

The desire for better fuel economy and reduced emissions in both the automotive and aerospace industries has increased the need for lightweight materials with sufficient mechanical properties for use as structural components [1]. Magnesium $(\mathrm{Mg})$ and its alloys are a promising class of metals to fill this need as they possess a density about $77 \%$ lower than steels, $60 \%$ lower than titanium alloys, and 35\% lower than aluminum alloys while maintaining a high nominal specific strength for use for certain structural applications [2]. Current commercial applications range from automotive transfer casings and steering components to cell phone and computer casings; however, only about $0.3 \%$ if the total weight of a typical family sedan is $\mathrm{Mg}$ [3]. In addition, $\mathrm{Mg}$ alloys are being investigated for use in batteries and fuel cells [4] as well as for biodegradable/bioresorbable implants [5]. Despite the great interest and positive attributes, $\mathrm{Mg}$ alloys suffer from poor intrinsic corrosion resistance primarily due to high reactivity of $\mathrm{Mg}$ in aqueous environments and lack of a naturally forming passive film over a reasonable or pertinent range of electrochemical potential and $\mathrm{pH}$ which has hindered their widespread application $[3,6]$.

Several approaches to mitigate the corrosion of $\mathrm{Mg}$ alloys have been attempted which can be separated into two categories: alloy development and surface treatments. Alloy development is often times driven by the need for improved mechanical properties which may rely on the formation of secondary phases to act as strengthening precipitates or particles. Such heterogeneous alloys introduce micro-galvanic couples between the secondary phases and the $\alpha-\mathrm{Mg}$ matrix which accelerates the intrinsic corrosion rate of a given alloy [7]. The heterogeneous natures of these alloys also produce non-homogeneous, porous surface films which allow for the penetration of detrimental anions such as $\mathrm{Cl}^{-}$in solution to adsorb on to and react with the bare metal [8-12]. 
However, it has been shown that increasing the concentration of elements that do form passive films such as $\mathrm{Al}$ in solid solution can lead to improvements of the corrosion resistance of $\mathrm{Mg}$ alloys [13]. Unfortunately, the equilibrium maximum solid solubility at room temperature of most alloying elements in $\mathrm{Mg}$ is limited which restricts the ability of large alloying additions to improve corrosion resistance [2]. As such, the development of coatings and other surface treatments have been explored to mitigate corrosion.

Several surface treatments for $\mathrm{Mg}$ alloys have been attempted which include plating, conversion coatings, gas-phase deposition, and laser surface modification (LSM) [14]. Plating typically involves the use of transition elements to create pore free coatings. While these coatings have good intrinsic corrosion resistance (i.e., as barriers to corrosion) they do not offer scratch protection which accelerates the corrosion rate of the underlying $\mathrm{Mg}$ alloy as a result of formation of a galvanic couple or dissimilar metal corrosion. In contrast, conversion coatings are produced by either chemical or electrochemical treatment of a substrate to produce an insulating film of low solubility between the metal surface and environment [15]. Conversion coatings have been shown to be successful but they typically use highly toxic treatment solutions such as chromates and do not provide sacrificial protection. However, gas-phase deposition and LSM have shown the ability to produce surfaces that have corrosion potentials more anodic than base commercial $\mathrm{Mg}$ alloys which indicates the potential of sacrificial protection but they have not been shown to exhibit inhibitor release to date $[16,17]$.

This research seeks to produce a multifunctional tunable surface alloy which acts as (1) a corrosion barrier, (2) provides sacrificial cathodic protection, and (3) provides a secondary means of chemical inhibition brought about by a reservoir of elements enabling ionic inhibitor release during dissolution. This can be achieved by alloying $\mathrm{Mg}$ with elements that produce a low 
corrosion rate relative to $\mathrm{Mg}$ and a corrosion potential more negative than the $\mathrm{Mg}$ alloy which is to be protected. In addition, elemental additions which show the ability for inhibitor release would ideally be added to provide the third desired function. Such a coating was recently evaluated and tuned for aluminum alloy AA2024 in the form of amorphous Al-Co-Ce based alloys [18-20] and presents the foundation for a similar coating for $\mathrm{Mg}$ alloys.

This dissertation focuses on furthering an understanding of the anomalous corrosion behavior of $\mathrm{Mg}$ and $\mathrm{Mg}$ alloys and how this behavior would affect the electrochemical properties of protective $\mathrm{Mg}$ galvanic couples in the presence of various electrolytes. In addition, the ability of $\mathrm{La}^{3+}$ and $\mathrm{Gd}^{3+}$ to inhibit $\mathrm{Mg}$ corrosion in chloride solutions is studied for viability as alloy additions for sacrificial coatings. Finally, $\mathrm{Mg}-\mathrm{Sn}$ alloys are evaluated for use as a viable sacrificial coating alloy.

\subsection{Background}

\subsubsection{Mechanisms of Mg Corrosion}

$\mathrm{Mg}$ possesses a standard reversible electrochemical potential $\left(\mathrm{E}^{\mathrm{o}}\right)$ of $-2.372 \mathrm{~V}$ vs. the standard hydrogen electrode (SHE) following the half-cell reaction [21]:

$$
M g^{2+}+2 e^{-} \rightleftharpoons M g
$$

Equation 1.1

This highly negative $\mathrm{E}^{\mathrm{o}}$ means that there is a great tendency for spontaneous oxidation of $\mathrm{Mg}$ when exposed to the natural environment and other elements. This is illustrated in Table $1.1 \mathrm{where} \mathrm{Mg}$ is among other known highly reactive elements such as $\mathrm{Ca}$ and lanthanide rare earth (RE) metals while traditional engineering metals are much more positive and less likely to oxidize or corrode. In the case of aqueous corrosion of $\mathrm{Mg}$, the primary cathodic reaction is the hydrogen evolution reaction (HER) which possesses a standard electrochemical potential of $0 \mathrm{~V}_{\text {SHE }}$ and occurs on the 
Table 1.1. The standard reversible electrochemical potentials in water at room temperature for elements relevant to $\mathrm{Mg}$ corrosion [21].

\begin{tabular}{|c|l|l|}
\hline Element & Reaction $^{2}$ & $\mathbf{E}^{\mathbf{0}}(\mathbf{V}$ SHE $)$ \\
\hline $\mathrm{Cu}$ & $\mathrm{Cu}^{2+}+2 \mathrm{e}^{-} \rightleftharpoons \mathrm{Cu}$ & 0.342 \\
\hline $\mathrm{ORR}$ & $\mathrm{O}_{2}+4 \mathrm{H}^{+}+2 \mathrm{e}^{-} \rightleftharpoons 2 \mathrm{H}_{2} \mathrm{O}$ & 1.230 \\
\hline $\mathrm{HER}$ & $2 \mathrm{H}^{+}+2 \mathrm{e}^{-} \rightleftharpoons \mathrm{H} 2$ & 0.000 \\
\hline $\mathrm{Ni}$ & $\mathrm{Ni}^{2+}+2 \mathrm{e}^{-} \rightleftharpoons \mathrm{Ni}$ & -0.257 \\
\hline $\mathrm{Fe}$ & $\mathrm{Fe}^{2+}+2 \mathrm{e}^{-} \rightleftharpoons \mathrm{Fe}$ & -0.447 \\
\hline $\mathrm{Zn}$ & $\mathrm{Zn}^{2+}+2 \mathrm{e}^{-} \rightleftharpoons \mathrm{Zn}$ & -0.7618 \\
\hline $\mathrm{Mn}$ & $\mathrm{Mn}^{2+}+2 \mathrm{e}^{-} \rightleftharpoons \mathrm{Mn}$ & -1.185 \\
\hline $\mathrm{Ti}$ & $\mathrm{Ti}^{+2} 2 \mathrm{e}^{-} \rightleftharpoons \mathrm{Ti}$ & -1.630 \\
\hline $\mathrm{Al}$ & $\mathrm{Al}^{3+}+3 \mathrm{e}^{-} \rightleftharpoons \mathrm{Al}$ & -1.676 \\
\hline $\mathrm{Gd}$ & $\mathrm{Gd}^{3+}+3 \mathrm{e}^{-} \rightleftharpoons \mathrm{Gd}$ & -2.279 \\
\hline $\mathrm{Nd}$ & $\mathrm{Nd}^{3+}+3 \mathrm{e}^{-} \rightleftharpoons \mathrm{Nd}$ & -2.323 \\
\hline $\mathrm{Ce}$ & $\mathrm{Ce}^{3+}+3 \mathrm{e}^{-} \rightleftharpoons \mathrm{Ce}$ & -2.336 \\
\hline $\mathrm{Pr}$ & $\mathrm{Pr}^{3+}+3 \mathrm{e}^{-} \rightleftharpoons \mathrm{Pr}$ & -2.353 \\
\hline $\mathrm{Y}$ & $\mathrm{Y}^{3+}+3 \mathrm{e}^{-} \rightleftharpoons \mathrm{Y}$ & -2.372 \\
\hline $\mathrm{Mg}$ & $\mathrm{Mg}^{2+}+\mathbf{2 e}-\mathrm{Mg}$ & $-\mathbf{2 . 3 7 2}$ \\
\hline $\mathrm{La}$ & $\mathrm{La}^{3+}+3 \mathrm{e}^{-} \rightleftharpoons \mathrm{La}$ & -2.379 \\
\hline $\mathrm{Na}$ & $\mathrm{Na}^{+}+\mathrm{e}^{-} \rightleftharpoons \mathrm{Na}$ & -2.710 \\
\hline $\mathrm{Ca}$ & $\mathrm{Ca}^{2+}+2 \mathrm{e}^{-} \rightleftharpoons \mathrm{Ca}$ & -2.868 \\
\hline $\mathrm{Sr}$ & $\mathrm{Sr}^{2+}+2 \mathrm{e}-\rightleftharpoons \mathrm{Sr}$ & -2.899 \\
\hline $\mathrm{K}$ & $\mathrm{K}^{+}+\mathrm{e}^{-+} \rightleftharpoons \mathrm{K}$ & -2.931 \\
\hline $\mathrm{Li}$ & $\mathrm{Li}^{+}+\mathrm{e}^{-} \rightleftharpoons \mathrm{Li}$ & -3.040 \\
\hline & & \\
\hline
\end{tabular}

$\mathrm{Mg}$ surface [6]. This translates to very negative corrosion potentials of about $-1.6 \mathrm{~V}$ vs. the saturated calomel electrode $\left(\mathrm{E}_{\mathrm{SCE}}=\mathrm{E}_{\mathrm{SHE}}-0.241 \mathrm{~V}\right)$ in aqueous medium. The HER may be written in acid form as shown in Table 1.1 but can alternately be written in its neutral or alkaline form to account for the presence of water as shown in Equation 1.2:

$$
2 \mathrm{H}_{2} \mathrm{O}+2 e^{-} \rightleftharpoons \mathrm{H}_{2}+2 \mathrm{OH}^{-}
$$

Equation 1.2

The overall reaction for $\mathrm{Mg}$ corrosion can therefore be written as:

$$
2 M g+2 H^{+}=M g^{2+}+H_{2}
$$

acid or:

$$
\mathrm{Mg}+2 \mathrm{H}_{2} \mathrm{O}=\mathrm{Mg}(\mathrm{OH})_{2}+\mathrm{H}_{2}
$$

Equation 1.4 
in neutral or alkaline environments. The stability of $\mathrm{Mg}$ in water with respect to electrochemical potential and $\mathrm{pH}$ when accounting for these electrochemical reactions and chemical reaction as shown in Figure 1.1. Examination of Figure 1.1 reveals that $\mathrm{Mg}$ is susceptible to corrosion in acidic and near neutral environments and does not form a naturally passive oxide like aluminum alloys, stainless steels, and titanium alloys [22]. However, a thermodynamically passive hydroxide is observed over a range of neutral to alkaline $\mathrm{pH}$ depending on the concentration of $\mathrm{Mg}^{2+}$ in solution. This $\mathrm{Mg}(\mathrm{OH})_{2}$ film is typically porous and is susceptible to cracking and further attack in the presence of chloride which does not provide adequate protection [23]. Other anions such as sulfate have shown to be less aggressive than chloride [24,25] while phosphate [15] and carbonates [26] have been shown to form corrosion films other than $\mathrm{Mg}(\mathrm{OH})_{2}$ which retard the corrosion rate. Thus, formation of $\mathrm{Mg}(\mathrm{OH})_{2}$ and the native air formed oxide are not enough to provide satisfactory protection of $\mathrm{Mg}$ for engineering use in aqueous environments.

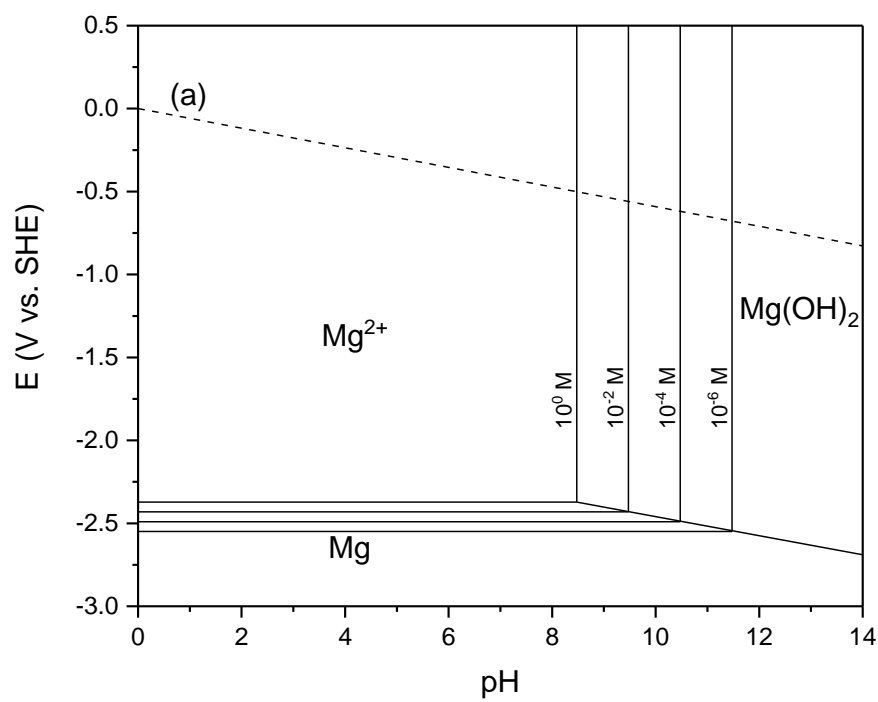

Figure 1.1. E-pH diagram for the stability of $\mathrm{Mg}$ in water. (a) is the equilibrium line for the HER. 


\subsubsection{Thermodynamic Protection vs. Kinetic Prevention of Mg}

Metals can be protected either on a thermodynamic or kinetic basis depending on the material, work environment, and other criteria such as cost or required lifetime [27]. Thermodynamic protection or immunity occurs when the metal element is in a stable state and thus no corrosion would occur. However, achieving thermodynamic protection with $\mathrm{Mg}$ would be very difficult due to its extremely low reversible potential $\left(-2.372 \mathrm{~V}_{\mathrm{SHE}}\right)$ and the lack of elements with a reversible potential more negative than $\mathrm{Mg}$, Table 1.1. Kinetic prevention of $\mathrm{Mg}$ is much more likely to occur if $\mathrm{Mg}$ is polarized in the cathodic direction relative to its open circuit potential (OCP). Such a range of cathodic potential whereupon cathodic protection of $\mathrm{Mg}$ could be achieved is indicated on the schematic E-pH diagram in Figure 1.2 and would be targeted for a sacrificial alloy. However, it is unclear how much cathodic current needs to be applied for cathodic prevention of $\mathrm{Mg}$ and whether or not this can be practically achieved through galvanic coupling with a sacrificial Mg alloy. This may be limited by the range of cathodic potentials that can be practically applied to an $\mathrm{Mg}$ alloy which is dependent on electrolyte concentration and $\mathrm{pH}$ and the negative difference effect (NDE) of Mg corrosion which will be discussed in detail in Section 1.2.4. 


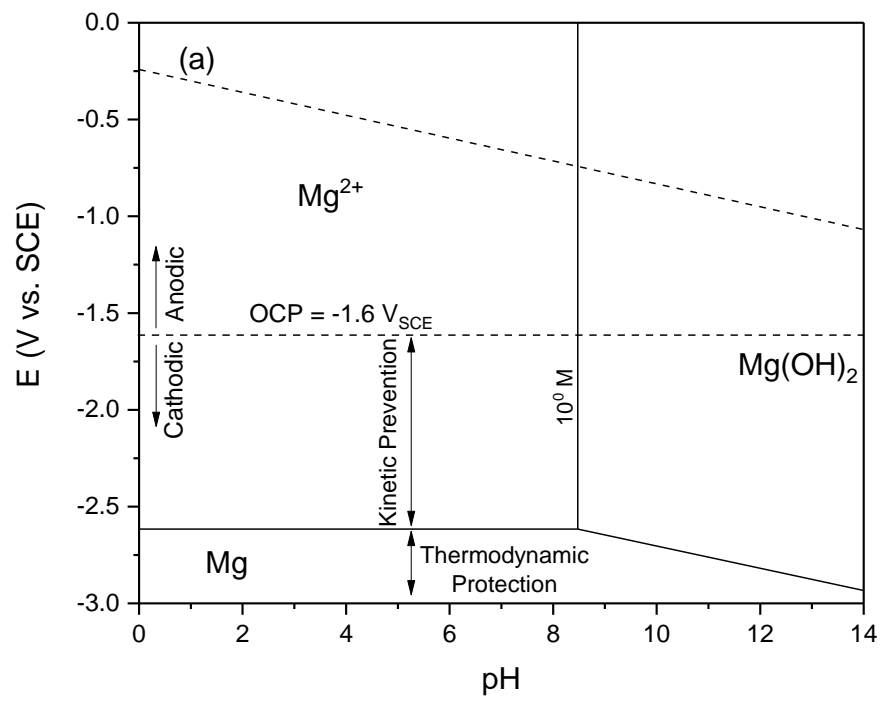

Figure 1.2. E-pH diagram of $\mathrm{Mg}$ in reference to SCE showing the range of kinetic immunity for $\mathrm{Mg}$. (a) is the equilibrium line for the HER.

\subsubsection{Principles of Sacrificial Cathodic Protection}

\subsubsection{Mixed Potential Theory of Galvanic Corrosion for Sacrificial Protection}

Galvanic corrosion occurs when two dissimilar metals are in electrical contact with each other while immersed in an electrolyte which provides an ionic path. As with corrosion of a single metal, there must be an anodic and cathodic half-cell reaction. However, the anodic and cathodic halfcell reactions do not occur on the same surface like with a single metal. In its simplest form, one of the metals will become the anode where oxidation occurs and one will become the cathode where the corresponding cathodic reaction occurs. Thus, in the conventional view of galvanic corrosion, a galvanic couple can be used to reduce the dissolution rate of the metal of interest by making it the cathode while the other metal dissolves preferentially as the anode. This principle is the basis for a sacrificial alloy coating and is explained using mixed potential theory in Figure 1.3 for a galvanic couple where both metals exhibit Tafel behavior. As in the case of a single metal, 
the cathodic and anodic reactions must occur at the same potential termed the galvanic couple potential, $E_{\text {couple. }}$ It is determined where the sum of all anodic currents is equal to the sum of all cathodic currents in the electrochemical system. It is at this couple potential that all reactions will occur. Thus, the total galvanic couple current $\left(I_{g}\right)$, the dissolution current of the anode in the couple $\left(I_{g}^{A}\right)$, and the dissolution current of the cathode $\left(I_{g}^{C}\right)$ can be determined at $E_{\text {couple }}$. When these coupled currents are compared to the corrosion currents of the anode $\left(I_{\text {corr }}^{A}\right)$ and cathode $\left(I_{\text {corr }}^{C}\right)$, it is clear that $I_{g}^{C}$ is reduced from $I_{\text {corr }}^{C}$ which is desired for sacrificial cathodic protection. In this sense, the coating is sacrificial to underlying substrate and cathodically polarizes the substrate. The decrease in $I_{g}^{C}$ depends on the anodic Tafel slope of the cathode for an activation controlled reaction which can be described by Equation 1.5:

$$
\frac{\eta_{a}}{\beta_{a}}=\log \frac{i_{a}}{i_{c o r r}}
$$

For example, if the anodic Tafel slope $\left(\beta_{a}\right)$ is $120 \mathrm{mV} /$ decade, then an anodic overpotential $\left(\eta_{a}\right)$ of $-120 \mathrm{mV}$ will result in a $10 \mathrm{x}$ decrease in the anodic current density $\left(i_{a}\right)$ for a constant corrosion current density $\left(i_{\text {corr }}\right)$. The anodic overpotential is defined as the difference in the applied potential and the corrosion potential $\left(\eta_{a}=E_{a}-E_{c o r r}\right)$. It is obvious based on Equation 1.5, that a small value of $\beta_{a}$ will decrease $i_{a}$ greater for a given value of $\eta_{a}$ than a large value of $\beta_{a}$. Thus, the anodic process controls the degree of protection that could be afforded in a sacrificial couple. Furthermore, it should be apparent in Figure 1.3 that $I_{g}^{C}$ can be decreased if the exchange current density of any of the anodic or cathodic reaction rates is decreased and $E_{\text {couple }}$ will vary with changes in the exchange current density of the anodic and cathodic reactions. Thus, it is important to understand how the addition of alloying elements to $\mathrm{Mg}$ affects the anodic and cathodic reaction 
kinetics (i.e., Tafel slopes and exchange current densities) and the corresponding $E_{c o r r}$ such that a sacrificial alloy can be designed to provide an $E_{\text {couple }}$ that results in a sufficiently low $I_{g}^{C}$.

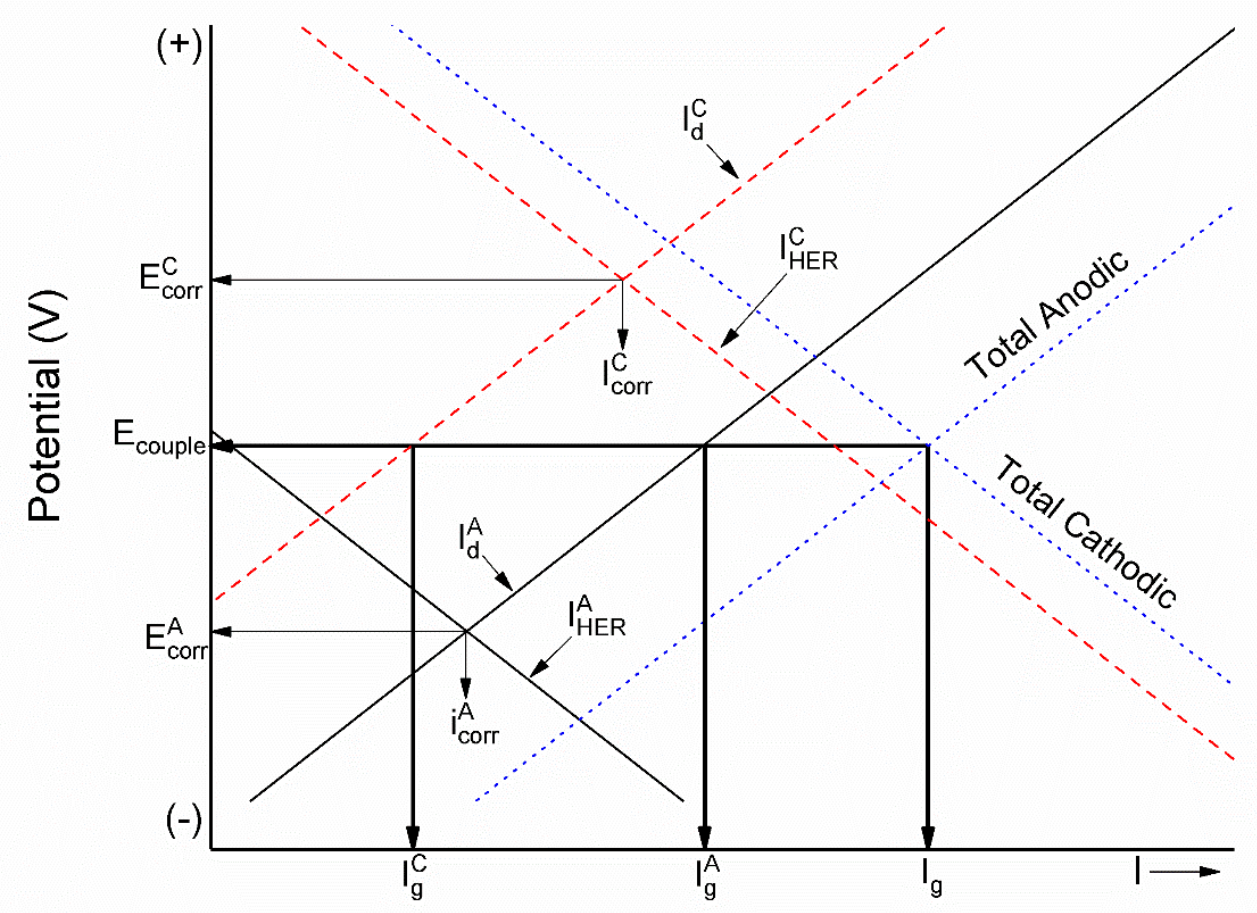

Figure 1.3. Schematic E-log I plot for a conventional galvanic couple exhibiting Tafel behavior. The reversible potentials of each half-cell reaction are omitted for simplicity thus illustrating the case of cathodic prevention.

\subsubsection{Criteria for Ideal Sacrificial Cathodic Protection}

An ideal sacrificial anode is characterized by several traits: the polarization of the anode must be low enough to permit current flow from the anode to the cathode and the anode should have a high theoretical output or available charge density and a high output efficiency [27]. Based on these criteria, passive alloys would not be suitable as they will significantly decrease the amount of current that could be supplied to the cathode in comparison to an active alloy. $\mathrm{Zn}$ is a classic case of an ideal sacrificial anode for steels which fits the above criteria. It possesses an intermediate 
corrosion potential, low polarization due to lack of a passive film, and a high anodic efficiency or low rate of self-corrosion [27]. $\mathrm{Mg}$ is similar to $\mathrm{Zn}$ except it is well known for its high rate of selfcorrosion which leads to a decreased anode lifetime [28]. Thus, Mg is regarded as a poor sacrificial anode in concentrated electrolytes such as sea water [27]. This high rate of self-corrosion is due to the negative difference effect which will be discussed in detail in Section 1.2.4.

\subsubsection{Specification for Sacrificial Cathodic Protection of Mg Alloys}

A standard anode material specification for sacrificial cathodic protection of $\mathrm{Mg}$ alloys does not exist to date whereas several standards exist for the sacrificial cathodic protection of non-Mg based alloys using Al, Mg, and $\mathrm{Zn}$ anodes [29-31]. As such, these guidelines may not be suitable for sacrificial cathodic protection of $\mathrm{Mg}$ alloys and new criteria must be established. It would be preferable to found the criteria for sacrificial cathodic protection of $\mathrm{Mg}$ alloys based on the corrosion rate of the $\mathrm{Mg}$ alloy to be protected and the anodic Tafel slope of that alloy. Thus, a potential range can be specified based on the anodic Tafel slope of the protected $\mathrm{Mg}$ alloy for which a practical decrease in corrosion rate will occur. The anodic Tafel slope of $\mathrm{Mg}$ alloys has been reported over a wide range varying from as low as $25.1 \mathrm{mV} / \mathrm{dec}$ to as large as $180 \mathrm{mV} / \mathrm{dec}$ but are typically $<100 \mathrm{mV} / \mathrm{dec}$ as summarized by Bland et al. [32]. As such, achieving two orders of magnitude decrease in corrosion rate of the protected $\mathrm{Mg}$ alloy may not be practical due to the amount of polarization required in a galvanic couple. However, any decrease in corrosion rate of the protected alloy is beneficial.

\subsubsection{The Negative Difference Effect and Anodically Induced Cathodic Activation}

One aspect associated with $\mathrm{Mg}$ dissolution which has not been mechanistically elucidated in full is the phenomenon known as the negative difference effect (NDE) [6]. This effect is 
characterized by an increase in the rate of hydrogen evolution with increasing anodic overpotential relative to the open circuit which provides a local cathodic reaction for a significant portion of the anodic reaction [33]. The persistent cathodic reaction rate during anodic polarization decreases the net anodic current that can be measured and leads to underestimates of the actual Mg dissolution rate. This phenomenon confounds the understanding of Mg dissolution mechanisms, establishment of a Tafel law and other reaction kinetic parameters, as well as other issues including accurate analysis of corrosion rates from electrochemical impedance spectroscopy (EIS) [32,34,35]. There are several theories purporting to explain the origins of the NDE among which include noble impurity element enrichment $[7,36]$, non-Faradaic mass loss via metal spalling [37,38], formation and dissolution of hydrides and partially protective films [39-42], and univalent $\mathrm{Mg}$ based dissolution followed by further oxidation of $\mathrm{Mg}^{+} \rightarrow \mathrm{Mg}^{2+}$ in solution (leading to hydrogen evolution from the reduction of water away from the electrode in the electrolyte) [43]; however, no consensus has been reached on the physical origins of the NDE.

The contemporary paradigm for the manifestation of the NDE centers on report of enhanced cathodic activity of dissolving Mg anodes [44]. Evidence of enhanced cathodic activity has been published by Williams and co-workers through use of the scanning vibrating electrode technique (SVET) which has shown the temporal evolution of net cathodically active regions at prior net anodic sites on 99.9\% [36] and 99.99\% [33] pure Mg, Mg-Al-Zn alloy AZ31B [7], and Mg-Nd binary alloy surfaces [45] under free corrosion and during galvanostatic anodic polarization. Another important aspect of the SVET work is that the measured net cathodic current density at these cathodic sites increased as the net anodic current density became greater to maintain charge balance $\left(\int I_{\text {anodic }} d t-\left|\int I_{\text {cathodic }} d t\right|=\int I_{\text {applied }} d t\right)$. However, the integrated net cathodic current density with time from the SVET at steady state is much less than the 
volumetric hydrogen evolution rate ${ }^{i}$ [46]. Moreover, the majority of hydrogen evolved is visibly seen to originate at the head of most actively advancing corrosion fronts and is not uniform across the blackened areas which may suggest that the 'older' and net cathodic regions are not the primary source of anodic hydrogen evolution ${ }^{\mathrm{ii}}$ [46-48]. As such, the NDE being a manifestation of enhanced cathodic activity affiliated with anodic sites may be considered non-controversial. However, the important remaining question still remains as to what physical mechanism is responsible for the enhanced cathodic activity. So-called 'activated' cathodic areas are characterized by the appearance of an optically 'black' corrosion film but it is unclear as to what characteristics of such dark regions translate to cathodic activation.

Further electrochemical evidence for cathodic activation was shown through a series of alternating anodic and cathodic polarization scans which revealed increasing cathodic kinetics with increasing anodic polarization of $\mathrm{Mg}$ surfaces [49]. Additional cathodic potentiodynamic polarization scans performed after various anodic treatments revealed an increase in the corrosion potential in addition to increased cathodic kinetics $[49,50]$. However, it was shown recently by Fajardo and Frankel that extrapolation of cathodic potentiodynamic polarization does not account for the high enhanced HER rates measured by $\mathrm{H}_{2}$ gas collection measured during anodic polarization [51]. A further study by Fajardo, Frankel, and co-workers has shown agreement between extrapolation of cathodic polarization curves and the integrated net cathodic current measured by SVET [52]. This is consistent with the notion that the anodic dissolution itself plays a causal role for the enhanced catalytic effect; whilst noting that it is difficult to assess anodic HER kinetics via cathodic potentiodynamic polarization without the original pertinent "anodic" based

\footnotetext{
${ }^{\mathrm{i}}$ This is common place for the SVET method as the time taken to map all cathodic sites often exceeds the time period over which anodic events that are short lived occur. Therefore, it is an "expected outcome."

ii The most recent anodic sites evolve more $\mathrm{H}_{2}$ but these sites have the greatest net anodic current observed.
} 
surface chemistry changing throughout the duration of the scan. The total rate of HER can be described by:

$$
H E_{\text {Total }}=H E_{\text {anode }}+H E_{\text {Impurities }}+H E_{\text {Film }}
$$

Equation 1.6

where $H E_{\text {anode }}$ represents a contribution of HER at anodic sites, $H E_{\text {Impurities }}$ is the contribution to enhanced rates of reduction from impurity metal enrichment, and $H E_{F i l m}$ is the contribution to enhanced rates of reduction from filmed areas [46]. Thus $H E_{\text {Impurities }}+H E_{\text {Film }}$ represents a small contribution while the majority of HER occurs at $H E_{\text {anode }}$. Recently, Fajardo and Frankel have shown a kinetic model whereby the manifestation of $H E_{\text {anode }}$ during $\mathrm{Mg}$ dissolution occurs when the charge transfer coefficient for $\mathrm{Mg}$ oxidation is larger than the charge transfer coefficient for HER [53]. While this theorized mechanism may have clarified the origins of the NDE of Mg, it is still important to understand the relative contributions of impurity enrichment and film formation on the reaction kinetics of dissolving $\mathrm{Mg} / \mathrm{Mg}$ alloy surfaces.

Several studies have recently been performed to evaluate the enrichment of noble metal elements and secondary phases on corroding Mg surfaces. Transmission electron microscopy (TEM) of focused ion beam (FIB) cross sections have shown that secondary phase particles such as Fe-rich particles (99.9\% pure $\mathrm{Mg}$ ) [50] and $\mathrm{Al}_{\mathrm{x}} \mathrm{Mn}_{\mathrm{y}}$ particles (AZ31B) are [8] incorporated in the $\mathrm{MgO} / \mathrm{Mg}(\mathrm{OH})_{2}$ bilayer in addition to the enrichment of solute elements such as $\mathrm{Al}[54]$ and $\mathrm{Zn}$ $[8,55]$ at the metal/oxy-hydroxide interface. Noble metal enrichment has also been shown using particle induced X-ray emission measurements [56]. In addition, solution analysis by in situ atomic emission spectroelectrochemistry (AESEC) of pure Mg with various concentrations of Fe $[25,57]$ did not reveal any detectable amounts of Fe or other noble elements in solution which strengthens the notion that noble elements are enriching on the surface. The evidence of noble metals enriching on the corroding $\mathrm{Mg}$ surface is important, as the concentration of Fe and other noble impurities is 
well known to have a large effect on hydrogen evolution kinetics of $\mathrm{Mg}$ alloys [51,58,59]; however, it is still unclear as to what extent any metal enrichment contributes to the manifestation of the NDE, as the enrichment efficiency has been empirically demonstrated to be poor [56,59]. Furthermore, the attendant change in surface Fe concentration is unlikely to fully account for the NDE based on extrapolation of cathodic data to anodic regions albeit for slow cathodic scans where kinetics are underestimated [51,56,59]. As such, whilst some enrichment of metals undoubtedly occurs on dissolving Mg surfaces, this might only partly account for the NDE phenomenon, meaning that the NDE as observed might also be influenced by the effects of $\mathrm{pH}$ and the formation of surface films - also posited to play a dominant role [60-63].

The effect of $\mathrm{pH}$ on the NDE was recently studied by Rossrucker et al. using an electrochemical flow cell with downstream inductively coupled plasma-mass spectroscopy (ICPMS) [64] as well as in bulk solutions with no external convection for buffered $0.1 \mathrm{M} \mathrm{NaCl}$ solutions in the $\mathrm{pH}$ range 3-10.5. It was found that the NDE was strong in alkaline environments but decreased with decreasing $\mathrm{pH}$. Decreasing $\mathrm{pH}$ will decrease the tendency to form hydroxide films, but also was posited to perhaps influence impurity enrichment on the basis that impurity metals may dissolve at lower $\mathrm{pH}$. Moreover, in the work of Rossrucker et al. [64] the NDE was not observed up to an applied current density of $10 \mathrm{~mA} / \mathrm{cm}^{2}$ for $6000 \mathrm{~s}$ in $\mathrm{pH}=3,0.1 \mathrm{M} \mathrm{NaCl}$ buffered solution, and no corrosion films were observed to form optically. Interestingly, the HER rate decreased at small applied anodic current densities and then increased in both $\mathrm{pH}=3$ and 7 buffered solutions, before increasing at higher applied anodic current densities. The increase in HER rate was attributed to the buffering capacity being locally overwhelmed (and hence allowing local alkalization) by the large applied current density. This behavior was also previously observed by James et al. in several unbuffered dilute acids [65]. In addition, Lebouil et al. showed that no 
NDE occurred in a $\mathrm{pH}=6.7$ phosphate buffer solution but did note the presence of a film different than $\mathrm{Mg}(\mathrm{OH})_{2}$, likely to be $\mathrm{Mg}\left(\mathrm{HPO}_{4}\right)_{2}$ from thermodynamic considerations, as the buffer would not produce a $\mathrm{pH}$ high enough for $\mathrm{Mg}(\mathrm{OH})_{2}$ to form [66]. Additional work by Lebouil et al. [66] considered two mechanisms occurring on corroding Mg surface: dissolution following Equation 1.1 where $\mathrm{e}^{-}$are consumed by a remotely located cathodic reaction and an insoluble film-forming mechanism resulting in manifestation of the NDE where $x$ is the fraction of soluble $\mathrm{Mg}^{2+}$ formed that is consumed by the local cathodic reaction:

$$
\mathrm{Mg}+2 \mathrm{H}_{2} \mathrm{O} \rightarrow x \mathrm{Mg}^{2+}+(1-x) \mathrm{Mg}(\mathrm{OH})_{2}+\mathrm{H}_{2}(g)+2 x \mathrm{OH}^{-} \quad \text { Equation } 1.7
$$

This reaction occurs at cathodes proximate to the anodic sites and is supported by the observation that the $\mathrm{H}_{2}$ produced is proportional to the $\mathrm{Mg}(\mathrm{OH})_{2}$ film formation. ${ }^{\text {iii }}$ Moreover, HER in such a reaction may not necessarily be assessed in a cathodic polarization scan. It should be noted that the film forming mechanism may also be described by:

$$
\mathrm{Mg}+\mathrm{H}_{2} \mathrm{O} \rightarrow \mathrm{MgO}+\mathrm{H}_{2}(g) \quad \text { Equation } 1.8
$$

based on the observations of a nanoscale thin layer of $\mathrm{MgO}$ at the interface of the $\mathrm{Mg}$ metal and $\mathrm{Mg}(\mathrm{OH})_{2}$, from TEM analysis $[8,10,23,54,55,67,68]$. The film forming mechanism is consistent with observations that the majority of $\mathrm{H}_{2}$ evolution occurs at the head of the advancing corrosion front where the dark corrosion product forms; however, it does not explain observations of net cathodically active regions far away from the anodic front as shown by SVET [7,33,36,45] and also increased cathodic kinetics associated with $\mathrm{Mg}(\mathrm{OH})_{2}$ covered surfaces [61].

Elucidating a comprehensive understanding of enhanced cathodic activity on $\mathrm{Mg}$ is important because it is unclear how it will affect the ability of an $\mathrm{Mg}$ alloy to sacrificially provide

\footnotetext{
iii It should be further noted that Equation 1.7 would not be discerned by extrapolation of cathodic data into the anodic range as the $\mathrm{H}_{2}$ generated from Equation 1.7 requires local $\mathrm{Mg}$ dissolution and is not the same source as from the Volmer or Heyrovsky HER mechanism on a net cathodic surface.
} 
cathodic prevention to AZ31B. One major concern is if the manifestation of anodically induced cathodic activation will cause polarity reversal in a sacrificial galvanic couple as has been shown in Mg alloy weld zones [69]. In this case, enrichment of noble metals or formation of dissolution products on the surface of the sacrificial anode may lead to increases in the potential of the sacrificial alloy such that it becomes more positive than substrate to be protected. The coating will therefore become cathodically polarized and will no longer be able to provide sacrificial protection to the underlying substrate. In addition, an increase self-corrosion of the anode with an increase in the exchange current density as a result of increased cathodic kinetics may produce an increase in the anodic kinetics which raises the galvanic couple potential and therefore increases the dissolution rate of the substrate alloy. Suppression of this effect is an area of interest where alloy elements which have shown to reduce this effect like As, Ge, and Sn are attractive [70-72].

\subsubsection{Potential for Sacrificial Cathodic Protection of Mg via Mg Alloy Coatings}

\subsubsection{Studies of Sacrificial Cathodic Protection of Mg to Date}

Few attempts have been made in the literature to synthesize and evaluate sacrificial coatings for Mg alloys. These have taken the form of physical vapor deposition (PVD) of 99.9\% pure Mg onto AZ31B and AZ91D substrates [73-75], magnetron sputter coating of 99.9\% La on AZ91D substrates followed by an $\mathrm{LaPO}_{4}$ conversion coating [76], Mg-rich pigments in an organic resin [77-79], and alkali metal intercalation coatings $[80,81]$. These studies have shown that pure $\mathrm{Mg}$ and pure La coatings have the ability to be sacrificial to the AZ class (Mg-Al-Zn) of Mg alloys tested in each respective study but could also be extended to AM (Mg-Al-Mn) type alloys which possess similar corrosion potentials to AZ alloys. However, their corrosion rates may be unsatisfactory as stand-alone metallic coatings particular when galvanically coupled to a more 
noble substrate. As such, $\mathrm{LaPO}_{4}$ conversion coatings were explored due to their insolubility over a broad range of $\mathrm{pH}$ and potential [76]. This conversion coating demonstrated success in restricting the dissolution of La to provide dissolution rates around 1.5 orders of magnitude less than that of the La coated samples in $0.1 \mathrm{M} \mathrm{NaCl}$. Mg-rich primers have also shown similar success in producing low corrosion rates while providing sacrificial protection. The studies of high purity $\mathrm{Mg}$ pigments in Mg-rich organic primers have shown the ability to protect scratches on AZ91D for up to 168 hours under full immersion testing in $3 \mathrm{wt} \% \mathrm{NaCl}$ [77] and supply galvanic currents on the order of 10-100's of $\mathrm{nA}$ in $3 \mathrm{wt} \% \mathrm{NaCl}$ depending somewhat on the $\mathrm{Mg}$ particle loading density in the primer [79]. While these studies have shown promise for the development of sacrificial high purity $\mathrm{Mg}$ coatings for $\mathrm{Mg}$ alloys, there is room for further development of these coatings through the use of smart alloying and processing methods so that a coating can be tailored (tuned) for the corrosion behavior of specific $\mathrm{Mg}$ (or other) alloys.

\subsubsection{Target Alloying Elements for Tunable Sacrificial Anodic Mg Coatings}

Alloying elements can either raise or lower the OCP of an Mg alloy in reference to pure Mg. Generally, most elements when alloyed with $\mathrm{Mg}$ will raise the OCP primarily due to being much more noble than $\mathrm{Mg}$ in the electrochemical series [21]. This is shown in Figures 1.4-1.6 where the corrosion potential of several commercial $\mathrm{Mg}$ alloys and custom $\mathrm{Mg}$ alloys have been compiled from the literature. These plots indicate that most alloying elements in commercial $\mathrm{Mg}$ alloys as well as custom Mg alloys produce corrosion potentials more positive than pure $\mathrm{Mg}$. This is primarily the case with $\mathrm{Al}, \mathrm{Mn}$, and $\mathrm{Zn}$ alloying additions as indicated by $\mathrm{AZ}(\mathrm{Al}+\mathrm{Zn})$ and $\mathrm{AM}$ $(\mathrm{Al}+\mathrm{Mn})$ alloys. Furthermore, custom additions to these alloys using atypical alloying additions such as $\mathrm{Au}, \mathrm{Bi}$, and Si provided small changes in OCP from the base AZ alloy which increased the corrosion potential. In contrast, rare earth (RE) alloying additions such as $\mathrm{Ce}, \mathrm{Gd}$, and La have 


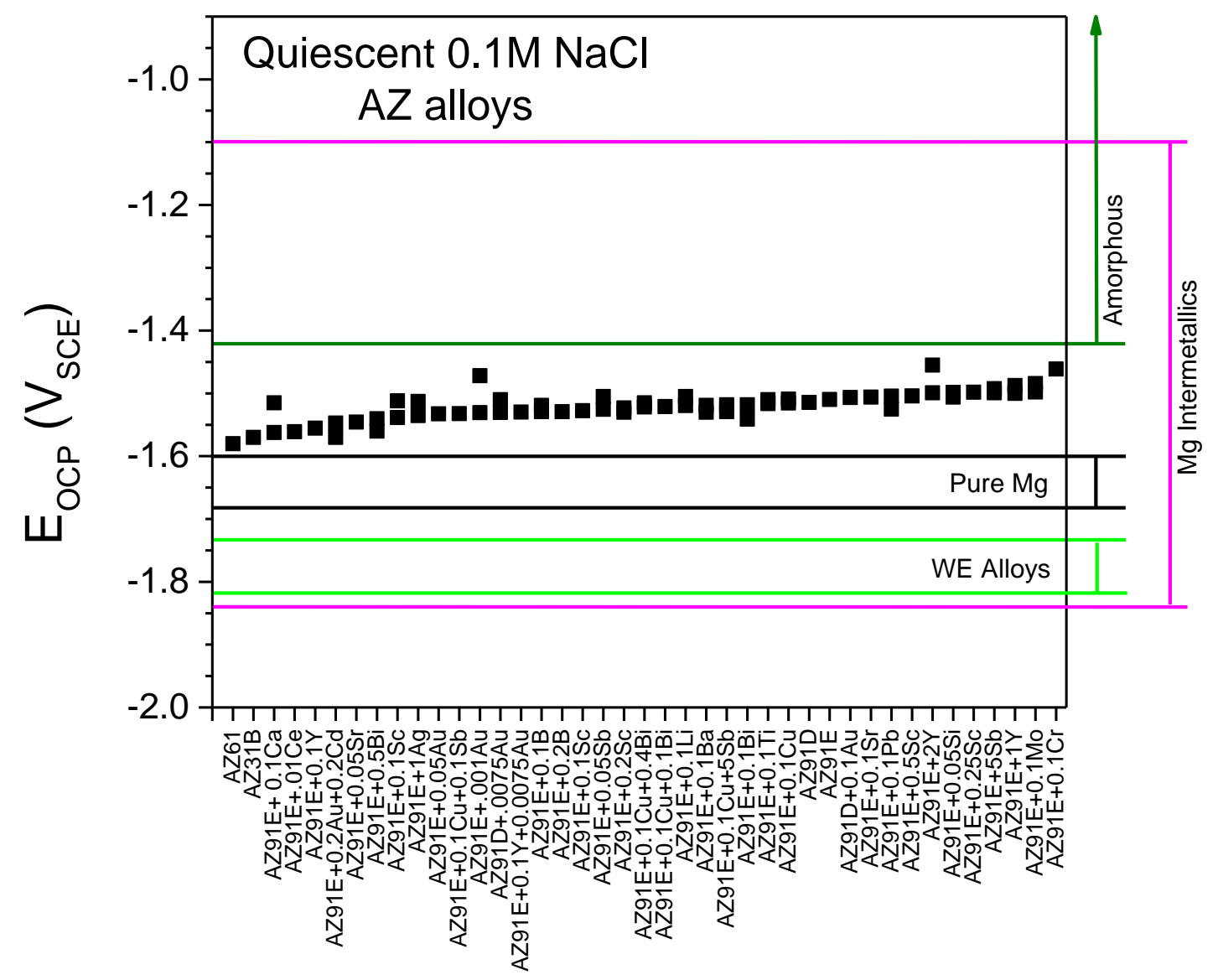

Figure 1.4. Summary of AZ alloy corrosion potentials ( $\left.\mathrm{E}_{\mathrm{corr}}\right) \mathrm{V}_{\mathrm{SCE}}$ measured in quiescent 0.1 $\mathrm{M} \mathrm{NaCl}$. Note: all alloying additions to AZ91E are in wt\%. Data from $[95,96]$.

displayed the ability to produce corrosion potentials more negative than those of AZ alloys with small alloying additions. However, larger alloying additions of RE elements displayed an increase in corrosion potential possibly due to the increased volume fraction of RE-rich secondary phases causing an increase in the cathodic kinetics from micro-galvanic coupling [13]. A large decrease in corrosion potential is evident in Figure 1.5 for commercial WE alloys which contain $\mathrm{Y}$ and lanthanide RE metal elements as the alloying additions. However, the concentration and identity of RE elements present in WE alloys varies due to the use of mischmetal which is a random combination of RE elements. Mischmetal is typically composed of some combination of $\mathrm{Ce}$, La, and $\mathrm{Nd}$ depending on manufacturer [3]. Ca and Sn addition have also shown the ability to decrease the OCP as shown in Figure 1.6. Based on this survey, RE elements present the most likely path 
to designing a sacrificial surface alloy for Mg alloys. In addition, Gd and La have displayed corrosion potentials more negative than that of pure $\mathrm{Mg}$ which make them primary candidates for investigation and design of sacrificial alloys [82]. However, attention needs to be given to how the OCP decreased.

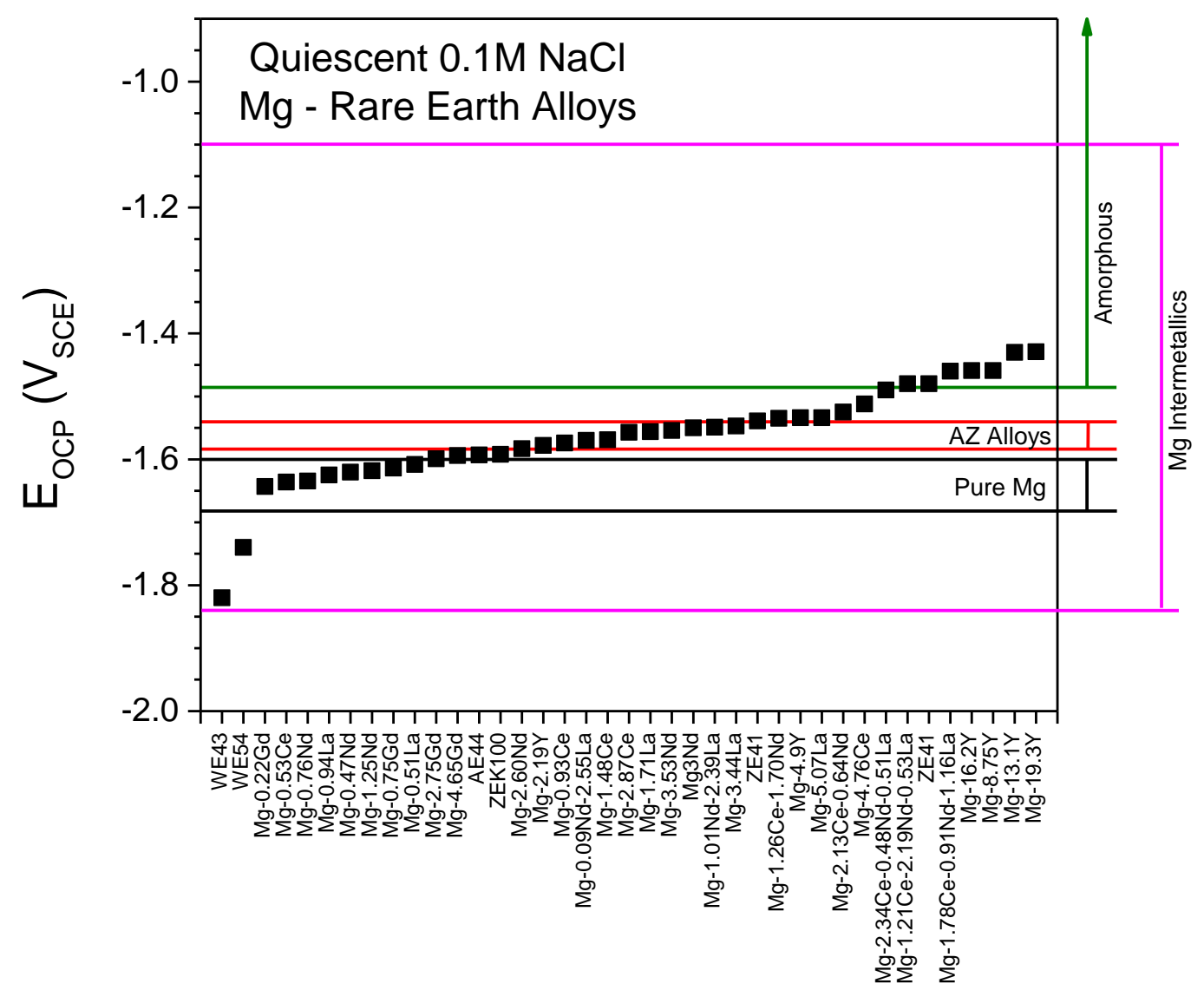

Figure 1.5. Summary of corrosion potentials $\left(\mathrm{E}_{\text {corr }}\right)$ versus a saturated calomel electrode measured in quiescent $0.1 \mathrm{M} \mathrm{NaCl}$ for rare earth additions to $\mathrm{Mg}$. Note: Alloying additions to $\mathrm{Mg}$ are in wt\%. Data from [5,35,96-101]. 


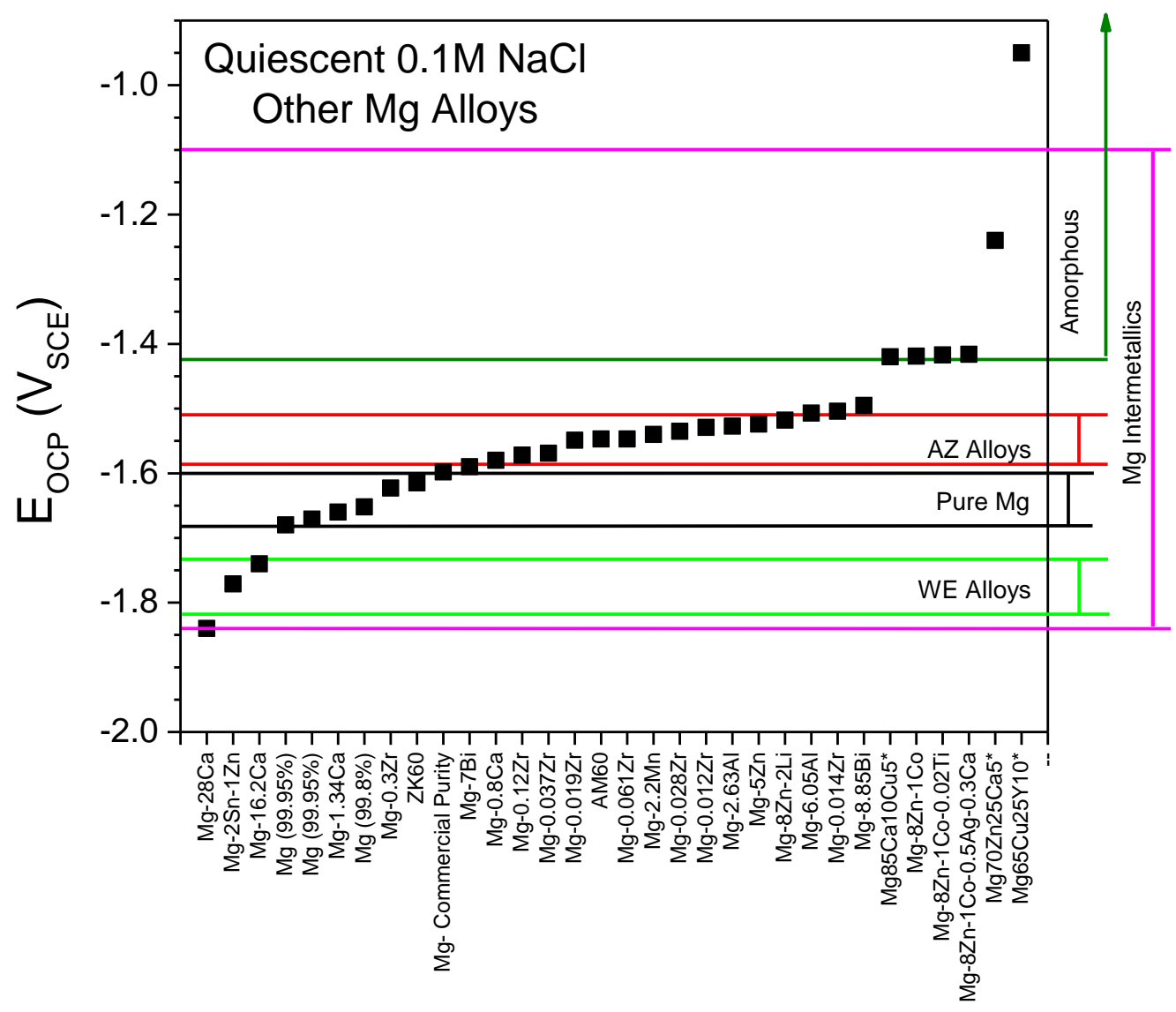

Figure 1.6. Summary of corrosion potentials ( $\left.\mathrm{E}_{\text {corr }}\right)$ versus a saturated calomel electrode measured in quiescent $0.1 \mathrm{M} \mathrm{NaCl}$ in the case of alternative alloying additions. Data from $[5,35,99,100,102-104]$.

According to mixed potential theory, the OCP of a metal can decrease by either an increase the anodic kinetics, a decrease in cathodic kinetics, or a combination of the two as shown in Figure 1.7. Increasing the anodic kinetics will increase the corrosion current density which is not desired in a coating. Therefore, elements which decrease the cathodic kinetics of a sacrificial Mg anode should be explored for sacrificial alloy protection. Recently, alloying additions of $<1 \mathrm{wt} \%$ As [70] and Ge [71] have shown the ability to greatly reduce cathodic kinetics due to the low exchange current density for HER of these elements. It has also been shown that Sn in solid solution with $\mathrm{Mg}$ up to $5 \mathrm{wt} \%$ produces a similar decrease the cathodic kinetics and $\mathrm{E}_{\text {corr }}$ as $\mathrm{Ge}$ and As [72]. These findings have been further supported by DFT modeling which has shown that other 
metalloid elements such as $\mathrm{In}, \mathrm{Ga}, \mathrm{Sb}, \mathrm{Si}$ could be capable of producing a similar decrease in a dilute alloy. Therefore, these elements would all be candidates for producing a sacrificial alloy.

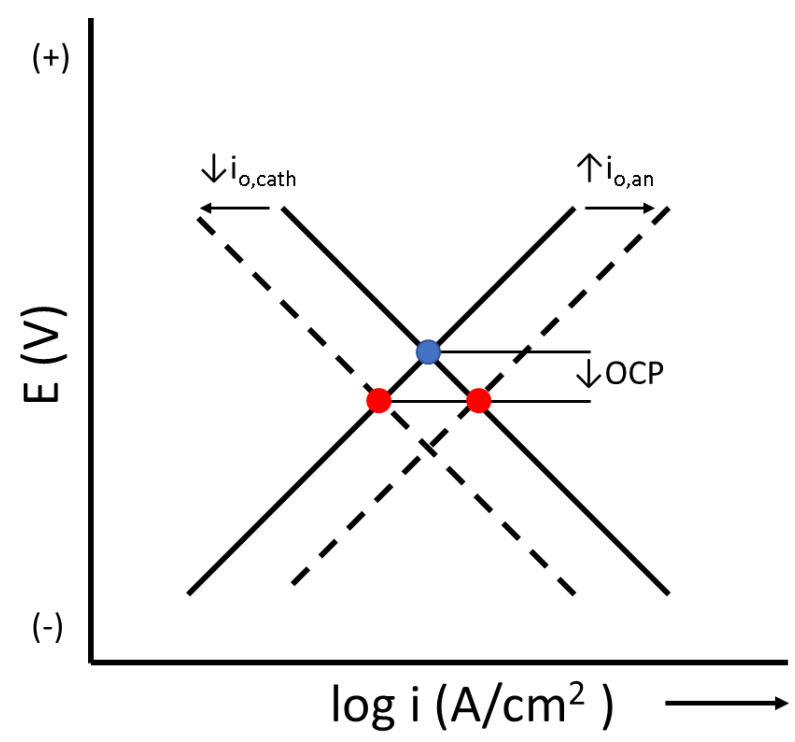

Figure 1.7. Schematic E vs log I plot showing how an increase in anodic kinetics or decrease in cathodic kinetics leads to a decrease in the OCP of an electrode.

\subsubsection{Critical Assessment of Current Protection Strategies}

Coating systems for Mg alloys typically involve multi-layer systems including combinations of a conversion coating, sealant, primer, and topcoat [83].To date conversion coatings such as Tagnite $^{\mathrm{TM}}$ and sealants such as Rockhard ${ }^{\mathrm{TM}}$ are barrier coatings only and have not demonstrated the ability to protect bare $\mathrm{Mg}$ at scratches, cracks, and other defects $[84,85]$. Conversion coatings also have the disadvantage of using toxic treatments such as chromium compounds which has increased the need for environmentally friendly coatings [14]. In addition, few attempts have been made to produce sacrificial coatings for Mg alloys. The use of RE elements as environmentally safe conversion coatings and performance of existing sacrificial coatings are assessed below.

Conversion coatings can be applied either chemically of electrochemically to Mg surfaces. Several RE conversion coatings have been evaluated for $\mathrm{Mg}$ and its alloys and have shown ability as corrosion barriers to $\mathrm{Mg}$ substrates [86,87]. Barrier properties are attributed to the formation of 
Table 1.2. Partial listing of RE-containing precursor solutions for conversion coatings illustrating the wide range of coating conditions used

\begin{tabular}{|c|c|c|c|c|}
\hline Alloy & Coating Conditions & RE-containing Precursor & Inhibiting Film Formed & Reference \\
\hline AM60 & $\begin{array}{l}20 \text { min immersion, } \\
50^{\circ} \mathrm{C} \text {, initial pH } \\
\text { unknown }\end{array}$ & $\begin{array}{l}0.01 \mathrm{M} \text { to } 5 \mathrm{M} \mathrm{Ce}\left(\mathrm{NO}_{3}\right)_{3}+ \\
0.1 \mathrm{M} \mathrm{NaCl}\end{array}$ & $\mathrm{CeO}_{2}$ & {$[86]$} \\
\hline \multirow[t]{2}{*}{ AZ31 } & \multirow{2}{*}{$\begin{array}{l}1 \mathrm{~min}, 10 \mathrm{~min}, 60 \mathrm{~min} \\
\text { immersion, } \\
\text { Temperature, } \\
\text { pH }=6\end{array}$} & $0.001 \mathrm{M} \mathrm{Ce}\left(\mathrm{NO}_{3}\right)_{3}$ & $\begin{array}{lcc}\mathrm{Ce}^{4+} & \text { and } & \mathrm{Ce}^{3+} \\
\text { oxide/hydroxide } & \\
\end{array}$ & \multirow[t]{2}{*}[87]{} \\
\hline & & $0.001 \mathrm{M} \mathrm{La}\left(\mathrm{NO}_{3}\right)_{3}$ & $\mathrm{La}(\mathrm{OH})_{3}$ & \\
\hline \multirow[t]{3}{*}{ WE43 } & \multirow{3}{*}{$\begin{array}{l}5 \text { min immersion, } \\
\text { Room Temperature, } \\
\text { initial } \mathrm{pH} \text { unknown }\end{array}$} & $0.05 \mathrm{M} \mathrm{Ce}\left(\mathrm{NO}_{3}\right)_{3}$ & \multirow[t]{3}{*}{--} & \multirow[t]{3}{*}[88]{} \\
\hline & & $0.05 \mathrm{M} \mathrm{La}\left(\mathrm{NO}_{3}\right)_{3}$ & & \\
\hline & & $0.05 \mathrm{M} \operatorname{Pr}\left(\mathrm{NO}_{3}\right)_{3}$ & & \\
\hline AZ63 & $\begin{array}{l}\text { Varying immersion } \\
\text { times up to } 3 \text { min, } \\
\text { Room Temperature, } \\
\text { initial pH unknown }\end{array}$ & $\begin{array}{l}4 \times 10^{-5} \mathrm{M} \mathrm{CeCl} \mathrm{Ce}_{3}+ \\
\text { varying amounts of } 33 \% \\
\mathrm{H}_{2} \mathrm{O}_{2}(\text { up to } 50 \mathrm{~mL} / \mathrm{L})\end{array}$ & $\begin{array}{lll}\mathrm{Ce}^{4+} & \text { and } & \mathrm{Ce}^{3+} \\
\text { oxide/hydroxide } & \end{array}$ & [89] \\
\hline AZ91 & $\begin{array}{l}20 \text { min immersion, } \\
50^{\circ} \mathrm{C}, \text { initial pH } \\
\text { unknown }\end{array}$ & $\begin{array}{l}0.015 \mathrm{M} \mathrm{Nd}\left(\mathrm{NO}_{3}\right)_{3}+20 \\
\mathrm{~mL} / \mathrm{L} \mathrm{H}_{2} \mathrm{O}_{2}\end{array}$ & $\mathrm{Nd}_{2} \mathrm{O}_{3}$ & [93] \\
\hline
\end{tabular}

hydrated RE-oxide blocking films over the cathodic sites on the metal surface which slows the overall corrosion rate through control of cathodic sites. However, the ability of these coatings as barriers for Mg over long time periods remains an important issue. In addition, relatively little is known about the coating mechanisms [15]. Part of this originates from the wide range of conditions which have been used to apply conversion coatings. Several pre-treatments and coating solutions have been used which vary immersion time, $\mathrm{pH}$, temperature, and concentration of $\mathrm{RE}$ containing salt precursors. A partial listing of precursor solutions illustrating the wide range of coating conditions is given in Table 1.2. Such varying coating conditions complicate evaluation of the corrosion resistance of RE films especially when very few studies provide thicknesses of the conversion coating formed on the $\mathrm{Mg}$ surface. In addition, most inhibiting $\mathrm{RE}$ films have been formed in solutions which do not contain chlorides and thus it is unclear if effective protective 
films can be formed in the presence of chlorides. However, evaluation of the corrosion behavior in several studies of RE conversion coatings have shown the ability of coatings to provide a passive window, increase breakdown potentials, and decrease cathodic kinetics which are of interest in this investigation [86,88-93]. As such, RE elements are promising candidates to provide a reservoir of ions to inhibit the corrosion of base $\mathrm{Mg}$ alloys.

\subsubsection{Benefits of Multifunctional Electrochemically Tunable Alloys for Scratch Protection}

Recently, the amorphous Al-Co-Ce alloy system was investigated at UVA to provide three important functions when used as a metallic coating for AA2024-T351 [18-20]. The first function it provided was to act as a corrosion barrier with a low inherent corrosion rate due to its structural amorphicity and chemical homogenization whilst the second function it provided was the ability to act as a sacrificial anode to protect the bare $\mathrm{Al}$ alloy in the event of a scratch or other defect in the coating. Various compositions of these elements in solid solution were used to regulate the OCP through control of anodic and cathodic reaction rates. The Al-Co-Ce alloys system exemplified a broad range of compositions for which alloys could be made amorphous [94]. The single-phase nature of amorphous alloys allows for simpler control and modeling of corrosion due to the lack of micro-galvanic coupling. This salient feature allows for the electrochemical properties to be modeled and optimized for a given alloy. For example, electrochemical parameters such as the open circuit potential, pitting potential, and repassivation potential were effectively measured and modeled as a function of composition and used to determine the optimal electrochemical properties for protection of AA2024-T351 [20]. A figure displaying the predicted OCP of Al-Co-Ce alloys over a range of Co and Ce concentrations in shown in Figure 1.8. As 
such, the Al-Co-Ce system could be optimized in this same way for any alloy for which sacrificial protection applies.

The third and final function was the ability of the coating to provide a reservoir for ionic inhibitor release during dissolution of the coating upon which inhibitor ions migrate to the scratch or defect and form a passive film effectively self-healing the scratch. The coating must store enough inhibitor to supply the critical inhibitor concentration to stop corrosion for reasonable time periods. However, the critical inhibitor concentration must be lower than the saturation concentration of the inhibitor in solution so that enough inhibitor can readily be released to arrest corrosion while not completely depleting the inhibitor capacity of the coating [18-20]. Transport of these ions in solution is driven by a chemical potential gradient from the inhibitor-rich coating to the unprotected sites. The distance over which these ions can be transported will depend on the chemical throwing power which is a function of the chemical potential gradient of inhibiting ions in solution. The ability of RE ions to provide this function for Mg alloys is unknown.

This novel coating strategy has provided a framework which could be implemented to any alloy including Mg-based alloys. However, there is no indication in the literature that this framework has been attempted for Mg alloys. The difficulty of designing such an alloy for $\mathrm{Mg}$ lies in what combination of alloying elements can form solid solution, extended solid solution, or amorphous $\mathrm{Mg}$ alloys that can provide a corrosion potential more negative than the alloy desired to be protected and whether or not the electrochemical properties can be tuned over a range of compositions. In addition, it is unclear what the best method of achieving a $\mathrm{Mg}$ based metallic coating on an $\mathrm{Mg}$ alloy surface is and whether or not the solid solution will be retained. 


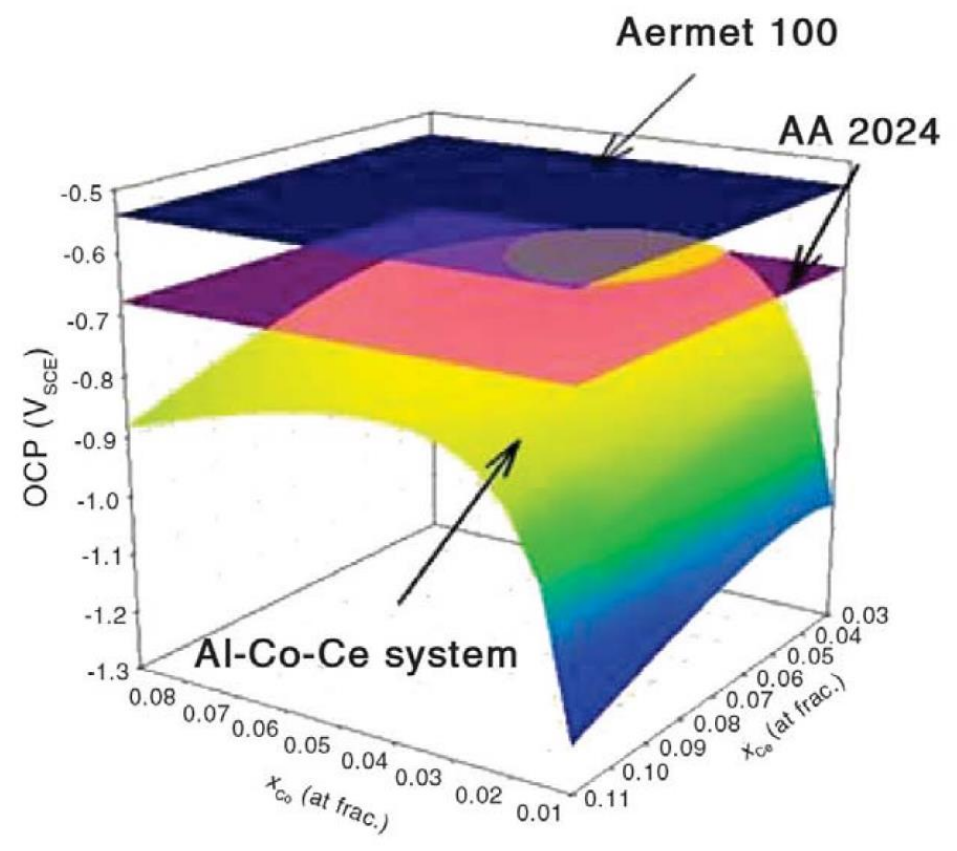

Figure 1.8. Predicted values of the OCP for amorphous Al-Co-Ce alloys over a range of Co and Ce concentrations in at\% utilizing a Scheffé regression model [19].

\subsection{Critical Unresolved Issues}

$\mathrm{Mg}$ corrosion has been widely studied and has gained significant interest in recent years. However, there are a number of critical unresolved issues and questions with respect to designing a tunable multifunctional coating for Mg alloys that need to be answered. Primary all studies of the corrosion of $\mathrm{Mg}$ and $\mathrm{Mg}$ alloys have focused on corrosion at $\mathrm{OCP}$ or during anodic polarization. There have been essentially no studies on the cathodic corrosion of $\mathrm{Mg}$ or $\mathrm{Mg}$ alloys which needs to be understood to successfully implement a sacrificial cathodic protection scheme. An understanding of cathodic corrosion will lead to determination of what corrosion rates of base $\mathrm{Mg}$ are acceptable for kinetic prevention and what range of potentials needs to be targeted to provide a galvanic couple potential in the range of kinetic prevention. In addition, thorough studies on the enhanced cathodic activity of Mg have only begun within the last five years. The effect of enhanced cathodic activity on the dissolution of $\mathrm{Mg}$ under potentiostatic control remains unclear 
and needs to be understood with respect to sacrificial cathodic protection as the protection potential range may be a complex function of not only alloy composition, structure, and environment, but also corrosion history.

Development of a surface alloy for the purposes of providing sacrificial protection to $\mathrm{Mg}$ alloys has not been fully realized at this time. There are several existing alloys which may provide sacrificial cathodic protection to other Mg alloys; however, they have not been evaluated for their abilities to act sacrificially. This presents a major opportunity for study. In addition, the ability of Mg alloys to provide a secondary means of chemical inhibition brought about by a reservoir of elements enabling ionic inhibitor release during dissolution has not been evaluated. Several conversion coatings containing inhibitor ions have been evaluated, but they have never been investigated for their ability to heal scratches and other defects in the coating that exposes the substrate in chloride environments. Moreover, smart of release of inhibiting ions from metal dissolution has not been evaluated. 


\subsection{Objectives}

The primary purpose of this research is to provide an understanding of the critical factors that govern the cathodic protection of $\mathrm{Mg}$ alloys via sacrificial Mg-based anodes. Such an understanding will provide a framework to guide the design of an Mg-based sacrificial alloy tuned for AZ31B-H24. It is desired that this alloy will provide not only sacrificial cathodic protection to AZ31B-H24 but also barrier protection and a secondary means of chemical inhibition brought about by a reservoir of elements enabling ionic inhibitor release during dissolution. Specifically, this research will:

- Further the understanding of Mg corrosion, in particular cathodic corrosion of $\mathrm{Mg}$ below open circuit potentials. These investigations will determine an acceptable corrosion rate for sacrificial cathodic protection and provide a range of potentials for kinetic prevention of AZ31B-H24. Furthermore, this study will provide an understanding of the relationship between potential and $\mathrm{Mg}$ alloy dissolution in several environments of interest.

- Address the discrepancies in the mechanisms of Mg dissolution under anodic polarization due to the NDE and enhanced cathodic activity of $\mathrm{Mg}$ surfaces through thorough evaluation of corrosion rate and $\mathrm{Mg}$ surface chemistry.

- Develop an understanding of the electrochemical behavior of commercial $\mathrm{Mg}$ alloys galvanically coupled to AZ31B-H24 including an evaluation of self-corrosion rates of coupled $\mathrm{Mg}$ in order to establish guidelines for improving sacrificial cathodic protection performance.

- Comprehensively study the ability of solution phase rare earth chlorides in isolation to provide chemical inhibition of AZ31B-H24 with some attention to inhibitor concentrations. 
- Study model Mg-Sn based sacrificial anodes for their ability to provide sacrificial cathodic protection to AZ31B-H24 and validate the guidelines established and assess the tunability of the $\mathrm{Mg}-\mathrm{Sn}$ alloy system. 


\subsection{Thesis Organization}

The research performed in this dissertation was strategically developed to address critical unresolved issues and meet the objectives of this work; this is separated into five tasks. In chapter 2, the cathodic corrosion of AZ31B-H24 is studied under potentiostatic control to assess what range of potentials is necessary to be applied in order to achieve practical cathodic protection. This will provide targets for coupled corrosion rate and potential of sacrificial $\mathrm{Mg}$ alloys for the cathodic protection of AZ31B-H24.

Chapters 3, 4, and 5 contribute synergistically to guide which alloy elements should be chosen to synthesize a tunable sacrificial alloy. Chapter 3 investigates the electrochemical and structural factors that control enhanced cathodic activity using high purity $\mathrm{Mg}$ as a simplified material for study. Chapter 4 studies the behavior of commercially pure Mg and Mg alloy WE43 galvanically coupled to AZ31B and assesses two different galvanic couple potentials ranges and what role enhanced cathodic activity contributes to the coupled corrosion behavior of both the anode and cathode. Next, Chapter 5 investigates the use of $\mathrm{La}^{3+}$ and $\mathrm{Gd}^{3+}$ ions to function as inhibitors to corrosion of AZ31B in chloride environments for their inclusion in a multifunctional alloy.

Chapter 6 investigates Mg-Sn based alloys as tunable sacrificial anodes for AZ31B-H24. In this investigation, the corrosion behavior of solid solution $\mathrm{Mg}$-Sn alloys is characterized both in isolation and also when galvanically coupled with AZ31B. In addition, Mg-Sn coatings produced by pulsed laser deposition on AZ31B-H24 substrates are evaluated for sacrificial cathodic protection. 
Chapter 7 presents the conclusions of this work and suggestions for future work. Here, the framework for designing sacrificial Mg-based alloys for cathodic protection of AZ31B-H24 is summarized. 


\subsection{References}

[1] T.B. Abbott, "Magnesium: Industrial and Research Developments Over the Last 15 Years," CORROSION. 71 (2) , 120-127, 2015.

[2] I. Polmear, Light Alloys: From Traditional Alloys to Nanocrystals, Elsevier Science, 2005.

[3] M.O. Pekguleryuz, K.U. Kainer, A.A. Kaya, Fundamentals of Magnesium Alloy Metallurgy, Woodhead Publishing, 2013.

[4] H.D. Yoo, I. Shterenberg, Y. Gofer, G. Gershinsky, N. Pour, D. Aurbach, "Mg rechargeable batteries: an on-going challenge," Energy Environ. Sci. 6 (8), 2265, 2013.

[5] N.T. Kirkland, In Vitro Assessment of the Physiological Biocorrosion Behaviour of Magnesium-Based Biomaterials, Ph.D. Dissertation, University of Canterbury, 2011.

[6] G.L. Makar, J. Kruger, "Corrosion of magnesium,” Int. Mater. Rev. 38 (3) , 138-153, 1993.

[7] G. Williams, H. ap Llwyd Dafydd, R. Grace, "The localised corrosion of Mg alloy AZ31 in chloride containing electrolyte studied by a scanning vibrating electrode technique," Electrochimica Acta. 109, 489-501, 2013.

[8] Z.P. Cano, M. Danaie, J.R. Kish, J.R. McDermid, G.A. Botton, G. Williams, "Physical Characterization of Cathodically-Activated Corrosion Filaments on Magnesium Alloy AZ31B," CORROSION. 71 (2), 146-159, 2015.

[9] J.R. Kish, Y. Hu, J. Li, W. Zheng, J.R. McDermid, "Technical Note: Examination of focused ion beam-sectioned surface films formed on AM60B Mg alloy in an aqueous saline solution," Corrosion. 68 (6) , 468-474, 2012.

[10] R.C. Phillips, J.R. Kish, "Nature of Surface Film on Matrix Phase of Mg Alloy AZ80 Formed in Water," CORROSION. 69 (8) , 813-820, 2013.

[11] M. Danaie, R.M. Asmussen, P. Jakupi, D.W. Shoesmith, G.A. Botton, "The role of aluminum distribution on the local corrosion resistance of the microstructure in a sand-cast AM50 alloy," Corros. Sci. 77 , 151-163, 2013.

[12] M. Danaie, R.M. Asmussen, P. Jakupi, D.W. Shoesmith, G.A. Botton, "The cathodic behaviour of Al-Mn precipitates during atmospheric and saline aqueous corrosion of a sandcast AM50 alloy," Corros. Sci. 83 , 299-309, 2014.

[13] K. Gusieva, C.H.J. Davies, J.R. Scully, N. Birbilis, "Corrosion of magnesium alloys: the role of alloying," Int. Mater. Rev. 60 (3) , 169-194, 2015.

[14] J.E. Gray, B. Luan, "Protective coatings on magnesium and its alloys-a critical review," J. Alloys Compd. 336 (1), 88-113, 2002.

[15] X.B. Chen, N. Birbilis, T.B. Abbott, "Review of corrosion-resistant conversion coatings for magnesium and its alloys," Corrosion. 67 (3) , 035005-1, 2011.

[16] F. Viejo, Z. Aburas, A.E. Coy, F.J. Garcia-Garcia, Z. Liu, P. Skeldon, G.E. Thompson, "Performance of Al alloys following excimer LSM-anodising approaches," Surf. Interface Anal. 42 (4) , 252-257, 2010.

[17] K. Schlüter, C. Zamponi, J. Hapke, N. Hort, K.U. Kainer, E. Quandt, "Mechanical properties and corrosion behaviour of freestanding, precipitate-free magnesium WE43 thin films," Int. J. Mater. Res. 104 (3) , 286-292, 2013.

[18] M.A. Jakab, J.R. Scully, "On-demand release of corrosion-inhibiting ions from amorphous Al-Co-Ce alloys," Nat. Mater. 4 (9) , 667-670, 2005.

[19] F. Presuel-Moreno, M.A. Jakab, N. Tailleart, M. Goldman, J.R. Scully, "Corrosion-resistant metallic coatings," Mater. Today. 11 (10) , 14-23, 2008. 
[20] J.R. Scully, F. Presuel-Moreno, M. Goldman, R.G. Kelly, N. Tailleart, "User-selectable barrier, sacrificial anode, and active corrosion inhibiting properties of Al-Co-Ce alloys for coating applications," Corrosion. 64 (3) , 210-229, 2008.

[21] P. Vanysek, "Electrochemical Series," Handb. Chem. Phys. 2013.

[22] M. Pourbaix, Atlas of Electrochemical Equilibria in Aqueous Solutions, Pergamon Press, n.d.

[23] M. Taheri, R.C. Phillips, J.R. Kish, G.A. Botton, "Analysis of the surface film formed on Mg by exposure to water using a FIB cross-section and STEM-EDS," Corros. Sci. 59 , 222-228, 2012.

[24] G. Song, A. Atrens, D. St John, X. Wu, J. Nairn, "The anodic dissolution of magnesium in chloride and sulphate solutions," Corros. Sci. 39 (10-11) , 1981-2004, 1997.

[25] J. Światowska, P. Volovitch, K. Ogle, "The anodic dissolution of Mg in NaCl and Na2SO4 electrolytes by atomic emission spectroelectrochemistry," Corros. Sci. 52 (7) , 2372-2378, 2010.

[26] M. Esmaily, J.E. Svensson, S. Fajardo, N. Birbilis, G.S. Frankel, S. Virtanen, R. Arrabal, S. Thomas, L.G. Johansson, "Fundamentals and advances in magnesium alloy corrosion," Prog. Mater. Sci. 89 , 92-193, 2017.

[27] D.A. Jones, Principles and Prevention of Corrosion, Pearson-Prentice Hall, 2005.

[28] C.F. Schreiber, V. Ashworth, C.J.L. Booker, Cathodic Protection Theory and Practice, Wiley (Harwood), Chichester, West Sussex, 1986.

[29] “ASTM F1182-07(2013) Standard Specification for Anodes, Sacrificial Zinc Alloy, ASTM International, West Conshohocken, PA, 2013, https://doi.org/10.1520/F1182," n.d.

[30] MIL-DTL-24779B(SH), Anodes, Sacrificial, Aluminum Alloy, 2006.

[31] "SP0169-2013 (formerly RP0169), "Control of External Corrosion on Underground or Submerged Metallic Piping Systems,"” n.d.

[32] L.G. Bland, A.D. King, N. Birbilis, J.R. Scully, "Assessing the Corrosion of Commercially Pure Magnesium and Commercial AZ31B by Electrochemical Impedance, Mass-Loss, Hydrogen Collection, and Inductively Coupled Plasma Optical Emission Spectrometry Solution Analysis," CORROSION. 71 (2) , 128-145, 2015.

[33] G. Williams, N. Birbilis, H.N. McMurray, "The source of hydrogen evolved from a magnesium anode," Electrochem. Commun. 36 , 1-5, 2013.

[34] P.F. King, "The Role of the Anion in the Anodic Dissolution of Magnesium," J. Electrochem. Soc. 113 (6) , 536-539, 1966.

[35] A.D. King, N. Birbilis, J.R. Scully, "Accurate Electrochemical Measurement of Magnesium Corrosion Rates; a Combined Impedance, Mass-Loss and Hydrogen Collection Study," Electrochimica Acta. 121 , 394-406, 2014.

[36] G. Williams, H. Neil McMurray, "Localized Corrosion of Magnesium in ChlorideContaining Electrolyte Studied by a Scanning Vibrating Electrode Technique," J. Electrochem. Soc. 155 (7), C340, 2008.

[37] M.E. Straumanis, B. Bhatia, "Disintegration of Magnesium While Dissolving Anodically in Neutral and Acidic Solutions," J. Electrochem. Soc. 110 (5), 357-360, 1963.

[38] G.R. Hoey, M. Cohen, "Corrosion of Anodically and Cathodically Polarized Magnesium in Aqueous Media,” J. Electrochem. Soc. 105 (5) , 245-250, 1958.

[39] G. Song, A. Atrens, D. Stjohn, J. Nairn, Y. Li, "The electrochemical corrosion of pure magnesium in $1 \mathrm{~N} \mathrm{NaCl,"} \mathrm{Corros.} \mathrm{Sci.} 39$ (5) , 855-875, 1997.

[40] E. Gulbrandsen, "Anodic behaviour of $\mathrm{Mg}$ in $\mathrm{HCO}-3 / \mathrm{CO} 2-3$ buffer solutions. Quasi-steady measurements," Electrochimica Acta. 37 (8) , 1403-1412, 1992. 
[41] E. Gulbrandsen, J. Taftø, A. Olsen, "The passive behaviour of Mg in alkaline fluoride solutions. Electrochemical and electron microscopical investigations," Corros. Sci. 34 (9) , 1423-1440, 1993.

[42] G.G. Perrault, "Potentiostatic study of the magnesium electrode in aqueous solution," J. Electroanal. Chem. Interfacial Electrochem. 27 (1) , 47-58, 1970.

[43] Z. Shi, F. Cao, G.-L. Song, A. Atrens, "Low apparent valence of Mg during corrosion," Corros. Sci. 88 , 434-443, 2014.

[44] G.S. Frankel, A. Samaniego, N. Birbilis, "Evolution of hydrogen at dissolving magnesium surfaces," Corros. Sci. 70 , 104-111, 2013.

[45] G. Williams, K. Gusieva, N. Birbilis, "Localized corrosion of binary Mg-Nd alloys in chloride-containing electrolyte using a scanning vibrating electrode technique," Corrosion. 68 (6) , 489-498, 2012.

[46] G.S. Frankel, S. Fajardo, B.M. Lynch, "Introductory lecture on corrosion chemistry: a focus on anodic hydrogen evolution on Al and Mg," Faraday Discuss. 180 , 11-33, 2015.

[47] Y. Yang, F. Scenini, M. Curioni, "A study on magnesium corrosion by real-time imaging and electrochemical methods: relationship between local processes and hydrogen evolution," Electrochimica Acta. 198 , 174-184, 2016.

[48] M. Curioni, J.M. Torrescano-Alvarez, Y.F. Yang, F. Scenini, “Application of Side-View Imaging and Real-Time Hydrogen Measurement to the Investigation of Magnesium Corrosion," CORROSION. 73 (5) , 463-470, 2017.

[49] N. Birbilis, A.D. King, S. Thomas, G.S. Frankel, J.R. Scully, "Evidence for enhanced catalytic activity of magnesium arising from anodic dissolution," Electrochimica Acta. 132 , 277-283, 2014.

[50] M. Taheri, J.R. Kish, N. Birbilis, M. Danaie, E.A. McNally, J.R. McDermid, "Towards a Physical Description for the Origin of Enhanced Catalytic Activity of Corroding Magnesium Surfaces," Electrochimica Acta. 116 , 396-403, 2014.

[51] S. Fajardo, G.S. Frankel, "Effect of impurities on the enhanced catalytic activity for hydrogen evolution in high purity magnesium," Electrochimica Acta. 165 , 255-267, 2015.

[52] S. Fajardo, C.F. Glover, G. Williams, G.S. Frankel, "The Source of Anodic Hydrogen Evolution on Ultra High Purity Magnesium," Electrochimica Acta. 212 , 510-521, 2016.

[53] S. Fajardo, G.S. Frankel, "A kinetic model explaining the enhanced rates of hydrogen evolution on anodically polarized magnesium in aqueous environments," Electrochem. Commun. 84, 36-39, 2017.

[54] Z.P. Cano, J.R. McDermid, J.R. Kish, "Cathodic activity of corrosion filaments formed on Mg alloy AM30,” J. Electrochem. Soc. 162 (14), C732-C740, 2015.

[55] K.A. Unocic, H.H. Elsentriecy, M.P. Brady, H.M. Meyer, G. Song, M. Fayek, R.A. Meisner, B. Davis, "Transmission electron microscopy study of aqueous film formation and evolution on magnesium alloys," J. Electrochem. Soc. 161 (6) , C302-C311, 2014.

[56] N. Birbilis, T. Cain, J.S. Laird, X. Xia, J.R. Scully, A.E. Hughes, "Nuclear microprobe analysis for determination of element enrichment following magnesium dissolution," ECS Electrochem. Lett. 4 (10), C34-C37, 2015.

[57] S. Thomas, O. Gharbi, S.H. Salleh, P. Volovitch, K. Ogle, N. Birbilis, "On the effect of Fe concentration on $\mathrm{Mg}$ dissolution and activation studied using atomic emission spectroelectrochemistry and scanning electrochemical microscopy," Electrochimica Acta. 210 , 271-284, 2016. 
[58] J.D. Hanawalt, C.E. Nelson, J.A. Peloubet, "Corrosion Studies of Magnesium and Its Alloys," Trans AIME. 147, 273-299, 1942.

[59] D. Lysne, S. Thomas, M.F. Hurley, N. Birbilis, "On the Fe Enrichment during Anodic Polarization of $\mathrm{Mg}$ and Its Impact on Hydrogen Evolution,” J. Electrochem. Soc. 162 (8), C396-C402, 2015.

[60] K.S. Williams, V. Rodriguez-Santiago, J.W. Andzelm, "Modeling reaction pathways for hydrogen evolution and water dissociation on magnesium," Electrochimica Acta. 210 , 261270, 2016.

[61] S.H. Salleh, S. Thomas, J.A. Yuwono, K. Venkatesan, N. Birbilis, "Enhanced hydrogen evolution on $\mathrm{Mg}(\mathrm{OH}) 2$ covered $\mathrm{Mg}$ surfaces," Electrochimica Acta. 161 , 144-152, 2015.

[62] R.L. Liu, S. Thomas, J.R. Scully, G. Williams, N. Birbilis, "An Experimental Survey of the Cathodic Activation of Metals Including $\mathrm{Mg}, \mathrm{Sc}, \mathrm{Gd}, \mathrm{La}, \mathrm{Al}, \mathrm{Sn}, \mathrm{Pb}$, and $\mathrm{Ge}$ in Dilute Chloride Solutions of Varying pH," CORROSION. 73 (5) , 494-505, 2017.

[63] J.A. Yuwono, N. Birbilis, K.S. Williams, N.V. Medhekar, "Electrochemical Stability of Magnesium Surfaces in an Aqueous Environment," J. Phys. Chem. C. 120 (47) , 2692226933, 2016.

[64] L. Rossrucker, A. Samaniego, J.-P. Grote, A.M. Mingers, C.A. Laska, N. Birbilis, G.S. Frankel, K.J.J. Mayrhofer, "The pH dependence of magnesium dissolution and hydrogen evolution during anodic polarization," J. Electrochem. Soc. 162 (7), C333-C339, 2015.

[65] W.E. James, M.E. Straumanis, B. Bhatia, J.W. Johnson, "The Difference Effect on Magnesium Dissolving in Acids," J. Electrochem. Soc. 110 (11) , 1117-1120, 1963.

[66] S. Lebouil, O. Gharbi, P. Volovitch, K. Ogle, "Mg Dissolution in Phosphate and Chloride Electrolytes: Insight into the Mechanism of the Negative Difference Effect," CORROSION. 71 (2) , 234-241, 2015.

[67] M. Taheri, M. Danaie, J.R. Kish, "TEM examination of the film formed on corroding Mg prior to breakdown,” J. Electrochem. Soc. 161 (3) , C89-C94, 2014.

[68] M.P. Brady, G. Rother, L.M. Anovitz, K.C. Littrell, K.A. Unocic, H.H. Elsentriecy, G.-L. Song, J.K. Thomson, N.C. Gallego, B. Davis, "Film breakdown and nano-porous $\mathrm{Mg}(\mathrm{OH}) 2$ formation from corrosion of magnesium alloys in salt solutions," J. Electrochem. Soc. 162 (4) , C140-C149, 2015.

[69] L.G. Bland, B.C. Rincon Troconis, R.J. Santucci Jr., J.M. Fitz-Gerald, J.R. Scully, "Metallurgical and Electrochemical Characterization of the Corrosion of a Mg-Al-Zn Alloy AZ31B-H24 Tungsten Inert Gas Weld: Galvanic Corrosion Between Weld Zones," CORROSION. 72 (10) , 1226-1242, 2016.

[70] G. Williams, H.A.-L. Dafydd, H.N. McMurray, N. Birbilis, "The influence of arsenic alloying on the localised corrosion behaviour of magnesium," Electrochimica Acta. 219 , 401-411, 2016.

[71] R.L. Liu, M.F. Hurley, A. Kvryan, G. Williams, J.R. Scully, N. Birbilis, "Controlling the corrosion and cathodic activation of magnesium via microalloying additions of Ge," Sci. Rep. 6 (1) 2016.

[72] J. Yang, C.D. Yim, B.S. You, "Characteristics of Surface Films Formed on Mg-Sn Alloys in $\mathrm{NaCl}$ Solution,” J. Electrochem. Soc. 163 (8) , C395-C401, 2016.

[73] B. Yu, J. Uan, "Sacrificial Mg film anode for cathodic protection of die cast Mg-9wt.\%Al1wt.\%Zn alloy in $\mathrm{NaCl}$ aqueous solution," Scr. Mater. 54 (7) , 1253-1257, 2006. 
[74] H. Tsubakino, A. Yamamoto, S. Fukumoto, A. Watanabe, K. Sugahara, H. Inoue, "Highpurity magnesium coating on magnesium alloys by vapor deposition technique for improving corrosion resistance," Mater. Trans. 44 (4) , 504-510, 2003.

[75] A. Yamamoto, A. Watanabe, K. Sugahara, S. Fukumoto, H. Tsubakino, "Deposition Coating of Magnesium Alloys with Pure Magnesium," Mater Trans JIM. 42 (7), 1237-1242, 2001.

[76] Y.-J. Wu, X.-B. Chen, G. Williams, J.R. Scully, T. Gengenbach, N. Birbilis, "Stifling magnesium corrosion via a novel anodic coating," RSC Adv. 6 (49), 43408-43417, 2016.

[77] X. Lu, Y. Zuo, X. Zhao, Y. Tang, X. Feng, "The study of a Mg-rich epoxy primer for protection of AZ91D magnesium alloy," Corros. Sci. 53 (1) , 153-160, 2011.

[78] X. Lu, Y. Zuo, X. Zhao, Y. Tang, "The improved performance of a Mg-rich epoxy coating on AZ91D magnesium alloy by silane pretreatment," Corros. Sci. 60 , 165-172, 2012.

[79] X. Lu, Y. Zuo, X. Zhao, S. Shen, "The Effects of Magnesium Particles in Mg-rich Primers Applied on AZ91D Magnesium Alloy," Int. J. Electrochem. Sci. 10 (11) , 9586-9604, 2015.

[80] G.-L. Song, N.J. Dudney, J. Li, R.L. Sacci, J.K. Thomson, "The possibility of forming a sacrificial anode coating for Mg," Corros. Sci. 87 , 11-14, 2014.

[81] M.D. Bharadwaj, A.K. Sachdev, M.W. Verbrugge, Sacrificial coatings for magnesium components

[82] X.-B. Chen, T. Cain, J.R. Scully, N. Birbilis, "Technical Note: Experimental Survey of Corrosion Potentials for Rare Earth Metals Ce, Er, $\mathrm{Gd}, \mathrm{La}$, and $\mathrm{Nd}$ as a Function of $\mathrm{pH}$ and Chloride Concentration," CORROSION. 70 (4) , 323-328, 2014.

[83] J. Hawkins, Assessment of Protective Finishing Systems for Magnesium, in: Washington, D.C., 1993.

[84] R.B. Griffin, D. Zuniga, M. Datta, Coating Adhesion for Mg Alloy ZE41A, in: 2007: pp. 455-458.

[85] W. Zheng, C. Derushie, R. Zhang, J. Lo, "Protection of Mg Alloys for Structural Applications in Automobiles," SAE World Congr. Exhib. SP-1845 , 25-40, 2004.

[86] F.E.-T. Heakal, O.S. Shehata, N.S. Tantawy, "Enhanced corrosion resistance of magnesium alloy AM60 by cerium(III) in chloride solution," Corros. Sci. 56 , 86-95, 2012.

[87] M.F. Montemor, A.M. Simões, M.J. Carmezim, "Characterization of rare-earth conversion films formed on the AZ31 magnesium alloy and its relation with corrosion protection," Appl. Surf. Sci. 253 (16) , 6922-6931, 2007.

[88] A.L. Rudd, C.B. Breslin, F. Mansfeld, "The corrosion protection afforded by rare earth conversion coatings applied to magnesium," Corros. Sci. 42 (2) , 275-288, 2000.

[89] M. Dabalà, K. Brunelli, E. Napolitani, M. Magrini, "Cerium-based chemical conversion coating on AZ63 magnesium alloy," Surf. Coat. Technol. 172 (2) , 227-232, 2003.

[90] T. Ishizaki, Y. Masuda, K. Teshima, "Composite film formed on magnesium alloy AZ31 by chemical conversion from molybdate/phosphate/fluorinate aqueous solution toward corrosion protection," Surf. Coat. Technol. 217, 76-83, 2013.

[91] O.V. Karavai, A.C. Bastos, M.L. Zheludkevich, M.G. Taryba, S.V. Lamaka, M.G.S. Ferreira, "Localized electrochemical study of corrosion inhibition in microdefects on coated AZ31 magnesium alloy," Electrochimica Acta. 55 (19) , 5401-5406, 2010.

[92] L. Li, Q. Qu, Z.W. Fang, L. Wang, Y. He, R. Yuan, Z. Ding, "Enhanced corrosion resistance of AZ31B magnesium alloy by cooperation of rare earth cerium and stannate conversion coating," Int J Electrochem Sci. 7 , 12690-12705, 2012.

[93] G. Jin, Y. Yang, X. Cui, E. Liu, Z. Wang, Q. Li, "Chrome-free neodymium-based protective coatings for magnesium alloys," Mater. Lett. 65 (8) , 1145-1147, 2011. 
[94] M.C. Gao, N. Ünlü, M. Mihalkovic, M. Widom, G.J. Shiflet, "Glass Formation, Phase Equilibria, and Thermodynamic Assessment of the Al-Ce-Co System Assisted by FirstPrinciples Energy Calculations," Metall. Mater. Trans. A. 38 (10) , 2540-2551, 2007.

[95] A.D. Südholz, N. Birbilis, C.J. Bettles, M.A. Gibson, "Corrosion behaviour of Mg-alloy AZ91E with atypical alloying additions," J. Alloys Compd. 471 (1-2) , 109-115, 2009.

[96] M. Finšgar, "Galvanic series of different stainless steels and copper- and aluminium-based materials in acid solutions," Corros. Sci. 68 , 51-56, 2013.

[97] H.B. Yao, Y. Li, A.T.S. Wee, "Corrosion behavior of melt-spun Mg65Ni20Nd15 and Mg65Cu25Y10 metallic glasses,” Electrochimica Acta. 48 (18), 2641-2650, 2003.

[98] M.-C. Zhao, M. Liu, G.-L. Song, A. Atrens, "Influence of pH and chloride ion concentration on the corrosion of Mg alloy ZE41," Corros. Sci. 50 (11) , 3168-3178, 2008.

[99] A.D. Südholz, N.T. Kirkland, R.G. Buchheit, N. Birbilis, "Electrochemical Properties of Intermetallic Phases and Common Impurity Elements in Magnesium Alloys," Electrochem. Solid-State Lett. 14 (2), C5, 2011.

[100] "H.Yang, Unpublished Data, Monash University, 2011," n.d.

[101] X. Xia, N. Birbilis, C.H.J. Davies, J.-F. Nie, Composition effects on the corrosion of Aluminum-free magnesium alloys, in: Melbourne, Australia, 2012.

[102] N. Birbilis, M.A. Easton, A.D. Sudholz, S.M. Zhu, M.A. Gibson, "On the corrosion of binary magnesium-rare earth alloys,” Corros. Sci. 51 (3) , 683-689, 2009.

[103] A.D. Sudholz, K. Gusieva, X.B. Chen, B.C. Muddle, M.A. Gibson, N. Birbilis, "Electrochemical behaviour and corrosion of Mg-Y alloys," Corros. Sci. 53 (6) , 2277-2282, 2011.

[104] Sudholz, A.D., Development of Magnesium Alloys for Improved Corrosion Resistance, Ph.D. Dissertation, Monash University, 2010. 


\section{Range of Potentials for Kinetic Immunity of HP Mg and AZ31B-H24}

\subsection{Introduction}

This chapter seeks to determine what range of potentials is required for the cathodic protection of AZ31B-H24. Since thermodynamic protection of $\mathrm{Mg}$ and its alloys is nearly impossible by any type of galvanic protection scheme, a range of potentials by which kinetic prevention can be afforded will be explored. This is important as the cathodic corrosion of $\mathrm{Mg}$ and its alloys has seldom been explored in the literature. Furthermore, studies of sacrificial protection of $\mathrm{Mg}$ has been limited to date. These studies have primarily investigated the corrosion rate of coated $\mathrm{Mg}$ and the couple behavior through electrochemical testing but have not measured cathode dissolution rate, defined acceptable cathode dissolution rates, or tuned a coating for a target cathode dissolution rate [1-5]. In terms of a target dissolution rate for this study, the Army Research Lab has specified a $7.5 \mathrm{mpy}\left(\approx 0.19 \mathrm{~mm} /\right.$ year, $\left.1.1 \mu \mathrm{A} / \mathrm{cm}^{2}\right)$ corrosion rate for $\mathrm{Mg}$ alloys in armor applications [6]. However, this corrosion rate was determined using atmospheric corrosion testing and would not be a suitable comparison for the full immersion tests performed in this dissertation. As such, a cathode dissolution rate reduction of at least one order of magnitude in current density will be targeted for cathodic protection of AZ31B-H24. The anodic Tafel slope of AZ31B-H24 has been measured between $27 \mathrm{mV} / \mathrm{dec}$ and $112.5 \mathrm{mV} / \mathrm{dec}$ in various environments which means that the galvanic couple potential must be conservatively reduced below $112.5 \mathrm{mV}$ below the OCP of AZ31B-H24 to reach this target [7]. To carry out this study, potentiostatic polarization of AZ31B-H24 over a wide range of potentials is performed for 24 hours as a scoping study. The dissolution rate was characterized by mass loss measurements and solution analysis by inductively coupled plasma optical emission spectroscopy to determine a threshold for practical cathodic protection. 


\subsection{Experimental Procedures}

\subsubsection{Materials}

AZ31B-H24 was used in all investigations in this dissertation as supplied by Magnesium Elektron (Table 2.1). AZ31B-H24 sheets were sheared into squares approximately $2 \mathrm{~cm} \times 2 \mathrm{~cm}$ for electrochemical testing. All samples for electrochemical testing were mechanically ground to a 1200 grit $\mathrm{SiC}$ finish using ethanol $\left(\mathrm{C}_{2} \mathrm{H}_{6} \mathrm{O}\right)$ as lubricant. Sample surfaces were cleaned with ethanol and dried using compressed air after each grinding step.

Table 2.1. Composition of AZ31B-H24 used in this study in wt\%. Compositional analysis was performed by QUANT (Quality Analysis and Testing Corporation), USA.

\begin{tabular}{ccccccccc}
\hline Element & $\mathrm{Mg}$ & $\mathrm{Al}$ & $\mathrm{Zn}$ & $\mathrm{Mn}$ & $\mathrm{Fe}$ & $\mathrm{Zr}$ & $\mathrm{Ni}$ & $\mathrm{Cu}$ \\
\hline AZ31B-H24 & Bal. & 3.02 & 0.99 & 0.33 & 0.005 & $<0.001$ & 0.002 & 0.005 \\
\hline
\end{tabular}

\subsubsection{Electrochemical Testing}

In order to determine a range of potentials for practical kinetically enabled cathodic protection of AZ31B, potentiostatic polarization was performed at various potentials between $1.550 \mathrm{~V}_{\mathrm{SCE}}$ and $-1.800 \mathrm{~V}_{\mathrm{SCE}}$ in $250 \mathrm{~mL}$ of quiescent $0.6 \mathrm{M} \mathrm{NaCl}, 0.1 \mathrm{M} \mathrm{MgCl}_{2}$, and a $0.1 \mathrm{M}$ TRIS $\mathrm{HCl}$ buffer solution $\left(\mathrm{pH}=7.25\right.$ ) for 24 hours; the initial $\mathrm{pH}$ of $0.6 \mathrm{M} \mathrm{NaCl}$ and $0.1 \mathrm{M} \mathrm{MgCl}_{2}$ was in the range 5-6. All solutions were prepared utilizing ACS grade materials and 18.2 M $\Omega$ deionized water. $\mathrm{NaCl}$ and $\mathrm{MgCl}_{2}$ were chosen in this study because they are environments relevant to $\mathrm{Mg}$ corrosion while TRIS was chosen due to its ability to act as chelating agent and buffer to minimize formation of $\mathrm{Mg}(\mathrm{OH})_{2}$ [8]. Electrochemical testing was performed using a three electrode vertical cell with a platinum mesh counter electrode and saturated calomel reference electrode (SCE). An electrolyte filled burette with an inverted funnel attached was centered over the sample to aid in collection of $\mathrm{H}_{2}$ as described elsewhere [9]. Solutions were saturated with hydrogen prior to commencement of testing to ensure that hydrogen evolved on the Mg surface would be captured 
in the burette and not dissolve in solution. This setup provided an exposed area of $1 \mathrm{~cm}^{2}$ for AZ31B specimens. Note that applied potentials were not corrected for the solution resistance prior to potentiostatic polarization but was determined to be approximately $20 \Omega-\mathrm{cm}^{2}, 65 \Omega-\mathrm{cm}^{2}$, and 110 $\Omega$ - $\mathrm{cm}^{2}$ respectively for $0.6 \mathrm{M} \mathrm{NaCl}, 0.1 \mathrm{M} \mathrm{MgCl}_{2}$, and $0.1 \mathrm{M}$ TRIS by high frequency EIS measurement at $10^{5} \mathrm{~Hz}$. Following testing, samples were cleaned using $200 \mathrm{~g} / \mathrm{L} \mathrm{CrO}_{3}$ according to ASTM G1 [10] to remove all corrosion products for determination of mass loss and evaluation using optical microscopy. Negligible mass loss was recorded on as-polished samples as seen elsewhere verifying this method [11].

Under anodic polarization the total anodic charge is described by Equation 2.1:

$$
Q_{\Delta m}=Q_{H_{2}}+Q_{\text {inet anodic }}
$$

Equation 2.1

following fundamental mixed potential theory [4], whereas the total anodic charge is:

$$
Q_{\Delta m}+Q_{\text {i net cathodic }}=Q_{\mathrm{H}_{2}}
$$

Equation 2.2

during cathodic polarization. $Q_{\Delta m}$ is the anodic charge consumed from metal dissolution which can be accessed from gravimetric mass loss after removing corrosion products, $Q_{\mathrm{H}_{2}}$ is the cathodic charge found on the sample surface due to hydrogen evolution, and $Q_{i}$ net anodic/cathodic is the net charge measured by the potentiostat as the measured current density over time. The gravimetric mass loss from for each sample with $\pm 0.01 \mathrm{mg}$ resolution was converted to the equivalent anodic charge density $\left(Q_{\Delta m}\right)$ via Equation 2.3:

$$
Q_{\Delta m}=\frac{z n F}{A}=\frac{z \Delta m F}{A a}
$$

where $z$ is the equivalent electrons per mole of $\mathrm{Mg}$ oxidized, $\mathrm{n}$ is the number of moles of $\mathrm{Mg}$ consumed, $\Delta \mathrm{m}$ is the change in mass, $F$ is Faraday's constant, $A$ is the area of the electrode, and $a$ is the molar mass of $\mathrm{Mg}$. In this study, $\mathrm{z}$ is assumed to be $2 \mathrm{for} \mathrm{Mg}$ following the half-cell reaction 
$\mathrm{Mg} \rightarrow \mathrm{Mg}^{2+}+2 \mathrm{e}^{-}$. Congruent dissolution is assumed for AZ31B-H24 which changes Equation 2.3 to:

$$
Q_{\Delta m}=\frac{N_{e q} \times \Delta m \times F}{A}
$$

where $N_{e q}$ is the weighted average equivalent number of electrons per mole of the $i_{t h}$ element being dissolved:

$$
N_{e q}=\sum \frac{f_{i} \times z_{i}}{a_{i}}
$$

$\mathrm{Al}^{3+}, \mathrm{Mg}^{2+}, \mathrm{Mn}^{2+}$, and $\mathrm{Zn}^{2+}$ are assumed to be dissolving congruently in this equation where $f$ is the mass fraction of each element yielding a value of $N_{e q}=0.0787$ or an equivalent weight of 12.71 g/eq.

\subsubsection{Inductively Coupled Plasma-Optical Emission Spectroscopy}

A Thermo Scientific ${ }^{\mathrm{TM}}$ iCAP 7200 ICP-OES was used for analysis. Samples were acidified by adding $1 \mathrm{M} \mathrm{HCl}$ into each solution after electrochemical testing in order to dissolve any insoluble corrosion products suspended in solution. Any corrosion products remaining on the surface could not be analyzed because of $\mathrm{Cr}$ interferences with $\mathrm{Fe}$ emission signals due to the $\mathrm{CrO}_{3}$ cleaning. This is an issue primarily during anodic polarization in that ICP-OES cannot be used to calculate accurate $\mathrm{Q}_{\Delta \mathrm{m}}$ where corrosion product is formed. Solution analysis for $0.1 \mathrm{M} \mathrm{MgCl}_{2}$ tests were not performed as the $\mathrm{Mg}$ content in the electrolyte was greater than the saturation limit of the instrument detector. Furthermore, dilution of these samples to produce an $\mathrm{Mg}^{2+}$ concentration below the instrument saturation limit would not yield accurate determination of $\mathrm{Mg}^{2+}$ dissolved during testing because the amount of $\mathrm{Mg}^{2+}$ measured by mass loss was several orders of magnitude less than that of the $\mathrm{Mg}^{2+}$ content in the $\mathrm{MgCl}_{2}$ electrolyte. In this work, the emission intensity of $\operatorname{Mg}(279.553 \mathrm{~nm}), \mathrm{Mg}(280.270 \mathrm{~nm}), \mathrm{Al}(226.910 \mathrm{~nm}), \mathrm{Al}(308.215 \mathrm{~nm}), \mathrm{Al}(396.152 \mathrm{~nm}), \mathrm{Fe}$ 
$(238.204 \mathrm{~nm}), \mathrm{Fe}(239.562 \mathrm{~nm}), \mathrm{Mn}(257.610 \mathrm{~nm}), \mathrm{Mn}(259.373 \mathrm{~nm}), \mathrm{Zn}(206.200 \mathrm{~nm}), \mathrm{Zn}$ $(213.856 \mathrm{~nm})$ were recorded and used for the calculation of charge consumed and percent of elements in solution using solution analysis. The approximate detection limit for each element is shown in Table 2.2.

Table 2.2. Approximate elemental detection limits for the ICP-OES used in this investigation in $\mathrm{ppm}(\mathrm{mg} / \mathrm{L})$.

\begin{tabular}{ccccccccc}
\hline Element & $\mathrm{Mg}$ & $\mathrm{Al}$ & $\mathrm{Zn}$ & $\mathrm{Mn}$ & $\mathrm{Fe}$ & $\mathrm{Zr}$ & $\mathrm{Ni}$ & $\mathrm{Cu}$ \\
\hline $\mathrm{ppm}$ & 0.005 & 0.030 & 0.005 & 0.005 & 0.005 & 0.020 & 0.005 & 0.010 \\
\hline
\end{tabular}

\subsection{Results}

\subsubsection{Mass Loss Measurements During Potentiostatic Polarization}

The net anodic current density was determined as a function of potential with the aim of identifying a range of potentials for cathodic protection by reduced anodic kinetics. Figure 2.1 shows representative net current densities measured at each applied potential in each electrolyte for AZ31B-H24 along with the corresponding average mass loss converted to anodic charge density at each potential; the indicated OCP of each alloy in Figure 2.1 is an average measurement of the steady state corrosion potential after 24-hour immersion in each solution. Figure 2.1a illustrates net applied current density versus time over a range of potentials from $-1.575 \mathrm{~V}_{\mathrm{SCE}}$ to $1.800 \mathrm{~V}_{\mathrm{SCE}}$. In the range $-1.575 \mathrm{~V}_{\mathrm{SCE}}$ to $-1.650 \mathrm{~V}_{\mathrm{SCE}}$, the net current density changes over time from net anodic to net cathodic in $0.6 \mathrm{M} \mathrm{NaCl}$. The most positive applied potential tested in $0.6 \mathrm{M}$ $\mathrm{NaCl},-1.575 \mathrm{~V}_{\mathrm{SCE}}$, was net anodic for around 2000 seconds before becoming net cathodic which was the longest time spent being net anodic out of all tested applied potentials in $0.6 \mathrm{M} \mathrm{NaCl}$ as would be expected. It should be noted that the net anodic current density increased before decreasing and ultimately became net cathodic for samples that exhibited polarity reversal under 

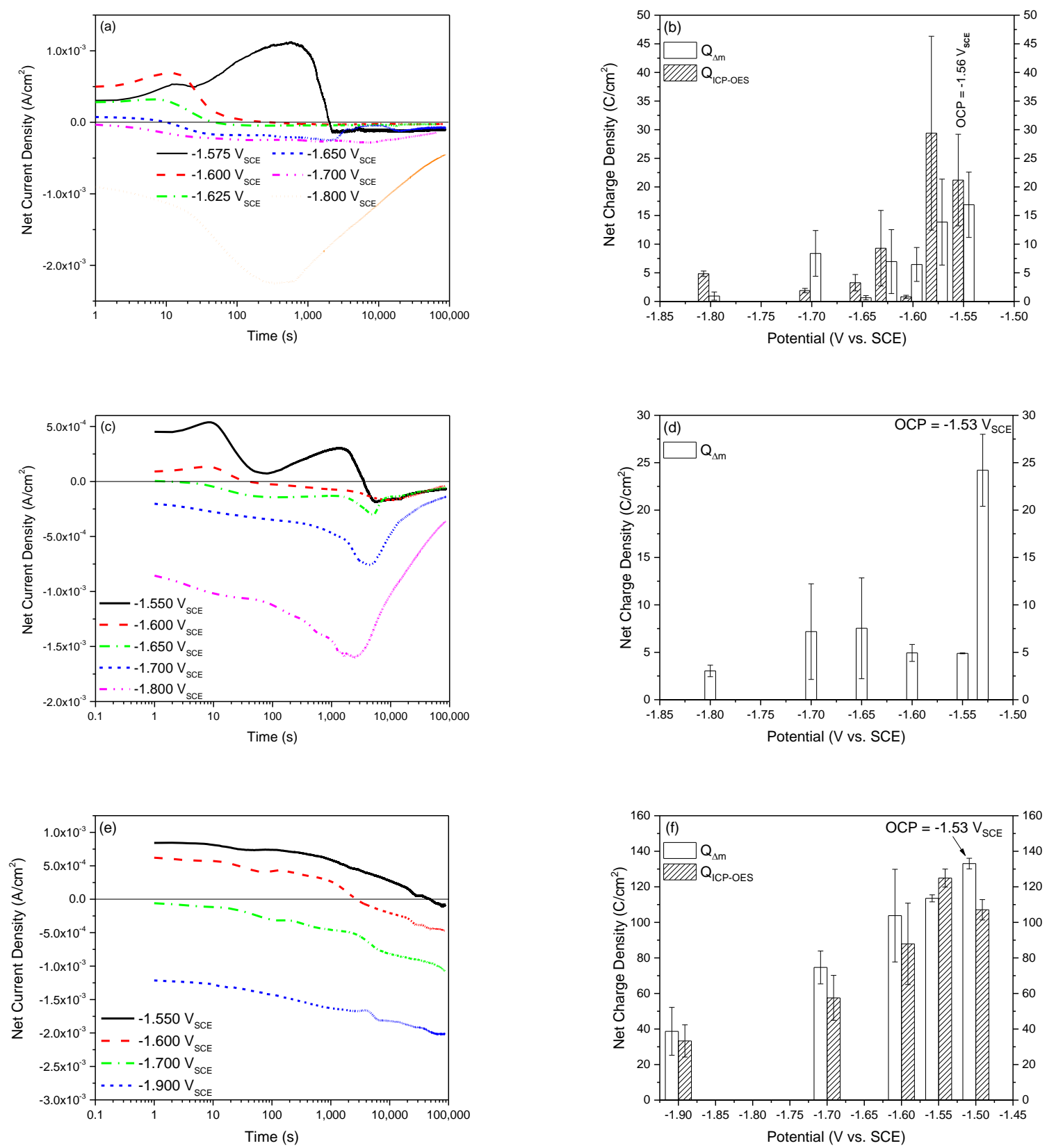

Figure 2.1. Representative curves for the net current density vs. time for AZ31B-H24 in (a) 0.6 $\mathrm{M} \mathrm{NaCl}$, (c) $0.1 \mathrm{M} \mathrm{MgCl}_{2}$, and (e) $0.1 \mathrm{M}$ TRIS. The average equivalent charge density after 24 hours by mass loss at each potential are shown in (b) $0.6 \mathrm{M} \mathrm{NaCl}$, (d) $0.1 \mathrm{M} \mathrm{MgCl}_{2}$, and (f) 0.1 M TRIS. At least three measurements were taken at each potential with the error bars being one standard deviation except where deviations are too small to be seen. 
potentiostatic polarization. As the applied potential became more negative, the time spent as net anodic decreased until applied potentials more negative than $-1.700 \mathrm{~V}_{\mathrm{SCE}}$ where the current density was net cathodic for the duration of the test ( 24 hours). Hereafter, the net current density became increasingly more cathodic with more negative applied potentials as expected. The effects of this for AZ31B-H24 in $0.6 \mathrm{M} \mathrm{NaCl}$ on the mass loss is also shown in Figure $2.1 \mathrm{~b}$. Here, the anodic charge density determined 24 hours immersion from gravimetric mass loss or alternatively by ICPOES at OCP was determined to be approximately $23 \mathrm{C} / \mathrm{cm}^{2}$ and $17 \mathrm{C} / \mathrm{cm}^{2}$, respectively. For reference, $10 \mathrm{C} / \mathrm{cm}^{2}$ anodic charge density translates to approximately average current density of $1.16 \times 10^{-4} \mathrm{~A} / \mathrm{cm}^{2}, 82 \mathrm{mpy}$ or $2.1 \mathrm{~mm} /$ year assuming continuous uniform corrosion at the same rate. The anodic charge density measured by gravimetric mass loss was then observed to decrease approximately $3 \mathrm{C} / \mathrm{cm}^{2}\left(1.2 \mathrm{x}\right.$ decrease) at $-1.575 \mathrm{~V}_{\mathrm{SCE}}$ while the anodic charge density measured by ICP-OES actually increased slightly by approximately $6 \mathrm{C} / \mathrm{cm}^{2}$ although with a large standard deviation. At more negative applied potentials, the trend of anodic charge density measured exhibited a non-linear decrease with increasingly negative applied potentials. Post mortem optical images of $\mathrm{CrO}_{3}$ cleaned surfaces in Figure 2.2 show that the dissolution of samples more negative than $-1.575 \mathrm{~V}_{\mathrm{SCE}}$ incurred similar damage agreeing with the mass loss measurements.

Similar behavior to that of $0.6 \mathrm{M} \mathrm{NaCl}$ was observed for $0.1 \mathrm{M} \mathrm{MgCl}_{2}$ in Figure 2.1c and d. In Figure $2.1 \mathrm{c}$, polarity reversal was observed between applied potentials of $-1.550 \mathrm{~V}_{\mathrm{SCE}}$ to $1.650 \mathrm{~V}_{\mathrm{SCE}}$ with $-1.550 \mathrm{~V}_{\mathrm{SCE}}$ spending the most time as net anodic for approximately 2500 seconds. Samples tested at applied potentials more negative than $-1.650 \mathrm{~V}_{\mathrm{SCE}}$ remained net cathodic for the duration of the test. As with $0.6 \mathrm{M} \mathrm{NaCl}$, the net anodic current density increased before decreasing and becoming net cathodic for samples that exhibited polarity reversal in $0.1 \mathrm{M} \mathrm{MgCl}$. The resulting anodic charge measured by gravimetric mass loss shown in Figure 1d revealed a large 
decrease from OCP to $-1.550 \mathrm{~V}_{\mathrm{SCE}}$ where the anodic charge density decreased from approximately $24 \mathrm{C} / \mathrm{cm}^{2}$ to $5 \mathrm{C} / \mathrm{cm}^{2}$, nearly a $5 \mathrm{x}$ decrease. The anodic charge measured did not show a decreasing trend with more negative applied potentials but remained small relative to the OCP through the range of potentials tested which is shown further by the post mortem optical images in Figure 2.3.

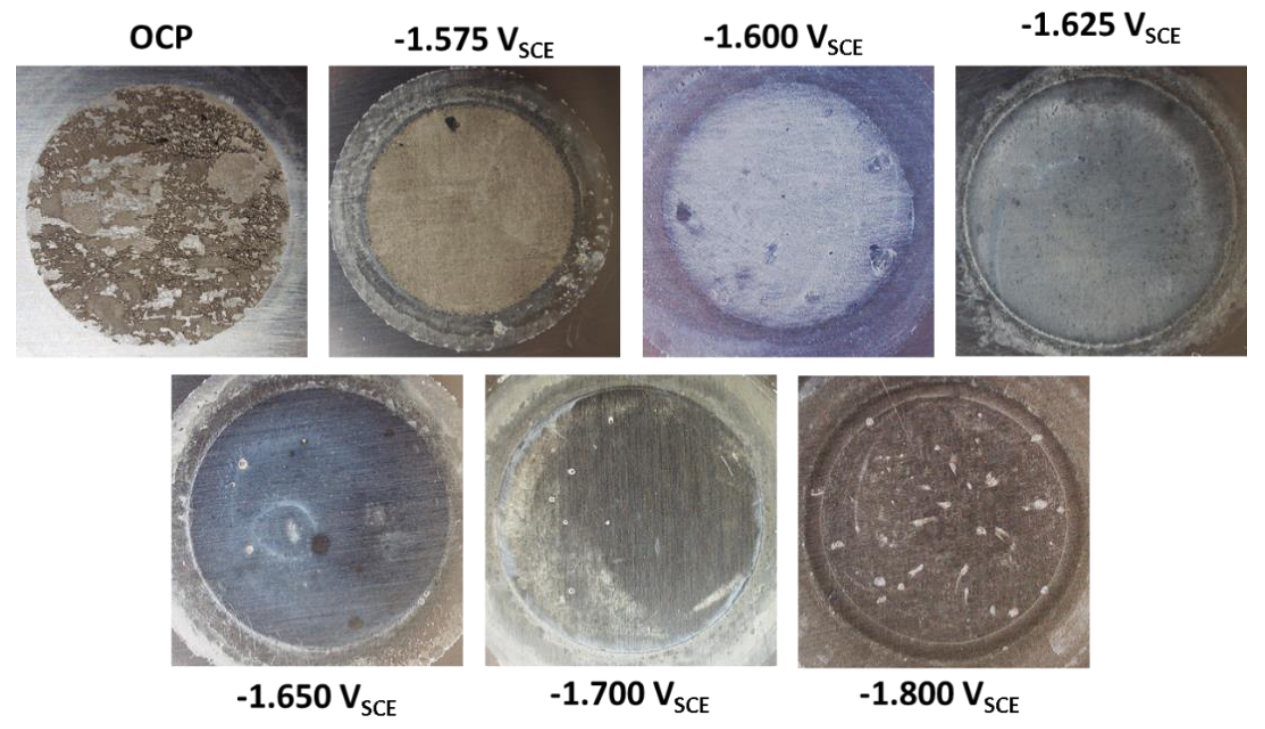

Figure 2.2. Optical images of the typical $\mathrm{CrO}_{3}$ cleaned surfaces revealing dissolution damage on the surface of AZ31B-H24 after 24-hour potentiostatic polarization in $0.6 \mathrm{M} \mathrm{NaCl}$ at the indicated potential. The sample area is $1 \mathrm{~cm}^{2}$.

In Figure 2.1e, the net current density vs. time behavior for $0.1 \mathrm{M}$ TRIS revealed polarity reversal for potentiostatic polarization of AZ31B-H24 at $-1.550 \mathrm{~V}_{\mathrm{SCE}}$ and $-1.600 \mathrm{~V}_{\mathrm{SCE}}$ while the current remained net cathodic throughout the duration of the test at $-1.700 \mathrm{~V}_{\mathrm{SCE}}$ and $-1.900 \mathrm{~V}_{\mathrm{SCE}}$. The net current density is observed to continuously become more cathodic at each potential tested which is in contrast to the behavior observed in $\mathrm{Cl}^{-}$solutions. Moreover, the anodic charge density due to mass loss in $0.1 \mathrm{M}$ TRIS is an order of magnitude greater at $\mathrm{OCP}$ than that in either $\mathrm{Cl}^{-}$ solution, Figure 2.1e. Furthermore, the post mortem optical images in Figure 2.4 show significant damage on the surface despite cathodic polarization in agreement with mass loss measurements. As such, there does not appear to be a practical range for substantial sacrificial cathodic protection 
of AZ31B-H24 in TRIS based on the notion of achieving reduced anodic dissolution kinetics at some potential.
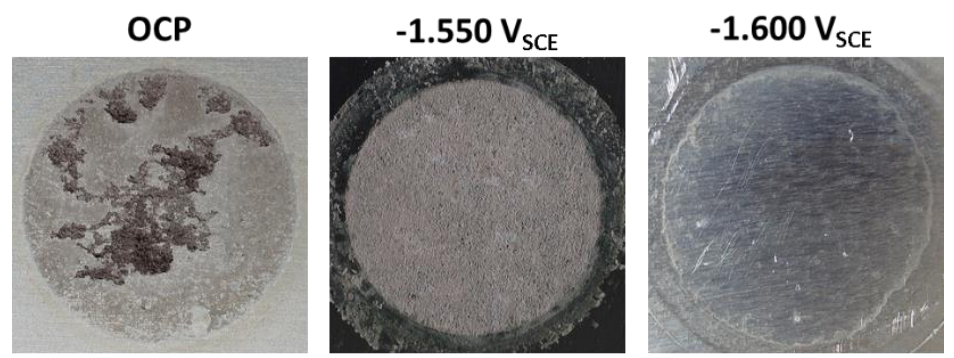

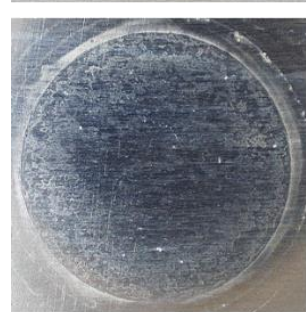

$-1.650 V_{S C E}$

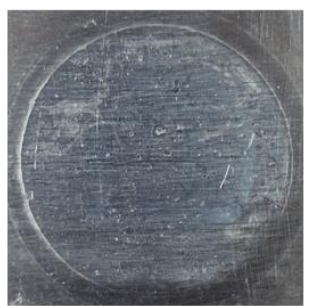

$-1.700 V_{S C E}$

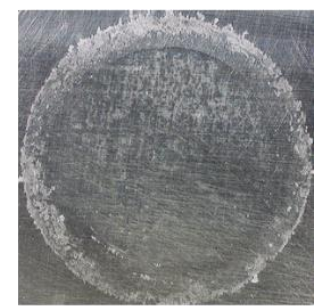

$-1.800 V_{S C E}$

Figure 2.3. Optical images of the typical $\mathrm{CrO}_{3}$ cleaned surfaces revealing dissolution damage on the surface of AZ31B-H24 after 24-hour potentiostatic polarization in $0.1 \mathrm{M} \mathrm{MgCl}_{2}$ at the indicated potential. The sample area is $1 \mathrm{~cm}^{2}$.

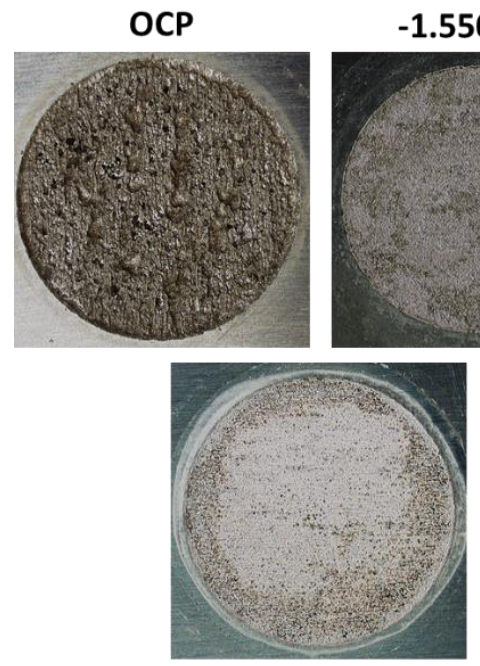

$-1.700 \mathrm{~V}_{\mathrm{SCE}}$
$-1.550 V_{S C E}$
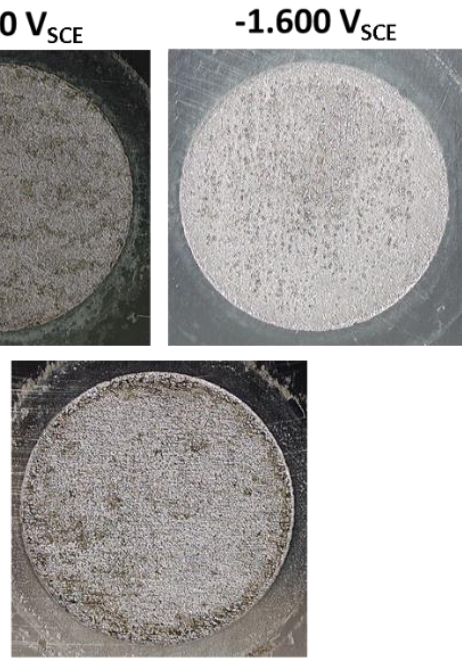

$-1.900 V_{S C E}$

Figure 2.4. Typical optical images of AZ31B-H24 surfaces revealing dissolution damage after 24-hour potentiostatic polarization in 0.1 M TRIS at the indicated potential. The sample area is $1 \mathrm{~cm}^{2}$. Samples were not $\mathrm{CrO}_{3}$ cleaned due to lack of a film. 


\subsubsection{Change in $\mathbf{p H}$ with Potentiostatic Polarization}

The change in $\mathrm{pH}$ for each environment at each of the applied potentials is shown in Figure 2.5. The $\mathrm{pH}$ was observed to decrease slightly for $0.6 \mathrm{M} \mathrm{NaCl}$ during cathodic polarization while a little various in the $\mathrm{pH}$ was observed in $0.1 \mathrm{M}$ TRIS. The $\mathrm{pH}$ in $0.1 \mathrm{M} \mathrm{MgCl}_{2}$ experienced an increase of 2 to $3 \mathrm{pH}$ at each potential except for $-1.65 \mathrm{~V}_{\mathrm{SCE}}$ which increased approximately 0.5 $\mathrm{pH}$.

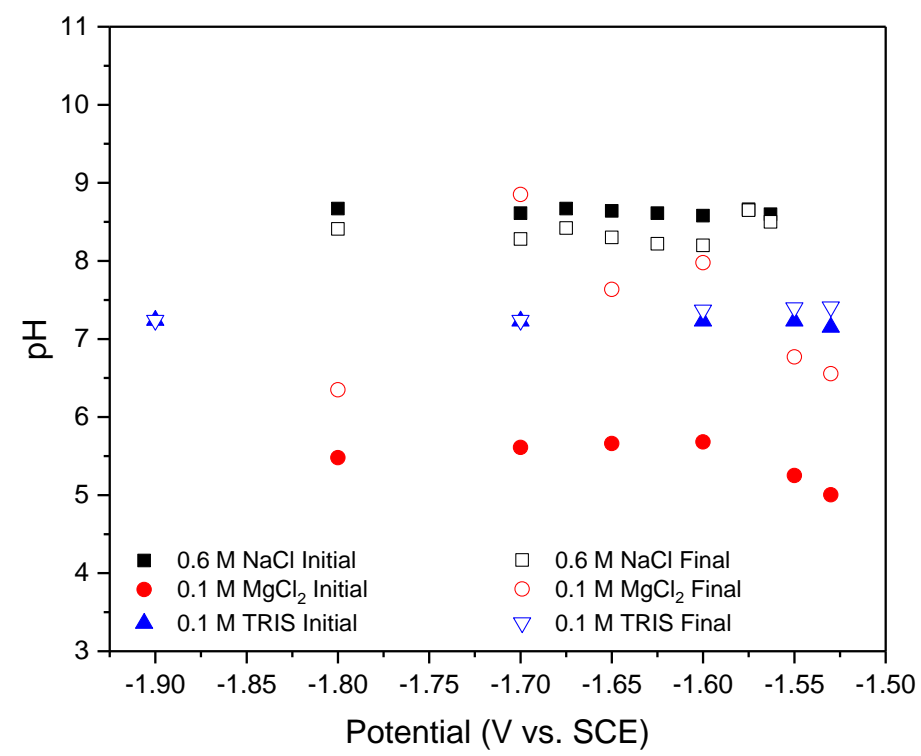

Figure 2.5. The change in bulk solution $\mathrm{pH}$ after 24-hour potentiostatic polarization of AZ31B-H24 in $0.6 \mathrm{M} \mathrm{NaCl}, 0.1 \mathrm{M} \mathrm{MgCl}_{2}$, and $0.1 \mathrm{M}$ TRIS at the indicated potentials.

\subsubsection{Dissolved Element Analysis}

The percentage of elements dissolving in solution for $0.6 \mathrm{M} \mathrm{NaCl}$ and $0.1 \mathrm{M}$ TRIS is shown in Table 2.3 and Table 2.4 respectively. These tables reveal that over $99 \%$ of the dissolved elements in solution is $\mathrm{Mg}$ which is greater than the $95.66 \%$ assumed to be dissolving by congruent dissolution. This results in approximately a 4\% underestimation in anodic charge by mass loss when assuming congruent dissolution. 
Table 2.3. Percent of dissolved elements in solution as a function of applied potential for AZ31B-H24 in $0.6 \mathrm{M} \mathrm{NaCl}$ for 24 hours.

\begin{tabular}{ccccccc}
\hline $\begin{array}{c}\text { Potential } \\
\left(\mathbf{V}_{\text {SCE }}\right)\end{array}$ & $\mathbf{M g}$ & $\mathbf{A l}$ & $\mathbf{F e}$ & $\mathbf{M n}$ & $\mathbf{Z n}$ & $\mathbf{N}_{\text {eq }}$ \\
\hline $\mathbf{- 1 . 5 2 5}$ & $98.70 \%$ & $0.48 \%$ & $0.00 \%$ & $0.00 \%$ & $0.82 \%$ & 0.0820 \\
$\mathbf{- 1 . 5 5 0}$ & $99.07 \%$ & $0.72 \%$ & $0.00 \%$ & $0.00 \%$ & $0.21 \%$ & 0.0824 \\
$\mathbf{- 1 . 5 7 5}$ & $100.00 \%$ & $0.00 \%$ & $0.00 \%$ & $0.00 \%$ & $0.00 \%$ & 0.0823 \\
$\mathbf{- 1 . 6 0 0}$ & $100.00 \%$ & $0.00 \%$ & $0.00 \%$ & $0.00 \%$ & $0.00 \%$ & 0.0823 \\
$\mathbf{- 1 . 6 2 5}$ & $100.00 \%$ & $0.00 \%$ & $0.00 \%$ & $0.00 \%$ & $0.00 \%$ & 0.0823 \\
$\mathbf{- 1 . 6 5 0}$ & $100.00 \%$ & $0.00 \%$ & $0.00 \%$ & $0.00 \%$ & $0.00 \%$ & 0.0823 \\
$\mathbf{- 1 . 7 0 0}$ & $100.00 \%$ & $0.00 \%$ & $0.00 \%$ & $0.00 \%$ & $0.00 \%$ & 0.0823 \\
$\mathbf{- 1 . 8 0 0}$ & $100.00 \%$ & $0.00 \%$ & $0.00 \%$ & $0.00 \%$ & $0.00 \%$ & 0.0823 \\
\hline
\end{tabular}

Table 2.4. Percent of dissolved elements in solution as a function of applied potential for AZ31B-H24 in 0.1 M TRIS for 24 hours.

\begin{tabular}{ccccccc}
\hline $\begin{array}{c}\text { Potential } \\
\text { (VscE) }\end{array}$ & Mg & Al & Fe & Mn & Zn & $\mathbf{N}_{\text {eq }}$ \\
\hline OCP & $99.58 \%$ & $0.36 \%$ & $0.00 \%$ & $0.12 \%$ & $0.16 \%$ & 0.0824 \\
$\mathbf{- 1 . 5 5 0}$ & $99.23 \%$ & $0.14 \%$ & $0.00 \%$ & $0.17 \%$ & $0.24 \%$ & 0.0819 \\
$\mathbf{- 1 . 6 0 0}$ & $99.54 \%$ & $0.16 \%$ & $0.00 \%$ & $0.11 \%$ & $0.19 \%$ & 0.0822 \\
$\mathbf{- 1 . 7 0 0}$ & $99.64 \%$ & $0.17 \%$ & $0.00 \%$ & $0.09 \%$ & $0.10 \%$ & 0.0822 \\
$\mathbf{- 1 . 9 0 0}$ & $99.38 \%$ & $0.36 \%$ & $0.00 \%$ & $0.11 \%$ & $0.15 \%$ & 0.0822 \\
\hline
\end{tabular}

\subsection{Discussion}

The results of this study have shown that partial kinetic based cathodic protection of $\mathrm{Mg}$ alloys is possible in $0.6 \mathrm{M} \mathrm{NaCl}$ and $0.1 \mathrm{M} \mathrm{MgCl}_{2}$ but is limited in $0.1 \mathrm{M}$ TRIS. The limited protection in 0.1 M TRIS is likely due to its buffering capacity and ability as a chelating agent to metal ions which restrict the formation of a partially protective surface film on $\mathrm{Mg}$ anode surfaces as the surface $\mathrm{pH}$ increases into the $\mathrm{Mg}(\mathrm{OH})_{2}$ stable region. As such, the AZ31B-H24 is free to dissolve at much faster rates relative to that measured in $0.6 \mathrm{M} \mathrm{NaCl}$ and $0.1 \mathrm{M} \mathrm{MgCl}_{2}$. However, the decrease in $\mathrm{Q}_{\Delta \mathrm{m}}$ of $\mathrm{AZ31B}-\mathrm{H} 24$ under cathodic potentiostatic polarization at cathodic overpotentials greater than $-150 \mathrm{mV}$ relative to OCP produced less than an order of magnitude decrease in dissolution charge density compared to the measured at OCP in each case (Figure 2.1). 
This was contrary to expectations from conventional electrochemical mixed potential theory for corrosion cells where changes in the anodic kinetics as a function of applied cathodic potential might be estimated by assuming a Tafel relationship for activation controlled corrosion kinetics of $\mathrm{Mg}$ for the half-cell reaction $\mathrm{Mg} \rightarrow \mathrm{Mg}^{2+}+2 \mathrm{e}^{-}$rearranged as:

$$
\frac{\eta_{a}}{\beta_{a}}=\log \frac{i_{a}}{i_{c o r r}}
$$

where the $\eta_{a}$ is the anodic overpotential (+) or underpotential (-) relative to OCP, $\beta_{a}$ is the anodic Tafel slope, $i_{a}$ is the anodic current density and $i_{\text {corr }}$ is the corrosion current density at the OCP. From this equation, it would be expected that $\eta_{a}$ more negative than $-112.5 \mathrm{mV}$ would produce more than an order of magnitude reduction in $i_{a}$ when $\beta_{a}$ for AZ31B-H24 is assumed to be between 27-112.5 mV/dec [7]. This is shown more clearly in Figure 2.6 where the measured dissolution charge density from mass loss measurements and ICP-OES are converted to a current density $(i=$ $Q t)$ and compared to this range of Tafel slopes where the respective Tafel slopes pass through the OCP corrosion current density. The Tafel slopes were also adjusted for IR drop in each test environment to enable comparison as calculating the true electrode potential after testing is not always accurate. Calculation of these curves is discussed further in the Appendix in Section 2.7. The difficulty in cathodically protecting $\mathrm{Mg}$ may be a result of the negative difference effect (NDE) where the hydrogen evolution reaction persists on anodes during anodic polarization [12]. The anode develops an elevated OCP with time and there may be a greater rate of self-corrosion than expected. This leads to observations of greater $\mathrm{Q}_{\Delta \mathrm{m}}$ than expected from applied net anodic currents during anodic polarization [12]. This is also likely to occur albeit to a lesser extent even on net cathodes when the cathode is an Mg alloy such as AZ31B-H24 meaning that Mg alloys functioning as cathode in a galvanic couple still corrode significantly. In this case the fraction of active anodic sites on the Mg surface remains high at small cathodic overpotentials. 
(a)

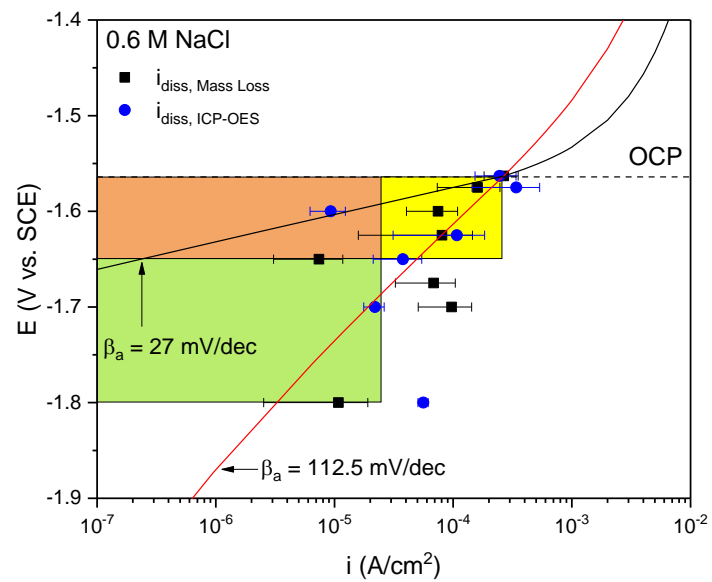

(c)

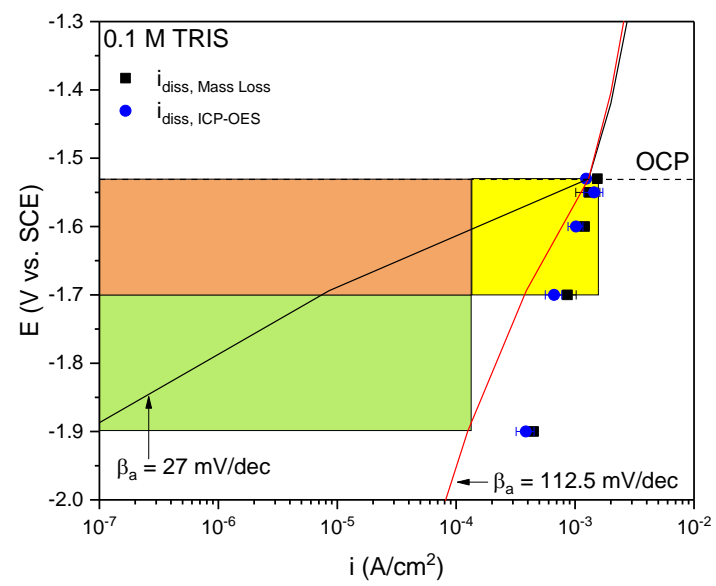

(b)

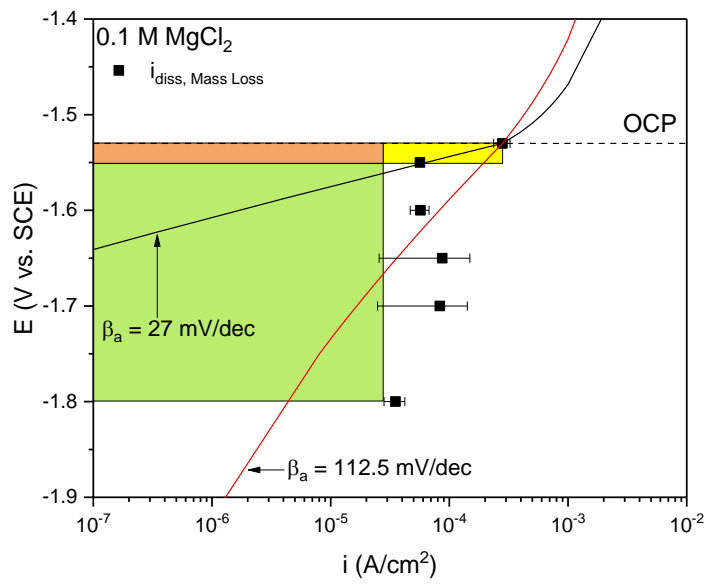

Figure 2.6. The anodic dissolution charge density measured by mass loss and ICP-OES converted to current density assuming a fixed rate of corrosion over the entire test period and plotted as a function of applied potential forAZ31B-H24 in (a) $0.6 \mathrm{M} \mathrm{NaCl}$, (b) $0.1 \mathrm{M} \mathrm{MgCl}_{2}$, and (c) $0.1 \mathrm{M}$ TRIS. The green rectangle outlines a region where the dissolution rate is an order of magnitude or less than the OCP dissolution rate and is not susceptible to polarity reversal, the orange region outlines a region where the dissolution rate is an order of magnitude or less than the OCP dissolution rate and is susceptible to polarity reversal, the yellow region outlines potentials where the dissolution rate is less than an order of magnitude decrease in OCP dissolution rate and it susceptible to polarity reversal. The red and black lines indicate the anodic Tafel slope corrected for the ohmic resistance in each solution as described in Section 2.7. 
Figure 2.6 outlines three regions of potential and current density to determine a target potential range for sacrificial cathodic protection. The green box highlights dissolution current densities that are more than 10x decreased from the OCP dissolution and where polarity reversal does not occur. This current density is chosen as a practical goal for cathodic protection due to the minimal decrease in dissolution rates measured in this study. Furthermore, an ideal couple will not undergo polarity reversal so that cathodic protection can be maximized. However, there may be some applied potentials where the polarity reversal occurs but is still below the one order of magnitude decrease threshold (orange box) which suggests that a limited time of polarity reversal may be tolerable if there is a long-term benefit. Ideally polarity reversal should be mitigated and may be a function of anodically enhanced cathodic kinetics of $\mathrm{Mg}$ alloys [13]. Thus, the factors which control anodically enhanced cathodic kinetics need to be understood. The yellow box shows cathodic potentials where the dissolution rate is less than the proposed one order of magnitude decrease used as an indicator of successful cathodic protection and thus would not be targeted for sacrificial cathodic protection. With this criterion, the potential range for practical cathodic protection of $\mathrm{AZ31BB}-\mathrm{H} 24$ in $0.6 \mathrm{M} \mathrm{NaCl}$ is below $-1.65 \mathrm{~V}_{\mathrm{SCE}}$. AZ31B cathodically polarized in 0.1 $\mathrm{M} \mathrm{MgCl}_{2}$ and $0.1 \mathrm{M}$ TRIS did not result in an order of magnitude decrease in dissolution rate in the range of $-1.55 \mathrm{~V}_{\mathrm{SCE}}$ to $-1.90 \mathrm{~V}_{\mathrm{SCE}}$ but the results for $0.1 \mathrm{MgCl}_{2}$ is close to achieving this target within error at potentials less than $-1.65 \mathrm{~V}_{\mathrm{SCE}}$. 


\subsection{Conclusions}

This study sought to discover a range of potentials where practical cathodic protection of AZ31BH24 may be achieved. The following can be concluded:

- Cathodic protection of AZ31B-H24 with more than a one order of magnitude decrease in dissolution rate compared to the OCP corrosion rate is more difficult than expected based on Tafel predictions due to the persistence of self-corrosion during cathodic polarization.

- Partial sacrificial cathodic protection of Mg alloy AZ31B-H24 was shown to be possible in $0.6 \mathrm{M} \mathrm{NaCl}$ and $0.1 \mathrm{M} \mathrm{MgCl}_{2}$ at potentials below $-1.65 \mathrm{~V}_{\mathrm{SCE}}$ but could not be achieved in $0.1 \mathrm{M}$ TRIS over the range of potentials tested due to its ability to chelate metal ions prevent passive film formation.

- Polarity reversal from a net anode to a net cathode at low cathodic overpotentials may not be detrimental to the long term cathodic protection of AZ31B-H24 if it is a net anode for a brief period of time and stays net cathodic after polarity reversal occurs. The factors controlling polarity reversal need to be understood such that polarity reversal can be mitigated. 


\subsection{References}

[1] X. Lu, Y. Zuo, X. Zhao, S. Shen, "The Effects of Magnesium Particles in Mg-rich Primers Applied on AZ91D Magnesium Alloy,” Int. J. Electrochem. Sci. 10 (11), 9586-9604, 2015.

[2] X. Lu, Y. Zuo, X. Zhao, Y. Tang, "The improved performance of a Mg-rich epoxy coating on AZ91D magnesium alloy by silane pretreatment," Corros. Sci. 60 , 165-172, 2012.

[3] X. Lu, Y. Zuo, X. Zhao, Y. Tang, X. Feng, "The study of a Mg-rich epoxy primer for protection of AZ91D magnesium alloy," Corros. Sci. 53 (1) , 153-160, 2011.

[4] B. Yu, J. Uan, "Sacrificial Mg film anode for cathodic protection of die cast Mg-9wt.\%Al1wt.\%Zn alloy in $\mathrm{NaCl}$ aqueous solution," Scr. Mater. 54 (7) , 1253-1257, 2006.

[5] Y.-J. Wu, X.-B. Chen, G. Williams, J.R. Scully, T. Gengenbach, N. Birbilis, "Stifling magnesium corrosion via a novel anodic coating," RSC Adv. 6 (49) , 43408-43417, 2016.

[6] MIL-DTL-32333 Armor Plate, Magnesium Alloy, AZ31B, Applique, 2009.

[7] L.G. Bland, A.D. King, N. Birbilis, J.R. Scully, "Assessing the Corrosion of Commercially Pure Magnesium and Commercial AZ31B by Electrochemical Impedance, Mass-Loss, Hydrogen Collection, and Inductively Coupled Plasma Optical Emission Spectrometry Solution Analysis," CORROSION. 71 (2) , 128-145, 2015.

[8] B.E. FISCHER, U.K. HÄRING, R. TRIBOLET, H. SIGEL, "Metal ion/buffer interactions," FEBS J. 94 (2), 523-530, 1979.

[9] A.D. King, N. Birbilis, J.R. Scully, "Accurate Electrochemical Measurement of Magnesium Corrosion Rates; a Combined Impedance, Mass-Loss and Hydrogen Collection Study," Electrochimica Acta. 121 , 394-406, 2014.

[10] "ASTM G1-03(2011), Standard Practice for Preparing, Cleaning, and Evaluating Corrosion Test Specimens, ASTM International, West Conshohocken, PA, 2011, www.astm.org," n.d.

[11] Z. Shi, F. Cao, G.-L. Song, M. Liu, A. Atrens, "Corrosion behaviour in salt spray and in 3.5\% $\mathrm{NaCl}$ solution saturated with $\mathrm{Mg}(\mathrm{OH}) 2$ of as-cast and solution heat-treated binary $\mathrm{Mg}-\mathrm{RE}$ alloys: RE=Ce, La, Nd, Y, Gd," Corros. Sci. 76 , 98-118, 2013.

[12] G.L. Makar, J. Kruger, “Corrosion of magnesium,” Int. Mater. Rev. 38 (3) , 138-153, 1993.

[13] N. Birbilis, A.D. King, S. Thomas, G.S. Frankel, J.R. Scully, "Evidence for enhanced catalytic activity of magnesium arising from anodic dissolution," Electrochimica Acta. 132 , 277-283, 2014. 


\subsection{Appendix - Calculating IR corrected Anodic Tafel Slopes}

Plotting of the theoretical IR affected anodic Tafel slopes can be performed via the following treatment beginning with the Tafel Law:

$$
\eta_{a}^{\text {true }}=\beta_{a} \log \frac{i_{a}}{i_{\text {corr }}}
$$

where the $\eta_{a}$ is the anodic overpotential relative to OCP, $\beta_{a}$ is the anodic Tafel slope, $i_{a}$ is the anodic current density and $i_{c o r r}$ is the corrosion current density at the corrosion potential. $\eta_{a}$ can also be written as:

$$
\eta_{a}^{\text {true }}=E_{\text {applied }}-E_{\text {corr }}
$$

Equation 2.8

where $E_{\text {applied }}$ is the applied anodic potential and $E_{\text {corr }}$ is the corrosion potential. The anodic IR drop in solution, $E_{s, a}$, can be calculated using Ohm's law:

$$
E_{s, a}=i_{a} R_{s}
$$

Equation 2.9

where $R_{S}$ is the solution resistance. The true potential accounting for IR drop in solution during anodic polarization can then be calculated by:

$$
E_{I R, a}=E_{a, a p p, I R}-E_{s, a}
$$

Equation 2.10

where $E_{a, a p p, I R}$ is the uncorrected applied anodic potential (i.e., what would be measured experimentally). Thus, the anodic IR corrected overpotential is:

$$
\eta_{a, I R}=\left(E_{a, a p p, I R}-i_{a p p} R_{s}\right)-E_{c o r r}
$$

Equation 2.11

By combining Equation 2.7 and Equation 2.11, $E_{a, a p p, I R}$ can be calculated as:

$$
E_{a, a p p, I R}=\beta_{a} \log \frac{i_{a}}{i_{c o r r}}+E_{c o r r}+i_{a} R_{s}
$$

Equation 2.12

Note that this relation only valid for plotting the anodic Tafel slope during anodic polarization. 
To plot the IR corrected anodic Tafel relation during cathodic polarization, the IR drop is governed by the cathodic reaction and must be calculated based on the cathodic reaction rate. The cathodic Tafel law follows:

$$
\eta_{c}^{\text {true }}=\beta_{c} \log \frac{i_{c}}{i_{c o r r}}
$$

where the $\eta_{c}$ is the cathodic overpotential relative to OCP, $\beta_{c}$ is the cathodic Tafel slope, $i_{c}$ is the anodic current density and $i_{\text {corr }}$ is the corrosion current density at the corrosion potential. $\eta_{c}$ can also be written as:

$$
\eta_{c}^{\text {true }}=E_{\text {corr }}-E_{\text {applied }}
$$

The true potential accounting for IR drop in solution during cathodic polarization can then be calculated by:

$$
E_{I R, c}=E_{c, a p p, I R}-E_{S, c}
$$

Equation 2.15

where $E_{c, a p p, I R}$ is the uncorrected applied cathodic potential and $E_{s, c}$ is the cathodic IR drop. The IR affected potential during cathodic polarization can be written as Equation 2.16 using the framework above:

$$
E_{c, a p p, I R}=E_{c o r r}-\beta_{c} \log \frac{i_{c}}{i_{c o r r}}-i_{c} R_{s}
$$

The anodic current density during cathodic polarization can then be calculated using Equation 2.7 for an equivalent value of $\eta_{c}$ and will occur at the potential $E_{c, a p p, I R}$ corresponding to that cathodic overpotential.

The anodic and cathodic Tafel slopes and their corresponding IR affected slopes are shown in the Figure 2.7. In Figure 2.7a, the anodic Tafel slope is $27 \mathrm{mV} / \mathrm{dec}$ while it is $112.5 \mathrm{mV} / \mathrm{dec}$ in Figure $2.7 \mathrm{~b}$. In each case, the solution resistance is taken to be $20 \Omega-\mathrm{cm}^{2}$ and the cathodic Tafel slope is $315 \mathrm{mV} / \mathrm{dec}$. It is apparent that current density for a given cathodic potential deviates $\mathrm{t}$ a 
greater extent between the theoretical anodic Tafel slope and IR affected anodic Tafel slope with increasing anodic Tafel slope. 


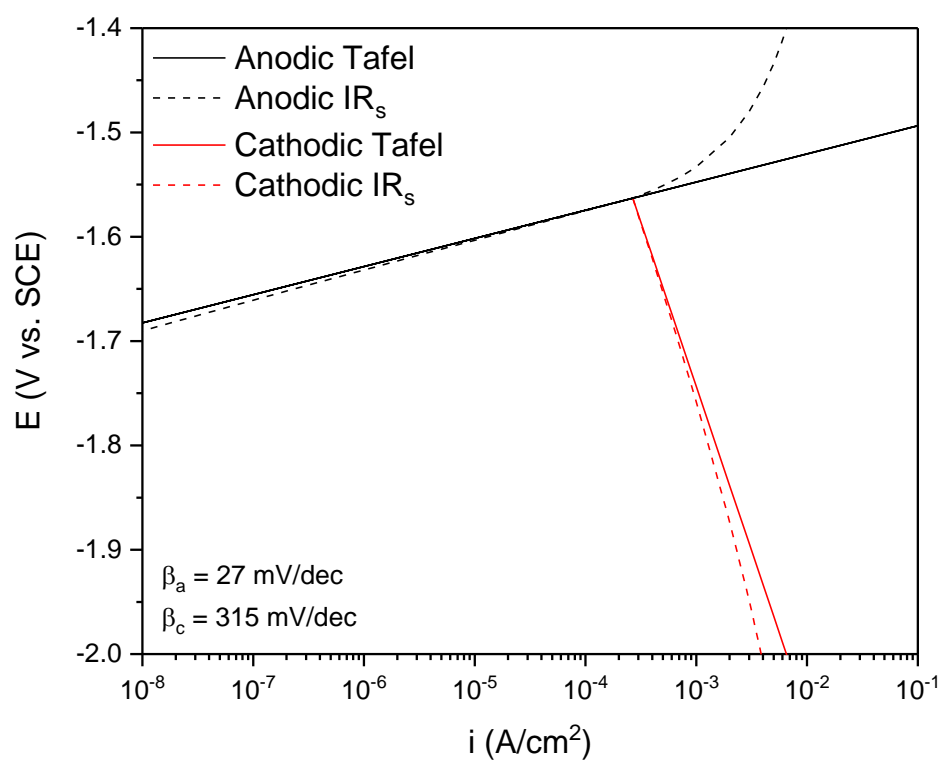

(a)

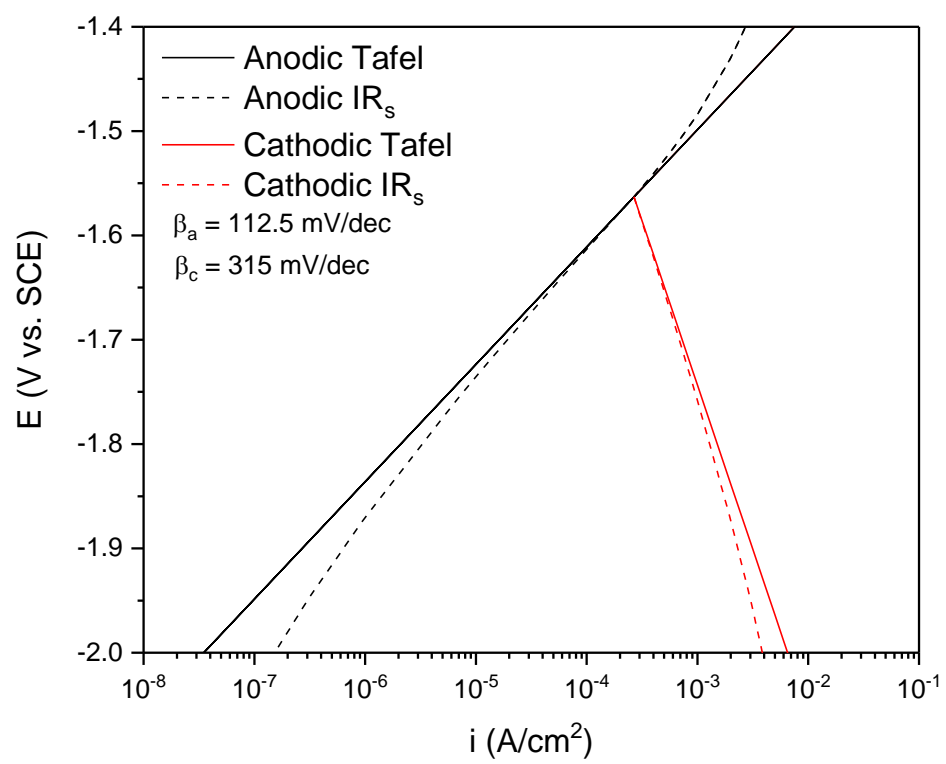

(b)

Figure 2.7. E vs. $\log$ i plots of the deviation between theoretical true Tafel slopes and apparent Tafel slopes experiencing IR drop in solution. The true anodic Tafel slope is $27 \mathrm{mV} / \mathrm{dec}$ in (a) and $112.5 \mathrm{mV} / \mathrm{dec}$ in (b). The solid black and red lines are the respective true anodic and cathodic Tafel slope while the dashed lines are the apparent Tafel slope. 


\section{Factors Controlling the Enhanced Cathodic Activity of HP Mg: The Role of Dissolution Films and Impurity Enrichment}

\subsection{Introduction}

This chapter seeks to further the understanding of the factors that primarily control enhanced cathodic activity and the NDE of Mg. Specifically, the role of dissolution films and noble metal enrichment on corroding $\mathrm{Mg}$ surfaces will be investigated for their relative contributions. Discerning this is important because it is unclear how the manifestation of enhanced cathodic kinetics and NDE will affect the performance of a sacrificial Mg-based anodic coating for $\mathrm{Mg}$ alloys and what design measures can be taken in the form of alloying to mitigate this effect. The number of studies on the NDE and enhanced cathodic kinetics has rapidly increased since the beginning of this dissertation work with at least new 40 publications on the subject according to Web of Science. However, little research has been performed on characterizing the enrichment of noble metals on corroding $\mathrm{Mg}$ surfaces.

In this chapter, Rutherford Backscattering Spectroscopy and Particle Induced X-Ray emission were performed on corroding $\mathrm{Mg}$ surfaces in order to provide for the first time, quantitative measurements of noble metals on a corroded $\mathrm{Mg}$ surface. Such measurements may provide evidence supporting the noble metal impurity theory for the manifestation of enhanced cathodic kinetics [1-3]. In addition, studies on the role of surface films and their contributions to enhanced cathodic kinetics have presented another area for investigation [4-6]. This chapter will focus on the role of stability of dissolution films formed during anodic polarization. Herein, 99.9\% nominal high purity $\mathrm{Mg}$ was subjected to 24 hour anodic potentiostatic polarization followed by cathodic potentiodynamic polarization in $0.6 \mathrm{M} \mathrm{NaCl}(\mathrm{pH} \approx 8.5), 0.6 \mathrm{M} \mathrm{NaCl}$ saturated with $\mathrm{Mg}(\mathrm{OH})_{2}(\mathrm{pH} \approx 10.25), 0.1 \mathrm{M} \mathrm{MgCl}_{2}(\mathrm{pH} \approx 5.6), 0.1 \mathrm{M} \mathrm{Na}_{2} \mathrm{SO}_{4}(\mathrm{pH} \approx 5.5)$, and $0.1 \mathrm{M}$ 
Tris(hydroxymethyl)aminomethane hydrochloride $\mathrm{pH} \approx 7.25$ buffer solution (referred to as TRIS for the remainder of this paper). These electrolytes were selected to provide a range of species, solution activities, and $\mathrm{pH}$ to explore conditions where formation of corrosion films would be either promoted or thermodynamically unlikely. Raman spectroscopy was used to determine the molecular identity of surface films that formed during anodic polarization in each environment, while solution analysis was performed by ICP-OES to determine the identity of soluble species in solution.

\subsection{Experimental Procedures}

\subsubsection{Materials}

High purity, $99.9 \%$ nominal, $\mathrm{Mg}$ rod (80 ppmw Fe) with a diameter of $7.9 \mathrm{~mm}$ was used in this study as supplied by Alfa Aesar (Table 3.1). Samples were mounted in epoxy resin with a $\mathrm{Ni}$ ribbon attached to provide an electrical connection and mechanically ground to a 1200 grit $\mathrm{SiC}$ finish using ethanol as lubricant. Sample surfaces were cleaned with ethanol and dried with compressed air after each successive grinding step. After completion of grinding, samples were placed under vacuum in a desiccator for up to 24 hours to ensure that all water content was removed from the epoxy for accurate mass loss measurements.

Table 3.1. Composition of high purity $\mathrm{Mg}$ used in this study in weight $\mathrm{ppm}(\mu \mathrm{g} / \mathrm{g})$. Compositional analysis was performed by QUANT (Quality Analysis and Testing Corporation), USA.

\begin{tabular}{c|cccccccc}
\hline Element & $\mathrm{Mg}$ & $\mathrm{Al}$ & $\mathrm{Zn}$ & $\mathrm{Mn}$ & $\mathrm{Fe}$ & $\mathrm{Zr}$ & $\mathrm{Ni}$ & $\mathrm{Cu}$ \\
\hline ppmw & Bal. & 200 & 300 & $<100$ & 80 & $<100$ & $<10$ & 30 \\
\hline
\end{tabular}




\subsubsection{Electrochemical Testing}

Electrochemical testing was performed using a three-electrode vertical 'flat-cell' with a saturated calomel reference electrode (SCE) and platinum mesh counter electrode. An electrolyte filled burette with a funnel attached was centered over the sample for $\mathrm{H}_{2}$ capture as described elsewhere [7]. Both the funnel and burette were made out of glass to minimize hydrogen bubbles forming on the funnel and burette walls and to prevent $\mathrm{H}_{2}$ permeation through polymeric materials [8]. In this study, quiescent $0.6 \mathrm{M} \mathrm{NaCl}, 0.6 \mathrm{M} \mathrm{NaCl}$ saturated with $\mathrm{Mg}(\mathrm{OH})_{2}, 0.1 \mathrm{M} \mathrm{MgCl}_{2}, 0.1$ $\mathrm{M} \mathrm{Na}_{2} \mathrm{SO}_{4}$, and 0.1 M TRIS buffer solutions were used. All solutions were prepared using 18.2 $\mathrm{M} \Omega$ deionized water at $25^{\circ} \mathrm{C}$ and pre-charged with hydrogen with exception to $0.1 \mathrm{M} \mathrm{MgCl}_{2}$ due to oxidation of $\mathrm{Cl}^{-}$to $\mathrm{Cl}_{2}$ gas on the counter electrode during charging. The initial $\mathrm{pH}$ of each solution was measured to be as their natural $\mathrm{pH}$ with exception to $0.6 \mathrm{M} \mathrm{NaCl}$ solution which produced an initial $\mathrm{pH}$ in the range of 8-9. The TRIS buffer solution was acquired as $1 \mathrm{M}, \mathrm{pH}=7$ solution and diluted to a concentration of $0.1 \mathrm{M}$ resulting in an initial $\mathrm{pH}$ of $\approx 7.25$.

The procedure for the electrochemical testing used in this investigation is outlined in Fig. 1. All samples were subjected to 24-hour anodic potentiostatic holds in the range of $-1.55 \mathrm{~V}_{\mathrm{SCE}}$ to $-1.40 \mathrm{~V}_{\mathrm{SCE}}$ immediately following exposure to the electrolyte; additional potentials were tested in certain electrolytes to validate any trends. IR correction was not carried out for the potentiostatic polarization as it is not required for charge balance calculations to be made and is not relevant to HER in the anodic region. Following potentiostatic polarization, samples were allowed to rest at their open circuit potential (OCP) for 1 min before a cathodic potentiodynamic polarization scan from OCP to $-3 \mathrm{~V}_{\mathrm{SCE}}$ at a scan rate of $2500 \mathrm{mV} / \mathrm{s}$. Such a fast scan rate allows for an expanded range of activation controlled kinetics to be explored which can lead to more confident estimations of Tafel kinetics and also minimize changes in solution chemistry (i.e. $\mathrm{pH}$ and other dissolved ion 
concentration) on the sample surface throughout the duration of the scan. This is exemplified in Figure 3.2 where the HP Mg was allowed to rest at OCP for 10 minutes followed by cathodic polarization at various scan rates. Here, the diffusion limiting current density shifts to higher current densities which expands the potential range of activation controlled kinetics. Furthermore, the non-Faradaic current measured, $i=c_{d l} \frac{d V}{d t}$, is several orders of magnitude smaller than the cathodic currents measured at a scan rate of $2,500 \mathrm{mV} / \mathrm{s}$ where $c_{d l}$ is the double layer capacitance and $\frac{d V}{d t}$ is the potential scan rate. $c_{d l}$ has been measured to be $51.5 \mu \mathrm{F} / \mathrm{cm}^{2}$ for $\mathrm{HP} \mathrm{Mg}$ in $0.6 \mathrm{M}$ $\mathrm{NaCl}$ [9] yielding a value of $1.28 \times 10^{-4} \mathrm{~A} / \mathrm{cm}^{2}$ for the capacitive current density.

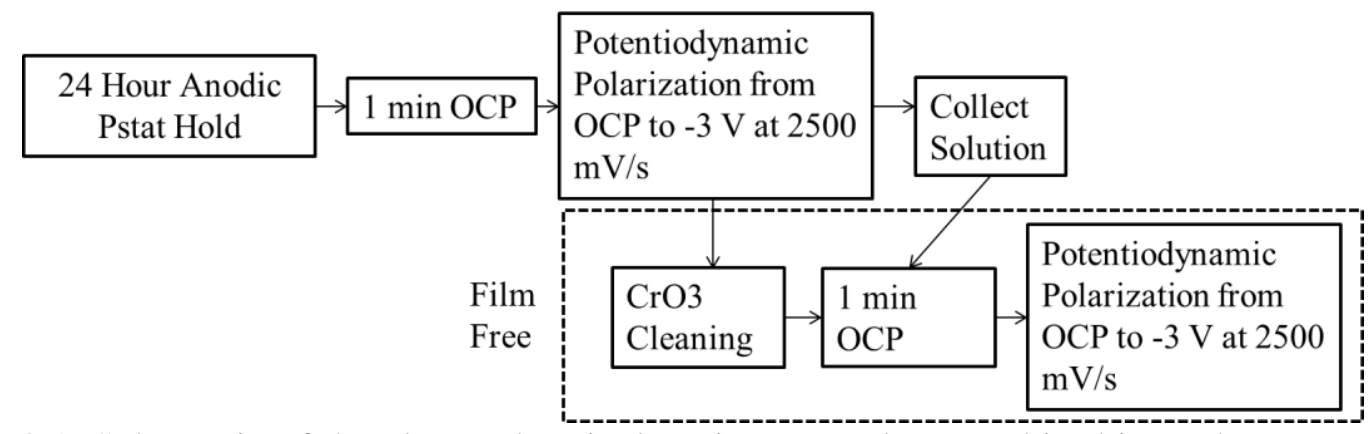

Figure 3.1. Schematic of the electrochemical testing procedure used in this study.

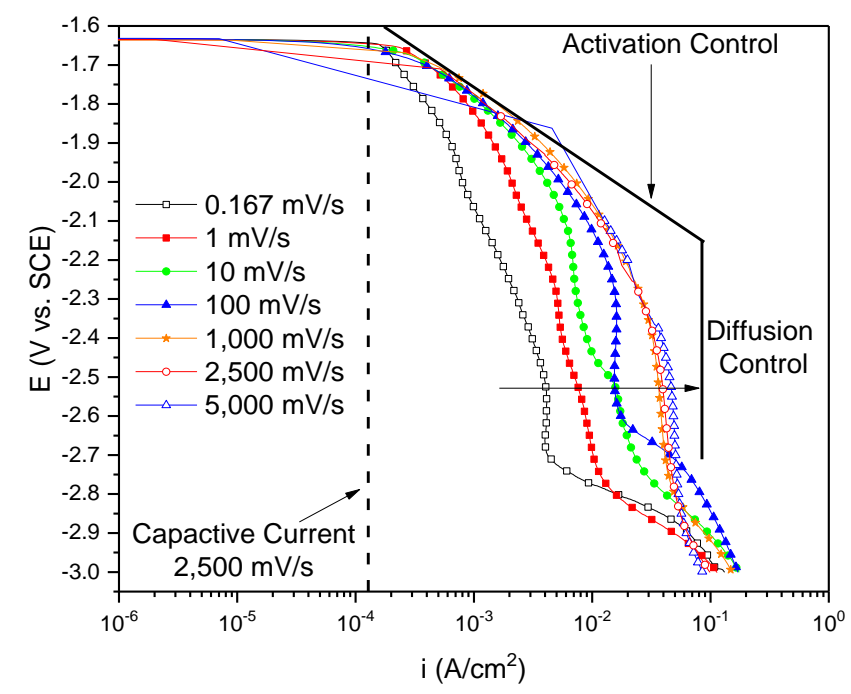

Figure 3.2. The Effect of scan rate on measurements of the cathodic kinetics of HP Mg in $0.6 \mathrm{M}$ $\mathrm{NaCl}$. Scans were performed after the OCP was allowed to stabilize for 10 minutes. Schematic activation controlled and diffusion controlled regions are shown by the arrows. 


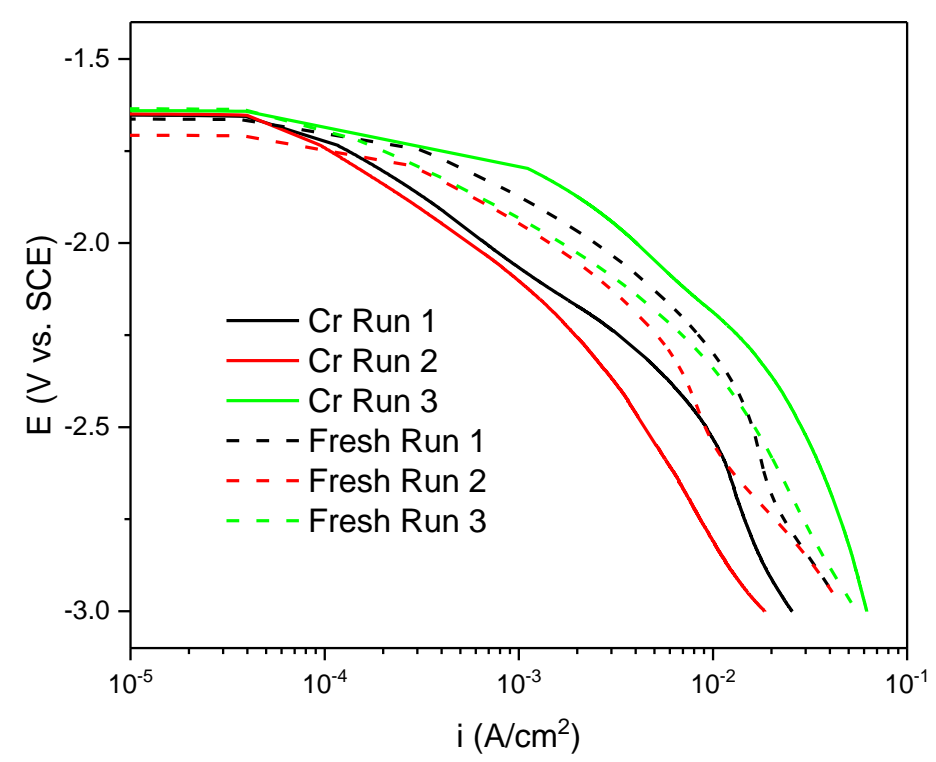

Figure 3.3. The effect of $\mathrm{CrO}_{3}$ acid treatment according to ASTM G1 [10] on the cathodic kinetics of $\mathrm{HP} \mathrm{Mg}$ in $0.6 \mathrm{M} \mathrm{NaCl}$ after stabilizing at OCP for one minute. Each sample was prepared to 1200 grit $\mathrm{SiC}$ finish. 'Cr' runs represents $\mathrm{CrO}_{3}$ treated samples and 'Fresh' runs have not been $\mathrm{CrO}_{3}$ treated. The scan rate was $2,500 \mathrm{mV} / \mathrm{s}$.

After potentiostatic testing, all solutions were retained for cathodic polarization scans of film free surfaces after removing dissolution products and for analysis by ICP-OES. Dissolution products were cleaned from sample surfaces using $200 \mathrm{~g} / \mathrm{L} \mathrm{CrO} 3$ according to ASTM G1 [10], which removes corrosion films whilst not causing further dissolution of the Mg metal. Samples were then placed under vacuum in a desiccator for a 24-hour period before the final mass was measured. Following mass loss measurements, the cleaned samples were then subjected to an additional cathodic polarization scan at $2500 \mathrm{mV} / \mathrm{s}^{\mathrm{iv}}$ from OCP to $-3 \mathrm{~V}_{\mathrm{SCE}}$ after completion of 1 minute at OCP using the solution that was retained from previous cathodic polarization scans, to enable a comparison of cathodic kinetics with the surface films intact and after cleaning of any

\footnotetext{
iv The non-Faradaic current associated with this scan rate is on the order of $1 \times 10^{-4} \mathrm{~A} / \mathrm{cm}^{2}$ which is several orders of magnitude smaller than the net cathodic currents measured in this study.
} 
surface films from the surface (referred to as 'film' and 'film free', respectively) without alteration of the bulk solution environment. Cathodic polarization scans on freshly ground samples which were subjected to $\mathrm{CrO}_{3}$ (Figure 3.3) acid cleaning did not reveal a statistically significant difference in the measured cathodic kinetics compared to samples to freshly ground samples which were not $\mathrm{CrO}_{3}$ cleaned thus bringing confidence in analysis of film vs film free kinetics. It should be noted that some scans were terminated before reaching $-3 \mathrm{~V}_{\mathrm{SCE}}$ due to a $10 \mathrm{~mA}$ limit for potentiodynamic scans on certain potentiostats used in this study.

Gravimetric mass loss measurements were performed as previously described in Chapter 2 using a scale with $\pm 0.01 \mathrm{mg}$ resolution and converted to a corresponding charge density via Equation 3.1:

$$
Q_{\Delta m}=\frac{z n F}{A}=\frac{z \Delta m F}{A a}
$$

where $z$ is the equivalent electrons per mole of Mg oxidized, $n$ is the number of moles of $\mathrm{Mg}$ consumed, $\Delta m$ is the change in mass, $F$ is Faraday's constant, $A$ is the area of the electrode, and $a$ is the molar mass of Mg. In this study, $z$ is assumed to be 2 for $\mathrm{HP} \mathrm{Mg}$ following the half-cell reaction $\mathrm{Mg} \rightarrow \mathrm{Mg}^{2+}+2 \mathrm{e}^{-}$. The hydrogen collected during testing of pre-saturated solutions was converted to a corresponding cathodic charge density using the ideal gas law in combination with Faraday's Law:

$$
\mathrm{Q}_{\mathrm{H}_{2}}=\frac{z n F}{A}=\frac{z P V F}{A R T}
$$

Equation 3.2

where $z=2$ (i.e., $2 \mathrm{H}^{+}+2 \mathrm{e}^{-} \rightarrow \mathrm{H}_{2}$ ), $P$ is the pressure inside the burette ( $1 \mathrm{~atm}$ ), $n$ is the number of moles of $\mathrm{H}_{2}$ gas given by the ideal gas law, $V$ is the volume of gas in the burette, $F$ is Faraday's constant, $R$ is the ideal gas constant, and $T$ is temperature. The net charge density from the measured current was determined from the integrated signal of current density vs. time transient at each potential. 


$$
\mathrm{Q}_{\mathrm{inet} \text { anodic }}=\int \frac{I_{\text {measured }}}{A} \mathrm{dt}
$$

Equation 3.3

The charge balance under anodic polarization is therefore described by Equation 3.4:

$$
Q_{\Delta m}=Q_{H_{2}}+Q_{\text {inet anodic }}
$$

Equation 3.4

following fundamental mixed potential theory [11] where $Q_{\mathrm{H}_{2}}$ is the summation of all HER

occurring on the surface (ie $Q_{\mathrm{H}_{2}}=Q_{\text {anode }}+Q_{\text {film }}+Q_{\text {impurities }}$ following the notation of [12]).

\subsubsection{Inductively Coupled Plasma - Optical Emission Spectroscopy (ICP-OES)}

All solutions tested were recovered for solution analysis using a Thermo Scientific ${ }^{\mathrm{TM}}$ iCAP 7200 ICP-OES. Each solution was acidified with additions of $1 \mathrm{M} \mathrm{HCl}$ to dissolve all insoluble dissolution products. Furthermore, the $\mathrm{CrO}_{3}$ solution used to clean dissolution products off samples was collected and analyzed to account for impurity atoms which may be trapped in the dissolution product films. However, analysis of the dissolution products collected from $\mathrm{CrO}_{3}$ cleaning proved to be unsuccessful due to the impurity concentration of $\mathrm{Fe}$ in the $\mathrm{CrO}_{3}$ which is was measured to be between 100-300 ppmw and thus did not allow for accurate quantitative analysis. In this work, the emission intensity of $\mathrm{Mg}(279.553 \mathrm{~nm}, 280.270 \mathrm{~nm}), \mathrm{Al}(226.910 \mathrm{~nm}$, $308.215 \mathrm{~nm}, 396.152 \mathrm{~nm})$, Fe (238.204 nm, $239.562 \mathrm{~nm})$, Mn (257.610 nm, $259.373 \mathrm{~nm})$, and Zn $(206.200 \mathrm{~nm}, 213.856 \mathrm{~nm})$ were recorded and used for the calculation of charge consumed and percent of elements in solution. The approximate detection limit for each element is shown in Table 3.2.

Table 3.2. Approximate elemental detection limits for the ICP-OES used in this investigation in $\mathrm{ppm}(\mathrm{mg} / \mathrm{L})$.

\begin{tabular}{cccccc}
\hline Element & $\mathrm{Mg}$ & $\mathrm{Al}$ & $\mathrm{Zn}$ & $\mathrm{Mn}$ & $\mathrm{Fe}$ \\
\hline $\mathrm{ppm}$ & 0.005 & 0.030 & 0.005 & 0.005 & 0.005 \\
\hline
\end{tabular}




\subsubsection{Raman Micro-Spectroscopy of Mg Surfaces}

Raman Spectroscopy was performed on sample surfaces after completion of potentiostatic polarization with corrosion products intact using a Renishaw Leica Raman Microscope. Scans were performed from 150 to $1200 \mathrm{~cm}^{-1}$ utilizing a $200 \mathrm{~mW}, 514 \mathrm{~nm}$ laser at $50 \%$ power under a 20x objective lens through a 1800 1/mm visible grating; the laser spot size was on the order of 5 $\mu \mathrm{m}$. Scans were accumulated twice with a 60 second exposure under standard confocality on at least three different areas of each sample. Background subtraction of spectra was not performed but spectral artifacts from the instrument were removed from each spectrum without interference of verified real peaks. Peak identification was made using standard spectra in the RRUFFTM project database [13]. No quantitative analysis of the concentration of identified species was performed as only species identification was desired for this study and a careful internal standard method must be adopted for each species.

\subsubsection{Rutherford Backscattering Spectroscopy Corroded Mg Surfaces}

RBS was carried out at the University of Western Ontario, using a 1.7 MV Tandetron, solid state, gas insulated, high frequency accelerator. The incident ion used for RBS was ${ }^{4} \mathrm{He}$ (referred to as an $\alpha$ particle hereafter) accelerated to an energy of $3050 \mathrm{keV}$. This energy was used in order to take advantage of the resonance of the elastic ${ }^{16} \mathrm{O}(\alpha, \alpha){ }^{16} \mathrm{O}$ scattering cross-section near 3040 $\mathrm{keV}$ which results in enhancement of the oxygen signal up to 29 times greater than that of the Rutherford cross-section depending on the scattering angle [14]. The energy of scattered particles without energy loss is defined by Equation 3.5 [15]:

$$
E=K E_{o}
$$

Equation 3.5 
where $E$ is the energy of the ${ }^{4} \mathrm{He}$ projectile after collision with the substrate, $K$ is the kinematic factor, and $E_{o}$ is the incident projectile energy. The kinematic factor is defined by Equation 3.6 [15]:

$$
K=\left(\frac{\left(M_{2}^{2}-M_{1}^{2} \sin ^{2} \theta\right)^{\frac{1}{2}}+M_{1} \cos \theta}{M_{1}+M_{2}}\right)^{2}
$$

where $M_{1}$ is the mass of the projectile, $M_{2}$ is the target mass, and $\theta$ is the scattering angle. The energy resolution, $\Delta E$, between two masses on the same target that differ by a small amount $\Delta M_{2}$ is therefore:

$$
\Delta E=E_{o}\left(\frac{d K}{d M_{2}}\right) \Delta M_{2}
$$

The values of $K$ and $E$ used for the elements detected in this study are given in Table 3.3. The energy loss of an alpha particle after passing through a layer with thickness $\mathrm{x}\left(\mathrm{atoms} / \mathrm{cm}^{2}\right)$ is given by the equation:

$$
E(x)=E_{0}-\int_{0}^{x} S(E) d x
$$

where $\mathrm{x}$ is the depth into the sample layer and $\mathrm{S}(\mathrm{E})$ is the specific energy dependent stopping cross section of an alpha particle for the elements considered in the $\alpha$ particle-substrate collision.

Table 3.3. The scattering factor $\mathrm{K}$ and energy $\mathrm{E}$ of ${ }^{4} \mathrm{He}$ projectiles after collision with the substrate under the conditions used in this experiment.

\begin{tabular}{ccc}
\hline Element & $\mathbf{K}$ & $\mathbf{E}(\mathbf{k e V})$ \\
\hline${ }^{16} \mathrm{O}$ & 0.3710 & 1132 \\
${ }^{24} \mathrm{Mg}$ & 0.5206 & 1588 \\
${ }^{25} \mathrm{Mg}$ & 0.5346 & 1631 \\
${ }^{26} \mathrm{Mg}$ & 0.5479 & 1671 \\
${ }^{28} \mathrm{Si}$ & 0.5723 & 1745 \\
${ }^{52} \mathrm{Cr}$ & 0.7415 & 2262 \\
${ }^{56} \mathrm{Fe}$ & 0.7576 & 2311
\end{tabular}


The geometry and design of the RBS experiments was as follows: the incident angle was 0 degrees with an exit angle of 20 degrees resulting in a scattering angle of 160 degrees. The beam spot size was approximately $1.5 \mathrm{~mm} \times 0.5 \mathrm{~mm}$ whilst the detector was a solid state device with an energy resolution of $15 \mathrm{keV}$. The beamline contained a quadrupole magnet for focusing, an analyzer magnet, a raster-scanner, and a steerer. The chamber pressure was in the range of $1.3 \times 10^{-}$

${ }^{5} \mathrm{~Pa}$. Data analysis was performed with the program SIMNRA v6.06 [16]. In this analysis the composition depth profile was established by iterative simulation of both elements in each layer and layer thicknesses until the experimental RBS data was matched for a given beam energy. The match was achieved accounting for energy loss and element concentration in a Mg matrix. Three zones were assumed: oxide/hydroxide outer layer, metallic enriched zone with the $\mathrm{Mg}$ below the oxide/hydroxide, and bulk Mg. This layered situation was modeled based on the ${ }^{4} \mathrm{He}$ stopping cross-sections for a given layer thickness and composition. To achieve a match, the layer thickness, atomic numbers included in each zone, and thickness assumed needed to accurately reproduce the experimental RBS spectrum. Hence the atomic mass resolution produces the only uncertainty. After this match was achieved, a composition versus depth plot was constructed only after a match the experimental data was obtained.

\subsubsection{Micro Particle Induced X-ray Emission of Corroded Mg Surfaces}

PIXE analysis was performed on HP Mg samples that were anodically dissolved in each solution via a galvanostatic pulse of $2 \mathrm{~mA} / \mathrm{cm}^{2}$ and $10 \mathrm{~mA} / \mathrm{cm}^{2}$ for 2 minutes yielding two different levels of anodic dissolution. PIXE analysis was performed both with the corrosion film intact and after $\mathrm{CrO}_{3}$ cleaning. The as prepared samples were loaded into the CSIRO Nuclear Microprobe chamber and exposed to a focused 3.0 MeV proton beam at the University of Melbourne Pelletron 
accelerator. Micro-PIXE induced X-ray measurements were performed over a 200 x $160 \mu \mathrm{m}$ are for the filmed condition and $100 \times 175 \mu \mathrm{m}$ area in the film free condition employing a spot size of $2 \mu \mathrm{m}$. The Pelletron current ranged from 0.3 to $0.5 \mathrm{nA}$ yielding an applied charge of $3.2 \mu \mathrm{C}$ for the filmed condition and $2 \mu \mathrm{C}$ for $\mathrm{CrO}_{3}$ cleaned samples. A $100 \mu \mathrm{m}$ Al filter was placed on the face of a Canberra Hyper-pure germanium X-ray detector mounted 45 degrees to the incident beam in order to minimize the count rate of $\mathrm{Mg}$ for improved detection limits of impurity elements. The MicrodaQ system [17] was used to collect dead-time corrected image data while quantitative analysis of PIXE spectra were performed using the GeoPIXE software suite whose complex details are reported elsewhere [18]. Images of the spatial distribution of elements over the scan area were produced utilizing the dynamic analysis method within GeoPIXE. PIXE fitting was performed assuming a uniform $2 \mu \mathrm{m}$ 'surface layer' which is a typical corrosion depth at the level of polarization applied. Note that the X-ray yield depth of the proton beam is greater than this depth but assuming this thin layer allows for easier determination of the X-ray yields by avoiding nonlinear terms due to rapid stopping of the ion closer to the end of its range. The surface concentration of elements may be greater than that calculated from this volume but trends in the 'surface' concentration with increasing polarization can still be made.

\subsection{Results}

\subsubsection{Anodic Potentiostatic Polarization of HP Mg}

The potentiostat recorded net current density traces as a function of time are shown in Figure 3.4a-e for potentiostatic testing in in various solutions. The corresponding initial and final bulk $\mathrm{pH}$ of each solution at each potential are reported in Figure 3.4f. Two distinct regions are shown in Figure 3.4a for potentiostatic polarization of $\mathrm{Mg}$ in $0.6 \mathrm{M} \mathrm{NaCl}$. The first region occurs 
within the initial 1000 seconds of polarization where an increase in the net anodic current density is observed, followed by a decrease in net current density to a local minimum. During this time period, dark corroded regions, typically associated with enhanced cathodic kinetics, initiated on the sample surface and grew in the form of rapidly expanding disks. The maximum value and subsequent decrease in net anodic current in region one may be associated with increasing cathodic area and therefore increasing cathodic kinetics; however, $\mathrm{H}_{2}$ was not captured as a function of time so it is unclear whether or not the rate of $\mathrm{H}_{2}$ evolution increased during this time period. Growth of the dark corroded regions continued until the minimum current density value corresponding to when the entire $\mathrm{Mg}$ anode surface became covered with the dark film - which may indicate the end of dissolution governed by localized processes. The second regime of net current density would therefore occur under a more uniform type of dissolution with a decrease in net anodic current density attributed to thickening of the dark film on the $\mathrm{Mg}$ surface; the nature of the increase in net anodic current immediately following the minimum is unclear at this time. In addition, the dark film changes to a white color as it thickens which is normally associated with $\operatorname{Mg}(\mathrm{OH})_{2}$.

Similar behavior is observed with both $0.6 \mathrm{M} \mathrm{NaCl}$ saturated in $\mathrm{Mg}(\mathrm{OH})_{2}$ and $0.1 \mathrm{MgCl}_{2}$ solutions, over a similar range of time as indicated in Figure 3.4b,c. However, the maximum height of the first peak in current in $0.6 \mathrm{M} \mathrm{NaCl}$ saturated with $\mathrm{Mg}(\mathrm{OH})_{2}$ is less than that measured in non-saturated $0.6 \mathrm{M} \mathrm{NaCl}$, and the decrease in net current density between this maximum and corresponding minimum is also less for saturated $0.6 \mathrm{M} \mathrm{NaCl}$ solution compared to non- $\mathrm{Mg}(\mathrm{OH})_{2}$ saturated solution. In addition, the minimum in current density is shifted to later times for saturated $0.6 \mathrm{M} \mathrm{NaCl}$ solution which suggests that the possible increase in cathodic kinetics was not as great as in non-saturated $0.6 \mathrm{M} \mathrm{NaCl}$ solution and that the dissolution rate is less for $0.6 \mathrm{M} \mathrm{NaCl}$ saturated with $\mathrm{Mg}(\mathrm{OH})_{2}$. This is not surprising since $\mathrm{Mg}$ dissolution would occur in the $\mathrm{Mg}(\mathrm{OH})_{2}$ 
stable region of the $\mathrm{Mg} \mathrm{E}-\mathrm{pH}$ diagram for the entire duration tests in $0.6 \mathrm{M} \mathrm{NaCl}$ saturated in $\mathrm{Mg}(\mathrm{OH})_{2}$ whilst non-saturated $0.6 \mathrm{M} \mathrm{NaCl}$ samples would spend some period of time corroding in the $\mathrm{Mg}^{2+}$ stable region before increases in bulk $\mathrm{pH}$ cause dissolution of $\mathrm{Mg}$ to shift to the $\mathrm{Mg}(\mathrm{OH})_{2}$ region as indicated by the final $\mathrm{pH}$ values reported in Figure 3.4. Note that the change in $\mathrm{pH}$ is reflective of HER occurring on both the $\mathrm{Mg}$ working electrode and $\mathrm{Pt}$ counter electrode and should vary with the amount of charge for unbuffered solutions. However, local increases in $\mathrm{pH}$ due to rapid $\mathrm{H}_{2}$ evolution $\left(2 \mathrm{H}_{2} \mathrm{O}+2 \mathrm{e}^{-} \rightarrow \mathrm{H}_{2}+2 \mathrm{OH}^{-}\right)$and supersaturation of $\mathrm{Mg}^{2+}\left(\left[\mathrm{Mg}^{2+}\right]=\right.$ $1.12 \times 10^{-4} \mathrm{M}$ required for saturation of $\mathrm{Mg}(\mathrm{OH})_{2}$ in $\mathrm{H}_{2} \mathrm{O}$ [19]) in solution near the $\mathrm{Mg}$ surface is likely to be great enough to provide conditions where $\mathrm{Mg}(\mathrm{OH})_{2}$ films form behind the advancing anodic front. The change in $\mathrm{pH}$ for $0.1 \mathrm{M} \mathrm{MgCl}_{2}$ (Figure 3.4f) was not as great as that observed in $0.6 \mathrm{M} \mathrm{NaCl}$ which is not surprising given the smaller relative net anodic current densities observed at each applied potential. These lower current densities are a result of the decreased $\mathrm{Cl}^{-}$content in the $0.1 \mathrm{M} \mathrm{MgCl}_{2}$ solution tested here compared to $0.6 \mathrm{M} \mathrm{NaCl}$.

The potentiostatic behavior for $0.1 \mathrm{M} \mathrm{Na}_{2} \mathrm{SO}_{4}$ is shown in Figure 3.4d. The net anodic current densities at each potential are similar to those in $0.1 \mathrm{M} \mathrm{MgCl}_{2}$; however, there is little evidence of enhanced cathodic activity which is characteristic with the $\mathrm{Cl}^{-}$containing solutions test in this investigation. The net current density is relatively stable throughout the duration of the test with decreases in the net current density likely due to thickening of films on the $\mathrm{Mg}$ surface. Corrosion of $\mathrm{Mg}$ in the presence of sulfate also differed from the behavior observed with chlorides in that the anode surface became covered with white film which became progressively thicker with time immediately after breakdown of the air formed oxide. Few black filaments formed which are noted to form in $\mathrm{Cl}^{-}$containing environments. As in the case of $\mathrm{Na}_{2} \mathrm{SO}_{4}$, the net current density transient for samples tested in 0.1 M TRIS buffer solution (Figure 3.4e) were relatively stable with 
(a)

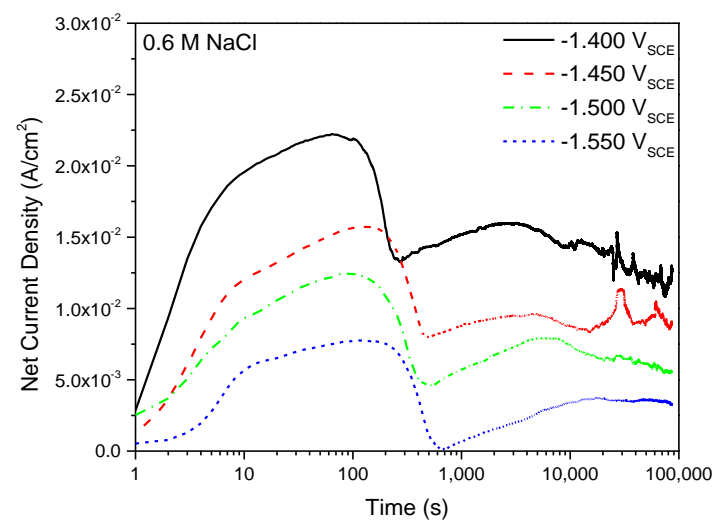

(c)

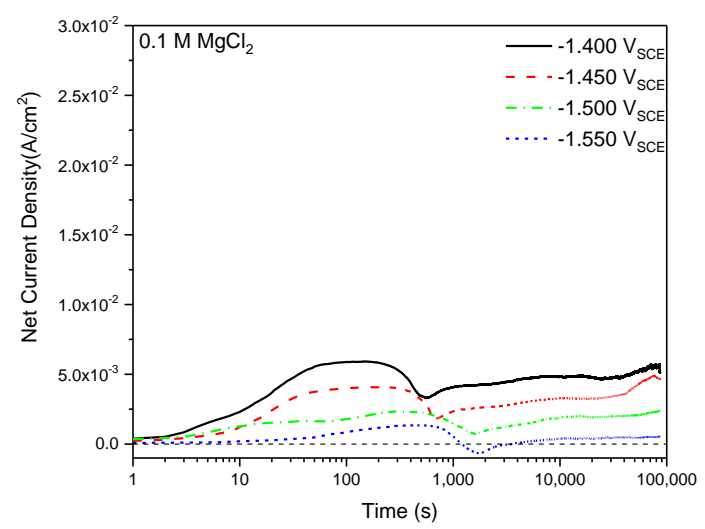

(e)

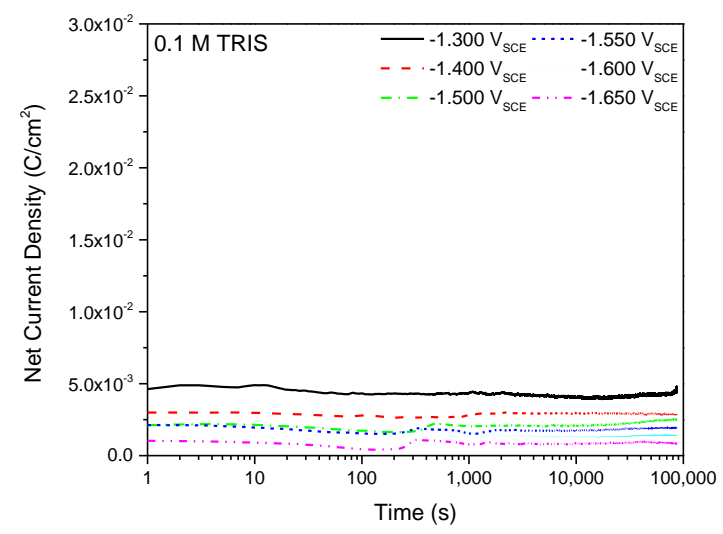

(b)

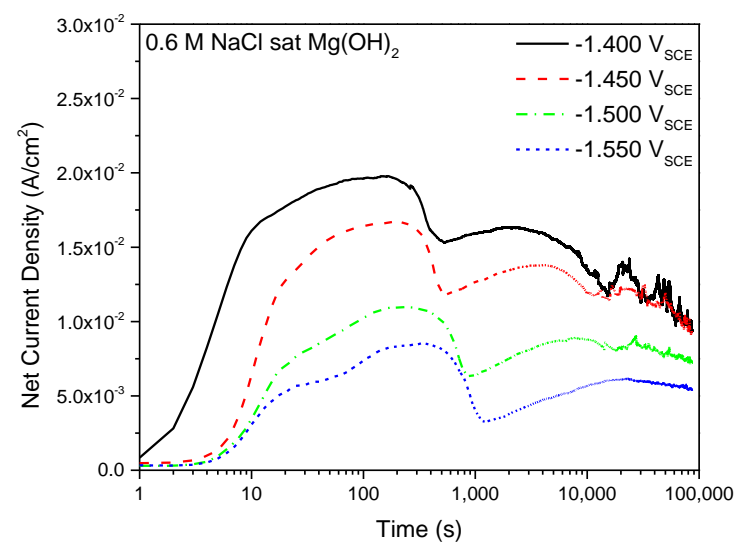

(d)

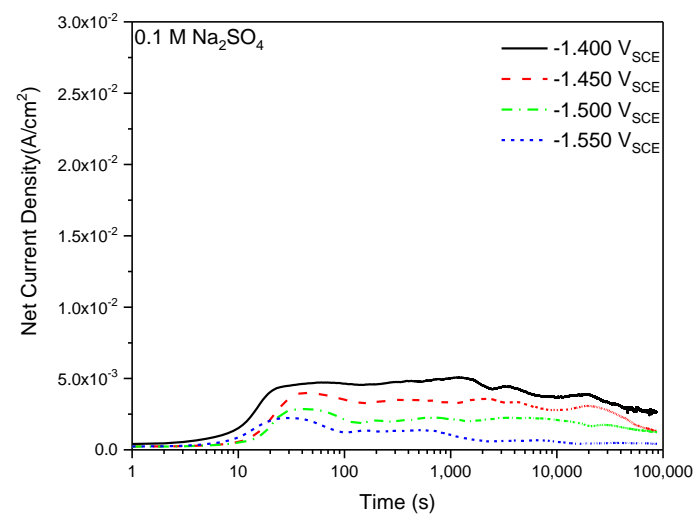

(f)

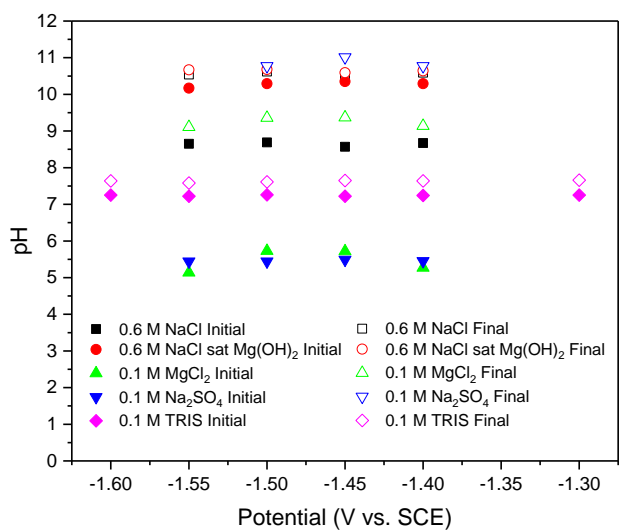

Figure 3.4. Potentiostat recorded net current density as a function of time for $99.9 \%$ pure $\mathrm{Mg}$ in solution for 24 hours at the designated potentials in quiescent (a) $0.6 \mathrm{M} \mathrm{NaCl}$, (b) $0.6 \mathrm{M} \mathrm{NaCl}$ saturated with $\mathrm{Mg}(\mathrm{OH})_{2}$, (c) $0.1 \mathrm{M} \mathrm{MgCl}_{2}$, (d) $0.1 \mathrm{M} \mathrm{Na}_{2} \mathrm{SO}_{4}$, and (e) $0.1 \mathrm{M}$ TRIS buffer solution. The change in measured $\mathrm{pH}$ before and after testing is shown in (f). 
time. Moreover, TRIS displayed no evidence of enhanced cathodic activity (typically indicated by a decrease in net anodic current density) and Mg samples exposed to TRIS buffer solution did not show the appearance of a surface film upon visual inspection. However, this does not exclude the possibility for nanoscale film formation on TRIS anode surfaces but an average final $\mathrm{pH}$ near 7.6 (Figure 3.4f) indicates that $\mathrm{Mg}(\mathrm{OH})_{2}$ films would not be thermodynamically stable throughout the duration of the test.

Characterization of sample surfaces after potentiostatic polarization by Raman spectroscopy is shown in Figure 3.5. The spectra shown are representative of the typical scan on sample surfaces in each electrolyte. The peaks present at $278 \mathrm{~cm}^{-1}$ and $443 \mathrm{~cm}^{-1}$ are indicative of brucite, $\mathrm{Mg}(\mathrm{OH})_{2}$ whilst the peak observed at $1075 \mathrm{~cm}^{-1}$ may be indicative of the formation of a carbonate species [13]. Note that the scattering intensities of each peak are related to incident laser intensity, molecular vibration frequencies, and the change in molecular polarizability and is not indicative of film thickness or amount while peak broadening arises from anharmonicities such as chemical (elemental) and physical (crystallinity) inhomogeneity [20]. There were no magnesium carbonate related samples in the RRUFF database which possessed a peak at $1075 \mathrm{~cm}^{-1}$ but carbonate peaks are known to occur in the range of wavenumbers with magnesite, $\mathrm{MgCO}_{3}$, possessing a peak at $1095 \mathrm{~cm}^{-1}$. The peak observed at $982 \mathrm{~cm}^{-1}$ is indicative of an $\mathrm{SO}_{4}{ }^{2-}$ containing species which most closely resembles the standard spectrum of epsomite $\left(\mathrm{MgSO}_{4} \cdot 7 \mathrm{H}_{2} \mathrm{O}\right)[13]$. The results in Figure 3.5 are interesting because they show that there is a thin $\operatorname{Mg}(\mathrm{OH})_{2}$ film present on TRIS samples despite there being no appearance of a surface film optically as shown in Fig. 4 for uncleaned TRIS sample surfaces which was also observed by Bland et al. [21]. The cleaned sample surfaces for $\mathrm{HP} \mathrm{Mg}$ corroded in $\mathrm{Cl}^{-}$and $\mathrm{SO}_{4}{ }^{2-}$ are also shown in Figure 3.6 and revealed a 
difference in dissolution morphology between $\mathrm{Cl}^{-}$and $\mathrm{SO}_{4}{ }^{2-}$. It is clear from this figure that the $\mathrm{HP}$ $\mathrm{Mg}$ exposed to $\mathrm{Cl}^{-}$yielded a rough surface with sharp features while the $\mathrm{SO}_{4}{ }^{2-}$ exposed surfaces were smooth and lustrous.

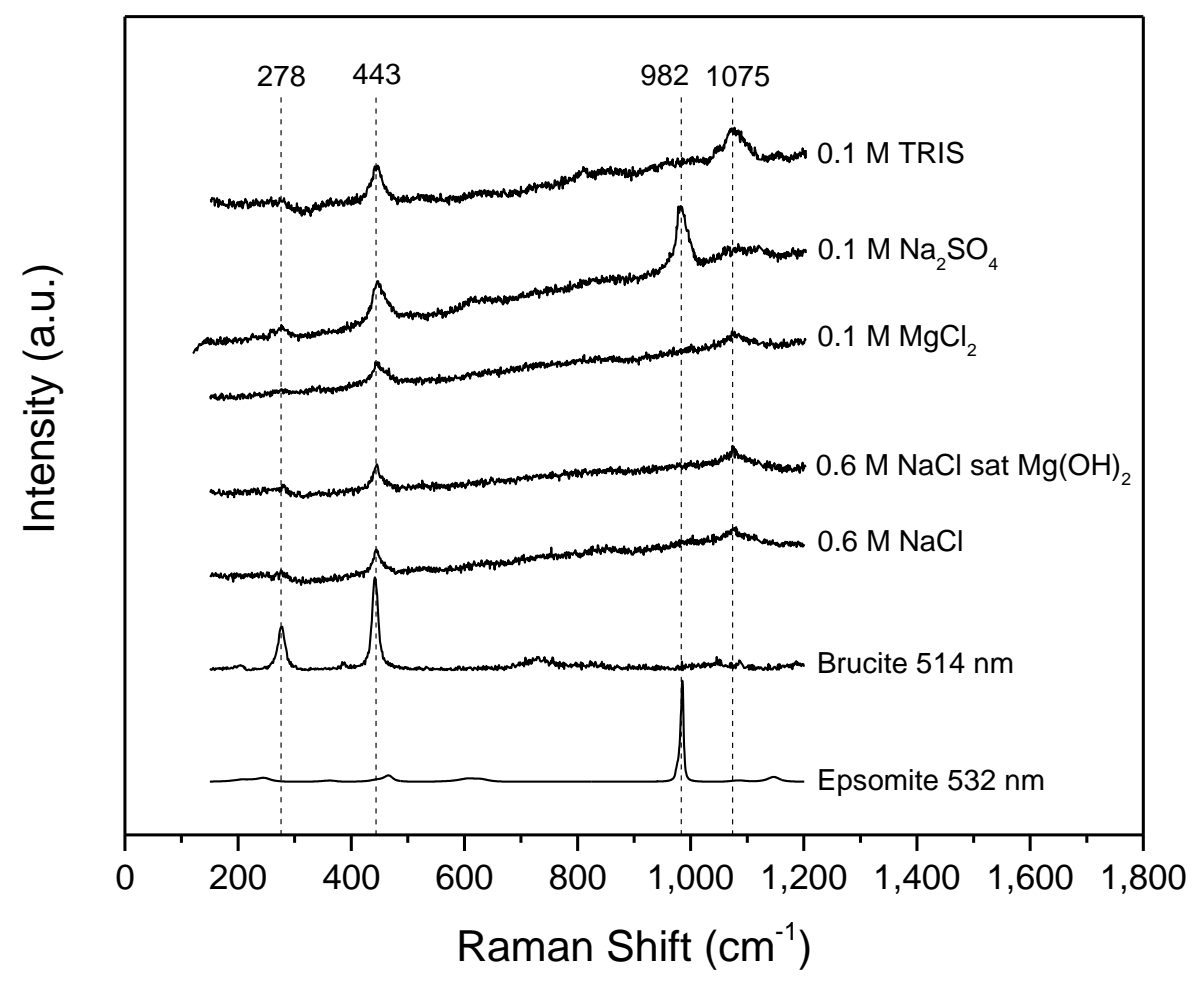

Figure 3.5. Raman spectra of sample surfaces after corrosion in each electrolyte. Standard spectra for Brucite $\left(\mathrm{Mg}(\mathrm{OH})_{2}\right.$, RRUFF ID: R040077) and Epsomite ( $\mathrm{MgSO}_{4} \cdot 7 \mathrm{H}_{2} \mathrm{O}, \mathrm{RRUFF}$ ID: $\mathrm{R} 150060$ ) are from the RRUFFTM database [13]. The peak at $1075 \mathrm{~cm}^{-1}$ is likely to be related to $\mathrm{CO}_{3}{ }^{2-}$ species. Instrument artifacts were subtracted from each spectrum. 


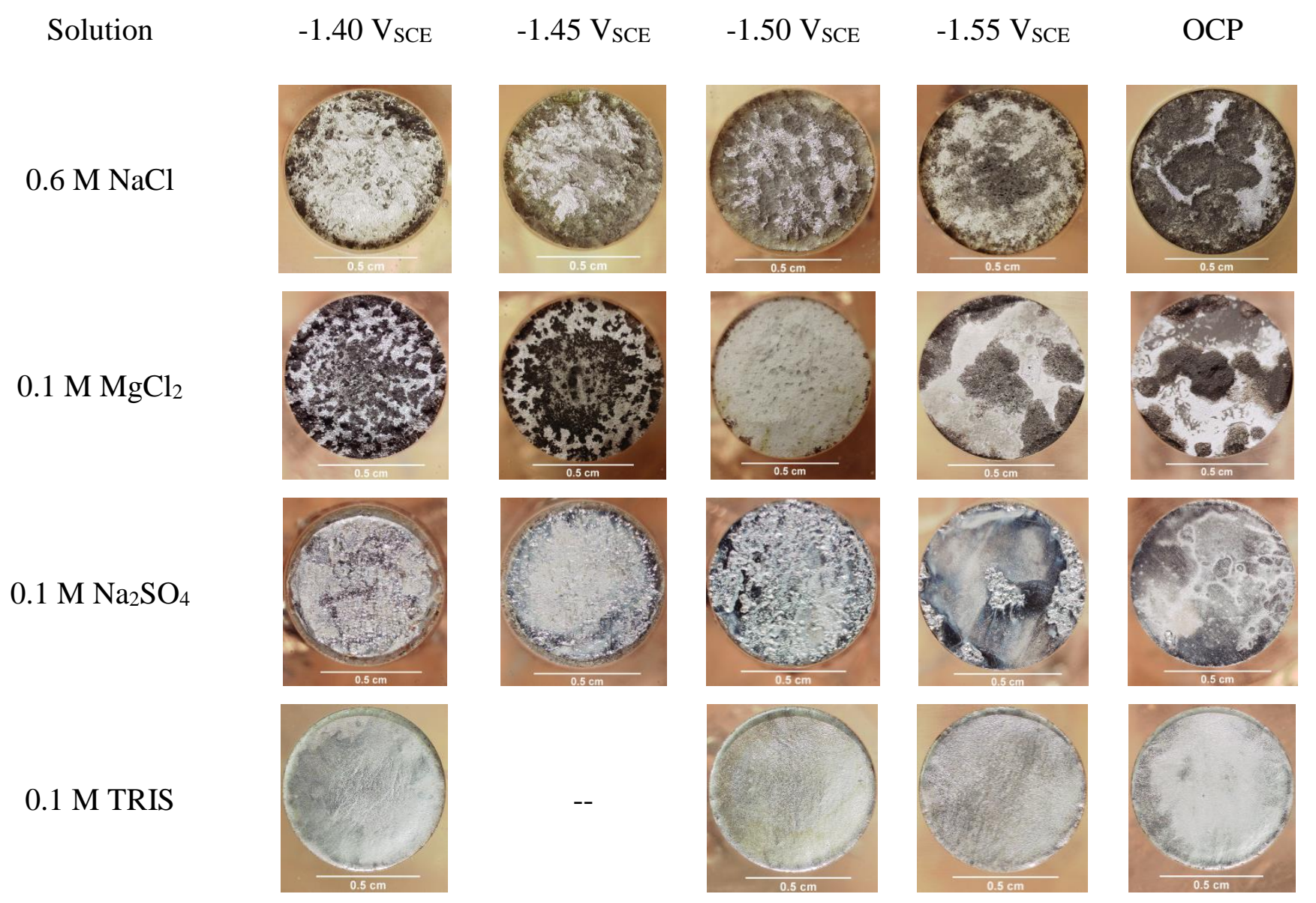

Figure 3.6. Optical micrographs of the surface morphology of corroded Mg samples after cleaning with $\mathrm{CrO}_{3}$. 0.1 M TRIS samples were not cleaned due to the absence of surface films.

\subsubsection{Charge Balance Analysis}

The charge balance for all solutions tested by potentiostatic polarization is shown in Figure

3.7. Inspection of Figure 3.7a shows that the conditions for charge balance described by Equation 3.4 are met assuming $\mathrm{Mg}$ dissolves only as an $\mathrm{Mg}^{2+}$ ion along with cathodic hydrogen evolution persisting on the corroded $\mathrm{Mg}$ anodes in $0.6 \mathrm{M} \mathrm{NaCl}$. This is observed in every solution tested in this investigation within one standard deviation ${ }^{\mathrm{v}}$. The values for mass loss, hydrogen evolved, and net anodic charge measured by the potentiostat are similar for both saturated and unsaturated 0.6

"Error bars are representative of one standard deviation from the mean and are present on each bar except where standard deviations are too small to be observed. 
$\mathrm{M} \mathrm{NaCl}$ which is in agreement with expectations from the net current density vs. time transients shown in Figure 3.4. However, the $\mathrm{NDE}$ is stronger in $0.6 \mathrm{M} \mathrm{NaCl}$ saturated with $\mathrm{Mg}(\mathrm{OH})_{2}$ owing in large part due to an OCP hydrogen evolution rate about half that measured in unsaturated 0.6 M $\mathrm{NaCl}$. Even lower corrosion rates were measured at $\mathrm{OCP}$ in $0.1 \mathrm{M} \mathrm{MgCl}_{2}$ and $0.1 \mathrm{M} \mathrm{Na}_{2} \mathrm{SO}_{4}$ with the values for mass loss and hydrogen evolution in $0.1 \mathrm{M} \mathrm{Na}_{2} \mathrm{SO}_{4}$ being $1.67 \pm 0.34 \mathrm{C} / \mathrm{cm}^{2}$ and $1.58 \pm 0.00 \mathrm{C} / \mathrm{cm}^{2}$, respectively (not visible in Figure $3.7 \mathrm{~d}$ ). As in the case of $\mathrm{NaCl}$, the volume of $\mathrm{H}_{2}$ captured for $\mathrm{MgCl}_{2}$ increased rapidly at small anodic overpotentials but increased linearly at larger overpotentials. In contrast, the amount of $\mathrm{H}_{2}$ captured increased linearly at every potential tested for $\mathrm{Na}_{2} \mathrm{SO}_{4}$. Moreover, the average charge due to mass loss at many potentials was slightly less than that of the sum of the charge for the hydrogen evolved and applied anodic charge measured by the potentiostat. However, this average is within error and also validates the choice of $z=2$.

The charge balance for TRIS is shown in Figure 3.7e. In contrast to the other electrolytes tested in this study, the average volume of $\mathrm{H}_{2}$ captured at all potentials was similar and did not change with increasing anodic overpotential for polarization between -1.65 $\mathrm{V}_{\mathrm{SCE}}$ and $-1.4 \mathrm{~V}_{\mathrm{SCE}}$. Moreover, it was less than that measured at OCP which suggests that there is no NDE in TRIS. This notion was confirmed at $-1.3 \mathrm{~V}_{\mathrm{SCE}}$ which showed a large decrease in the $\mathrm{H}_{2}$ captured compared to $-1.4 \mathrm{~V}_{\mathrm{SCE}}$ as well as at the OCP. It should be noted that the ohmic resistance of the TRIS buffered solution was about $110 \Omega-\mathrm{cm}^{2}$ producing a theoretical IR drop of $275 \mathrm{mV}$ at 2.5 $\mathrm{mA} / \mathrm{cm}^{2}$ which led to the relatively small changes in measured net anodic current density with increasing applied anodic potential by using increments of $100 \mathrm{mV}$ (Figure 3.4e) and thus small changes in mass loss and $\mathrm{H}_{2}$ captured are to be expected. 
(a)

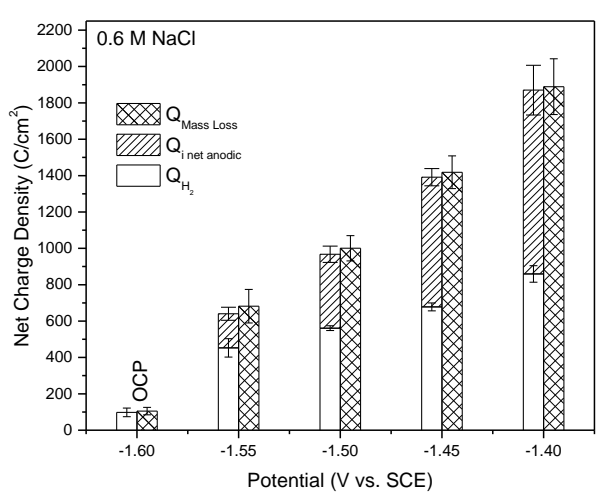

(c)

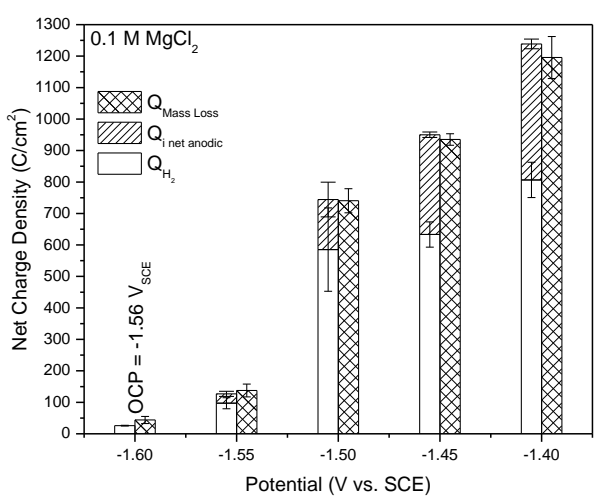

(e)

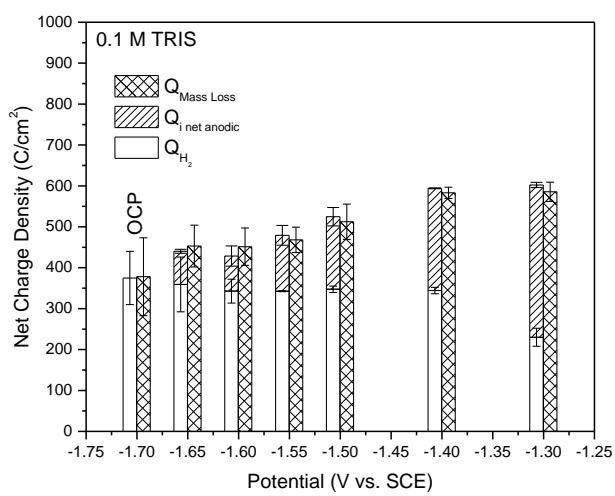

(b)

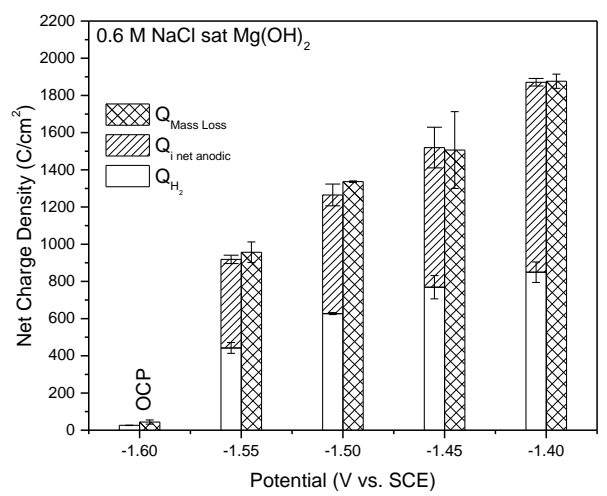

(d)

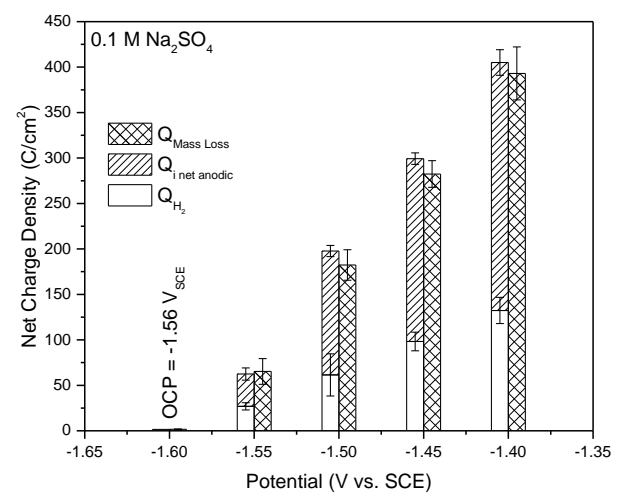

Figure 3.7. The charge calculated from mass loss compared to the charge calculated from captured hydrogen plus the charge measured by the potentiostat as a function of applied potential for $\mathrm{HP} \mathrm{Mg}$ in (a) $0.6 \mathrm{M} \mathrm{NaCl}$, (b) $0.6 \mathrm{M} \mathrm{NaCl}$ saturated with $\mathrm{Mg}(\mathrm{OH})_{2}$, (c) $0.1 \mathrm{M} \mathrm{MgCl}_{2}$, (d) $0.1 \mathrm{M} \mathrm{Na}_{2} \mathrm{SO}_{4}$, and (e) $0.1 \mathrm{M}$ TRIS buffer solution. Error bars are one standard deviation from the mean. 
The difference effect measured for each solution as a function of applied potential is shown in Figure 3.8a where the difference effect, $\Delta$, is defined as:

$$
\Delta=Q_{H_{2}, O C P}-Q_{H_{2}, \text { anodic }}
$$

The NDE is readily observed when plotting $\Delta$ vs. potential for $\mathrm{Cl}^{-}$containing solutions and displayed a linear increase with increasing potential. The NDE at each potential is greatest for 0.6 $\mathrm{M} \mathrm{NaCl}$ saturated with $\mathrm{Mg}(\mathrm{OH})_{2}$ but the change of $\Delta$ with potential is similar for all $\mathrm{Cl}^{-}$containing solutions. In comparison, the change in $\Delta$ vs. applied potential was much less for $\mathrm{Cl}^{-}$free $\mathrm{Na}_{2} \mathrm{SO}_{4}$ solution but NDE was still evident. TRIS, however, did not display an NDE which is what would be expected from classical mixed potential theory applied to metal corrosion [11]. Despite the presence of a positive difference effect for the TRIS solution, the faradaic efficiency for $\mathrm{Mg}$ dissolution $\left(\mathrm{Q}_{\mathrm{i} \text { net anodic }} / \mathrm{Q}_{\text {mass loss }}\right)$ is low at small anodic overpotentials as shown in Figure $3.8 \mathrm{~b}$ which suggests that the local cathodic reaction is still a significant factor to reducing the net applied anodic current compared to the true anodic current density. However, the faradaic efficiency increases with increasing anodic overpotential for TRIS and also for $0.6 \mathrm{NaCl}$ and $0.1 \mathrm{M} \mathrm{MgCl}_{2}$. In contrast, $0.6 \mathrm{M} \mathrm{NaCl}$ saturated with $\mathrm{Mg}(\mathrm{OH})_{2}$ (Figure 3.8b) displayed a relatively constant efficiency of about 0.5 within error while $0.1 \mathrm{M} \mathrm{Na}_{2} \mathrm{SO}_{4}$ indicated the greatest faradaic efficiency of all the electrolytes studied near 0.7 and revealed a decrease in faradaic efficiency at applied potentials greater than $-1.50 \mathrm{~V}_{\mathrm{SCE}}$. 


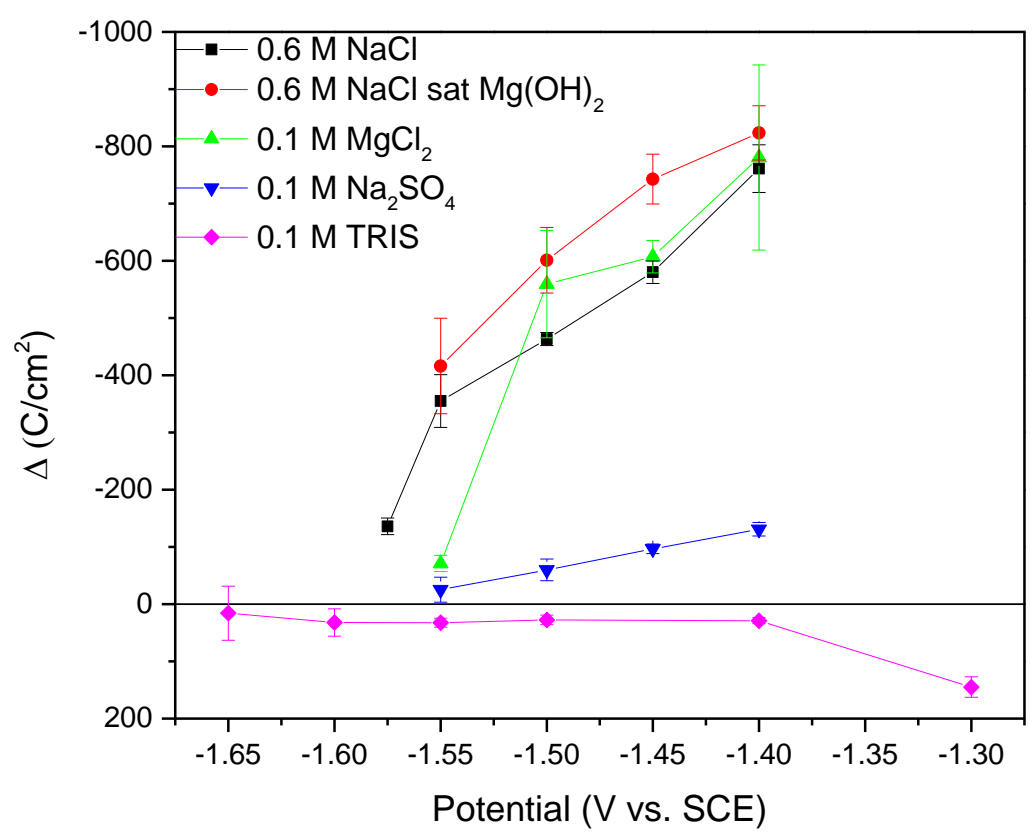

(a)

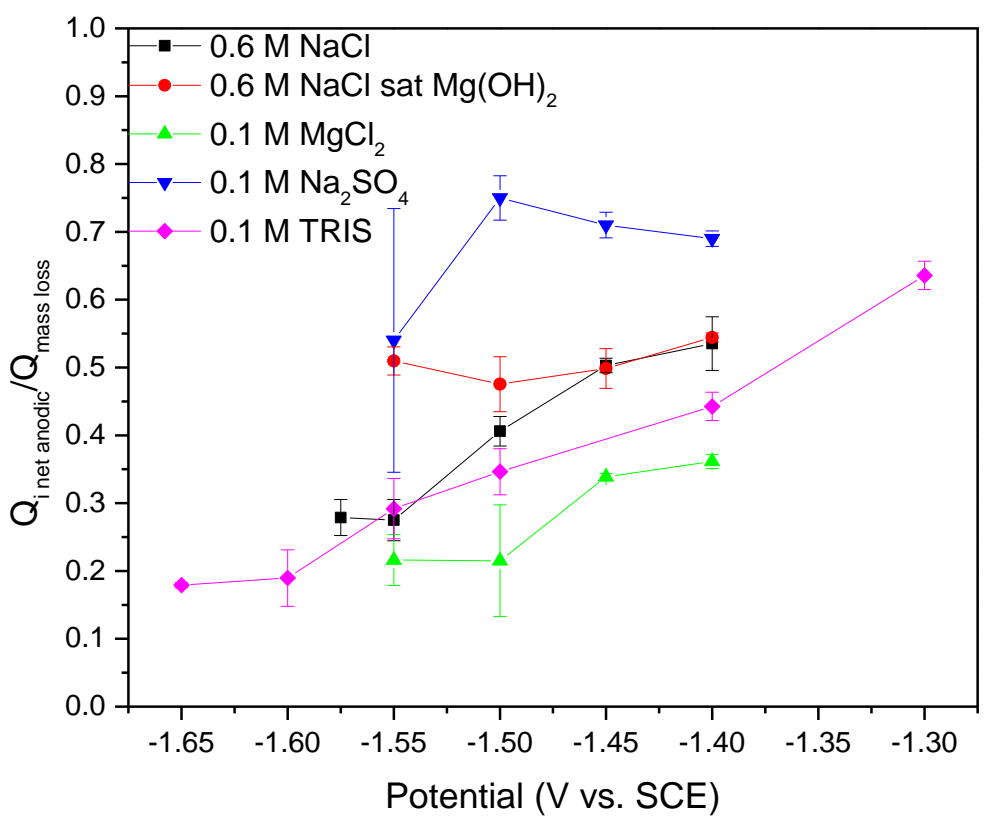

(b)

Figure 3.8. (a) The NDE as a function of applied potential and (b) the ratio of charge measured by the potentiostat to the charge consumed by mass loss. Error bars are one standard deviation from the mean. 


\subsubsection{Cathodic Potentiodynamic Polarization}

Potentiodynamic polarization was performed after anodic potentiostatic polarization with the anodic surface film intact and in a film free condition after cleaning sample surfaces with $\mathrm{CrO}_{3}$ to examine evidence of enhanced cathodic kinetics, Figure 3.9. E vs. log i polarization behavior for a freshly polished sample after $1 \mathrm{~min}$ immersion at OCP is displayed for reference to show the cathodic kinetics of an $\mathrm{Mg}$ surface that has no actively corroding filaments that might exhibit anodically enhanced cathodic kinetics. In addition, the calculated current density associated with the $\mathrm{H}_{2}$ captured at each potential during anodic polarization is shown for each solution assuming that the HER rate is constant with time. Figure 3.9a-c reveal that the cathodic kinetics are faster on samples that were immersed in $\mathrm{Cl}^{-}$and subject to anodic polarization with the surface film intact compared to those with no films. Moreover, the cathodic kinetics after dissolution in every environment tested are greater than the results for freshly polished samples when the dissolution film is intact which is consistent with previous reports in chloride containing environments [6]. However, there appears to be no clear trend of increasing cathodic kinetics with increasing prior anodic polarization potential as summarized in Figure 3.9f. No clear trend in the change in cathodic kinetics with increasing anodic dissolution was also observed in $0.1 \mathrm{M} \mathrm{Na}_{2} \mathrm{SO}_{4}$ (Figure 3.9d) but the cathodic kinetics for both the film and film free conditions were slower than that of a freshly polished sample. The film free condition tended to show faster cathodic kinetics than the filmed condition at large cathodic overpotentials but were similar at smaller overpotentials which is in contrast to $\mathrm{Cl}^{-}$environments. TRIS (Figure 3.9e) was distinctly different and did not show any variation in cathodic kinetics with increasing prior polarization between $-1.65 \mathrm{~V}_{\mathrm{SCE}}$ and $-1.4 \mathrm{~V}_{\mathrm{SCE}}$. However, the rate of HER decreased on samples polarized at $-1.3 \mathrm{~V}_{\mathrm{SCE}}$ (film free runs are not shown on this plot because there was no appearance of a surface film from visual inspection). The 
absence of any strong variation of cathodic kinetics for applied potentials between $-1.65 \mathrm{~V}_{\mathrm{SCE}}$ and -1.4 $\mathrm{V}_{\mathrm{SCE}}$ is consistent with the similar volume of hydrogen captured as shown in Fig. 5e. Moreover, the decrease in cathodic kinetics at $-1.3 \mathrm{~V}_{\mathrm{SCE}}$ compared to the other applied anodic potentials is also consistent with the decreased volume of hydrogen measured at this potential.

\subsubsection{Inductively Coupled Plasma - Optical Emission Spectroscopy}

The results of ICP-OES performed on solutions kept after potentiostatic polarization testing are shown in Tables 3.4-3.8. The results for $0.6 \mathrm{M} \mathrm{NaCl}$ (Table 3.4) and 0.6 M NaCl saturated with $\mathrm{Mg}(\mathrm{OH})_{2}$ (Table 3.5) reveal that no elements other than $\mathrm{Mg}$ could be detected. However, Fe and $\mathrm{Mn}$ are shown to be present in solution above the detection limit for $0.1 \mathrm{M} \mathrm{MgCl}_{2}$ (Table 3.6), 0.1 $\mathrm{M} \mathrm{Na}_{2} \mathrm{SO}_{4}$ (Table 3.7), and 0.1 M TRIS (Table 3.8). Furthermore, the Fe/Mg ratio calculated for $0.1 \mathrm{M} \mathrm{Na}_{2} \mathrm{SO}_{4}$ and $0.1 \mathrm{M}$ TRIS based on the measured concentrations are slightly greater than that of the bulk alloy which has a value of $8 \times 10^{-5}$. Note that these values of Fe/Mg ratio do not account for $\mathrm{Fe}$ and $\mathrm{Mg}$ present in the intact dissolution film on the $\mathrm{Mg}$ surface which could not be analyzed as discussed in Section 3.2.3.

Table 3.4. Average element concentration from the raw data intensities in $0.6 \mathrm{M} \mathrm{NaCl}$ after 24-hour potentiostatic polarization determined by ICP-OES. Solutions were acidified with 1 $\mathrm{M} \mathrm{HCl}$ to dissolve insoluble corrosion products. Grey cells are below the respective element detection limit.

\begin{tabular}{|c|c|c|c|c|c|}
\hline & \multicolumn{5}{|c|}{ Element Concentration (ppm) } \\
\hline Potential (VSCE) & $\mathbf{M g}$ & $\mathbf{A l}$ & $\mathbf{F e}$ & $\mathbf{M n}$ & $\mathbf{Z n}$ \\
\hline-1.400 & 27.470 & -0.020 & -0.010 & -0.019 & -0.020 \\
\hline-1.450 & 16.397 & -0.033 & -0.027 & -0.032 & -0.034 \\
\hline-1.500 & 13.036 & -0.010 & -0.031 & -0.032 & -0.034 \\
\hline-1.550 & 12.232 & -0.028 & -0.033 & -0.032 & -0.034 \\
\hline-1.600 & 6.202 & -0.036 & -0.032 & -0.032 & -0.034 \\
\hline-1.625 & 0.146 & 0.001 & -0.001 & -0.001 & -0.004 \\
\hline-1.650 & 0.038 & -0.002 & -0.003 & -0.002 & -0.007 \\
\hline-1.700 & 0.092 & 0.006 & -0.003 & -0.002 & -0.007 \\
\hline-1.800 & 0.024 & 0.002 & -0.002 & -0.002 & -0.007 \\
\hline
\end{tabular}


(a)

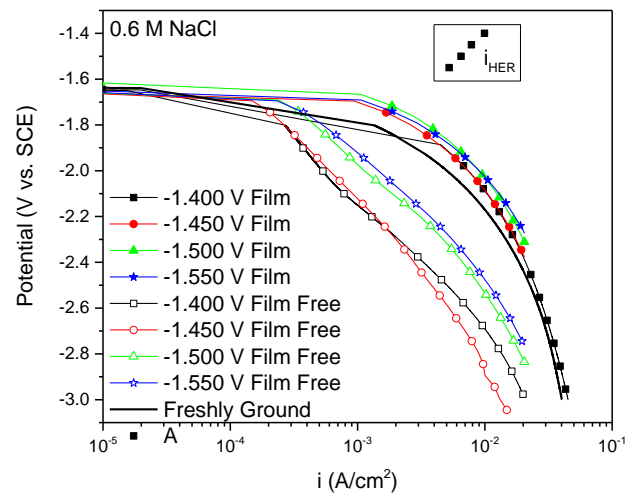

(c)

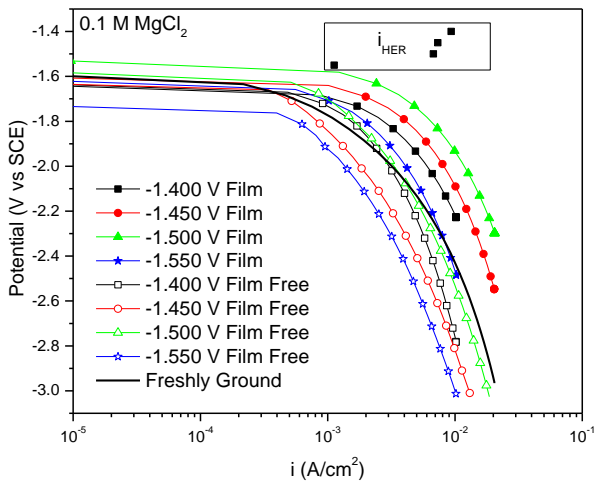

(e)

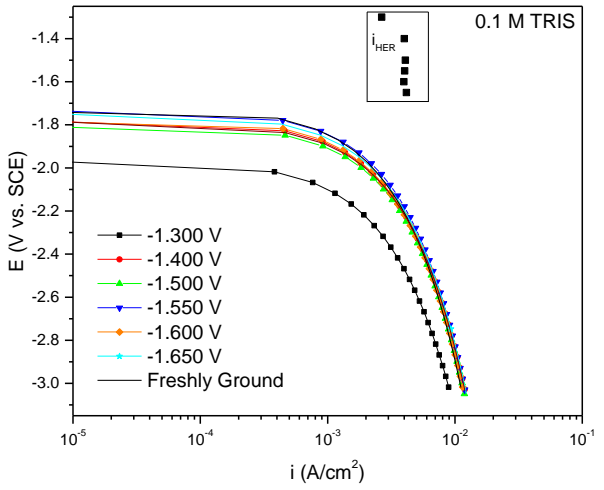

(b)

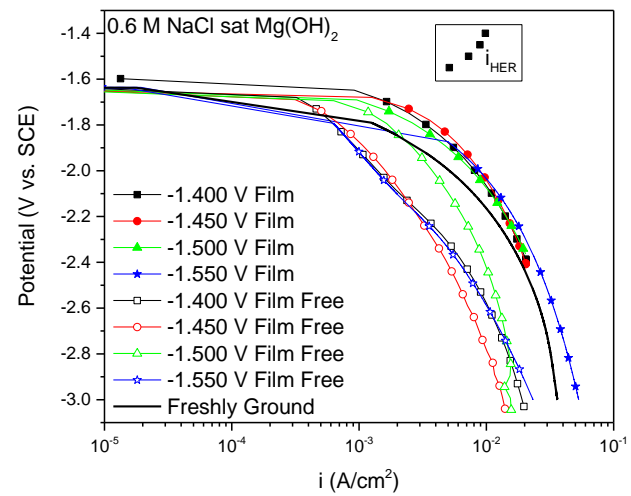

(d)

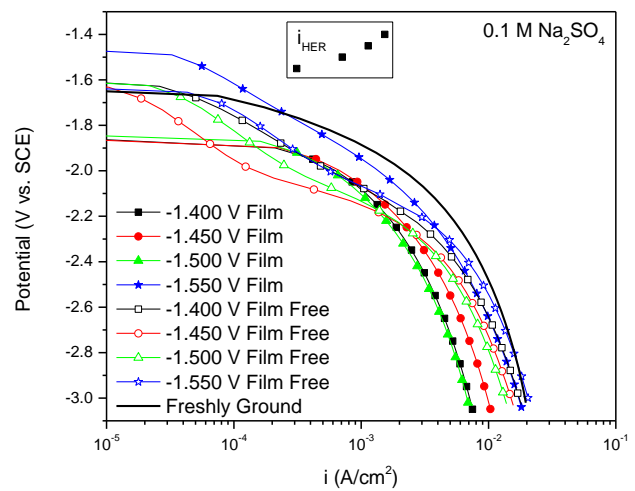

(f)

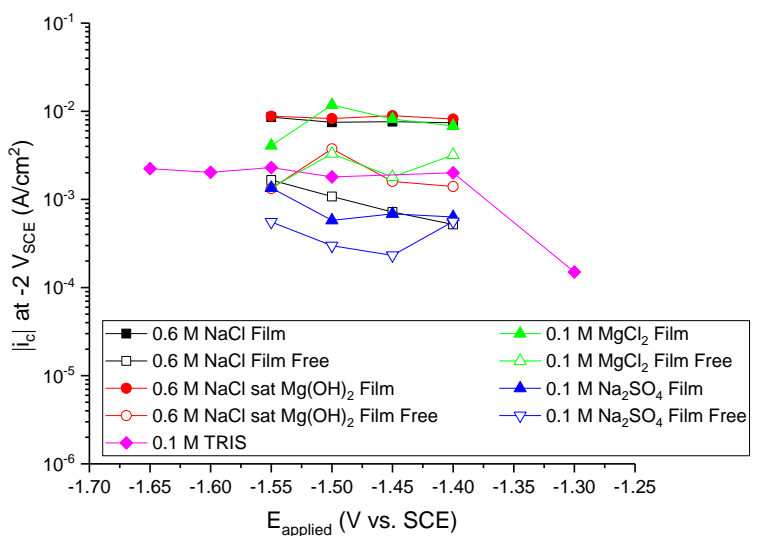

Figure 3.9. Cathodic potentiodynamic polarization scans with the corrosion films intact compared to film free condition after removing corrosion products with $\mathrm{CrO}_{3}$ for (a) $0.6 \mathrm{M} \mathrm{NaCl}$, (b) $0.6 \mathrm{M} \mathrm{NaCl}$ saturated with $\mathrm{Mg}(\mathrm{OH})_{2}$, (c) $0.1 \mathrm{M} \mathrm{MgCl}_{2}$, (d) $0.1 \mathrm{M} \mathrm{Na}_{2} \mathrm{SO}_{4}$, and (e) $0.1 \mathrm{M}$ TRIS. The average cathodic current density at $-2 \mathrm{~V}_{\mathrm{SCE}}$ is summarized in (f). Scans were performed after $1 \mathrm{~min}$ at OCP either after completion of potentiostatic polarization or re-immersion into solution after cleaning. The potential scan rate was $2500 \mathrm{mV} / \mathrm{s}$. 
Table 3.5. Average element concentration from the raw data intensities in $0.6 \mathrm{M} \mathrm{NaCl}$ saturated with $\mathrm{Mg}(\mathrm{OH})_{2}$ after 24-hour potentiostatic polarization determined by ICP-OES. Solutions were acidified with $1 \mathrm{M} \mathrm{HCl}$ to dissolve insoluble corrosion products. Grey cells are below the respective element detection limit.

\begin{tabular}{|c|c|c|c|c|c|}
\hline & \multicolumn{5}{|c|}{ Element Concentration (ppm) } \\
\hline Potential (VSCE) & Mg & Al & Fe & Mn & Zn \\
\hline-1.400 & -- & 0.038 & 0.003 & 0.001 & -0.001 \\
\hline-1.450 & -- & 0.039 & 0.003 & 0.002 & -0.003 \\
\hline-1.500 & -- & 0.032 & 0.005 & 0.001 & -0.004 \\
\hline-1.550 & -- & 0.031 & 0.001 & 0.001 & -0.003 \\
\hline OCP & -- & 0.041 & 0.002 & 0.001 & -0.002 \\
\hline
\end{tabular}

Table 3.6. Average element concentration from the raw data intensities in $0.1 \mathrm{M} \mathrm{MgCl}_{2}$ after 24-hour potentiostatic polarization determined by ICP-OES. Solutions were acidified with 1 $\mathrm{M} \mathrm{HCl}$ to dissolve insoluble corrosion products. Grey cells are below the respective element detection limit.

\begin{tabular}{|c|c|c|c|c|c|}
\hline & \multicolumn{5}{|c|}{ Element Concentration (ppm) } \\
\hline Potential (VSCE) & Mg & Al & Fe & Mn & Zn \\
\hline-1.400 & -- & 0.016 & 0.031 & 0.053 & -0.008 \\
\hline-1.450 & -- & 0.008 & 0.019 & 0.049 & -0.003 \\
\hline-1.500 & -- & 0.009 & 0.017 & 0.067 & -0.006 \\
\hline-1.550 & -- & 0.016 & 0.037 & 0.038 & -0.016 \\
\hline OCP & -- & -0.009 & 0.012 & 0.020 & 0.002 \\
\hline
\end{tabular}

Table 3.7. Average element concentration from the raw data intensities in $0.1 \mathrm{M} \mathrm{Na}_{2} \mathrm{SO}_{4}$ after 24-hour potentiostatic polarization determined by ICP-OES. Solutions were acidified with 1 $\mathrm{M} \mathrm{HCl}$ to dissolve insoluble corrosion products. Grey cells are below the respective element detection limit. The Fe: $\mathrm{Mg}$ ratio is given in the last column.

\begin{tabular}{|c|c|c|c|c|c|c|}
\hline & \multicolumn{5}{|c|}{ Element Concentration (ppm) } & \\
\hline Potential (VSCE) & $\mathbf{M g}$ & $\mathbf{A l}$ & $\mathbf{F e}$ & $\mathbf{M n}$ & $\mathbf{Z n}$ & Fe:Mg \\
\hline-1.400 & 87.965 & -0.005 & 0.018 & -0.018 & 0.000 & $2.05 \times 10^{-4}$ \\
\hline-1.450 & 62.234 & -0.012 & 0.011 & -0.025 & -0.006 & $1.77 \times 10^{-4}$ \\
\hline-1.500 & 44.349 & -0.007 & 0.017 & 0.025 & -0.010 & $3.83 \times 10^{-4}$ \\
\hline-1.550 & 14.457 & -0.006 & 0.007 & -0.017 & 0.006 & $4.84 \times 10^{-4}$ \\
\hline OCP & 15.656 & 0.007 & 0.007 & -0.019 & -0.003 & $4.47 \times 10^{-4}$ \\
\hline
\end{tabular}


Table 3.8. Average element concentration from the raw data intensities in 0.1 M TRIS after 24-hour potentiostatic polarization determined by ICP-OES. Solutions were acidified with 1 $\mathrm{M} \mathrm{HCl}$ to dissolve insoluble corrosion products. The total concentration of Fe with respect to $\mathrm{Mg}$ is calculated in the final column in units of ppm. Grey cells are below the respective element detection limit. The Fe: $\mathrm{Mg}$ ratio is given in the last column.

\begin{tabular}{|c|c|c|c|c|c|c|}
\hline & \multicolumn{5}{|c|}{ Element Concentration (ppm) } & \\
\hline Potential (VSCE) & $\mathbf{M g}$ & $\mathbf{A l}$ & $\mathbf{F e}$ & $\mathbf{M n}$ & $\mathbf{Z n}$ & Fe:Mg \\
\hline-1.300 & 179.142 & -0.043 & 0.010 & -0.008 & -0.012 & $5.58 \times 10^{-5}$ \\
\hline-1.400 & 179.974 & -0.045 & 0.020 & 0.005 & -0.011 & $1.11 \times 10^{-4}$ \\
\hline-1.500 & 167.676 & -0.038 & 0.022 & -0.012 & -0.013 & $1.31 \times 10^{-4}$ \\
\hline-1.550 & 171.604 & -0.042 & 0.023 & 0.006 & -0.009 & $1.34 \times 10^{-4}$ \\
\hline-1.600 & 152.385 & -0.024 & 0.025 & 0.008 & 0.002 & $1.64 \times 10^{-4}$ \\
\hline-1.650 & 158.923 & -0.036 & 0.028 & 0.003 & -0.011 & $1.76 \times 10^{-4}$ \\
\hline OCP & 137.516 & 0.005 & 0.019 & 0.008 & 0.013 & $1.38 \times 10^{-4}$ \\
\hline
\end{tabular}

\subsubsection{Rutherford Backscattering}

RBS analysis performed in this study is shown in Figures 3.10-3.12. Figure 3.10 displays RBS data for a ground specimen without chromic acid cleaning where the number of counts measured at a given energy level is shown in Figure 3.10a whilst Figure 3.10b shows the corresponding composition profile calculated from a simulation fit in the SIMNRA program. Note that the $\mathrm{x}$-axis for all concentration vs. depth profiles have been expanded to focus on the $\mathrm{Mg}$ surface while utilizing a linear axis. This figure indicates that the freshly prepared surface (not exposed to electrolyte) consists predominantly of a Mg oxide/hydroxide covered surface with a trace levels of Si which we have ascribed to mechanical grinding with the Si incorporated in the oxide/hydroxide layer and at the film/metal interface; note that hydrogen is not included in the analysis as it is a forward scattered particle and will not appear in the backscattered spectrum. The broad low energy shoulder on the left of Figure 3.10a indicates bulk Mg with the low energy near surface oxygen peak superimposed. The oxygen peak indicates little energy loss from its theoretical level and thus indicating that the oxygen resides at the surface. Fitting of the oxygen 
peak utilized input data for the elastic scattering cross section measured at a scattering angle of $165^{\circ}$. This data was used because the SIMNRA program does not possess an elastic scattering cross section for a scattering angle of $160^{\circ}$ which results in an overestimate of the oxygen peak intensity. The presence of elements in the zone just below the oxide is near the detection limit for all elements with an atomic mass ranging from Si (28.09 amu) to Fe (55.85 amu).

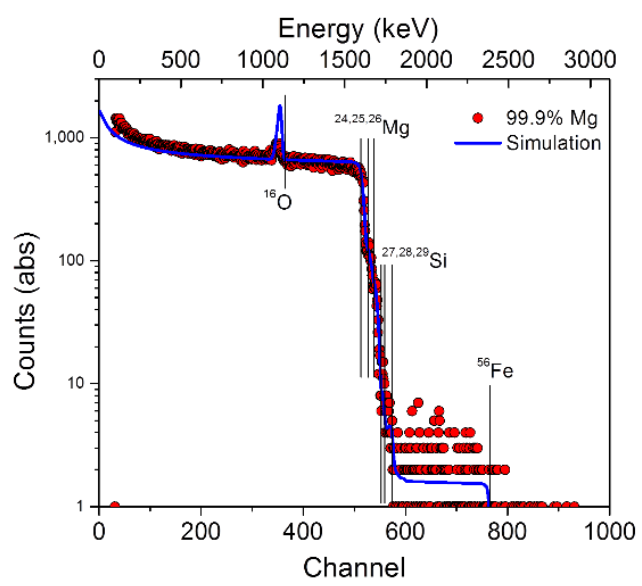

(a)

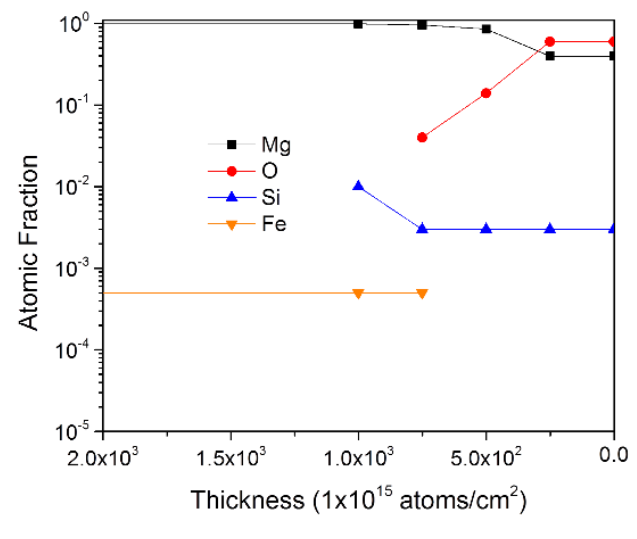

Figure 3.10. (a) RBS scan of high purity Mg ground to a 1200-grit finish in ethanol with (b) the corresponding concentration vs. depth profile as determined by the SIMNRA 6.06 computer code.

The RBS data of a ground sample followed by a chromic acid clean (Figure 3.11) indicates a sharp peak consistent with near surface Cr. It is noted from the raw RBS data in Figure 3.11a that the oxygen peak is negligible, indicating that chromic acid is indeed capable of corrosion product removal with minimal adverse effects such as additional oxidation and scale formation (as 
advocated in ASTM standard G-1 [10]). In addition, the composition of Fe (Figure 3.11b) remains constant on the surface.

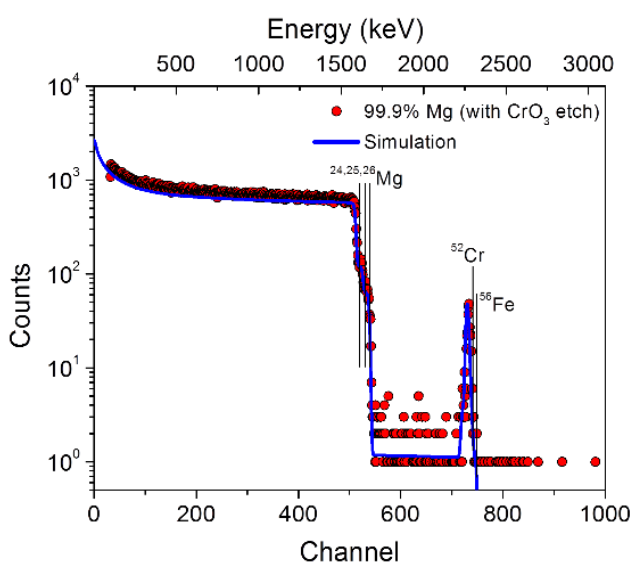

(a)

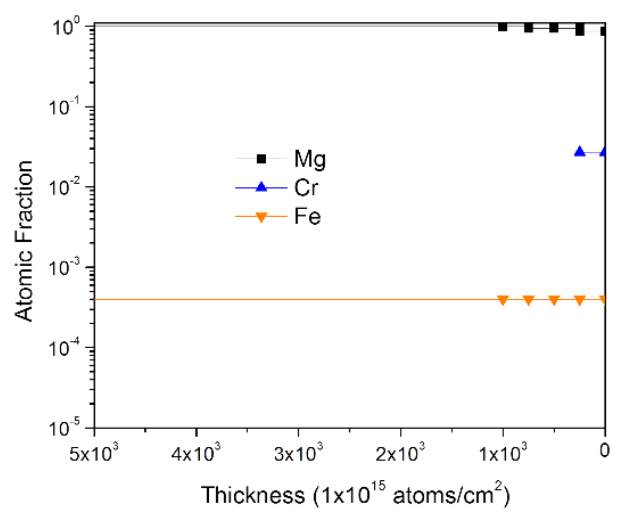

(b)

Figure 3.11. (a) RBS scan of high purity Mg ground to a 1200-grit finish in ethanol followed by $\mathrm{CrO}_{3}$ cleaning with (b) the corresponding concentration vs. depth profile as determined by the SIMNRA 6.06 computer code.

In order to detect possible enrichment of elements other than $\mathrm{Mg}$ upon the dissolving metal surface, RBS was performed on a specimen exposed for 24 hrs potentiostatic polarization at -1.625 $\mathrm{V}_{\mathrm{SCE}}$ in $0.6 \mathrm{M} \mathrm{NaCl}$ and cleaned using $\mathrm{CrO}_{3}$ solution (Figure 3.12). This specimen was chosen for analysis because accurate RBS requires a flat test surface with minimal roughness which was not available on the heavily corroded surfaces of anodically polarized samples. In addition, this sample experienced polarity reversal during potentiostatic polarization which made it ideal for RBS analysis testing for possible surface enrichment by noble elements. Figure 3.12 indicates the 
presence of $\mathrm{Cr}$ as well as Fe and a near surface oxide/hydroxide as expected from Figure 3.103.11. However, the measured intensity of the broad $\mathrm{Cr}$ peak in Figure 3.12a decreased gradually over a broad range of energy in contrast to the sharp Cr peak observed in the non-corroded sample (Figure 3.11). This suggests that $\mathrm{Cr}$ is not wholly responsible for the gradual decrease in energy. The interaction energies of $\mathrm{Cr}$ and $\mathrm{Fe}$ are only separated by $49 \mathrm{keV}$, thus measured intensities for both elements will be superimposed. The decrease in energy observed is indicative of an enrichment of $\mathrm{Fe}$ in the residual oxide/hydroxide and on the metal surface decreasing as a function of depth into the sample. The simulation of this peak shows the composition of Fe on the surface is ca. $18.5 \mathrm{x}$ greater than that in the bulk metal (Figure 3.12b). Additionally, Figure 3.12c shows that the Fe: $\mathrm{Mg}$ ratio (i.e., $\mathrm{C}_{\mathrm{Fe}} / \mathrm{C}_{\mathrm{Mg}}$ ) at the lowest value on the surface is ca. 30x greater than in the bulk metal $\left(2.38 \times 10^{-3}\right.$ versus $\left.8.00 \times 10^{-5}\right)$. This result represents, for the first time, quantitative enrichment of impurities on a dissolving $\mathrm{Mg}$ surface.

\subsubsection{Micro Particle Induced X-ray Emission of Corroded Mg Surfaces}

PIXE analysis was performed on $\mathrm{HP} \mathrm{Mg}$ samples in each solution which had undergone anodic dissolution at an applied current density of either $2 \mathrm{~mA} / \mathrm{cm}^{2}$ or $10 \mathrm{~mA} / \mathrm{cm}^{2}$ for 2 minutes. A typical PIXE spectrum for all samples tested is shown in Figure 3.13 where the circles represented the raw data, the red line shows the PIXE fit from the GeoPIXE program code, and the green line shows the baseline used. Figure 3.13 shows that excellent fits of the raw PIXE data are made using the GeoPIXE program. The concentration profiles as a function of total anodic charge passed for each solution tested both with the corrosion film intact and after $\mathrm{CrO}_{3}$ cleaning are shown in Figures 3.14-3.18. 
(a)

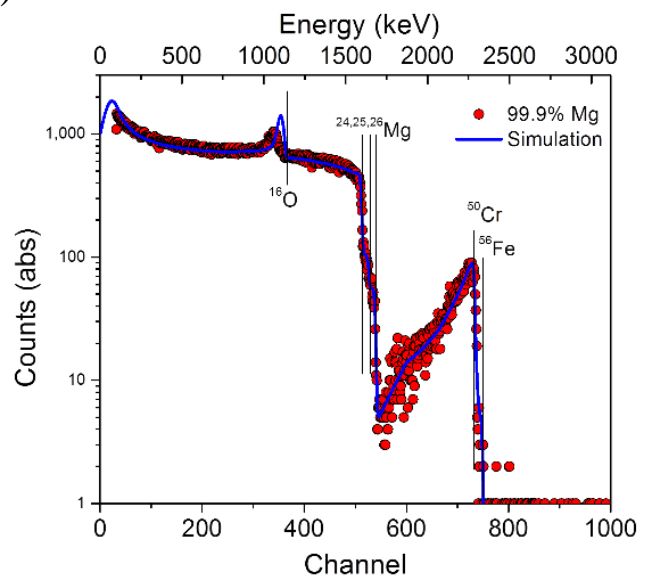

(c)

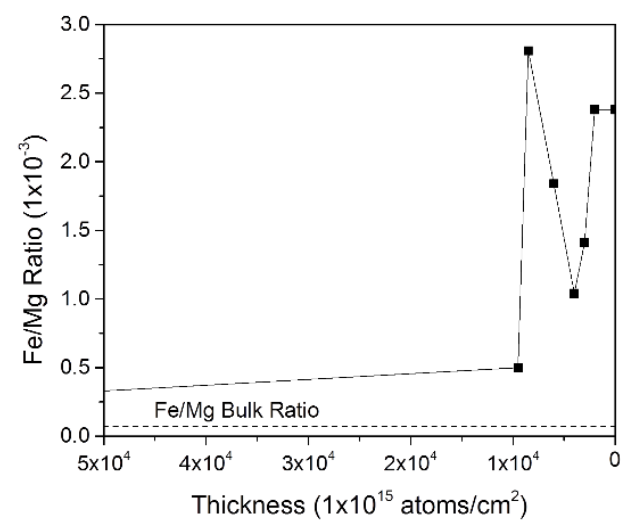

(b)

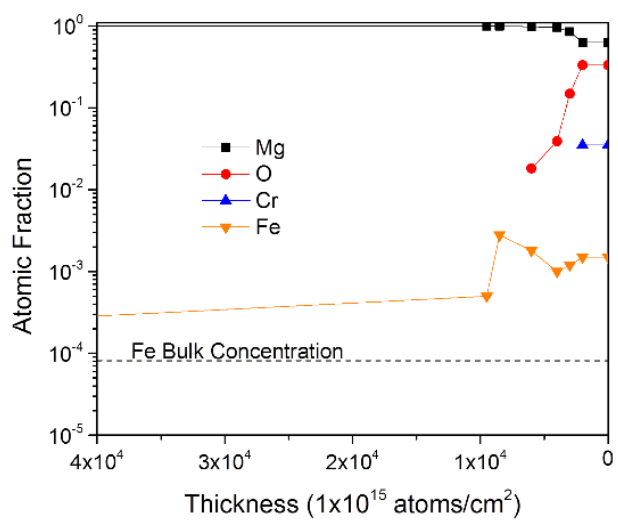

Figure 3.12. (a) RBS scan of high purity after 24 hour potentiostatic polarization at $-1.625 \mathrm{~V}_{\mathrm{SCE}}$ with (b) the corresponding concentration vs. depth profile as determined by the SIMNRA 6.06 computer code. Corrosion products were cleaned off using $\mathrm{CrO}_{3}$ solution. (c) shows the Fe:Mg ratio as a function of depth in the sample.

In Figure 3.14, the concentration of Fe is shown to increase by about 10x with both the dissolution film intact and after $\mathrm{CrO}_{3}$ after exposure of $\mathrm{HP} \mathrm{Mg}$ in $0.6 \mathrm{M} \mathrm{NaCl}$ while the enrichment of other elements detected did not show any enrichment or slight enrichment as in the case of Mn with the film intact and $\mathrm{Zn}$ after $\mathrm{CrO}_{3}$ cleaning. This general trend was observed in Figure 3.15 (0.6 M NaCl saturated with $\mathrm{Mg}(\mathrm{OH})_{2}$ and Figure $3.16\left(0.1 \mathrm{M} \mathrm{MgCl}_{2}\right)$ where enrichment of Fe was observed with increasing anodic charge passed while enrichment of other elements was not observed. Furthermore, no enrichment of any elements was observed with increasing anodic charge passed in $0.1 \mathrm{M} \mathrm{Na}_{2} \mathrm{SO}_{4}$ (Figure 3.17) and 0.1 M TRIS (Figure 3.18). 


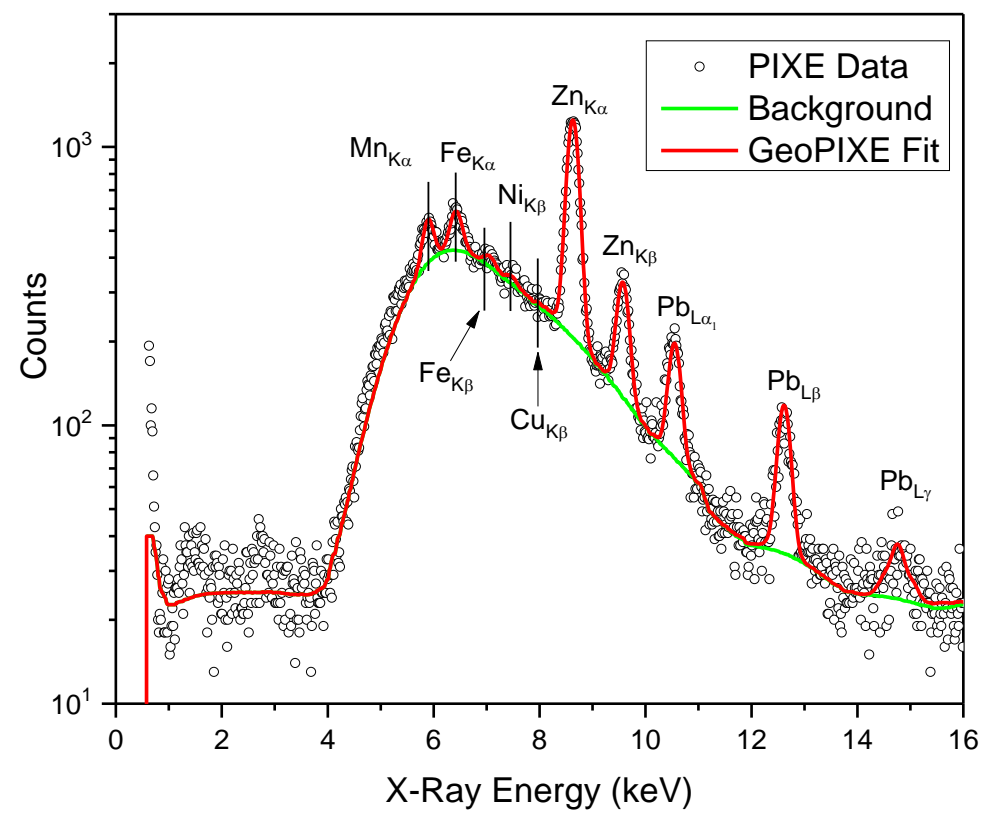

Figure 3.13. Typical fit of PIXE data using the GeoPIXE program code. This is the case for HP $\mathrm{Mg}$ immersed in $0.6 \mathrm{M} \mathrm{NaCl}$ after an anodic pulse of $2 \mathrm{~mA} / \mathrm{cm}^{2}$ for 2 minutes with the dissolution film intact.

(a)

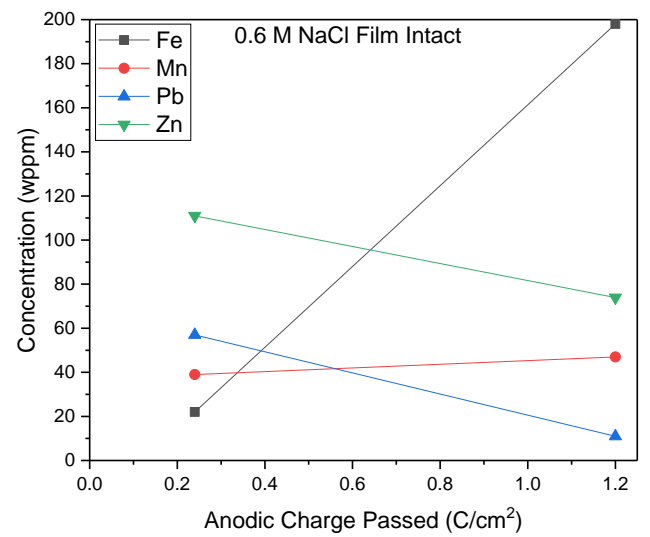

(b)

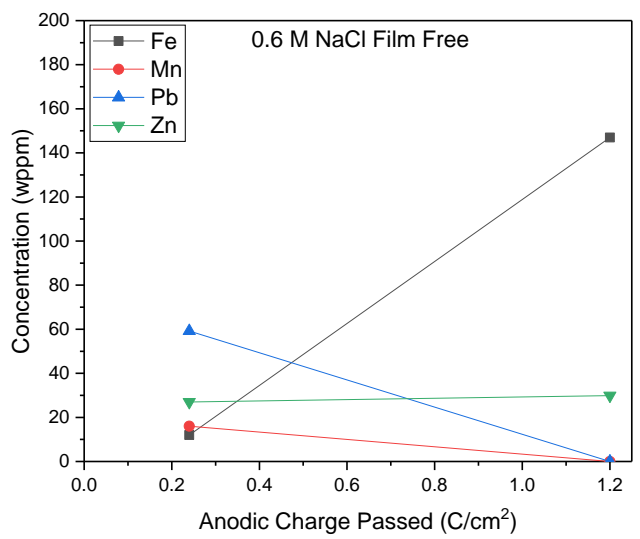

Figure 3.14. Processed PIXE data to reveal the change in surface composition of HP Mg due to increasing anodic dissolution in $0.6 \mathrm{M} \mathrm{NaCl}$ with (a) the dissolution film intact and (b) after $\mathrm{CrO}_{3}$ cleaning. 
(a)

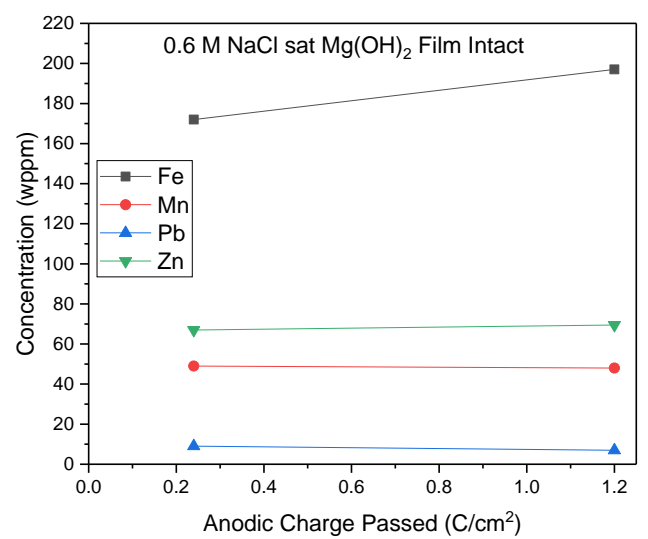

(b)

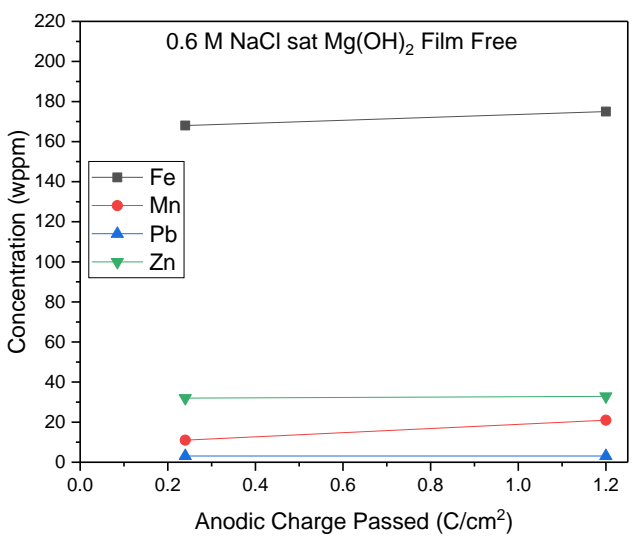

Figure 3.15. Processed PIXE data to reveal the change in surface composition of HP Mg due to increasing anodic dissolution in $0.6 \mathrm{M} \mathrm{NaCl}$ saturated with $\mathrm{Mg}(\mathrm{OH})$ with (a) the dissolution film intact and (b) after $\mathrm{CrO}_{3}$ cleaning.

(a)

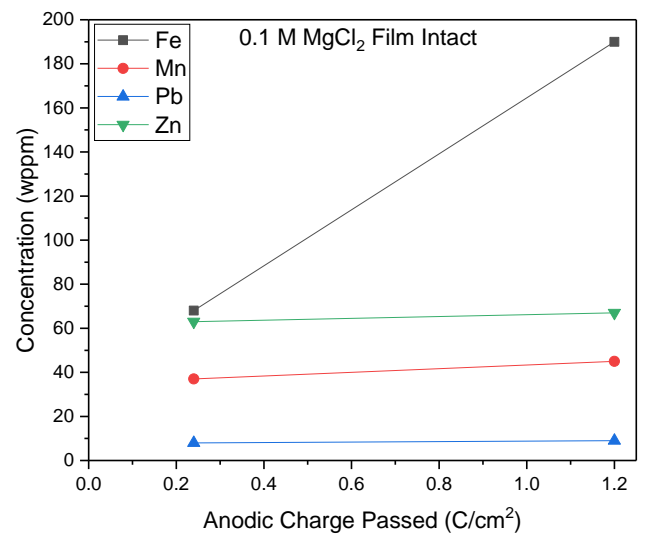

(b)

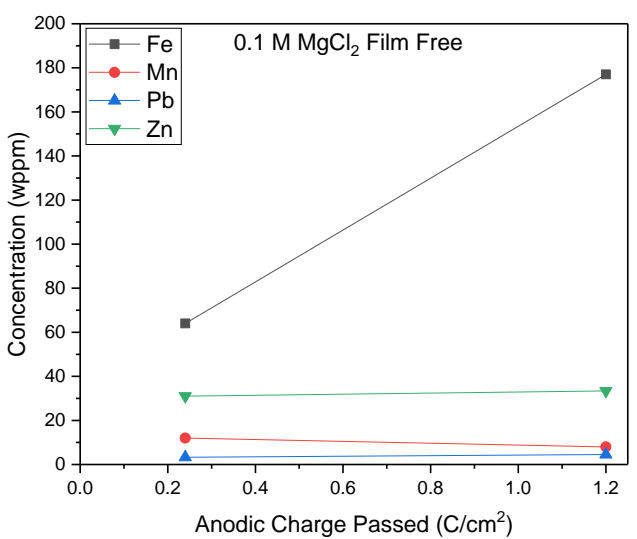

Figure 3.16. Processed PIXE data to reveal the change in surface composition of HP Mg due to increasing anodic dissolution in $0.1 \mathrm{M} \mathrm{MgCl}_{2}$ with (a) the dissolution film intact and (b) after $\mathrm{CrO}_{3}$ cleaning. 
(a)

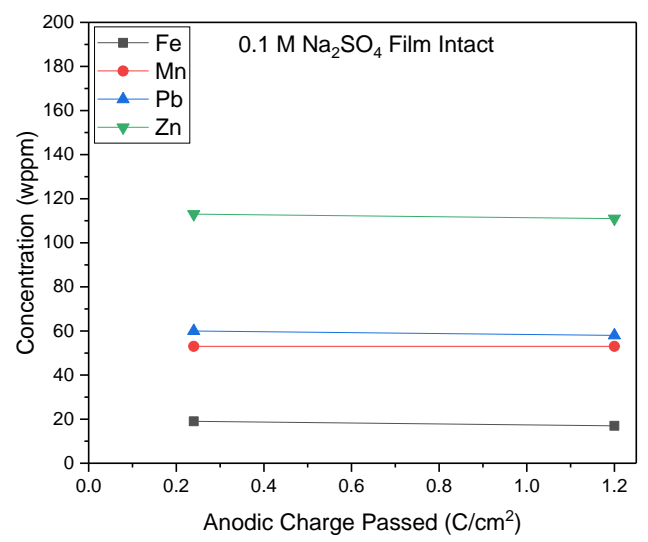

(b)

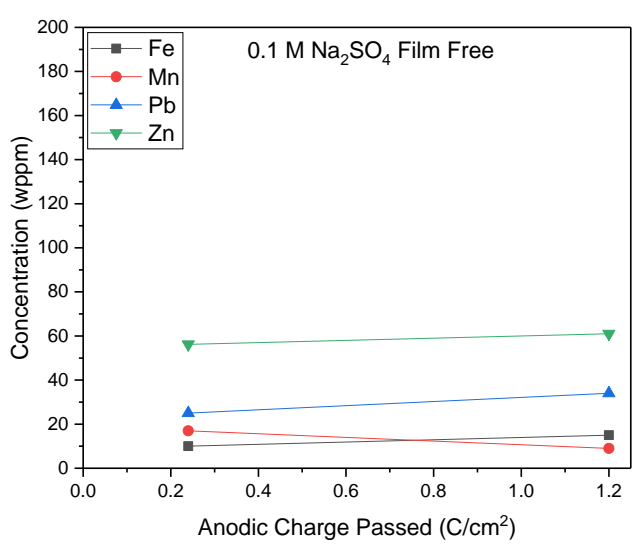

Figure 3.17. Processed PIXE data to reveal the change in surface composition of HP Mg due to increasing anodic dissolution in $0.1 \mathrm{M} \mathrm{Na}_{2} \mathrm{SO}_{4}$ with (a) the dissolution film intact and (b) after $\mathrm{CrO}_{3}$ cleaning.

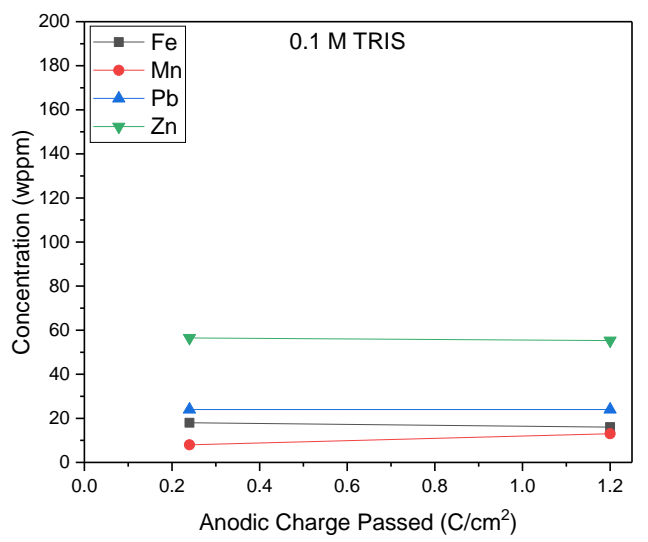

Figure 3.18. Processed PIXE data to reveal the change in surface composition of HP Mg due to increasing anodic dissolution in 0.1 M TRIS.

Spatial elemental mapping with $2 \mu \mathrm{m}$ resolution of selected samples are shown in Figure 3.19-3.2. Figure 3.19 reveals that Fe-rich particles can be detected using PIXE. In this case, HP $\mathrm{Mg}$ was anodically dissolved in $0.6 \mathrm{M} \mathrm{NaCl}$ at $2 \mathrm{~mA} / \mathrm{cm}^{2}$ for 2 minutes with the dissolution film intact. This was the only Fe-rich particle discovered in the PIXE analysis while all other PIXE 
elemental maps showed elements uniformly dispersed on the Mg surface. This is shown in Figure 3.20 which is typical for all other samples tested PIXE analysis.
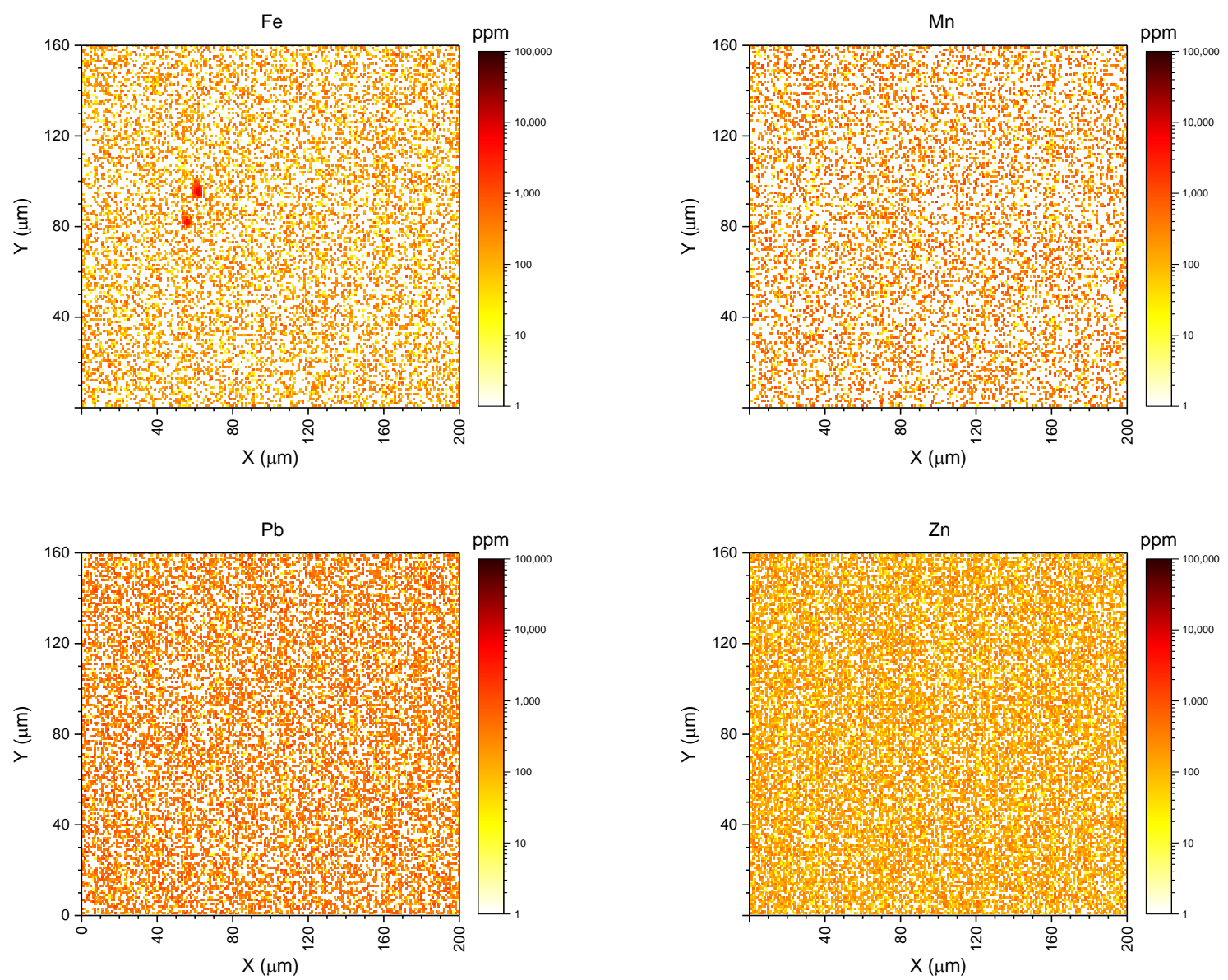

Figure 3.19. Spatially resolved elemental maps of $\mathrm{HP} \mathrm{Mg}$ anodically dissolved in $0.6 \mathrm{M} \mathrm{NaCl}$ at $2 \mathrm{~mA} / \mathrm{cm}^{2}$ for 2 minutes with the dissolution film intact. 

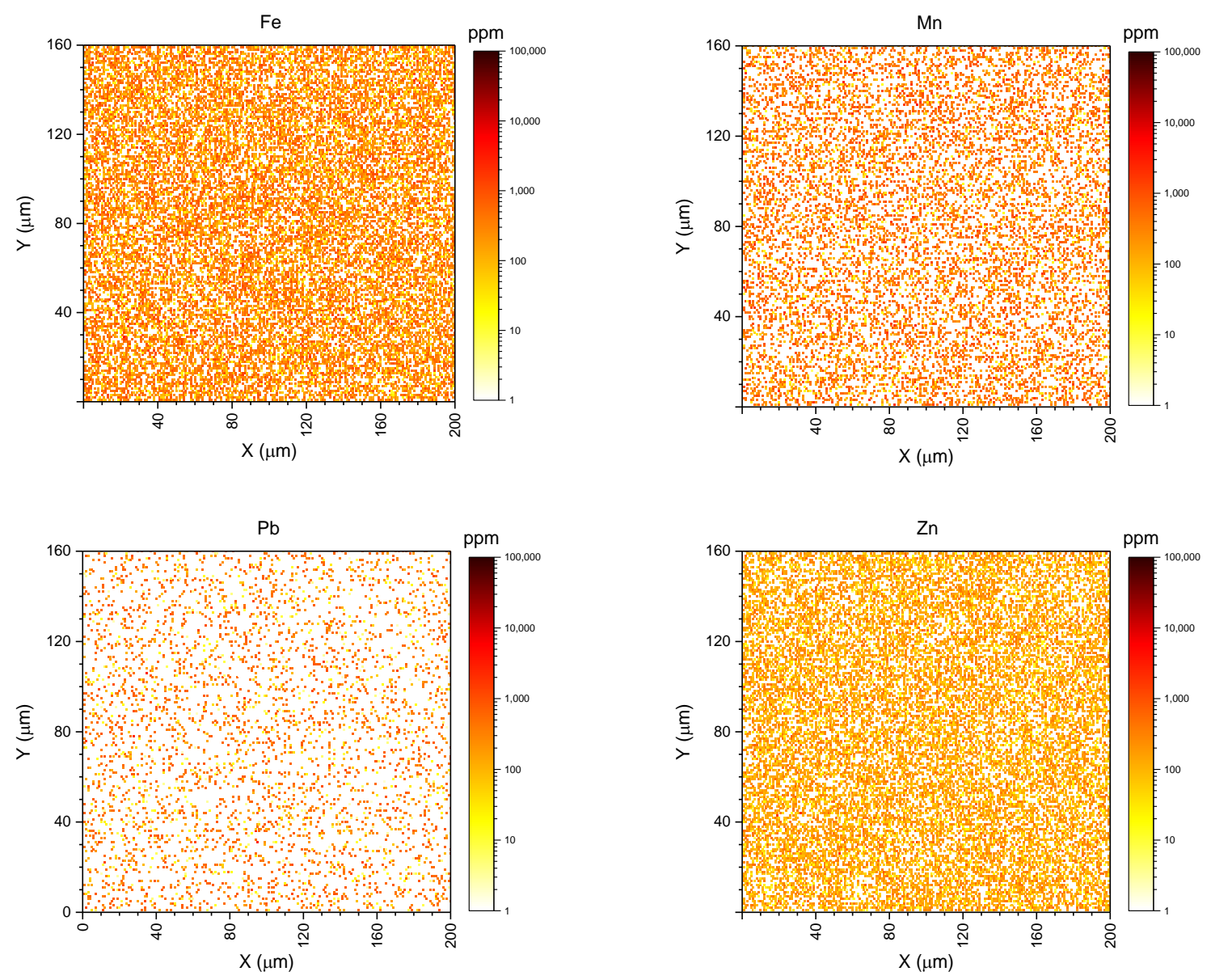

Figure 3.20. Spatially resolved elemental maps of HP Mg anodically dissolved in $0.6 \mathrm{M} \mathrm{NaCl}$ at $10 \mathrm{~mA} / \mathrm{cm}^{2}$ for 2 minutes with the dissolution film intact.

\subsection{Discussion}

\subsubsection{Role of Electrolyte and $\mathrm{Mg}(\mathrm{OH})_{2}$ Film Formation on the NDE}

The various electrolytes used in this study have provided a number of different conditions to study the phenomenon of the negative difference effect of $\mathrm{Mg}$. The effect of each electrolyte on the NDE is presented and summarized in Table 3.9. It is apparent from the results that the type and concentration of the anion produces a large difference on not only the corrosion and dissolution rate of $\mathrm{Mg}$ anodes but also in the extent of the NDE. The results presented herein suggest that the 
NDE is strongly dependent on both presence of absence of $\mathrm{Cl}^{-}$as well as $\mathrm{pH}$ changes in response to $\mathrm{Mg}^{2+}$ dissolution and the ability of $\mathrm{Mg}$ to produce stable films. In this study, the NDE was

Table 3.9. Common factors describing the negative difference effect

\begin{tabular}{c|c|c|c|c|c}
\multirow{2}{*}{ Electrolyte } & \multicolumn{2}{|c|}{ Fe } & \multicolumn{2}{c|}{$\begin{array}{c}\text { Enhanced Cathodic } \\
\text { Enrichment? }\end{array}$} & \multirow{2}{*}{ Kinetics vs. Polished Mg? } \\
\cline { 2 - 5 } & RBS & PIXE & Film & Film Free & NDE \\
\hline $\mathrm{NaCl}$ & Yes & Yes & Yes & No & Strong \\
\hline $\mathrm{Na}_{2} \mathrm{SO}_{4}$ & -- & No & No & No & Slight \\
\hline $\mathrm{MgCl}_{2}$ & --- & Yes & Yes & No & Strong \\
\hline $\mathrm{TRIS}$ & -- & No & No Film & No & None \\
\hline $\begin{array}{c}\text { Phosphate } \\
\text { Buffer [4] }\end{array}$ & -- & -- & -- & - & None \\
\hline
\end{tabular}

observed for all solutions that enabled the formation of thick $\mathrm{Mg}(\mathrm{OH})_{2}$ surface films (Figure 3.8a). Of these solutions, $0.6 \mathrm{M} \mathrm{NaCl}$ saturated with $\mathrm{Mg}(\mathrm{OH})_{2}$ produced the strongest NDE which is consistent with observations of greater NDE at alkaline initial $\mathrm{pH}$ values [5]. An initial $\mathrm{pH}$ in the $\mathrm{Mg}(\mathrm{OH})_{2}$ stable region combined with a solution that is saturated with $\mathrm{Mg}(\mathrm{OH})_{2}$ will greatly promote the formation of $\mathrm{Mg}(\mathrm{OH})_{2}$ films and thus this result is not surprising if the NDE is described by the stable film forming reaction mechanism proposed by Lebouil et al. [4]. However, a recent study by Yang et al. report that no NDE was observed for anodic polarization of Mg in 1 $\mathrm{M} \mathrm{NaOH}$ which promoted the formation of a white film on the surface and a passive current density during anodic potentiodynamic scans [22]. However, NDE was observed in $1 \mathrm{M} \mathrm{NaOH}+3.5 \mathrm{wt} \%$ $\mathrm{NaCl}$ and no passive region formed. Their suggestion was that the NDE is related to a $\mathrm{Cl}^{-}$induced film rupture mechanism where a stable $\mathrm{Mg}(\mathrm{OH})_{2}$ film is present as in the case of $\mathrm{NaOH}$ but the addition of $\mathrm{NaCl}$ enabled the breakdown of stable passive films. This local breakdown enabled fresh Mg surface to be exposed to the electrolyte which resulted in an amplified anodic current which is accompanied by a proportionally large increase in cathodic current in order to maintain charge balance. The result of film rupture is rapid HER behind the advancing dissolution front in 
the form of hydrogen streams which are well known in literature with a number of Mg alloys and processing conditions [23-25]. But this fresh Mg would also be repaired by the reactions described by Equations 3.10-3.11 which facilitates HER.

$$
\begin{array}{cc}
\mathrm{Mg}+2 \mathrm{H}_{2} \mathrm{O} \rightarrow x \mathrm{Mg}^{2+}+(1-x) \mathrm{Mg}(\mathrm{OH})_{2}+\mathrm{H}_{2}(g)+2 x \mathrm{OH}^{-} & \text {Equation 3.10 } \\
\mathrm{Mg}+\mathrm{H}_{2} \mathrm{O} \rightarrow \mathrm{MgO}+\mathrm{H}_{2}(g) & \text { Equation 3.11 }
\end{array}
$$

The effect of film stability on the NDE is apparent in this study with comparisons between $\mathrm{Cl}^{-}$environments and $\mathrm{Na}_{2} \mathrm{SO}_{4}$. Examination of the surface morphology after removing the anodically formed surface films revealed a contrast in attack as shown in Figure 3.6. Both $\mathrm{NaCl}$ and $\mathrm{MgCl}_{2}$ environments produced rough surfaces with many sharp features and pit like voids while $\mathrm{Na}_{2} \mathrm{SO}_{4}$ surfaces were smooth and lustrous. This suggests that $\mathrm{Cl}^{-}$was able to penetrate $\mathrm{Mg}(\mathrm{OH})_{2}$ films perhaps resulting in stress from electrostatic repulsion leading to local breakdown while more uniform dissolution with minimal localized breakdown or film rupture occurred in $\mathrm{Na}_{2} \mathrm{SO}_{4}$ which contributed to decreased dissolution rates and NDE. Moreover, this suggests that films formed in the presence of $\mathrm{Na}_{2} \mathrm{SO}_{4}$ are more stable than those in the presence of $\mathrm{Cl}^{-}$which could be related to $0.1 \mathrm{M} \mathrm{Na}_{2} \mathrm{SO}_{4}$ having an $\mathrm{SO}_{4}{ }^{2-}$ activity coefficient $<1$ [26]. The increased coverage of stable dissolution film on the surfaces leads to lower dissolution and HER rates by reducing the number of available sites for dissolution or HER on the Mg surface. In addition, it was more difficult to mechanically remove the $\mathrm{Na}_{2} \mathrm{SO}_{4}$ films when removing surface films for ICP-OES analysis compared to $\mathrm{Cl}^{-}$solutions films. Films formed in $\mathrm{Cl}^{-}$solutions readily spalled off whilst $\mathrm{Na}_{2} \mathrm{SO}_{4}$ films were adherent. In the case of TRIS, no visible films formed on the surface during anodic polarization and thus no film rupture would occur. Raman spectroscopy did reveal that $\mathrm{Mg}(\mathrm{OH})_{2}$ was present on the surface of samples tested in TRIS, but this film is likely to be tens of nanometers thick and may have formed in humid lab air. 


\subsubsection{Role of Impurities and Anodic Sites}

A general description of the factors that may lead to anodic hydrogen evolution from an anodically polarized $\mathrm{Mg}$ surface can be presented by the form of the simple expression in Equation 3.12, that includes the minimum number of terms as explored in recent works, whilst acknowledging there may be other unknown phenomena necessitating other terms.

$$
H E_{\text {Total }}=H E_{\text {anode }}+H E_{\text {Impurities }}+H E_{\text {Film }} \quad \text { Equation } 3.12
$$

In this equation, $H E_{\text {anode }}$ represents a contribution from an increase in $\mathrm{i}_{\mathrm{o}}$, HER as described in [27], $H E_{\text {impurities }}$ is the contribution to enhanced rates of reduction from impurity metal enrichment, and $H E_{F i l m}$ is the contribution to enhanced rates of reduction from filmed areas. These three phenomena have been purported to enhance the rate of the cathodic reduction reaction, and hence, the NDE. It is worth noting that Tafel extrapolation from net cathodic data [28] is inappropriate as $H E_{\text {anode }}$ would not be present in net cathodic data and $H E_{\text {Impurities }}$ may be reduced as well. Furthermore, such extrapolation is not relevant if the Tafel or Heyrovsky mechanism is dominant during net cathodic polarization and $\mathrm{H}_{2}$ evolution as described by the film forming mechanism in Equation 3.10 dominates during net anodic polarization as they are distinctly different reactions. It is regarded that enrichment of impurities might be relevant from three standpoints: (1) Mg impurities may result from transition metal replating, (2) impurities may occur in the form of particles trapped in oxides or hydroxides, (3) solute in solid solution may accumulate at the moving metal/solution interface which occurs when an element is not likely to dissolve thermodynamically. This is shown by the schematic in Figure 3.21 where elemental enrichment or replating can occur at or slightly behind the anodic front while Fe-rich particles are being trapped within the hydroxide or at the hydroxide/metal interface. The PIXE elemental maps from this investigation have shown both an Fe-rich particle on the near surface but also uniform, elemental, distribution of impurity elements 
on the surface in Figure 3.19-3.20. However, it is unclear whether or not this is a result of replating or solute accumulation at the metal surface bearing in mind that element yields are from the volume analyzed. It is likely that all three modes are occurring at varying degrees and the relative proportion of the terms in Equation 3.12 is important in terms of electrochemical engineering of $\mathrm{Mg}$, and a focal point of the work herein.

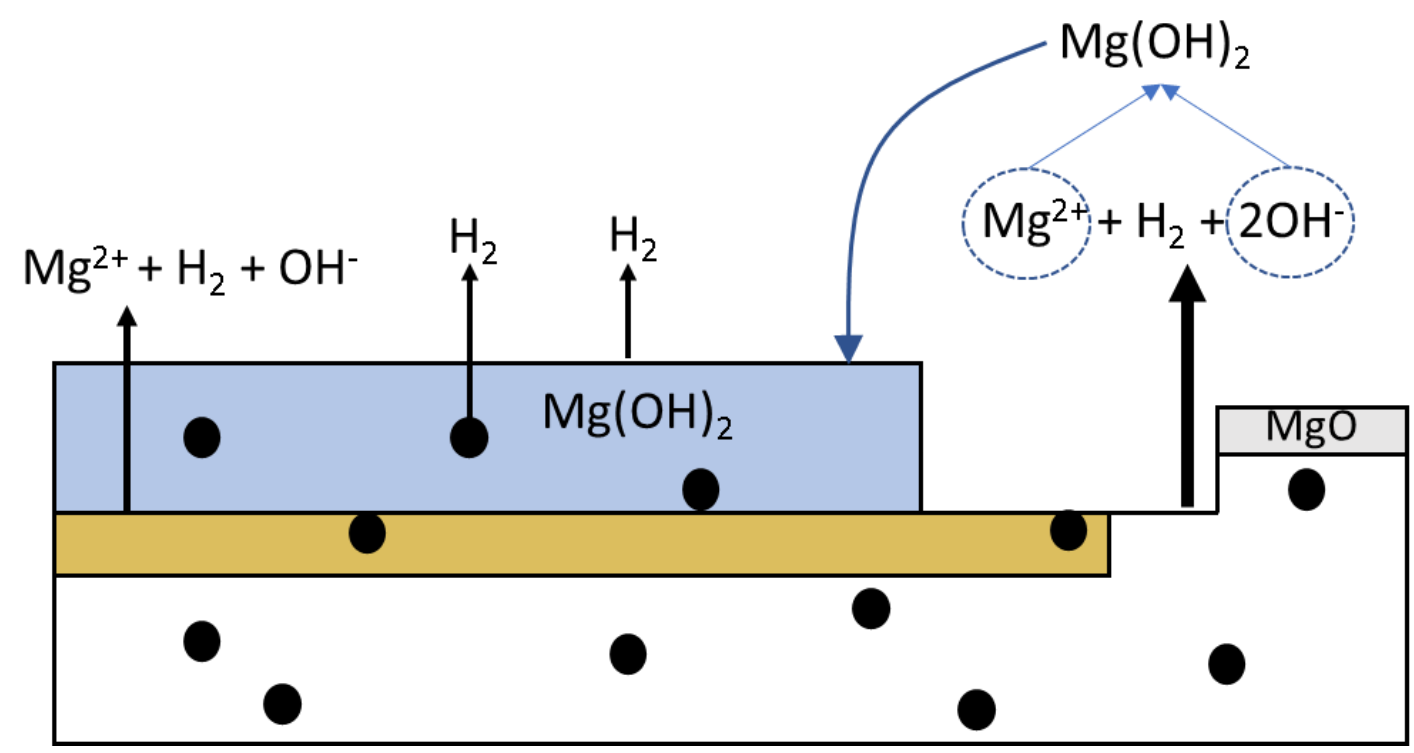

Figure 3.21. Schematic model of element enrichment showing impurity particles being trapped in the dissolution film and at the film/metal interface in addition to elemental enrichment (gold region) at the film/metal interface.

The physical reasoning for the large (and increasing) $i_{0, H E R}$ in the anodic region has never been definitively determined. Frankel et al. [20] state that the contributions of $H E_{\text {impurities }}+H E_{\text {Film }}$ have a small influence on the NDE based on extrapolation of cathodic polarization scans conducted long after anodic solutions may have dissipated from the anodic region. However, such an assertion is not entirely consistent with the growing number of works that have sought to quantify contributions of $H E_{\text {impurities }}+H E_{F i l m}$. Moreover, in such studies, slow scan rates were used to carry out the extrapolation of cathodic polarization which may lead to underestimation of the hydrogen evolution rate as the surface chemistry may have changed by the time the cathodic current density 
is assessed, due to rapid hydrogen evolution. Fast cathodic potentiodynamic polarization scans were used in this study to minimize changes in local solution chemistry after anodic polarization and to expand the range of activation controlled kinetics for Tafel extrapolation far away from OCP. However, applying Tafel extrapolation to fast cathodic scans $\left(\beta_{\mathrm{c}}=315 \mathrm{mV} / \mathrm{dec}\right.$, determined for fast scans of $\mathrm{Mg}$ microelectrodes and in agreement with [8]) still underestimates the anodic hydrogen evolution rate in each solution by several orders of magnitude at the anodic potentials explored here, and furthermore would still predict a decrease in cathodic kinetics with increasing anodic overpotentials as would extrapolations of the proposed Heyrovsky path [61]. Tafel extrapolation of cathodic polarization curves performed for each solution using the framework presented by Fajardo et al. [26] may be performed on the measured cathodic polarization curves to illustrate underestimation of the measured anodic HER rate. For example, the HER rate measured at $-1.4 \mathrm{~V}_{\mathrm{SCE}}$ in $0.6 \mathrm{M} \mathrm{NaCl}$ is about $1 \times 10^{-2} \mathrm{~A} / \mathrm{cm}^{2}$ (Fig. 7a) and extrapolation of its respective polarization curve to $-1.4 \mathrm{~V}_{\mathrm{SCE}}$ yielded an HER rate of on the order of $10^{-4} \mathrm{~A} / \mathrm{cm}^{2}$. Such an extrapolation may indicate the contribution of $H E_{\text {Impurities }}+H E_{\text {Film }}$ to the anodic $\mathrm{H}_{2}$ evolution rate but, again, would not capture possible contributions from Equation 3.10. It should be noted that Tafel extrapolations were performed within $100 \mathrm{mV}$ of the OCP despite an expanded region of activation controlled kinetics due to the fast scan rate used, which may lead to large errors in estimation of Tafel kinetics [9] which is a further condemnation of performing Tafel extrapolation to determine anodic $\mathrm{H}_{2}$ evolution rates on $\mathrm{Mg}$ and $\mathrm{Mg}$ alloys. Nonetheless, Tafel extrapolation of cathodic polarization curves could only account for the NDE if the cathodic kinetics continued to increase with increasing anodic overpotentials but this was not possible to posit or propose given the cathodic polarization findings in this investigation. Noble metal enrichment could, however, contribute to the manifestation of anodically enhanced cathodic kinetics as evidenced by the 
combination of cathodic polarization curves and enrichment profiles from PIXE measurements. Nonetheless, a mechanism describing the large $\mathrm{i}_{\mathrm{o}}$ region $H E_{\text {anode }}$ is still required to fully describe the NDE.

A mechanistic explanation has attempted recently by Yang et al. [22] who posited that cathodic activation resulting from surface films and cathodic particles contribute to the large anodic $i_{o}$ region instead of being regarded as separate from the large anodic $i_{o}$ region. The PIXE results presented here provide further evidence for this theory via the slight enrichment of impurity elements in the presence of chlorides where large NDE was observed in comparison to non- $\mathrm{Cl}^{-}$ environments which experienced little NDE and no enrichment. These results and the framework presented herein also explain what is observed in TRIS. Here, enrichment of impurities by replating is eliminated due to the ability of TRIS to chelate transition metal ions. The buffering capacity and ability of TRIS to complex $\mathrm{Mg}^{2+}$ also eliminates the possibility of impurity accumulation in the oxide/hydroxide. The lack of a film has also eliminated possibilities of enhanced cathodic kinetics resulting from the hydroxide film. Despite the lack of enrichment, the fact that there are always impurities present on the Mg surface could still stimulate remote anodic currents leading to $\mathrm{H}_{2}$ evolution as described by Yang et al. [21]. Such an effect could account for the residual high rate of HER despite a positive difference effect and would also explain the lack in efficiency ( $\mathrm{Q}_{\mathrm{i} \text { net anodic }} / \mathrm{Q}_{\mathrm{mass}}$ loss). Nevertheless, the new theory proposed by Fajardo and Frankel whereby the manifestation $H E_{\text {anode }}$ is due to the charge transfer coefficient of $\mathrm{Mg}$ oxidation being greater than the charge transfer coefficient of HER on $\mathrm{Mg}$ surfaces presents an alternative explanation to explain the residual high HER rate measured in TRIS. However, there is no physical or atomistic explanation for the values of charge transfer coefficient determined by Fajardo and Frankel. Moreover, it is unclear at this time how impurity enrichment and alloying of $\mathrm{Mg}$ effects 
the charge transfer coefficient and whether or not this can account for trends of NDE observed in Mg alloys. 


\subsection{Conclusions}

- Unique experiments herein reveal that $\mathrm{Mg}$ dissolves as $\mathrm{Mg}^{2+}$ with negative difference effect (NDE) manifest over a broad range of applied anodic potentials in $0.6 \mathrm{M} \mathrm{NaCl}, 0.1$ $\mathrm{M} \mathrm{MgCl}_{2}$, and 0.1 $\mathrm{M} \mathrm{Na}_{2} \mathrm{SO}_{4}$. However, NDE was not manifest for $\mathrm{Mg}$ dissolving in 0.1 M TRIS, $\mathrm{pH}=7.25$, buffered solution which suggests $\mathrm{Mg}(\mathrm{OH})_{2}$ film formation plays an important role in manifestation of the NDE.

- Surface film stability has been shown to play a major role in contributing to the manifestation and extent of NDE. Thick, but porous $\mathrm{Mg}(\mathrm{OH})_{2}$ films formed in $\mathrm{Cl}^{-}$ containing solutions exhibited a large NDE while more stable $\mathrm{Mg}(\mathrm{OH})_{2}$ films formed in $0.1 \mathrm{M} \mathrm{Na}_{2} \mathrm{SO}_{4}$ exhibited a small NDE with respect to increasing anodic potential.

- Rutherford Backscattering Spectroscopy (RBS) and Particle Induced X-ray Emission have shown to be suitable techniques for determining ppm levels of impurities on corroding $\mathrm{Mg}$ surfaces. RBS testing revealed for the first time, quantitative noble metal enrichment of a corroded Mg surface.

- Noble metal enrichment was observed on HP Mg surfaces which have been exposed to $\mathrm{Cl}^{-}$ containing solutions exhibited a large NDE while no enrichment was observed in $0.1 \mathrm{M}$ $\mathrm{Na}_{2} \mathrm{SO}_{4}$ exhibited a small NDE and 0.1 M TRIS which exhibited no NDE thus supporting the noble metal enrichment theory for enhanced cathodic kinetics.

- Fast cathodic potentiodynamic scans used to estimate anodic hydrogen evolution rates by Tafel extrapolation still underestimated the true rate of hydrogen evolved (by independent capture) and did not observe a continuous increase in cathodic kinetics due to enrichment of impurity elements and formation of $\mathrm{Mg}(\mathrm{OH})_{2}$ films which would be needed to predict NDE. 


\subsection{References}

[1] G. Williams, H. Neil McMurray, "Localized Corrosion of Magnesium in ChlorideContaining Electrolyte Studied by a Scanning Vibrating Electrode Technique," J. Electrochem. Soc. 155 (7), C340, 2008.

[2] D. Lysne, S. Thomas, M.F. Hurley, N. Birbilis, "On the Fe Enrichment during Anodic Polarization of $\mathrm{Mg}$ and Its Impact on Hydrogen Evolution," J. Electrochem. Soc. 162 (8), C396-C402, 2015.

[3] D. Höche, C. Blawert, S.V. Lamaka, N. Scharnagl, C. Mendis, M.L. Zheludkevich, "The effect of iron re-deposition on the corrosion of impurity-containing magnesium," Phys Chem Chem Phys. 18 (2) , 1279-1291, 2016.

[4] S. Lebouil, O. Gharbi, P. Volovitch, K. Ogle, "Mg Dissolution in Phosphate and Chloride Electrolytes: Insight into the Mechanism of the Negative Difference Effect," CORROSION. 71 (2), 234-241, 2015.

[5] L. Rossrucker, A. Samaniego, J.-P. Grote, A.M. Mingers, C.A. Laska, N. Birbilis, G.S. Frankel, K.J.J. Mayrhofer, "The $\mathrm{pH}$ dependence of magnesium dissolution and hydrogen evolution during anodic polarization,” J. Electrochem. Soc. 162 (7) , C333-C339, 2015.

[6] S.H. Salleh, S. Thomas, J.A. Yuwono, K. Venkatesan, N. Birbilis, "Enhanced hydrogen evolution on $\mathrm{Mg}(\mathrm{OH}) 2$ covered Mg surfaces," Electrochimica Acta. 161 , 144-152, 2015.

[7] A.D. King, N. Birbilis, J.R. Scully, "Accurate Electrochemical Measurement of Magnesium Corrosion Rates; a Combined Impedance, Mass-Loss and Hydrogen Collection Study," Electrochimica Acta. 121 , 394-406, 2014.

[8] S. Fajardo, G.S. Frankel, "Gravimetric method for hydrogen evolution measurements on dissolving magnesium,” J. Electrochem. Soc. 162 (14), C693-C701, 2015.

[9] L.G. Bland, A.D. King, N. Birbilis, J.R. Scully, "Assessing the Corrosion of Commercially Pure Magnesium and Commercial AZ31B by Electrochemical Impedance, Mass-Loss, Hydrogen Collection, and Inductively Coupled Plasma Optical Emission Spectrometry Solution Analysis," CORROSION. 71 (2) , 128-145, 2015.

[10] "ASTM G1-03(2011), Standard Practice for Preparing, Cleaning, and Evaluating Corrosion Test Specimens, ASTM International, West Conshohocken, PA, 2011, www.astm.org," n.d.

[11] D.A. Jones, Principles and Prevention of Corrosion, Pearson-Prentice Hall, 2005.

[12] G.S. Frankel, S. Fajardo, B.M. Lynch, "Introductory lecture on corrosion chemistry: a focus on anodic hydrogen evolution on $\mathrm{Al}$ and Mg," Faraday Discuss. 180 , 11-33, 2015.

[13] B. Lafuente, R.T. Downs, H. Yang, N. Stone, 2015 Power Databases RRUFF Proj. Highlights Mineral. Crystallogr. T Armbruster R M Danisi Eds Berl. Ger. W Gruyter Pp 1-30. n.d.

[14] J. Demarche, G. Terwagne, "Precise measurement of the differential cross section from the $\mathrm{O} 16(\alpha, \alpha) \mathrm{O} 16$ elastic reaction at $165^{\circ}$ and $170^{\circ}$ between 2.4 and $6.0 \mathrm{MeV}$," J. Appl. Phys. 100 (12), 124909, 2006.

[15] L.C. Feldman, J.W. Mayer, Fundamentals of surface and thin film analysis, North-Holland, 1986. https://books.google.com/books?id=wDdRAAAAMAAJ.

[16] M. Mayer, "SIMNRA Home Page. 2011 Feb, 15, 2011 [cited 2014 Jan 20]; Available from: http://home.rzg.mpg.de/ mam/," n.d.

[17] J.S. Laird, R. Szymanski, C.G. Ryan, I. Gonzalez-Alvarez, "A Labview based FPGA data acquisition with integrated stage and beam transport control," Nucl. Instrum. Methods Phys. Res. Sect. B Beam Interact. Mater. At. 306 , 71-75, 2013. 
[18] C.G. Ryan, "Quantitative trace element imaging using PIXE and the nuclear microprobe," Int. J. Imaging Syst. Technol. 11 (4) , 219-230, 2000.

[19] M. Pourbaix, Atlas of Electrochemical Equilibria in Aqueous Solutions, Pergamon Press, n.d.

[20] S. Shah, Surface and Interface Characterization in Corrosion, NACE International, Houston, TX, 1994.

[21] L.G. Bland, K. Gusieva, J.R. Scully, "Effect of Crystallographic Orientation on the Corrosion of Magnesium: Comparison of Film Forming and Bare Crystal Facets using Electrochemical Impedance and Raman Spectroscopy," Electrochimica Acta. 227 , 136-151, 2017.

[22] Y. Yang, F. Scenini, M. Curioni, "A study on magnesium corrosion by real-time imaging and electrochemical methods: relationship between local processes and hydrogen evolution," Electrochimica Acta. 198 , 174-184, 2016.

[23] Z.P. Cano, J.R. McDermid, J.R. Kish, "Cathodic activity of corrosion filaments formed on Mg alloy AM30,” J. Electrochem. Soc. 162 (14), C732-C740, 2015.

[24] M. Curioni, F. Scenini, T. Monetta, F. Bellucci, "Correlation between electrochemical impedance measurements and corrosion rate of magnesium investigated by real-time hydrogen measurement and optical imaging," Electrochimica Acta. 166 , 372-384, 2015.

[25] M. Melia, P. Steiner, N. Birbilis, J. Fitz-Gerald, J. Scully, "Excimer Laser Surface Modification of AZ31B-H24 for Improved Corrosion Resistance," Corrosion. 72 (1) , 95109, 2015.

[26] M.E. Guendouzi, A. Mounir, A. Dinane, "Water activity, osmotic and activity coefficients of aqueous solutions of Li2SO4, Na2SO4, K2SO4, (NH4)2SO4, MgSO4, MnSO4, NiSO4, CuSO4, and ZnSO4 at T=298.15 K," J. Chem. Thermodyn. 35 (2) , 209-220, 2003.

[27] G.S. Frankel, A. Samaniego, N. Birbilis, "Evolution of hydrogen at dissolving magnesium surfaces," Corros. Sci. 70 , 104-111, 2013.

[28] S. Fajardo, G.S. Frankel, "Effect of impurities on the enhanced catalytic activity for hydrogen evolution in high purity magnesium," Electrochimica Acta. 165 , 255-267, 2015. 


\section{Evaluation of the Commercial Mg Alloy Anodes for Sacrificial Cathodic Protection of Mg Alloy AZ31B-H24}

\subsection{Introduction}

This study evaluates the range of possible protection potentials determined in Chapter 2 taking into consideration for the first time the effects of anodically induced cathodic activation which could cause polarity reversal. Galvanic couple experiments of AZ31B to commercially pure $\mathrm{Mg}(\mathrm{CP} \mathrm{Mg})$ and commercial Mg-alloy WE43B (Mg-Y-RE) are investigated. These are chosen because they provide two separate ranges for the couple potential given that the OCP of $\mathrm{CP} \mathrm{Mg}(\approx$ $\left.-1.60 \mathrm{~V}_{\mathrm{SCE}}\right)$ being near that of AZ31B $\left(\approx-1.56 \mathrm{~V}_{\mathrm{SCE}}\right)$ and WE43B $\left(\approx-1.8 \mathrm{~V}_{\mathrm{SCE}}\right)$ being far away from the OCP of AZ31B. Moreover, the WE alloy class can be viewed as one whose composition can be varied for tunable electrochemical properties and chemical inhibitor release via rare earth metals. Choosing a candidate alloy such as $\mathrm{CP} \mathrm{Mg}$ with a corrosion potential close to that of AZ31B-H24 is also important as it relates to anodically induced cathodic activation (the negative difference effect) which has not been studied on $\mathrm{Mg}$ alloys with respect to sacrificial coatings. Here, increases in the cathodic kinetics due to anodic dissolution may cause polarity reversal which is not desired for successful application of galvanic based protection.

\subsection{Experimental}

\subsubsection{Materials}

Mg alloys AZ31B-H24 and WE43B-T5 were used in this investigation in addition to commercial purity Mg; AZ31B-H24 and WE43B-T5 were supplied by Magnesium Elektron while the CP Mg was supplied by Alfa Aesar. The compositions of these are found in Table 4.1. 
Table 4.1. Composition of materials used in this investigation. Analysis performed by Quantitative Testing Corporation (QUANT) using ICP-OES.

\begin{tabular}{|l|l|l|l|l|l|l|l|l|l|l|l|l|l|}
\hline Alloy & UNS\# & $\mathrm{Mg}$ & $\mathrm{Al}$ & $\mathrm{Zn}$ & $\mathrm{Mn}$ & $\mathrm{Zr}$ & $\mathrm{Y}$ & $\mathrm{Nd}$ & $\mathrm{La}$ & $\mathrm{Fe}$ & $\mathrm{Ni}$ & $\mathrm{Cu}$ & $\mathrm{Si}$ \\
\hline CP Mg & & $\mathrm{Bal}$ & 0.01 & 0.01 & 0.01 & $<0.001$ & $<0.001$ & $<0.001$ & $<0.001$ & 0.006 & 0.001 & 0.005 & 0.021 \\
\hline AZ31B-H24 & M11311 & Bal & 3.02 & 0.99 & 0.33 & $<0.001$ & $<0.001$ & $<0.001$ & $<0.001$ & 0.005 & 0.002 & 0.005 & 0.025 \\
\hline WE43B-T5 & M18430 & Bal & $<0.001$ & 0.01 & 0.02 & 0.56 & 3.84 & 2.28 & 0.33 & 0.01 & 0.001 & 0.006 & 0.025 \\
\hline
\end{tabular}

\subsubsection{Electrochemical testing}

To test whether or not it is possible for AZ31B-H24 to be protected in the window of sacrificial cathodic protection, zero resistance ammeter (ZRA) testing was performed for 24 hours in $250 \mathrm{~mL}$ of $0.6 \mathrm{M} \mathrm{NaCl}, 0.1 \mathrm{M} \mathrm{MgCl}_{2}$, and $0.1 \mathrm{M}$ TRIS using CP Mg and WE43B-T5 as sacrificial anodic metals coupled to AZ31B-H24. An electrochemical flat cell was used with AZ31B-H24 as the counter electrode and either CP Mg or WE43B-T5 as the working electrode such that positive currents are anodic for the sacrificial anode. These cells deployed an SCE reference electrode. Each window of the flat cell provided an area of $1 \mathrm{~cm}^{2}$ to give a 1:1 anode to cathode ratio. Mass loss was measured a minimum of three times to evaluate the ability of each anode material to protect AZ31B-H24. Gravimetric mass loss for each sample with $\pm 0.01 \mathrm{mg}$ resolution was converted to consumed anodic charge density $\left(\mathrm{Q}_{\Delta \mathrm{m}}\right)$ using the same procedures as Chapter 2. For WE43B-T5, $\mathrm{Mg}^{2+}, \mathrm{La}^{3+}, \mathrm{Nd}^{3+}, \mathrm{Y}^{3+}$, and $\mathrm{Zr}^{4+}$ are assumed to be dissolving yielding $N_{e q}=0.0786$ or $\mathrm{EW}=12.72 \mathrm{~g} / \mathrm{eq}$.

The effect of anodically induced cathodic activation for each couple was subsequently evaluated by cathodic potentiodynamic polarization of each electrode before and after ZRA testing from OCP to $-3 \mathrm{~V}_{\mathrm{SCE}}$. The initial polarization scan before galvanic couples was performed after allowing samples to stabilize at OCP for 10 minutes. Scans were performed on each electrode in the flat cell couple configuration consecutively using a scan rate of $2,500 \mathrm{mV} / \mathrm{s}$ to minimize the time between scans as polarization scans on each electrode could not be performed simultaneously 
(i.e. a polarization scan on AZ31B-H24 could be taken within 15 seconds to that of $\mathrm{CP} \mathrm{Mg}$ in the cell). Such a rapid scan rate also allows for an expanded range of potentials to be evaluated for activation controlled HER. After completion of a ZRA test, the used solution was replaced with fresh solution and samples were again allowed to stabilize at OCP for 10 minutes prior to performing additional polarization scans for comparison of cathodic kinetics prior to and after galvanic coupling and ZRA measurement.

\subsubsection{Optical and Scanning Electron Microscopy}

Optical microscopy was performed using two different microscopes. Macro images were taken using a Hirox KH-7700 with the MX-MACROZ IV lens while higher magnification images were taken with a Nikon Epihot 300. Additional microscopy of sample surfaces and surface films was performed with an FEI Quanta 200 scanning electron microscope (SEM) equipped with both conventional secondary electron and solid state backscatter detectors with semi-quantitative compositional analysis performed using an Oxford energy dispersive x-ray spectroscopy (EDS) system.

\subsubsection{Raman Spectroscopy}

Raman Spectroscopy was performed on sample surfaces after completion of ZRA testing with corrosion products intact using a Renishaw Leica Raman Microscope. Scans were performed from 150 to $1200 \mathrm{~cm}^{-1}$ utilizing a $200 \mathrm{~mW}, 514 \mathrm{~nm}$ laser at $50 \%$ power under a 20x objective lens through a 1800 1/mm visible grating. Scans were accumulated twice with a 60 second exposure under standard confocality. Peak identification was performed using standard samples in the RRUFFTM $^{\mathrm{TM}}$ project database [1]. 


\subsection{Results}

\subsubsection{Evaluation of the Sacrificial Cathodic Protection of AZ31B-H24 with CP Mg and WE43B}

\subsubsection{Potentiodynamic Polarization of AZ31B-H24, CP Mg, and WE43B}

Figure 4.1 shows potentiodynamic polarization scans of AZ31B-H24, CP Mg, and WE43B in each respective electrolyte tested in this investigation after resting at OCP for 10 minutes in $0.6 \mathrm{M}$ $\mathrm{NaCl}, 0.1 \mathrm{M} \mathrm{MgCl}_{2}$, and $0.1 \mathrm{M} \mathrm{TRIS}^{\mathrm{vi}}$. It is apparent from these scans that both CP Mg and WE43B have more negative OCP's than AZ31B and should function as sacrificial anodes relative to AZ31B-H24. Moreover, CP Mg and WE43B should produce two separate couple potentials in principle for $0.6 \mathrm{M} \mathrm{NaCl}$ and $0.1 \mathrm{M} \mathrm{MgCl}_{2}$ with the couple potential for $\mathrm{CP} \mathrm{Mg}$ being within 100 $\mathrm{mV}$ of the OCP of AZ31B-H24 and more than $150 \mathrm{mV}$ cathodic for WE43B. This allows for couple behavior to be evaluated near the OCP of AZ31B where the polarity reversal/enhanced cathodic activity may play a role in galvanic couple behavior and far away from the OCP where the effects of polarity reversal/enhanced cathodic activity should be minimal.

\subsubsection{ZRA tests of AZ31B-H24 to CP Mg and WE43B in $0.6 \mathrm{M} \mathrm{NaCl}$}

Galvanic couples of AZ31B-H24 to CP Mg and WE43B in $0.6 \mathrm{M} \mathrm{NaCl}$ produced by ZRA measurements are shown Figure 4.2. ZRA measurements were performed three times and the potential and net current density vs. time behavior presented is characteristic of that observed in each test run. The couple behavior of AZ31B-H24 to CP Mg shown in Figure 4.2a was complex and can be separated into five different regions labeled A-E based on maximum and minimum

vi These scans are meant to be used as a qualitative guide as potentiodynamic polarization scans of $\mathrm{Mg}$ and $\mathrm{Mg}$ alloys do not accurately predict corrosion rates and the measured kinetics are known to vary as a function of immersion time and scan rate $[2,3]$. 

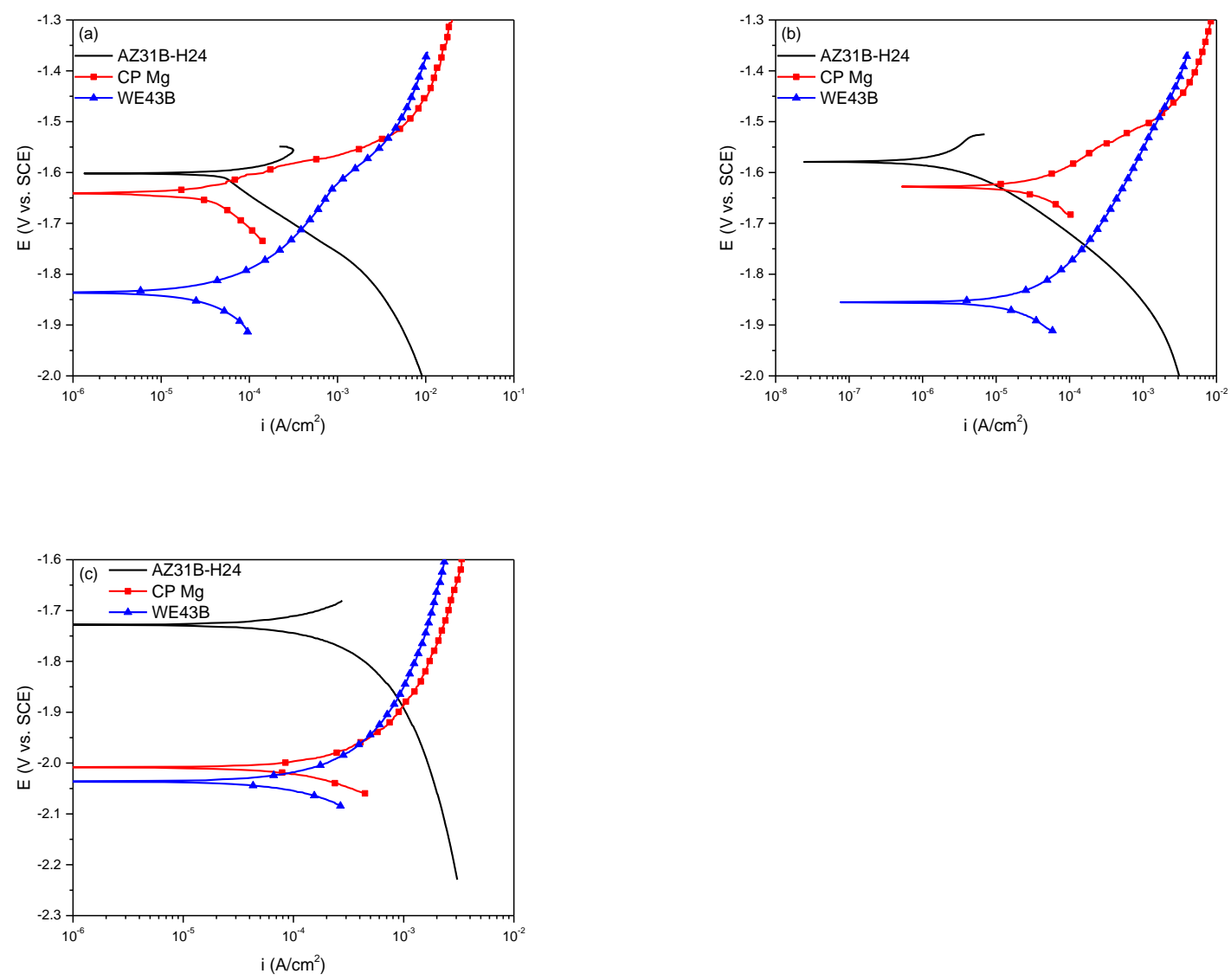

Figure 4.1. Potentiodynamic polarization scans at $1 \mathrm{mV} / \mathrm{s}$ for AZ31B, CP Mg, and WE43B after resting at $\mathrm{OCP}$ for $10 \mathrm{~min}$ in (a) $0.6 \mathrm{M} \mathrm{NaCl}$, (b) $0.1 \mathrm{M} \mathrm{MgCl}_{2}$, and (c) $0.1 \mathrm{M}$ TRIS.

values in the net couple current density. In region $\mathrm{A}$, the galvanic couple potential, $\mathrm{E}_{\mathrm{g}}$, increased while the galvanic couple current, $\mathrm{i}_{\mathrm{g}}^{\mathrm{ZRA}}$, increased to a maximum at about 36 seconds. Then, $\mathrm{E}_{\mathrm{g}}$ continued to increase at about 236 seconds while $\mathrm{i}_{\mathrm{g}}^{\mathrm{ZRA}}$ decreased to a minimum in region $\mathrm{B}$. After this minimum, $\mathrm{Z}_{\mathrm{g}}^{\mathrm{ZRA}}$ increased to a maximum at about 2985 seconds while $\mathrm{E}_{\mathrm{g}}$ decreased to a local minimum at about 1330 seconds and began to increase again as indicated by region $\mathrm{C}$-D. The couple current density then decreased to a minimum in region $\mathrm{D}$ while $\mathrm{E}_{\mathrm{g}}$ continued to increase to a maximum at about 8177 seconds. The remainder of the test was spent in region $\mathrm{E}$ where $\mathrm{i}_{\mathrm{g}}^{\mathrm{ZRA}}$ decreased briefly before continuously increasing to a maximum while $\mathrm{E}_{\mathrm{g}}$ decreased briefly 
and then increased to a steady state value of about $-1.56 \mathrm{~V}_{\mathrm{SCE}}$ which is nearly identical to the OCP of AZ31B-H24 which varies between $-1.54 \mathrm{~V}_{\mathrm{SCE}}$ and $-1.56 \mathrm{~V}_{\text {SCE. }} \mathrm{pH}$ measurements of solution before and after testing as shown in Table 4.2 indicated an increase in average $\mathrm{pH}$ from 5.7 to 9.8.

Table 4.2. The average initial and final $\mathrm{pH}$ measured in solution for each couple tested in this investigation.

\begin{tabular}{|l|l|l|l|l|}
\hline & \multicolumn{2}{|l|}{ AZ31B-H24 coupled to CP Mg } & AZ31B-H24 coupled to WE43B-T5 \\
\hline & pH prior to ZRA & pH After ZRA & pH prior to ZRA & pH After ZRA \\
\hline $0.6 \mathrm{M} \mathrm{NaCl}$ & 5.7 & 9.8 & 5.6 & 9.4 \\
\hline $0.1 \mathrm{M} \mathrm{MgCl}$ & 5.6 & 8.4 & 5.7 & 8.6 \\
\hline $0.1 \mathrm{M} \mathrm{TRIS}$ & 7.2 & 7.9 & 7.2 & 7.8 \\
\hline
\end{tabular}

In contrast, the couple behavior of AZ31B-H24 to WE43B in $0.6 \mathrm{M} \mathrm{NaCl}$ consisted of three separate regions, A-C. In region A, E $\mathrm{g}$ increased maximum at about 21 seconds then decreased to a minimum at about 74 seconds and increased afterwards. On the other hand, $\mathrm{i}_{\mathrm{g}}^{\mathrm{ZRA}}$ continuously increased to a maximum at about 196 seconds. The couple current density then continuously decreased in region B to a minimum value at about 48,040 seconds. During this same time period, $\mathrm{E}_{\mathrm{g}}$ increased to a relatively stable value around $-1.67 \mathrm{~V}_{\mathrm{SCE}}$ before decreasing for the remainder of the test at about 25,000 seconds. This was the highest $E_{g}$ measured which was approximately 100 $\mathrm{mV}$ below the OCP of AZ31B-H24. Finally, $\mathrm{i}_{\mathrm{g}}^{\mathrm{ZRA}}$ increased in region $\mathrm{C}$ following the decrease in E.

The anodic charge density measured by gravimetric mass loss of ZRA measurement of each couple in $0.6 \mathrm{M} \mathrm{NaCl}$ is shown in Figure 4.2c. For AZ31B-H24/CP Mg, Q $\Delta \mathrm{m}_{\mathrm{AZ} 31 \mathrm{~B}-\mathrm{H} 24}$ during galvanic coupling only decreased by approximately $3 \mathrm{x}$ compared to $\mathrm{Q} \Delta \mathrm{m}_{\mathrm{AZ} 31 \mathrm{~B}-\mathrm{H} 24, \mathrm{OCP}}$ measured at OCP for 24 hours. Moreover, Q $\Delta \mathrm{m}_{\mathrm{CP}} \mathrm{Mg}$ was nearly $18 \mathrm{x}$ greater than that of coupled AZ31B$\mathrm{H} 24$ and also 14.5x greater than the anodic charge measured by $\mathrm{Q}_{\text {couple. This latter observation is }}$ a larger discrepancy than typically observed in galvanic couples and will be discussed in Section 
4.4.1. Similar behavior was also observed for AZ31B-H24/WE43B where Q $\Delta \mathrm{m}_{W E 43 B}$ was $4 \mathrm{x}$ greater than $\mathrm{Q}_{\text {couple }}$ and 5.5x greater than $\mathrm{Q} \Delta \mathrm{m}_{\mathrm{AZ} 31 \mathrm{~B}-\mathrm{H} 24}$ whilst $\mathrm{Q} \Delta \mathrm{m}_{\mathrm{AZ} 31 \mathrm{~B}-\mathrm{H} 24}$ during galvanic coupling only decreased by approximately $2 \mathrm{x}$ compared to that measured at OCP.
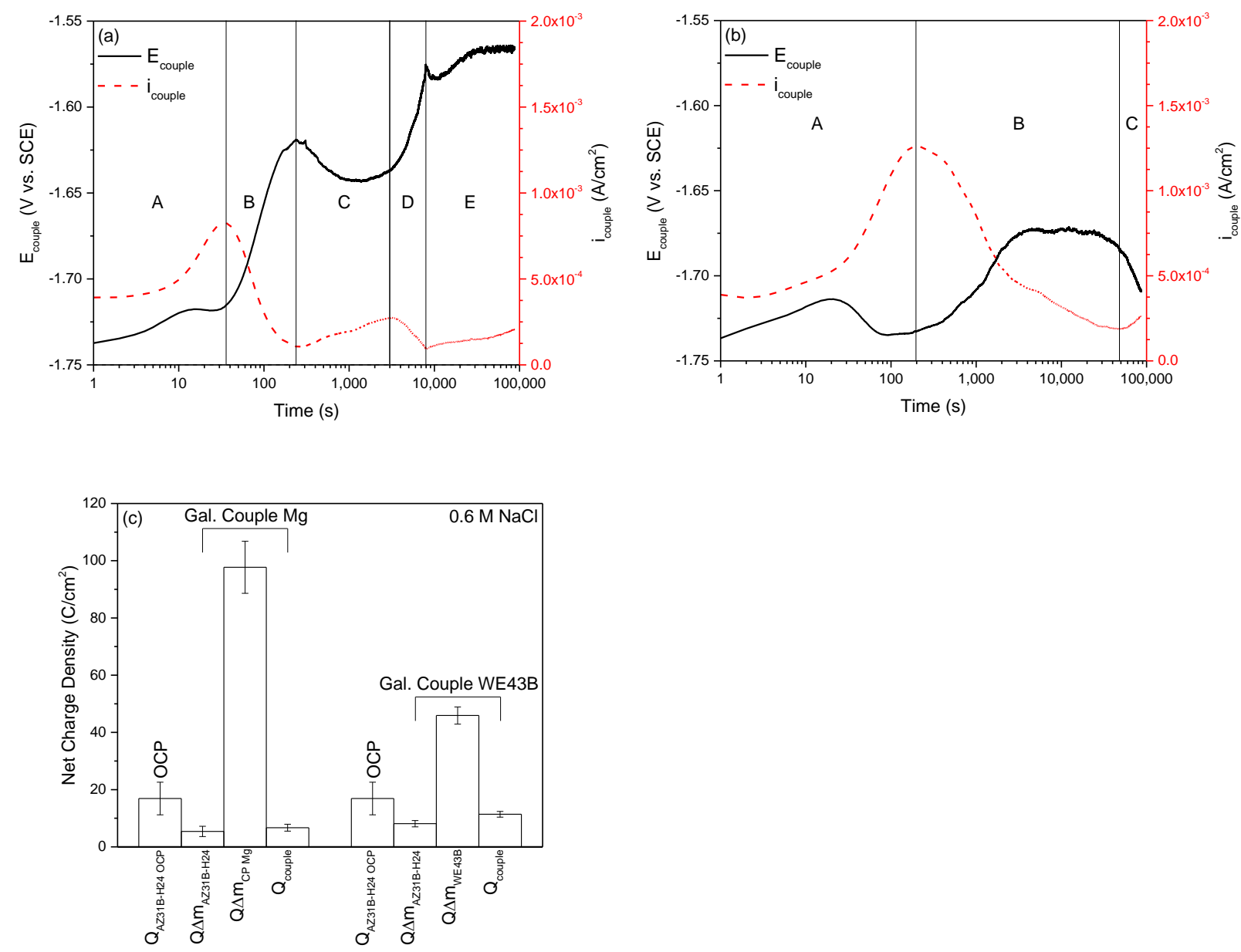

Figure 4.2. Zero resistance ammeter measurements for couples of (a) AZ31B-H24 to CP Mg, (b) AZ31B-H24 to WE43B, and (c) the corresponding charge density measured by gravimetric mass loss and the couple current density in $0.6 \mathrm{M} \mathrm{NaCl}$. CP Mg and WE43B were chosen as the working electrodes.

\subsubsection{ZRA tests of AZ31B-H24 to CP Mg and WE43B in $0.1 \mathrm{M} \mathrm{MgCl}_{2}$}

The couple behavior of AZ31B-H24 coupled to CP Mg and WE43B in $0.1 \mathrm{M} \mathrm{MgCl}_{2}$ is shown in Figure 4.3. The behavior of AZ31B-H24 coupled to CP Mg can be separated into four primary 
regions, Figure 4.3a. At the beginning of the test, $\mathrm{i}_{\mathrm{g}}^{\mathrm{ZRA}}$ continuously increased to a local maximum after 37 seconds while $\mathrm{E}_{\mathrm{g}}$ also increased in region $\mathrm{A}$. The couple potential continued to increase in region $\mathrm{B}$ to a maximum value at about 385 seconds and then began to decrease. Meanwhile, ig $\mathrm{ZRA}$ decreased to a minimum at about 530 seconds. In region $\mathrm{C}, \mathrm{i}_{\mathrm{g}}^{\mathrm{ZRA}}$ and $\mathrm{E}_{\mathrm{g}}$ both displayed a relative increase. $\mathrm{i}_{\mathrm{g}}^{\mathrm{ZRA}}$ reached a maximum at about 5140 seconds and then decreased in region D. $\mathrm{E}_{\mathrm{g}}$ reached a maximum 29,310 seconds before decreasing slightly for the remainder of the test. This value for $\mathrm{E}_{\mathrm{g}}$ was approximately $30 \mathrm{mV}$ more negative than the OCP of AZ31B-H24 (-1.53 $\left.\mathrm{V}_{\mathrm{SCE}}\right)$ in $0.1 \mathrm{M} \mathrm{MgCl}_{2}$.

The couple behavior of AZ31B-H24 to WE43B in $0.1 \mathrm{M} \mathrm{MgCl}_{2}$ can be separated into four general regions like with AZ31B-H24 to $\mathrm{CP} \mathrm{Mg}$ as indicated in Figure 4.3b. Here $\mathrm{E}_{\mathrm{g}}$ and $\mathrm{i}_{\mathrm{g}}^{\mathrm{ZRA}}$ increased after initiation of the test where $\mathrm{i}_{\mathrm{g}}^{\mathrm{ZRA}}$ reached a maximum at about 17 seconds. $\mathrm{E}_{\mathrm{g}}$ continued to increase in region $\mathrm{B}$ while $\mathrm{i}_{\mathrm{g}}^{\mathrm{ZRA}}$ decreased to a minimum at about 207 seconds. $\mathrm{E}_{\mathrm{g}}$ then remained relatively stable in region $C$ while $\mathrm{ig}_{\mathrm{g}}^{\mathrm{ZRA}}$ increased to a local maximum at 2910 seconds. The couple current density then decreased for the duration of the test in region D whereas $\mathrm{E}_{\mathrm{g}}$ increased to a maximum of about $-1.6 \mathrm{~V}_{\mathrm{SCE}}$ at about 20,140 seconds which is $70 \mathrm{mV}$ more negative than the OCP of $\mathrm{AZ31B}-\mathrm{H} 24$ in $0.1 \mathrm{M} \mathrm{MgCl}_{2}$ and then decreased for the remainder of the test.

The anodic charge density measured by gravimetric mass loss as a result of both couples in $0.1 \mathrm{M} \mathrm{MgCl}_{2}$ is shown in Figure 4.3c. As in the case of with $0.6 \mathrm{M} \mathrm{NaCl}$, the decrease in $\mathrm{Q} \Delta \mathrm{m}_{\mathrm{AZ31B}-\mathrm{H} 24}$ compared to that measured at OCP was minimal with only a $2 \mathrm{x}$ decrease but decreased by about $12 \mathrm{x}$ when AZ31B-H24 was coupled to WE43B. In addition, Q $\Delta \mathrm{m}_{\mathrm{CP}} \mathrm{Mg}$ was $8 \mathrm{x}$ greater than coupled $\mathrm{Q} \Delta \mathrm{m}_{\mathrm{AZ} 31 \mathrm{~B}-\mathrm{H} 24}$ and 9.5x greater than $\mathrm{Q}_{\text {couple }}$ for $\mathrm{AZ31B/CP} \mathrm{Mg}$ while 
$\mathrm{Q} \Delta \mathrm{m}_{\text {WE43B }}$ was $18 \mathrm{x}$ greater than coupled $\mathrm{Q} \Delta \mathrm{m}_{\mathrm{AZ31B}-\mathrm{H} 24}$ and $3 \mathrm{x}$ greater than $\mathrm{Q}_{\text {couple }}$ for AZ31BH24/WE43B.
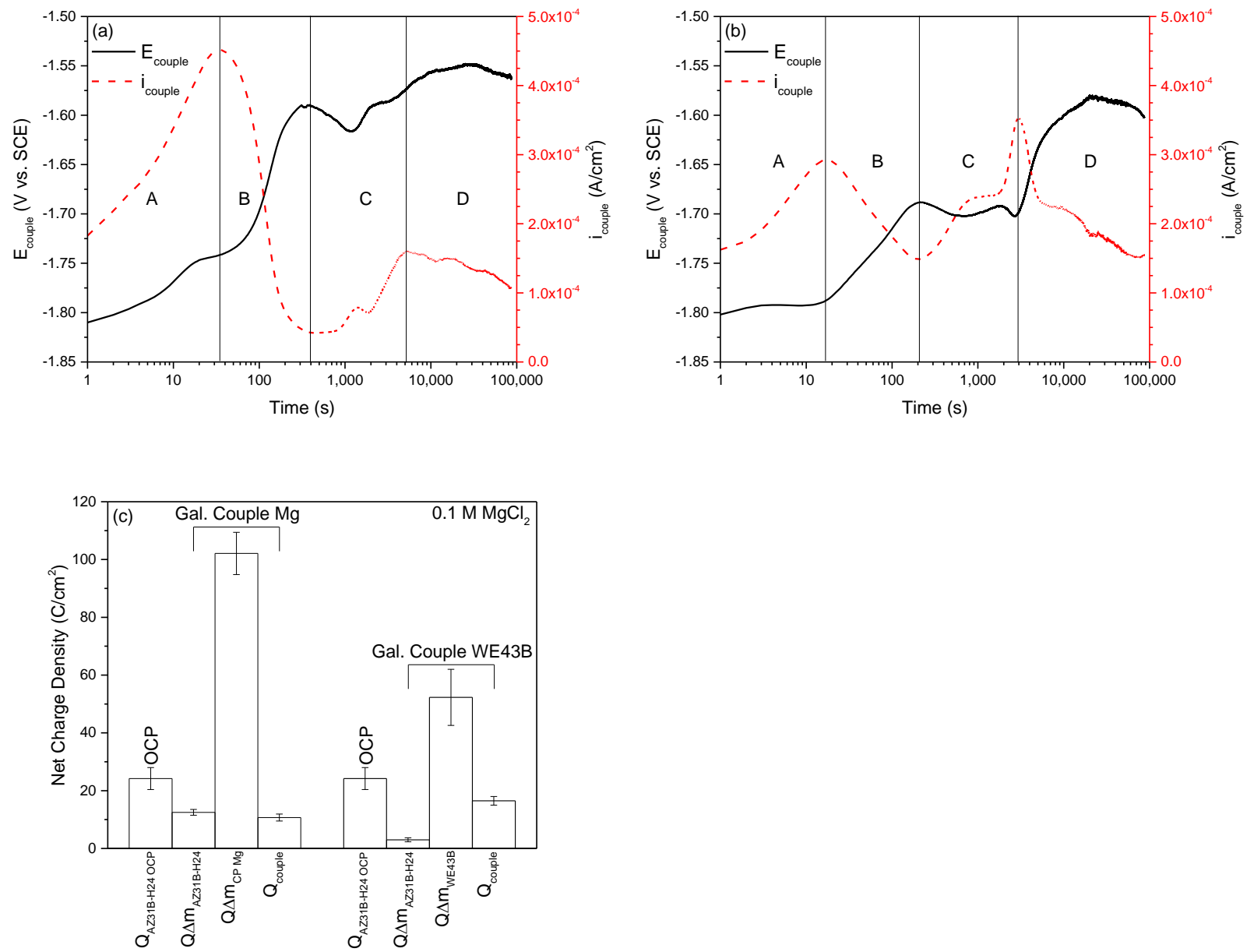

Figure 4.3. Zero resistance ammeter measurements for couples of (a) AZ31B-H24 to CP Mg, (b) AZ31B-H24 to WE43B, and (c) the corresponding charge density measured by gravimetric mass loss and the couple current density in $0.1 \mathrm{M} \mathrm{MgCl}_{2}$. $\mathrm{CP} \mathrm{Mg}$ and WE43B were chosen as the working electrodes.

\subsubsection{ZRA tests of AZ31B-H24 to CP Mg and WE43B in 0.1 M TRIS}

The couple behavior of AZ31B-H24 coupled to $\mathrm{CP}$ Mg and WE43B in 0.1 M TRIS is shown in Figure 4.4. The behavior of AZ31B-H24 coupled to CP Mg is shown in Figure 4.4a and is composed of four regions. At the beginning of the test, $\mathrm{E}_{\mathrm{g}}$ and $\mathrm{i}_{\mathrm{g}}^{\mathrm{ZRA}}$ both increased continuously for 29 seconds. After this, E $\mathrm{g}_{\mathrm{g}}$ continued to increase to a maximum in region B at about 93 seconds 
and then decreased until about 400 seconds while $\mathrm{ig}_{\mathrm{g}}^{\mathrm{ZRA}}$ decreased. $\mathrm{E}_{\mathrm{g}}$ then increased for the remainder of the test to a final value of approximately $-1.7 \mathrm{~V}_{\mathrm{SCE}}$ which is approximately $160 \mathrm{mV}$ more negative than the OCP of AZ31B-H24 in TRIS at $-1.54 \mathrm{~V}_{\mathrm{SCE}}$ while $\mathrm{i}_{\mathrm{g}}^{\mathrm{ZRA}}$ increased to a maximum couple current density at about 17,275 seconds in region $\mathrm{C}$ and then decreased for the remainder of the test. In contrast to every other couple tested in this investigation, AZ31B-H24 coupled to WE43B showed primarily one trend as shown in Figure 5b. Here, $\mathrm{i}_{\mathrm{g}}^{\mathrm{ZRA}}$ was relatively constant throughout the duration of the test while $\mathrm{E}_{\mathrm{g}}$ continuously increased from $-1.90 \mathrm{~V}_{\mathrm{SCE}}$ to $1.73 \mathrm{~V}_{\text {SCE }}$ which is approximately $200 \mathrm{mV}$ more negative than the OCP of AZ31B-H24 in TRIS. The anodic charge density measured by ZRA couples in 0.1 M TRIS is shown in Figure 4.4c. Consistent with the anodic charge measured in $0.6 \mathrm{M} \mathrm{NaCl}$ and $0.1 \mathrm{M} \mathrm{MgCl}_{2}, \mathrm{Q} \Delta \mathrm{m}_{\mathrm{AZ} 31 \mathrm{~B}-\mathrm{H} 24}$ under a galvanic couple did not decrease greatly compared to $\mathrm{Q} \Delta \mathrm{m}_{\mathrm{AZ} 31 \mathrm{~B}-\mathrm{H} 24}$ at OCP with about a 2x decrease for AZ31B-H24 coupled to both $\mathrm{CP}$ Mg and WE43B. In addition, $\mathrm{Q} \Delta \mathrm{m}_{\mathrm{CP}} \mathrm{Mg}$ was

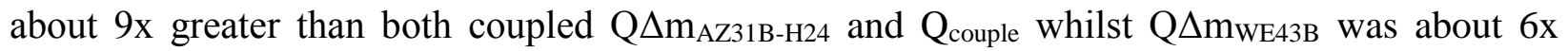

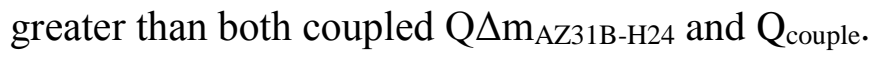



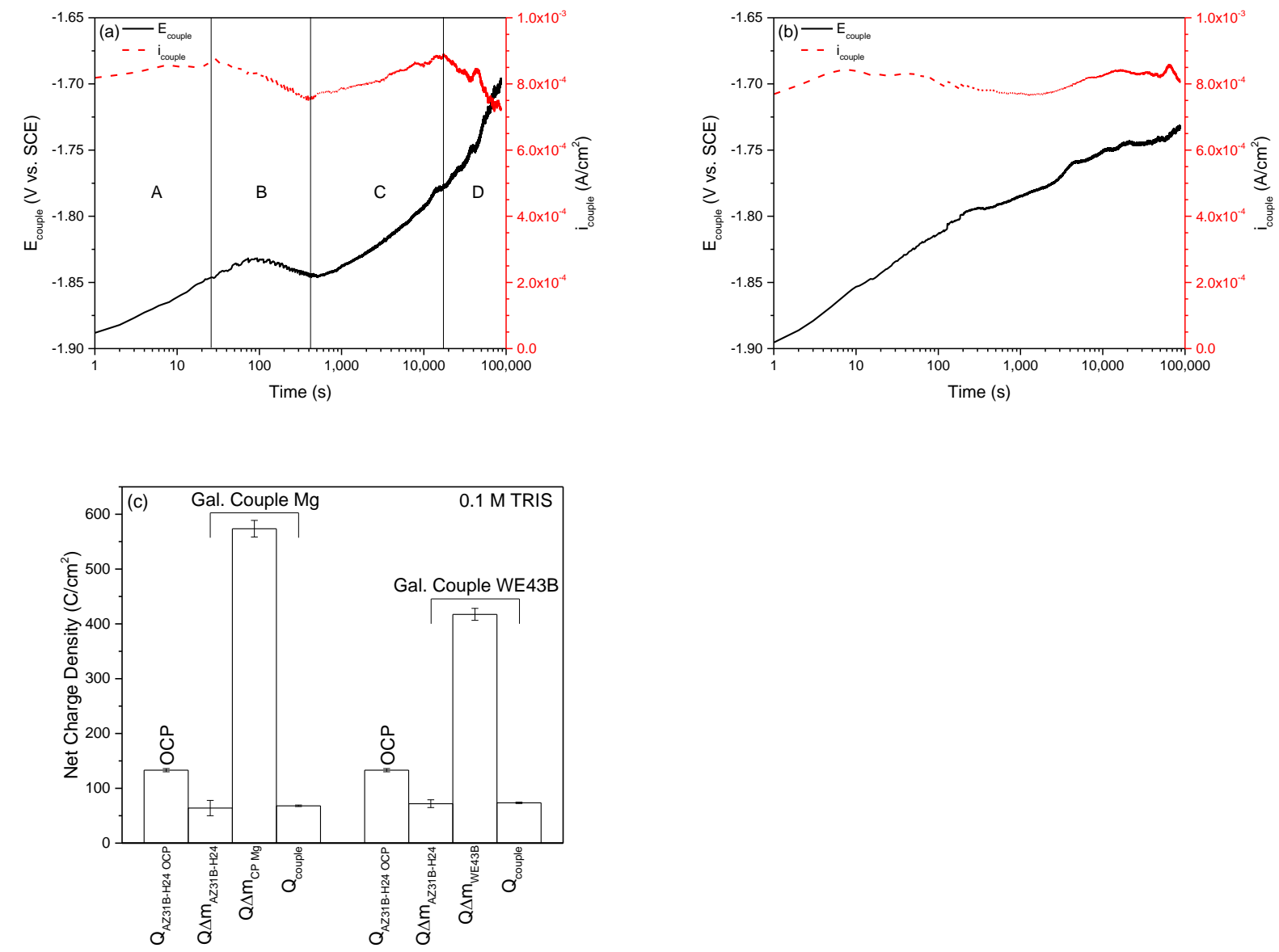

Figure 4.4. Zero resistance ammeter measurements for couples of (a) AZ31B-H24 to CP Mg, (b) AZ31B-H24 to WE43B, and (c) the corresponding charge density measured by gravimetric mass loss and the couple current density in 0.1 M TRIS. CP Mg and WE43B were chosen as the working electrodes.

\subsubsection{Evaluation of Anodically Induced Cathodic Activation}

The effects of anodically induced cathodic activation for the AZ31B-H24/CP Mg couple in each solution was evaluated by comparing cathodic potentiodynamic polarization scans before and after ZRA testing as shown in Figure 4.5. ${ }^{\text {vii }}$ In this figure, AZ31B-H24 experienced a small decrease in cathodic kinetics in fresh $0.6 \mathrm{M} \mathrm{NaCl}$ solution after ZRA measurements in $0.6 \mathrm{M} \mathrm{NaCl}$ (Figure 4.5a) and $0.1 \mathrm{M} \mathrm{MgCl}_{2}$ (Figure 4.6b) while there was no change in cathodic kinetics in 0.1

vii It should be noted that trends in cathodic kinetics were elucidated near $\mathrm{E}_{\text {corr }}$ because the solution resistance dominated the measured cathodic kinetics at potentials more negative than $-2.2 \mathrm{~V}_{\mathrm{SCE}}$. 
M TRIS (Figure 4.5c). Meanwhile, the cathodic kinetics of CP Mg increased slightly in $0.6 \mathrm{M}$ $\mathrm{NaCl}$ and $0.1 \mathrm{M} \mathrm{MgCl}_{2}$ while no change was observed in $0.1 \mathrm{M}$ TRIS. Furthermore, $\mathrm{E}_{\text {corr }}$ of $\mathrm{CP}$ Mg did not become more positive than AZ31B-H24 which indicates that polarity reversal would not occur during the ZRA test. The cathodic kinetics after ZRA testing was also performed in the original solution as ZRA testing for $0.6 \mathrm{M} \mathrm{NaCl}$ as shown in Figure $6 \mathrm{~d}$ and this did not produce significant changes to polarization curves compared to the case of the fresh solution.
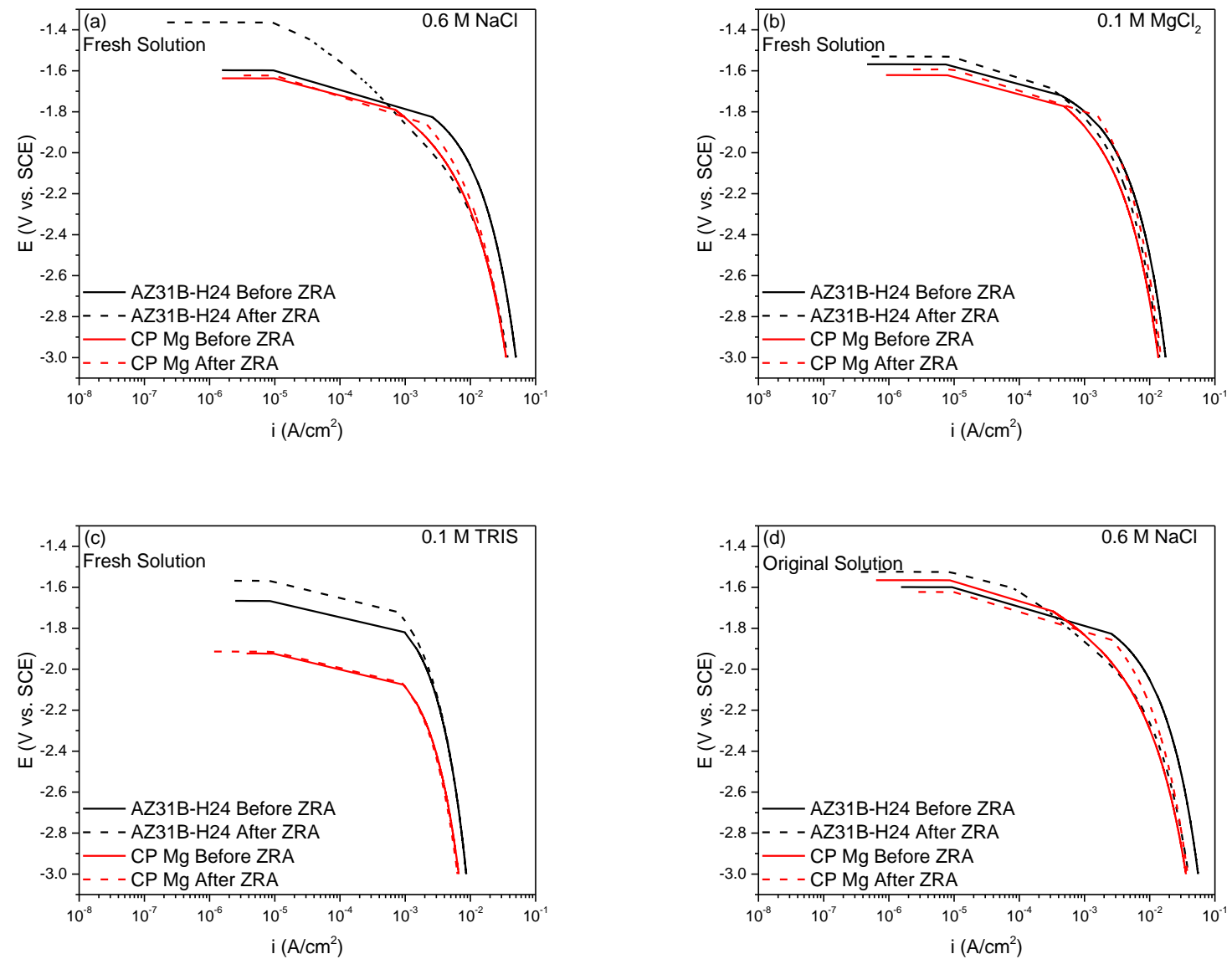

Figure 4.5. Cathodic polarization scans taken before and after ZRA measurements of AZ31B-H24 coupled to $\mathrm{CP} \mathrm{Mg}$ in each environment. The scans were performed after resting at OCP for 10 minutes prior to and after ZRA measurements. (a-c) Used fresh solution for testing of post-ZRA cathodic polarization while (d) used the original solution for testing of post-ZRA cathodic polarization

No evidence for polarity reversal was observed for AZ31B-H24 coupled to WE43B as suggested by the E-log i data in Figure 4.6. In contrast to the AZ31B-H24/CP Mg couple, there 
were virtually no changes in cathodic kinetics on either AZ31B-H24 or WE43B in each solution tested with exception to WE43B in $0.1 \mathrm{M} \mathrm{MgCl}_{2}$ which displayed a small increase in cathodic kinetics, Figure 4.6b. The cathodic kinetics of WE43B also did not change for cathodic polarization in the original solution as the ZRA measurement in $0.6 \mathrm{M} \mathrm{NaCl}$ but a decrease in cathodic kinetics was observed on AZ31B-H24 (Figure 7d). The minimal changes in the cathodic kinetics for both couples may be related to the small amount of anodic dissolution which occurred on each anode as will be discussed in section 5.2.
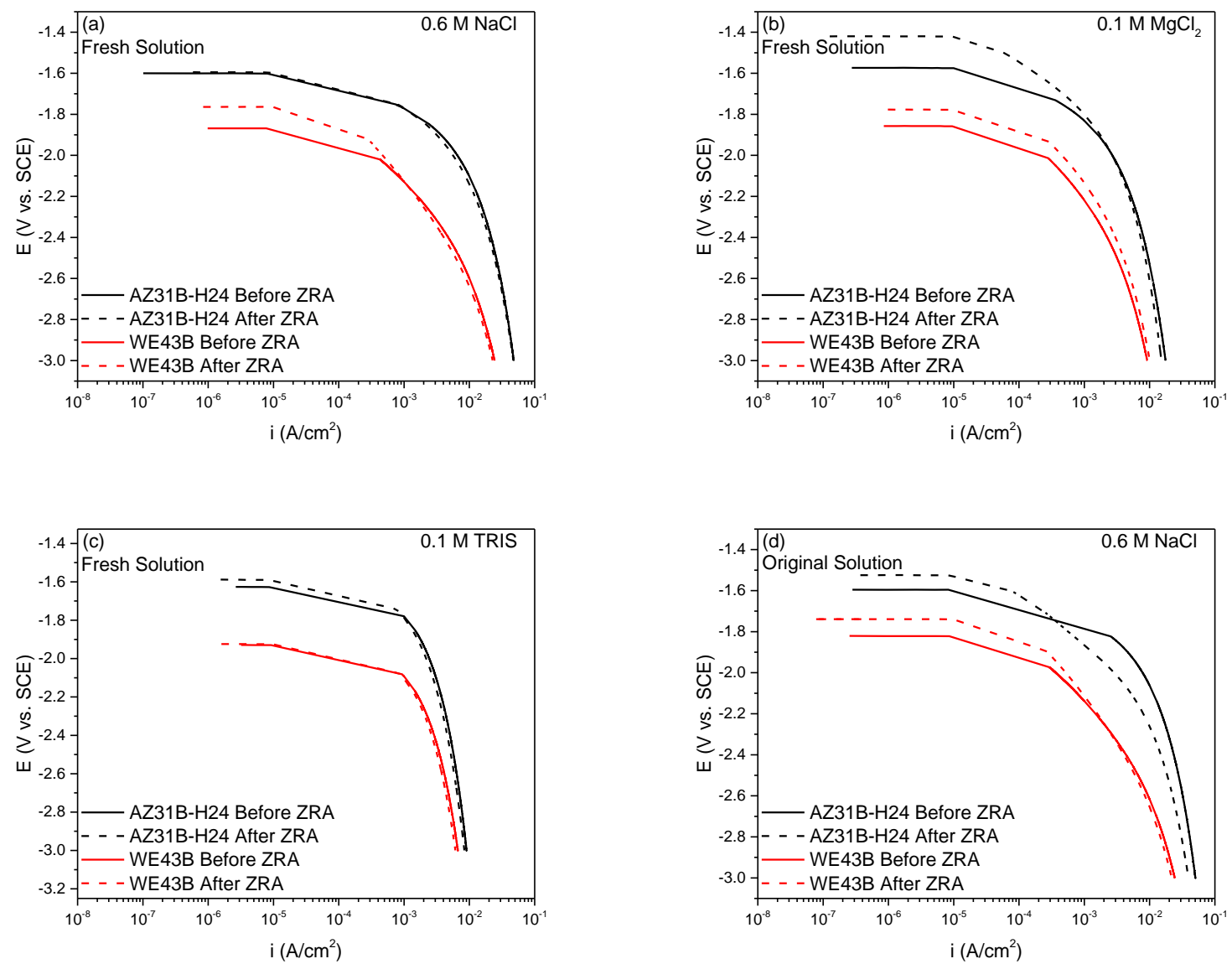

Figure 4.6. Cathodic polarization scans taken before and after ZRA measurements of AZ31B-H24 coupled to WE43B in each environment. The scans were performed after resting at OCP for 10 minutes prior to and after ZRA measurements. (a-c) Used fresh solution for testing of post-ZRA cathodic polarization while (d) used the original solution for testing of post-ZRA cathodic polarization 


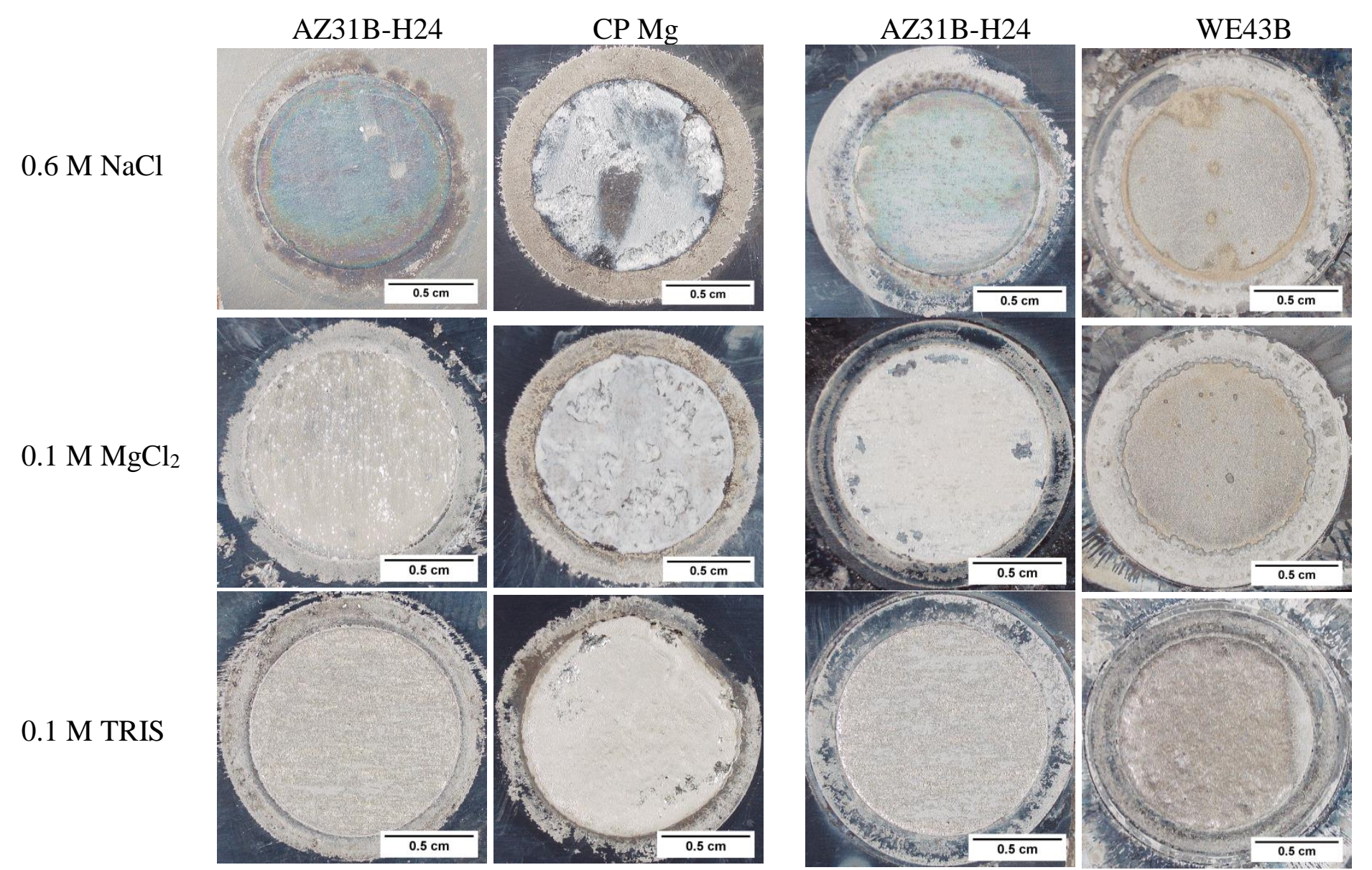

Figure 4.7. Optical micrographs of sample surfaces after ZRA measurements. Corrosion products were not cleaned from sample surfaces. 


\subsubsection{Surface Characterization of ZRA Samples}

Figure 4.7 shows optical micrographs of sample surfaces after completion of ZRA tests in each solution and several observations can be made. The corrosion damage to AZ31B-H24 in both couples in $0.6 \mathrm{M} \mathrm{NaCl}$ and $0.1 \mathrm{M} \mathrm{MgCl}_{2}$ appeared to be minimal. This is better shown on cleaned samples in Figure 4.8 with reference to the control cleaned samples after 24-hour immersion at OCP in each solution. However, the corrosion damage was still substantial on AZ31B-H24 coupled to CP Mg and WE43B in 0.1 M TRIS and displayed a similar morphology to that at OCP. In addition, the corrosion damage and film formation was much greater for $\mathrm{CP} \mathrm{Mg}$ and WE43B in comparison to AZ31B-H24 which is in agreement with expectations from mass loss measurements for an anode in a galvanic couple. The corrosion morphologies of CP Mg and WE43B were also different from each other in $\mathrm{Cl}^{-}$solutions. The corrosion observed for $\mathrm{CP} \mathrm{Mg}$ showed the presence of non-uniform corrosion and the formation of a white corrosion product. This white corrosion product is largely not observed on the WE43B surfaces except for the area where the rubber Oring contacted the metal surface. Indeed, the corrosion damage was greatest under the O-ring of WE43B samples in $\mathrm{Cl}^{-}$solutions but was not strong in TRIS as uniform corrosion dominated. Interestingly, gold colored corrosion and/or salt films appear to form on AZ31B samples in each medium but it was unclear whether or not these grew from the metal surface or were deposited on the metal surface. As such, further investigation of this gold corrosion product was performed using higher magnification optical microscopy, SEM-EDS, and Raman Spectroscopy.

Figure 4.9a shows a higher magnification optical microscopy image of the AZ31B-H24 sample which was coupled with WE43B in $0.1 \mathrm{M} \mathrm{MgCl}_{2}$ from Figure 4.7. This image shows that the film is being deposited on the AZ31B-H24 surface since the 1200 grit grind marks can be seen underneath of the partially transparent film. Moreover, optical micrographs in Figure 4.9b show 
almost no corrosion damage on the AZ31B-H24 surface after cleaning the corrosion products off with $\mathrm{CrO}_{3}$ which strengthens the notion that the corrosion film precipitated on the sample surface. EDS analysis of the film in Figure 4.9c suggests that the film is composed of $\mathrm{Mg}(\mathrm{OH})_{2}$ but also contains a significant amount of $\mathrm{Cl}$. Raman spectroscopy was performed on each sample surface as shown in Figure 4.10 confirmed the presence of $\mathrm{Mg}(\mathrm{OH})_{2}$ on each sample but did not detect the presence of any other corrosion products.

$0.6 \mathrm{M} \mathrm{NaCl}$

AZ31B-H24 OCP

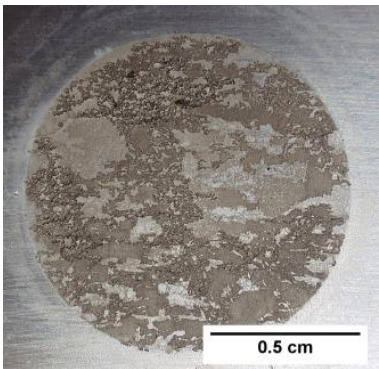

$0.1 \mathrm{M} \mathrm{MgCl}_{2}$

$0.1 \mathrm{M}$ TRIS
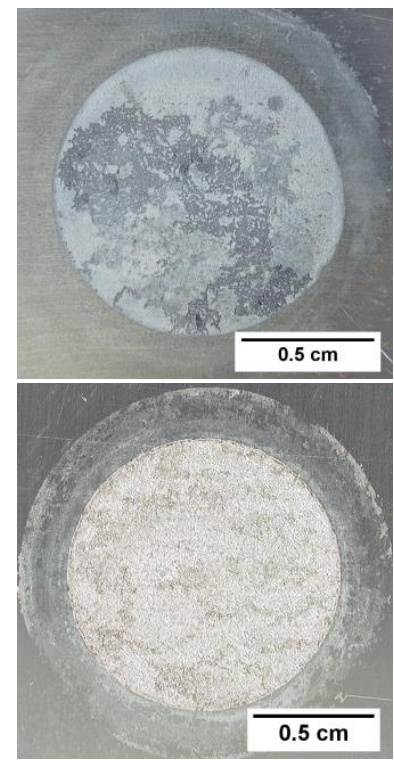

AZ31B-H24 to CP Mg
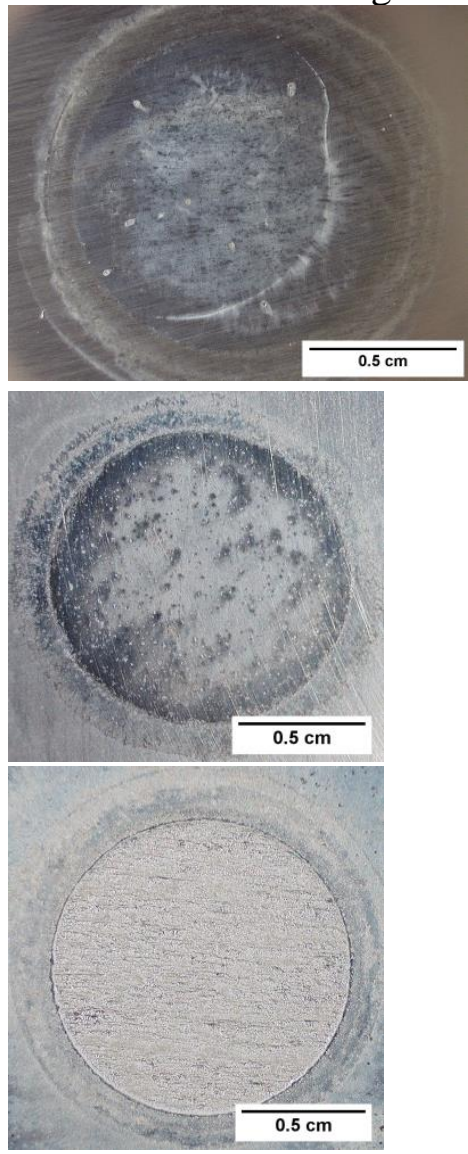

AZ31B-H24 to WE43B
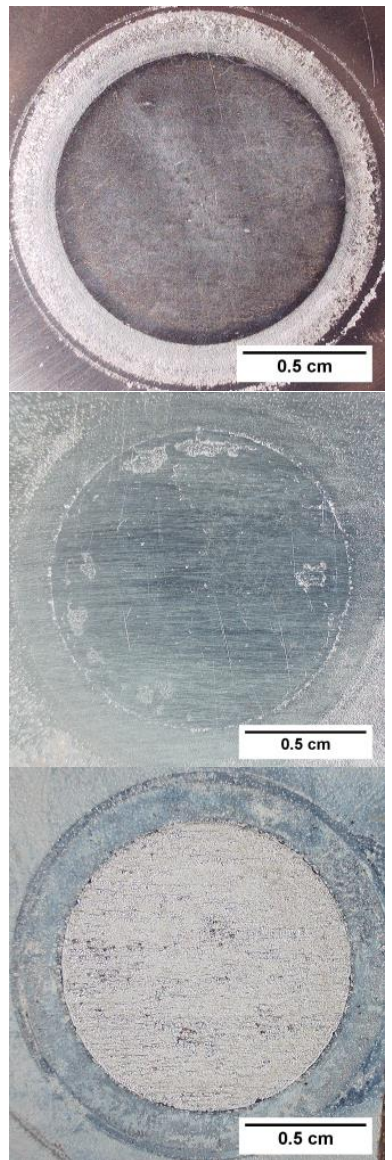

Figure 4.8. Optical micrographs of cleaned AZ31B-H24 surfaces after showing corrosion damage incurred at OCP after 24 hours compared to that by ZRA testing. 
(a)

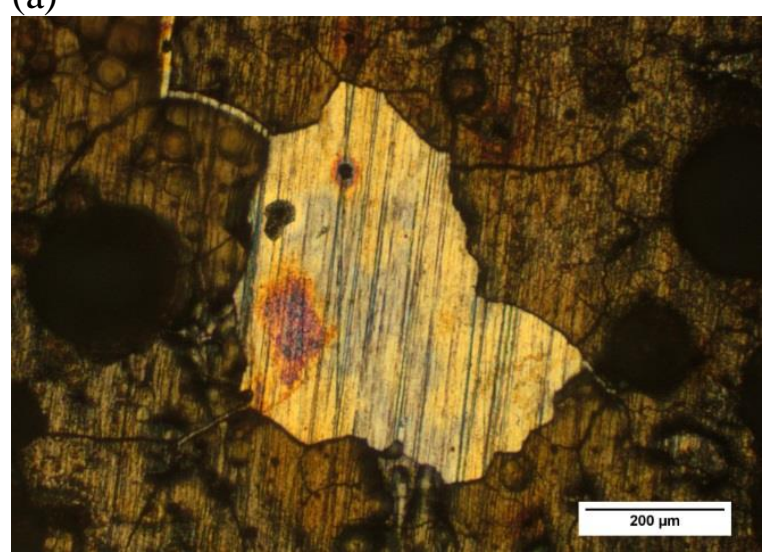

(c)

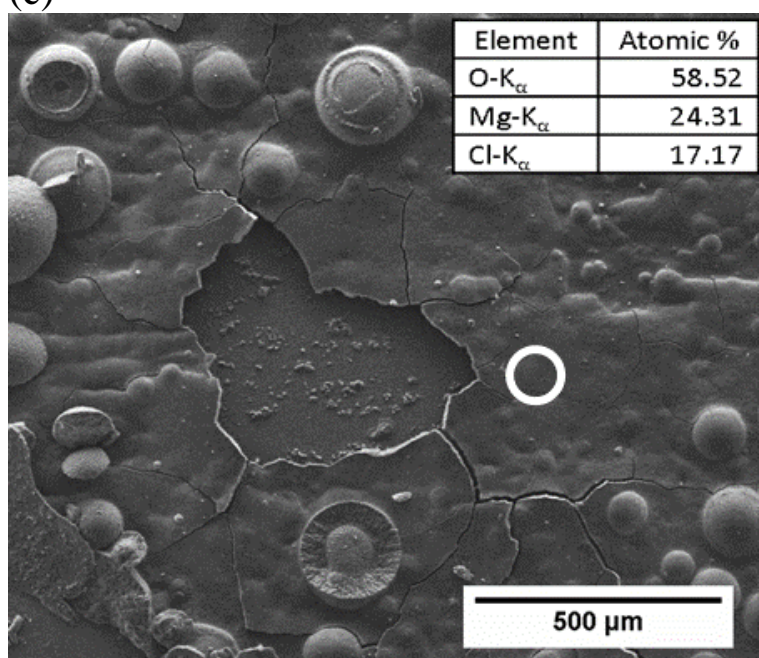

(b)

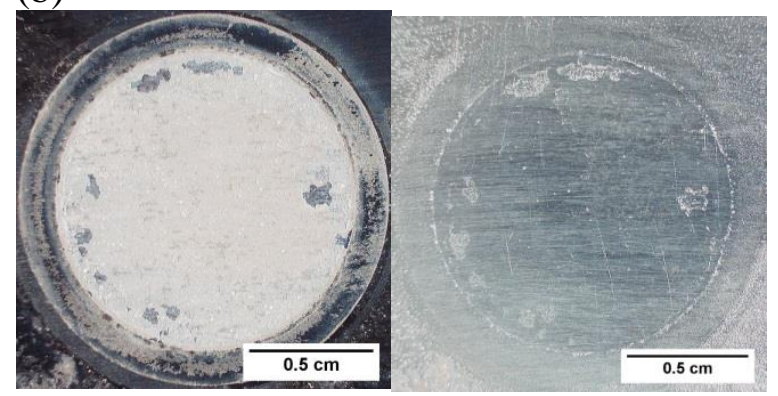

Figure 4.9. (a) Bright field optical micrograph of corrosion film forming on AZ31B-H24 sample after ZRA test with WE43B in $0.1 \mathrm{M} \mathrm{MgCl}_{2}$. (b) Bright field optical micrographs of the AZ31B$\mathrm{H} 24$ surface before and after cleaning with $\mathrm{CrO}_{3}$. (c) Secondary electron SEM image with EDS spot analysis of the film. 
(a)

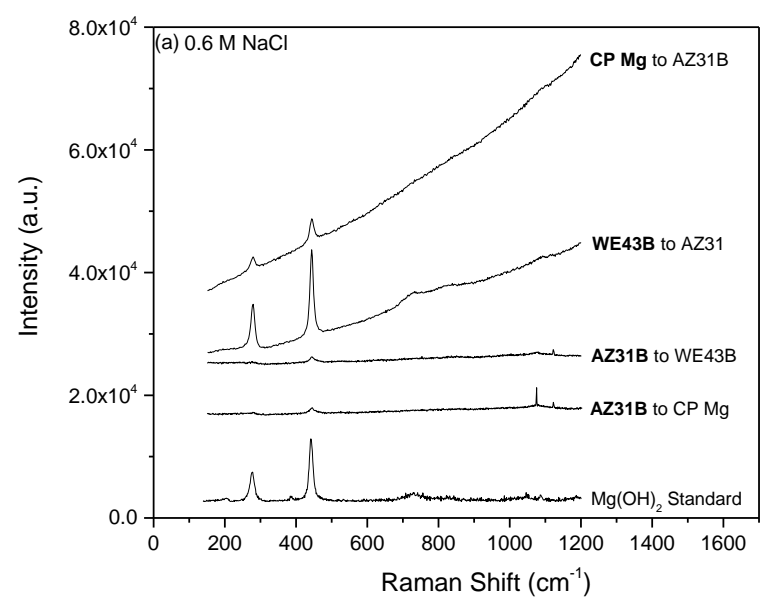

(c)

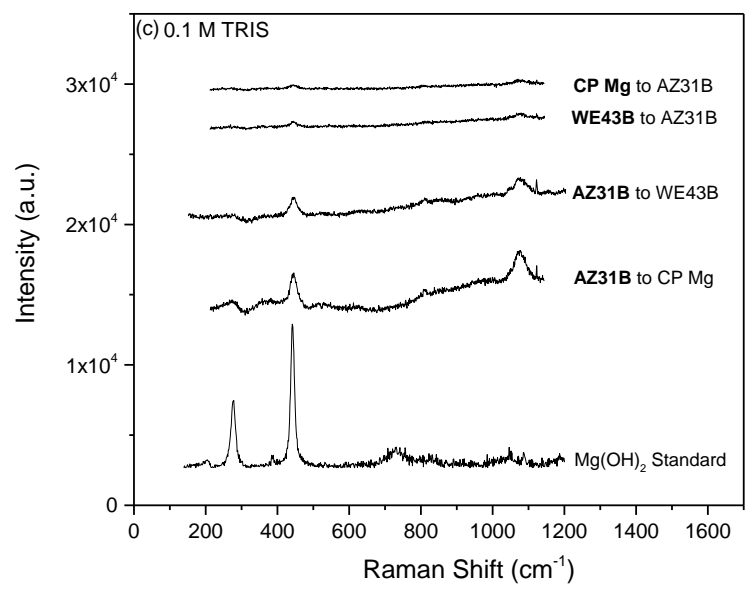

(b)

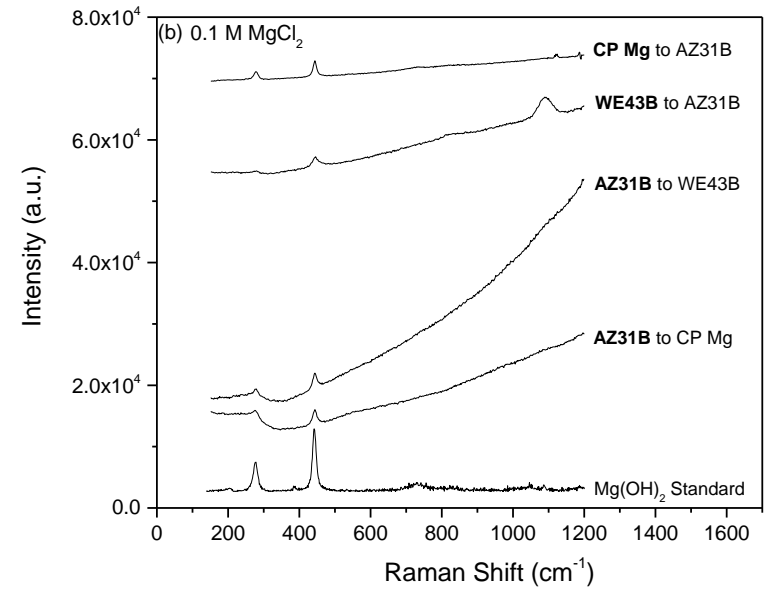

Figure 4.10. Raman spectroscopy of ZRA sample surfaces in (a) $0.6 \mathrm{M} \mathrm{NaCl}$, (b) $0.1 \mathrm{M} \mathrm{MgCl}_{2}$, and (c) $0.1 \mathrm{M}$ TRIS. The material listed first (bold) is the material that the scan was performed on. 


\subsection{Discussion}

\subsubsection{Range of Potentials for Sacrificial Cathodic Protection of AZ31B-H24 and Implications on Design of Sacrificial Mg-Based Alloys}

This study has validated that sacrificial cathodic protection of AZ31B-H24 can be achieved in the range of potentials determined in Chapter 2. However, as observed with potentiostatic polarization of AZ31B-H24, only a 2-3x decrease in $\mathrm{Q}_{\Delta \mathrm{m}}$ was observed for galvanically coupled AZ31B-H24 compared to $\mathrm{Q}_{\triangle \mathrm{m}}$ of AZ31B-H24 at OCP (EOCP - $\mathrm{E}_{\mathrm{g}}$ ranged between 50-200 mV). This is attributed to the NDE where persistent HER on the dissolving surface leads to greater $\mathrm{Mg}$ dissolution rates than would be expected under conventional Tafel Laws as discussed in Chapter 2. This is in contrast to observations of non-amphoteric materials such as Fe coupled to $\mathrm{Zn}$ which obey Tafel kinetics and often rely on kinetic suppression of corrosion and rarely achieve thermodynamic protection [4]. Furthermore, the detrimental effects of the NDE are best shown by measurements of $\mathrm{Q}_{\triangle \mathrm{m}}$ of CP Mg and WE43B after ZRA measurements compared to $\mathrm{Q}_{\text {couple. }}$

It was observed in Figure 4.2-4.4 that $\mathrm{Q}_{\Delta \mathrm{m}}$ of $\mathrm{CP} \mathrm{Mg}$ and WE43B anode materials was several times greater than their respective values for $Q_{\text {couple }}$ which is contrary to conventional mixed potential theory of galvanic couples with a fixed low cathodic reaction rate occurring on the anode [4]. This can be explained based on the schematic E vs I plots in Figure 4.11: a key for the symbols used in Figure 4.11 can be found in the appendix in Section 4.7 below. A typical galvanic couple exhibiting anodic and cathodic Tafel behavior of both anode and cathode is shown in Figure 4.11a considering the case of slow cathodic kinetics on the anode such as the case $\mathrm{Zn} / \mathrm{Fe}$ with $\mathrm{Zn}$ as the anode [4]. The galvanic couple current $\left(\mathrm{I}_{\mathrm{g}}^{\mathrm{ZRA}}\right)$ and potential $\left(\mathrm{E}_{\mathrm{g}}\right)$ are determined at the condition where the sum of the currents of all anodic reactions $\left(\sum \mathrm{I}_{\mathrm{A}}=\mathrm{I}_{\mathrm{d}}^{\mathrm{A}}+\mathrm{I}_{\mathrm{d}}^{\mathrm{C}}\right)$ is equal and opposite to the sum of the currents of all cathodic reactions $\left(\sum \mathrm{I}_{C}=\mathrm{I}_{H E R}^{\mathrm{A}}+\mathrm{I}_{\mathrm{HER}}^{\mathrm{C}}\right)$. It can be seen that at $\mathrm{E}_{\mathrm{g}}$, 
the dissolution current on the anode $\left(\mathrm{I}_{\mathrm{d}}^{\mathrm{A}}\right)$ is approximately equal to $\mathrm{I}_{\mathrm{g}}^{\mathrm{ZRA}}$. The dissolution current on the cathode $\left(\mathrm{I}_{\mathrm{g}}^{\mathrm{C}}\right)$ at the galvanic couple potential is very small and possibly negligible if thermodynamic protection is reached. This might be the case for large $\Delta \mathrm{E}$ between the anode and cathode that obey Tafel kinetics as shown by Mansfeld [6,7].

This differs from the observed couple behavior of an $\mathrm{Mg}$ anode to an $\mathrm{Mg}$ cathode where the NDE causes increases in HER rates at increasing anodic overpotentials as shown in Figure 4.11b. The result of this behavior causes a large difference between $\mathrm{I}_{\mathrm{g}}^{\mathrm{A}}$ and $\mathrm{I}_{\mathrm{g}}^{\mathrm{ZRA}}$ over a wide range of potentials where $\mathrm{I}_{\mathrm{g}}^{\mathrm{A}} \gg \mathrm{I}_{\mathrm{g}}^{\mathrm{ZRA}}$ whilst $\mathrm{I}_{\mathrm{g}}^{\mathrm{ZRA}}$ is slightly greater than $\mathrm{I}_{\mathrm{g}}^{\mathrm{C}}$. Moreover, $\mathrm{I}_{\mathrm{g}}^{\mathrm{C}}$ shows a small decrease in current compared to corrosion current at $\mathrm{OCP}, \mathrm{I}_{\text {corr }}^{\mathrm{C}}$. These observations from Figure 4.11b are in general agreement with results shown in Figure 4.2-4.4. It should be noted that the dissolution current in Figure 4.11b does approach the total current with increasing anodic overpotential (not shown in the range of potential and current) but there have not been any studies which have shown $I_{d}^{A}=I_{T}^{A}$ for an $M g$ alloy to the authors knowledge. However, since $I_{d}^{A}$ approaches $\mathrm{I}_{\mathrm{T}}^{\mathrm{A}}$, large differences between the $\mathrm{OCP}\left(\mathrm{E}_{\mathrm{corr}}^{\mathrm{A}}\right)$ of the anode and the galvanic couple potential $\left(E_{\mathrm{g}}\right)$ should yield a decrease in self-corrosion fraction:

$$
\frac{\mathrm{I}_{\mathrm{d}}^{\mathrm{A}}-\mathrm{I}_{T}^{\mathrm{A}}}{\mathrm{I}_{\mathrm{d}}^{\mathrm{A}}} \times 100 \%
$$

Equation 4.1

where the measured charge can be used alternatively to current. In this study, the fraction of selfcorrosion varies between $88-93 \%$ for AZ31B-H24/CP Mg couples and 68-82\% for AZ31BH24/WE43B couples. The decrease in self-corrosion fractions for AZ31B-H24/WE43B couples compared to AZ31B-H24/CP Mg couples is due to the difference in $\mathrm{E}_{\mathrm{g}}-\mathrm{E}_{\text {corr }}^{\mathrm{A}}$. Since $\mathrm{E}_{\mathrm{g}}-\mathrm{E}_{\text {corr }}^{\mathrm{A}}$ is greater for AZ31B-H24/WE43B, the difference between $\mathrm{I}_{\mathrm{g}}^{\mathrm{A}}$ and $\mathrm{I}_{\mathrm{g}}^{\mathrm{ZRA}}$ decreases and thus the selfcorrosion fraction will decrease (Table 4.3). 

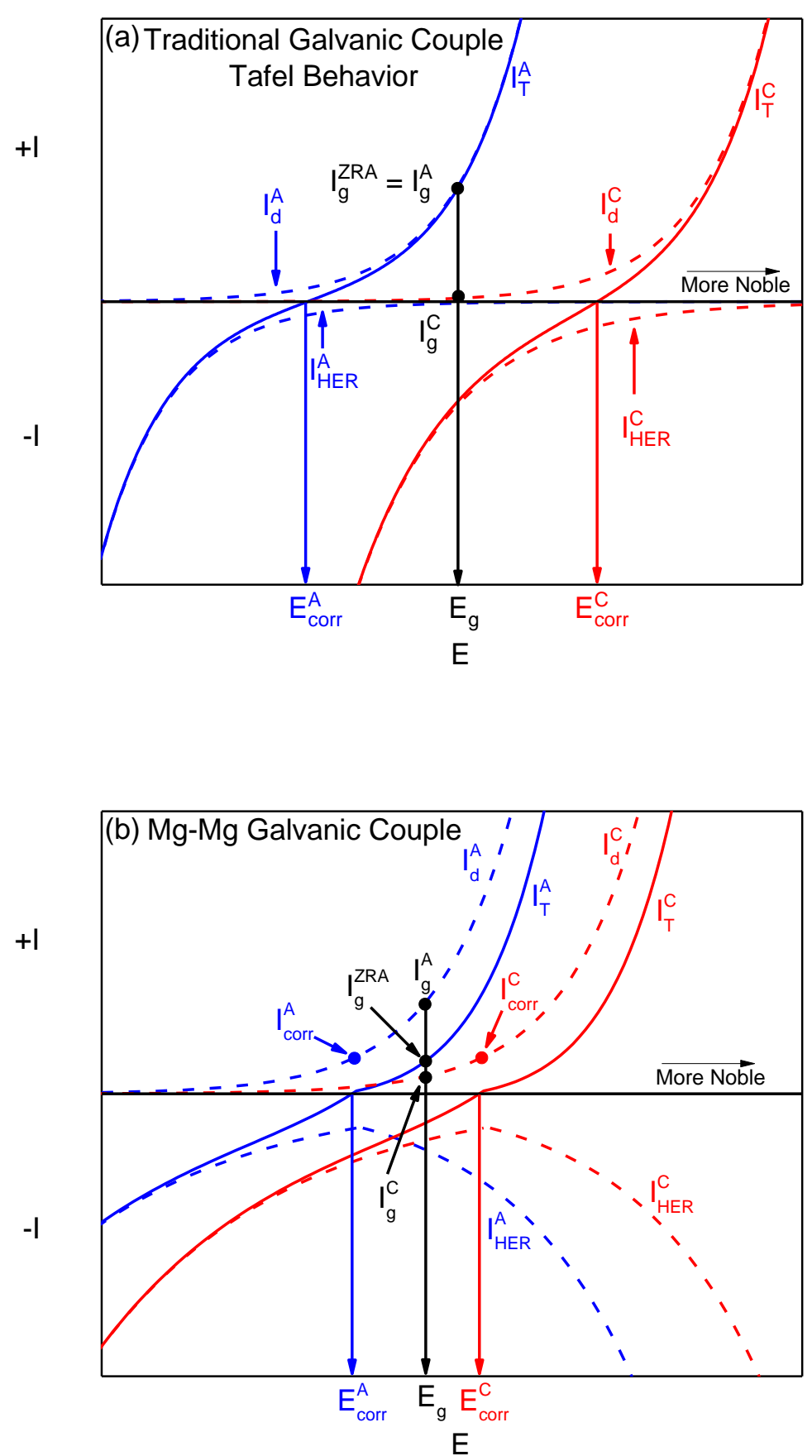

Figure 4.11. Schematic E vs. I plots for (a) traditional galvanic couples exhibiting anodic and cathodic Tafel behavior and (b) $\mathrm{Mg}-\mathrm{Mg}$ galvanic couples with increasing anodic hydrogen evolution reaction rates. 
Table 4.3. The average self-corrosion fraction for anode materials CP Mg and WE43B during galvanic couples in each solution tested in this study from ZRA measurements.

\begin{tabular}{|l|l|l|}
\hline & \multicolumn{2}{|l|}{ Average Fraction "Self-Corrosion" } \\
\hline & $\mathrm{CP} \mathrm{Mg}$ & WE43B \\
\hline $0.6 \mathrm{M} \mathrm{NaCl}$ & $93 \%$ & $75 \%$ \\
\hline $0.1 \mathrm{M} \mathrm{MgCl} 2$ & $90 \%$ & $68 \%$ \\
\hline $0.1 \mathrm{M} \mathrm{TRIS}$ & $88 \%$ & $82 \%$ \\
\hline
\end{tabular}

This couple behavior was also shown recently for $99.95 \%$ pure Mg coupled to A36 mild steel in $5 \mathrm{wt} \% \mathrm{NaCl}$ [8]. The authors in this study calculated self-corrosion fraction as a function of time up to 10 minutes and found that the self-corrosion fraction was independent of anode to cathode ratio. The average self-corrosion fraction after 10 minutes was between 33-35\% but the maximum average fraction of self-corrosion occurred after 3 minutes and reached values up to approximately $55 \%$. However, these values are much lower than observed in this study as shown in Table 4.3 despite similar values of $\mathrm{E}_{\mathrm{g}}-\mathrm{E}_{\mathrm{corr}}^{\mathrm{A}}(150-300 \mathrm{mV})$ for WE43B coupled to AZ31B and $\mathrm{Mg}$-Fe couples. An additional ZRA of $\mathrm{CP} \mathrm{Mg}$ to a Pt mesh in $0.6 \mathrm{M} \mathrm{NaCl}$ yielded $\mathrm{E}_{\mathrm{g}}-\mathrm{E}_{\text {corr }}^{\mathrm{A}}=$ $400 \mathrm{mV}$ and a self-corrosion fraction of about $35 \%$ which suggests that nature of the cathode plays a role in self-corrosion fraction. This increase in self-corrosion fraction on $\mathrm{Mg}-\mathrm{Mg}$ couples compared to $\mathrm{Mg}$ coupled to non- $\mathrm{Mg}$ based materials could be attributed to the couple being affected by both electrodes experiencing NDE since both are Mg-based and undergoes some corrosion at $\mathrm{E}_{\mathrm{g}}$ whereas $\mathrm{NDE}$ is not observed on Fe-based materials. This confirms the notion that using Mg-based anodes for sacrificial cathodic protection of Mg alloys complicates traditional application of galvanic based protection and mixed potential theory where the anode is primarily a source of anodic current while the cathode primarily is the site for the cathodic reaction. Further investigation of the detrimental effects of the NDE could be evaluated by using anode materials other than Mg-based alloys. La is one such metal ${ }^{11}$ and investigation of galvanic couples to $\mathrm{Mg}$ 
based alloys may produce improved couple behavior. Furthermore, La could be alloyed with elements with low exchange current densities for HER such as As, Bi, Ge, and Sn $[9,10]$.

\subsubsection{The Effects of Anodically Induced Cathodic Activation and Trends in ZRA \\ Behavior}

In this study, anodically induced increases in cathodic kinetics of CP Mg and WE43B were minimal according to the cathodic polarization curves in Figure 4.5-4.6. This is contrary to observations by recent studies where prior anodic dissolution has shown increases in the cathodic kinetics of Mg-based anodes by various electrochemical techniques [11-18]. This may be due partially to the relative small amount of corrosion damage observed on $\mathrm{CP} \mathrm{Mg}$ and WE43B. In Chapter 3, enhanced cathodic kinetics were found on $\mathrm{HP} \mathrm{Mg}$ anodes in $0.6 \mathrm{M} \mathrm{NaCl}$ at applied potentials more positive than $-1.55 \mathrm{~V}_{\mathrm{SCE}}$ during potentiostatic testing after 24 hours (Figure 3.9). The measured anodic charge densities due to mass loss on these samples were more than $3 \mathrm{x}$ greater than that measured on $\mathrm{CP}$ Mg anodes in this investigation in ZRA testing which suggests that not enough dissolution occurred on $\mathrm{CP} \mathrm{Mg}$ anodes in this testing to observe large increases in cathodic kinetics either by the coverage of corrosion products or enrichment of $\mathrm{Al}$ and transition metals which have been linked to enhanced cathodic kinetics $[11,14,19,20]$. This is strengthened further with observations that a 2-3x increase in cathodic kinetics occurred on HP Mg after 24 hours immersion at OCP compared to $10 \mathrm{~min}$ at OCP. Similar values for anodic charge density due to mass loss were measured after 24 hour immersion at $\mathrm{OCP}$ in $0.6 \mathrm{M} \mathrm{NaCl}$ for $\mathrm{HP} \mathrm{Mg}$ anodes compared to that measured for $\mathrm{CP} \mathrm{Mg}$ after ZRA measurements in this investigation $\left(105 \mathrm{C} / \mathrm{cm}^{2}\right.$ for $\mathrm{HP} \mathrm{Mg}$ and $\approx 100 \mathrm{C} / \mathrm{cm}^{2}$ for $\mathrm{CP} \mathrm{Mg}$ couples, respectively) which confirms the small increase in cathodic kinetics on CP Mg observed in this investigation in short term tests. In addition, no changes in cathodic kinetics were found for either anode or cathode exposed to $0.1 \mathrm{M}$ TRIS. This 
may be attributed to the lack of a dissolution film which has been linked to enhanced cathodic kinetics. $^{48}$

Similar trends in cathodic kinetics are observed on WE43B after potentiostatic polarization in $0.6 \mathrm{M} \mathrm{NaCl}$ as shown in Figure 4.12a. The anodic charge density of WE43B measured during ZRA measurements in this investigation $\left(\mathrm{Q}_{\Delta \mathrm{m}}=45 \mathrm{C} / \mathrm{cm}^{2}\right.$ in $\left.0.6 \mathrm{M} \mathrm{NaCl}\right)$ was similar to that at an applied potential of $-1.65 \mathrm{~V}_{\mathrm{SCE}}\left(\mathrm{Q}_{\Delta \mathrm{m}}=35 \mathrm{C} / \mathrm{cm}^{2}\right.$ in $\left.0.6 \mathrm{M} \mathrm{NaCl}\right)$ which possessed cathodic kinetics similar to the cathodic kinetics measured after 10 minute immersion of WE43B at OCP. This provides supporting evidence that limited change in cathodic kinetics would be expected on WE43B ZRA samples in the short term tests herein as observed in Figure 4.6. In contrast, the cathodic kinetics of AZ31B-H24 in $0.6 \mathrm{M} \mathrm{NaCl}$ (Figure 13b) decreased at applied potentials more negative than OCP compared to cathodic potentiodynamic polarization performed after 10 minute immersion at OCP. This confirms the slight decrease in cathodic kinetics observed on AZ31BH24 ZRA samples.

\subsubsection{Trends in ZRA Behavior}

The trends in the behavior observed by ZRA measurements can be summarized in Table 4.4 using electrochemical mixed potential theory. In region A of each couple tested, $\mathrm{E}_{\mathrm{g}}$ and $\mathrm{i}_{\mathrm{g}}^{\mathrm{ZRA}}$ were observed to increase for a brief period of time. This would indicate an increase in the sum of the cathodic kinetics which is likely to have occurred on primarily on the anode based on theories of anodically induced cathodic activation [11-18]. Indeed, the potentiodynamic polarization curves in Figure 4.5-4.6 support either no change or a decrease in cathodic kinetics on AZ31B-H24 and no change to a small increase in cathodic kinetics on $\mathrm{CP} \mathrm{Mg}$ and $\mathrm{WE} 43 \mathrm{~B}$ in $\mathrm{Cl}^{-}$. However, there is no change in cathodic kinetics in $0.1 \mathrm{M}$ TRIS so it is unclear why $\mathrm{E}_{\mathrm{g}}$ continuously increased (Figure 4.4) while $\mathrm{i}_{\mathrm{g}}^{\mathrm{ZRA}}$ remained relatively constant throughout the duration of ZRA 
measurements. Increases in cathodic kinetics may be attributed to Al and transition metal enrichment and formation of $\mathrm{Mg}(\mathrm{OH})_{2}$ corrosion films as they have been linked to enhanced cathodic kinetics $[11,14,19,20]$. However, the origins of enhanced cathodic kinetics on $\mathrm{Mg}$ anodes is greatly debated in the literature and has been linked to $\mathrm{pH}$ changes [21] and the nature of the dissolving surface [13] as well. Continuing formation of $\mathrm{Mg}(\mathrm{OH})_{2}$ on the corroding $\mathrm{Mg}$ surface can also decrease the dissolution kinetics due to its pseudo passive behavior [5] which is indicated by an increase in $\mathrm{E}_{\mathrm{g}}$ and decrease in $\mathrm{i}_{\mathrm{g}}^{\mathrm{ZRA}}$. This is typically observed in region B of Figure 4.2-4.4 after the period of anodically induced cathodic activation. Formation of $\mathrm{Mg}(\mathrm{OH})_{2}$ corrosion films in addition to precipitation of $\mathrm{MgCl}_{2}$ films on $\mathrm{Mg}$ surfaces can also serve to decrease the cathodic kinetics as shown best at the end of region $\mathrm{D}$ in Figure $4.2 \mathrm{~b}$ where both $\mathrm{E}_{\mathrm{g}}$ and $\mathrm{i}_{\mathrm{g}}^{\text {ZRA }}$ decrease with time. Such behavior may be due the decreased ability for water to diffuse to the electrode surface through $\mathrm{Mg}(\mathrm{OH})_{2} / \mathrm{MgCl}_{2}$ surface film. Finally, increases in anodic kinetics such as that observed in region $\mathrm{C}$ of Figure $4.2 \mathrm{~b}$ and Figure $4.3 \mathrm{~b}$ can be attributed to breakdown and cracking of $\mathrm{Mg}(\mathrm{OH})_{2}$ corrosion films which is known to occur in $\mathrm{Cl}^{-}$containing electrolytes [22].

Table 4.4. Dominating change in reaction kinetics due to variations in the couple potential and couple current.

\begin{tabular}{|l|l|}
\hline $\begin{array}{l}\text { Change in } \\
\text { Couple } \\
\text { Behavior }\end{array}$ & $\begin{array}{l}\text { Dominating Change } \\
\text { in Reaction Kinetics }\end{array}$ \\
\hline$\uparrow \mathrm{E}_{\mathrm{g}}, \uparrow \mathrm{i}_{\mathrm{g}}^{\text {ZRA }}$ & $\uparrow \sum \mathrm{i}_{\text {cathodic }}$ \\
\hline$\downarrow \mathrm{E}_{\mathrm{g}}, \downarrow \mathrm{i}_{\mathrm{g}}^{\text {ZRA }}$ & $\downarrow \sum \mathrm{i}_{\text {cathodic }}$ \\
\hline$\downarrow \mathrm{E}_{\mathrm{g}}, \uparrow \mathrm{i}_{\mathrm{g}}^{\text {ZRA }}$ & $\uparrow \sum \mathrm{i}_{\text {anodic }}$ \\
\hline$\uparrow \mathrm{E}_{\mathrm{g}}, \downarrow \mathrm{i}_{\mathrm{g}}^{\text {ZRA }}$ & $\downarrow \sum \mathrm{i}_{\text {anodic }}$ \\
\hline
\end{tabular}



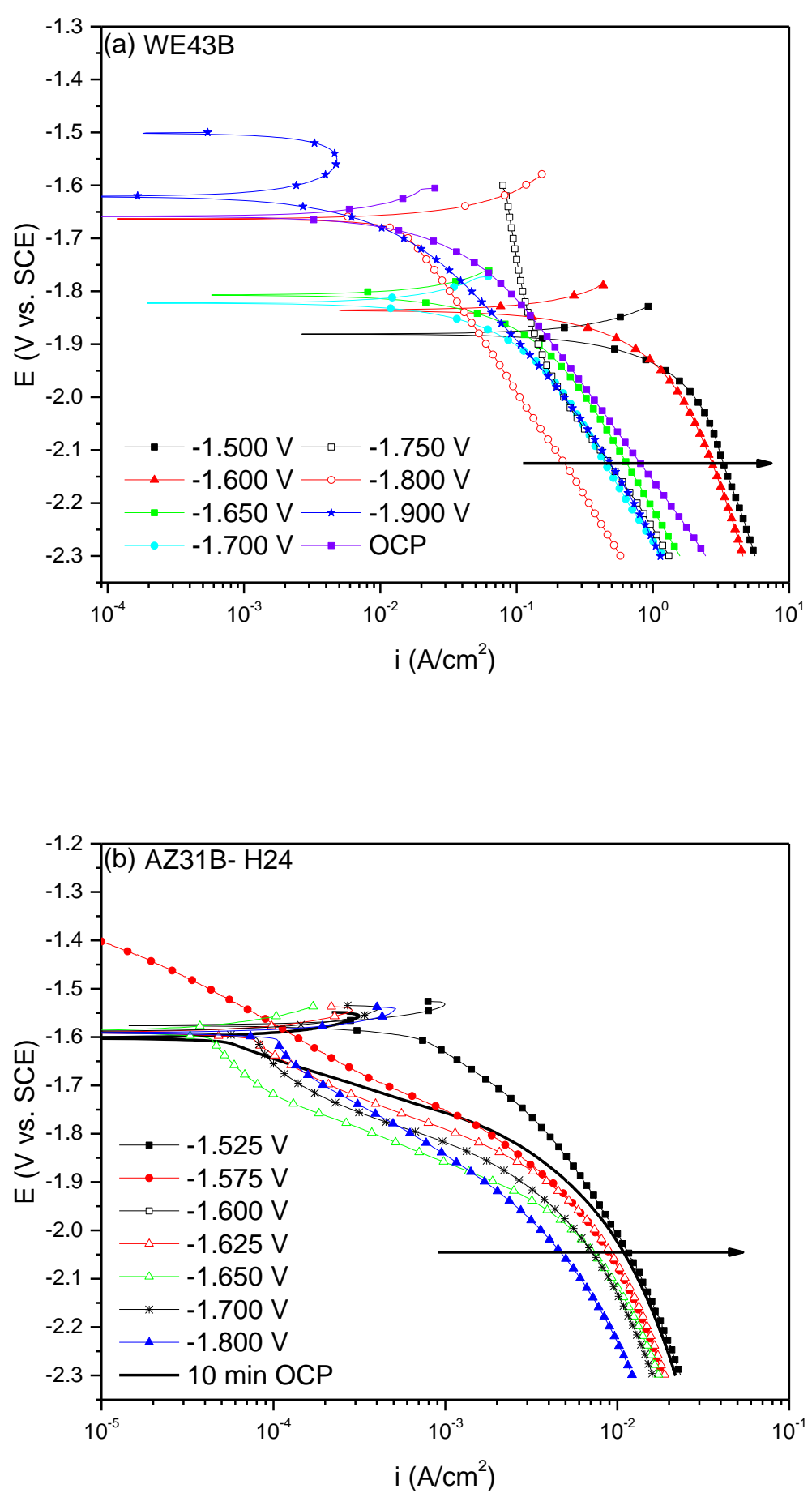

Figure 4.12. Cathodic potentiodynamic polarization curves performed after 24 hour potentiostatic polarization in $0.6 \mathrm{M} \mathrm{NaCl}$ at the indicated potentials. Scans were performed at 1 $\mathrm{mV} / \mathrm{s}$. 


\subsubsection{Effects of Polarity Reversal: Application to Laser Surface Modified AZ31B}

\section{Surfaces}

In this investigation, polarity reversal was not observed between AZ31B-H24 coupled to $\mathrm{CP} \mathrm{Mg}$ nor WE43B. This was initially a point of interest as polarity reversal has been shown between steel and $\mathrm{Zn}[23,24]$, steel and $\mathrm{Al}$ [25], and between different weld zones of tungsten inert gas (TIG) welded AZ31B-H24 [26,27]. However, Figure 4.5-4.6 revealed that the $\mathrm{E}_{\text {corr }}$ of both anode and cathode maintained the original net anode/cathode polarity. Thus, polarity reversal does not appear to be a concern given that the OCP's remain sufficiently different from each other. However, polarity reversal may be of concern if the OCP's are proximate to each other. This was shown for different TIG weld zones of AZ31B-H24 where the composition and OCP of each weld zone are similar [26,27]. In, this case, enrichment of $\mathrm{Al}$ and $\mathrm{Zn}$ in each weld zone as a function of corrosion was cited as a driving force for polarity reversal as well as the fraction corrosion coverage of each weld zone.

With this in mind, additional ZRA measurements were performed on AZ31B-H24 samples which underwent laser surface modification (LSM). LSM AZ31B-H24 was chosen because they possess an OCP more negative than that of base AZ31B-H24 which means they have practical implications for sacrificial anode based cathodic protection and the LSM surface layer possesses a similar composition to the base alloy [28]. Furthermore, LSM can reduce the cathodic kinetics of the modified layer by homogenization of the microstructure, reducing sites of preferential $\mathrm{H}_{2}$ evolution (i.e. cathodic particle density). Detailed characterization of LSM microstructure and electrochemical testing of LSM AZ31B-H24 has been shown elsewhere [28].

ZRA measurements of LSM AZ31B-H24 to base AZ31B-H24 are shown in Figure 4.13 where LSM AZ31B-H24 was chosen as the working electrode as the OCP of LSM AZ31B-H24 is 
$<-1.7 \mathrm{~V}_{\mathrm{SCE}}$ for up to $10,000 \mathrm{~s}$ depending on processing conditions. Figure 4.13 shows that polarity reversal indeed occurs in each solution tested in this investigation. In fact, polarity reversal can occur several times as indicated Figure 4.13a,b. The initial polarity reversal is likely a result of dissolution of the LSM layer which exposes the underlying, unaffected base AZ31B-H24. After this point, the polarity is governed by subtle differences in the surface composition and corrosion product coverage on each electrode.
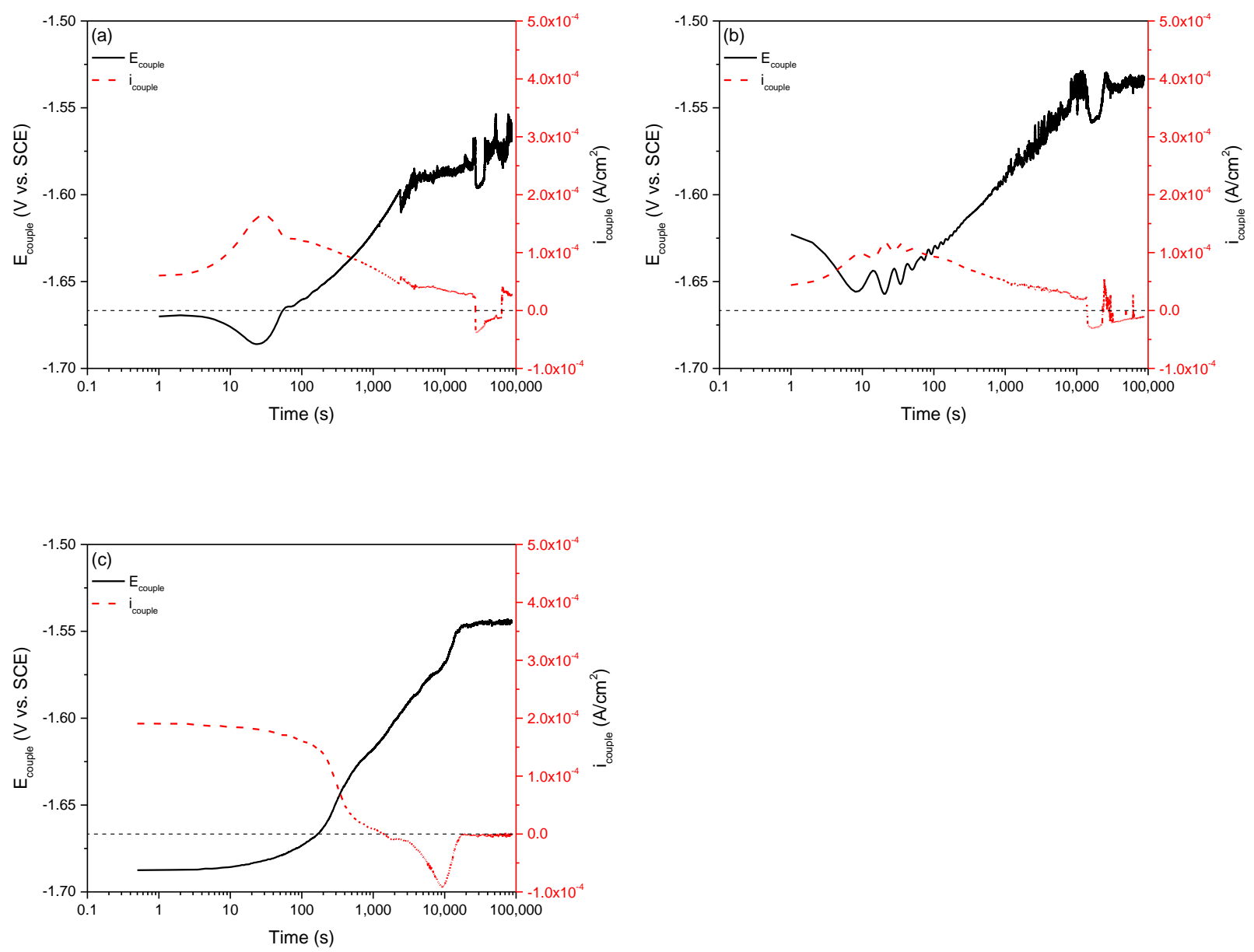

Figure 4.13. ZRA measurement of AZ31B LSM samples coupled to AZ31B base plate in (a) 0.6 $\mathrm{M} \mathrm{NaCl}$, (b) $0.1 \mathrm{MgCl}_{2}$, (c) $0.1 \mathrm{M}$ TRIS. 


\subsection{Conclusions}

- $\quad$ Partial sacrificial cathodic protection of Mg alloy AZ31B-H24 was shown to be possible based on zero resistance ammeter (ZRA) measurements with CP Mg and WE43B as anode materials in $0.6 \mathrm{M} \mathrm{NaCl}$ and $0.1 \mathrm{M} \mathrm{MgCl}_{2}$ while limited cathodic protection occurred in 0.1 M TRIS.

- $\quad$ The coupled corrosion rate of AZ31B-H24 decreased by about 2-3x compared that its corrosion rate at OCP for AZ31B-H24 coupled to CP Mg and decreased 2-12x for AZ31BH24 coupled to WE43B. However, greater decreases were expected based on the difference between corrosion potential (EоCP) of AZ31B-H24 and the galvanic couple potential, $\mathrm{E}_{\mathrm{g}}$. This discrepancy is attributed to the negative difference effect.

- $\quad$ The corrosion rate of coupled WE43B was much less than that of $\mathrm{CP} \mathrm{Mg}$ due to the larger difference in $\mathrm{E}_{\mathrm{OCP}}$ of $\mathrm{WE} 43 \mathrm{~B}$ and $\mathrm{E}_{\mathrm{g}}$. which makes it more favorable as a possible coating alloy. The self-corrosion fraction of coupled WE43B was also less than that of coupled CP $\mathrm{Mg}$ due to the larger difference between EOCP of WE43B and $\mathrm{E}_{\mathrm{g}}$.

- $\quad$ ZRA measurements did not show polarity reversal between couples of AZ31B-H24 to CP $\mathrm{Mg}$ and WE43B which is encouraging since such polarity reversal is not desired for a sacrificial anode based cathodic protection.

- $\quad$ Anodically induced cathodic activation was minimal on CP Mg and WE43B anodes as determined by potentiodynamic polarization scans performed after ZRA measurements. Anodes showed enhanced cathodic kinetics in the initial stages of ZRA testing but did not persist through the duration of the ZRA test. 
- $\quad$ ZRA measurements of LSM AZ31B-H24 coupled to base AZ31B-H24 showed polarity reversal after corroding through the anodic LSM layer which suggests LSM AZ31B-H24 can only provide cathodic protection when the LSM layer is present. 


\subsection{References}

[1] B. Lafuente, R.T. Downs, H. Yang, N. Stone, 2015 Power Databases RRUFF Proj. Highlights Mineral. Crystallogr. T Armbruster R M Danisi Eds Berl. Ger. W Gruyter Pp 1-30. n.d.

[2] T.B. Abbott, "Magnesium: Industrial and Research Developments Over the Last 15 Years," CORROSION. 71 (2) 120-127, 2015.

[3] M.O. Pekguleryuz, K.U. Kainer, A.A. Kaya, Fundamentals of Magnesium Alloy Metallurgy, Woodhead Publishing, 2013.

[4] D.A. Jones, Principles and Prevention of Corrosion, Pearson-Prentice Hall, 2005.

[5] G.L. Makar, J. Kruger, "Corrosion of magnesium," Int. Mater. Rev. 38 (3) 138-153, 1993.

[6] F. Mansfeld, "The Relationship Between Galvanic Current and Dissolution Rates," Corrosion. 29 (10) 403-405, 1973.

[7] F. Mansfeld, “Area Relationships in Galvanic Corrosion," Corrosion. 27 (10) 436-442, 1971.

[8] D.R. Banjade, S.D. Porter, B.M. McMullan, J.N. Harb, "Hydrogen Evolution during the Corrosion of Galvanically Coupled Magnesium," J. Electrochem. Soc. 163 (3) C116-C123, 2016.

[9] S. Trasatti, "Work function, electronegativity, and electrochemical behaviour of metals," J. Electroanal. Chem. Interfacial Electrochem. 39 (1) 163-184, 1972.

[10] N. Birbilis, G. Williams, K. Gusieva, A. Samaniego, M.A. Gibson, H.N. McMurray, "Poisoning the corrosion of magnesium," Electrochem. Commun. 34 295-298, 2013.

[11] M. Curioni, F. Scenini, T. Monetta, F. Bellucci, "Correlation between electrochemical impedance measurements and corrosion rate of magnesium investigated by real-time hydrogen measurement and optical imaging," Electrochimica Acta. 166 372-384, 2015.

[12] N. Birbilis, A.D. King, S. Thomas, G.S. Frankel, J.R. Scully, "Evidence for enhanced catalytic activity of magnesium arising from anodic dissolution," Electrochimica Acta. 132 277-283, 2014.

[13] S. Fajardo, G.S. Frankel, "Effect of impurities on the enhanced catalytic activity for hydrogen evolution in high purity magnesium," Electrochimica Acta. 165 255-267, 2015.

[14] M. Taheri, J.R. Kish, N. Birbilis, M. Danaie, E.A. McNally, J.R. McDermid, "Towards a Physical Description for the Origin of Enhanced Catalytic Activity of Corroding Magnesium Surfaces," Electrochimica Acta. 116 396-403, 2014.

[15] Z.P. Cano, J.R. McDermid, J.R. Kish, "Cathodic activity of corrosion filaments formed on Mg alloy AM30," J. Electrochem. Soc. 162 (14) C732-C740, 2015.

[16] Z.P. Cano, J.R. Kish, J.R. McDermid, "On the evolution of cathodic activity during corrosion of magnesium alloy AZ31B in a dilute $\mathrm{NaCl}$ solution," J. Electrochem. Soc. 163 (3) C62C68, 2016.

[17] G. Williams, N. Birbilis, H.N. McMurray, "The source of hydrogen evolved from a magnesium anode," Electrochem. Commun. 36 1-5, 2013.

[18] G. Williams, N. Birbilis, H.N. McMurray, "Controlling factors in localised corrosion morphologies observed for magnesium immersed in chloride containing electrolyte," Faraday Discuss. 180 313-330, 2015.

[19] S.H. Salleh, S. Thomas, J.A. Yuwono, K. Venkatesan, N. Birbilis, "Enhanced hydrogen evolution on $\mathrm{Mg}(\mathrm{OH}) 2$ covered Mg surfaces," Electrochimica Acta. 161 144-152, 2015.

[20] N. Birbilis, T. Cain, J.S. Laird, X. Xia, J.R. Scully, A.E. Hughes, "Nuclear microprobe analysis for determination of element enrichment following magnesium dissolution," ECS Electrochem. Lett. 4 (10) C34-C37, 2015. 
[21] L. Rossrucker, A. Samaniego, J.-P. Grote, A.M. Mingers, C.A. Laska, N. Birbilis, G.S. Frankel, K.J.J. Mayrhofer, "The $\mathrm{pH}$ dependence of magnesium dissolution and hydrogen evolution during anodic polarization," J. Electrochem. Soc. 162 (7) C333-C339, 2015.

[22] Y. Yang, F. Scenini, M. Curioni, "A study on magnesium corrosion by real-time imaging and electrochemical methods: relationship between local processes and hydrogen evolution," Electrochimica Acta. 198 174-184, 2016.

[23] G. Schikorr, "The cathodic behavior of zinc versus iron in hot tap water," Trans Electrochem Soc. 76 (1) 247-258, 1939.

[24] P. Gilbert, "An investigation into the corrosion of zinc and zinc-coated steel in hot waters," Sheet Met. Ind. 10 2003-2012, 1948.

[25] D.R. Gabe, A.M.E. Hassan, "Potential reversals for aluminium alloy-mild steel galvanic couples in simulated natural waters," Br. Corros. J. 21 (3) 185-190, 1986.

[26] L.G. Bland, B.C. Rincon Troconis, R.J. Santucci Jr., J.M. Fitz-Gerald, J.R. Scully, "Metallurgical and Electrochemical Characterization of the Corrosion of a Mg-Al-Zn Alloy AZ31B-H24 Tungsten Inert Gas Weld: Galvanic Corrosion Between Weld Zones," CORROSION. 72 (10) 1226-1242, 2016.

[27] L.G. Bland, J.M. Fitz-Gerald, J.R. Scully, "Metallurgical and Electrochemical Characterization of the Corrosion of AZ31B-H24 Tungsten Inert Gas Weld: Isolated Weld Zones," CORROSION. 72 (9) 1116-1132, 2016.

[28] M. Melia, P. Steiner, N. Birbilis, J. Fitz-Gerald, J. Scully, "Excimer Laser Surface Modification of AZ31B-H24 for Improved Corrosion Resistance," Corrosion. 72 (1) 95-109, 2015. 


\subsection{Appendix- List of Symbols Used for Galvanic Couples}

\section{$\underline{\text { List of Symbols }}$}

$\mathrm{I}_{\mathrm{T}}^{\mathrm{A}} \quad$ Total current of the anode

$\mathrm{I}_{\mathrm{d}}^{\mathrm{A}} \quad$ Anodic dissolution current of the anode

I $\mathrm{AER}$ Cathodic hydrogen evolution reaction rate of the anode

$\mathrm{I}_{\mathrm{T}}^{\mathrm{C}} \quad$ Total current of the cathode

$\mathrm{I}_{\mathrm{d}}^{\mathrm{C}} \quad$ Anodic dissolution current of the cathode

$\mathrm{I}_{\text {HER }}^{\mathrm{C}}$ Cathodic hydrogen evolution reaction rate of the cathode

$\mathrm{I}_{\mathrm{g}}^{\mathrm{A}}$ Anodic dissolution current of the anode when galvanically coupled

$\mathrm{I}_{\mathrm{g}}^{\mathrm{C}} \quad$ Anodic dissolution current of the cathode when galvanically coupled

$\mathrm{I}_{\mathrm{g}}^{\mathrm{ZRA}}$ The galvanic couple current/ current measured in a ZRA test

$\mathrm{E}_{\mathrm{g}} \quad$ The galvanic couple potential

$\mathrm{E}_{\text {corr }}^{\mathrm{A}}$ The open circuit potential of the uncoupled anode

$\mathrm{E}_{\text {corr }}^{\mathrm{C}}$ The open circuit potential of the uncoupled cathode

\section{$\underline{\text { Relations }}$}

$\mathrm{I}_{\mathrm{T}}^{\mathrm{A}}=\mathrm{I}_{\mathrm{d}}^{\mathrm{A}}+\mathrm{I}_{\mathrm{HER}}^{\mathrm{A}}$

$\mathrm{I}_{\mathrm{T}}^{\mathrm{C}}=\mathrm{I}_{\mathrm{d}}^{\mathrm{C}}+\mathrm{I}_{\mathrm{HER}}^{\mathrm{C}}$

$\mathrm{I}_{\mathrm{g}}^{\mathrm{ZRA}}$ is when $\mathrm{I}_{\mathrm{d}}^{\mathrm{A}}+\mathrm{I}_{\mathrm{d}}^{\mathrm{C}}=-\left(\mathrm{I}_{\mathrm{HER}}^{\mathrm{A}}+\mathrm{I}_{\mathrm{HER}}^{\mathrm{C}}\right)$

$\mathrm{E}_{\mathrm{g}}$ occurs atI $\mathrm{ZRA}$ 


\section{Evaluation of Rare Earth Ions for the Inhibition of AZ31B in Chloride}

\section{Environments}

\subsection{Introduction}

This chapter seeks to evaluate the ability of $\mathrm{La}^{3+}$ and $\mathrm{Gd}^{3+}$ ions to inhibit corrosion of AZ31B-H24 in the presence of $\mathrm{Cl}^{-}$as a function of anodic dissolution and enhanced cathodic kinetics. Rare earth elements are of interest for use as environmentally friendly, chromate free inhibitors for corrosion [1]. Compared to $\mathrm{Mg}, \mathrm{La}$ and $\mathrm{Gd}$ offer an extended $\mathrm{pH}$ range of stability with their respective hydroxides being thermodynamically stable at more acidic $\mathrm{pH}$ than $\mathrm{Mg}(\mathrm{OH})_{2}$ as shown in Error! Reference source not found.. These two ions were chosen for study based on t he elements possessing an $\mathrm{OCP}$ more negative than that of $\mathrm{Mg}$ during to exposure to $0.1 \mathrm{M} \mathrm{NaCl}$ [2] which presents the possibility that they may have the ability to decrease the OCP of Mg which is required for sacrificial galvanic based cathodic protection.

Knowledge of $\mathrm{RE}$ ion inhibition is relevant to this dissertation with respect to providing a secondary means of protection via ionic inhibitor release from a metallic sacrificial coating or a pigment. Targeted and controlled inhibitor ion release from a coating could lead to the self-healing of scratches or other defects in the coating by formation of a passive film on the cathode surface as has been demonstrated for amorphous Al-Co-Ce sacrificial alloys tuned for AA20224 [3-5]. The prospect of creating a similar inhibiting coating for Mg-based alloys containing these elements whether it is an amorphous coating or a crystalline solid solution has not been realized. An amorphous $\mathrm{Mg}-\mathrm{Y}-\mathrm{Mm}$ has been defined where $\mathrm{Mm}$ is mischmetal containing various rare earth elements but the corrosion behavior of this system as well as the individual contribution of individual RE elements to the corrosion behavior has not been explored [6]. Thus, investigating the inhibiting ability of these elements will help screen whether or not they should be included in 
a sacrificial Mg alloy. With respect to Mg alloys, little work has been done on deciphering whether or not $\mathrm{RE}$ ions in the presence of $\mathrm{Cl}^{-}$will form any passivating films during corrosion. However, $\mathrm{RE}$ conversion coatings in non- $\mathrm{Cl}^{-}$containing electrolytes such as rare earth nitrates have been shown to form successfully on $\mathrm{Mg}$ alloy surfaces [7-12]. However, these RE conversion coatings offer little long-term protection when exposed to $\mathrm{Cl}^{-}$containing environments.

(a)

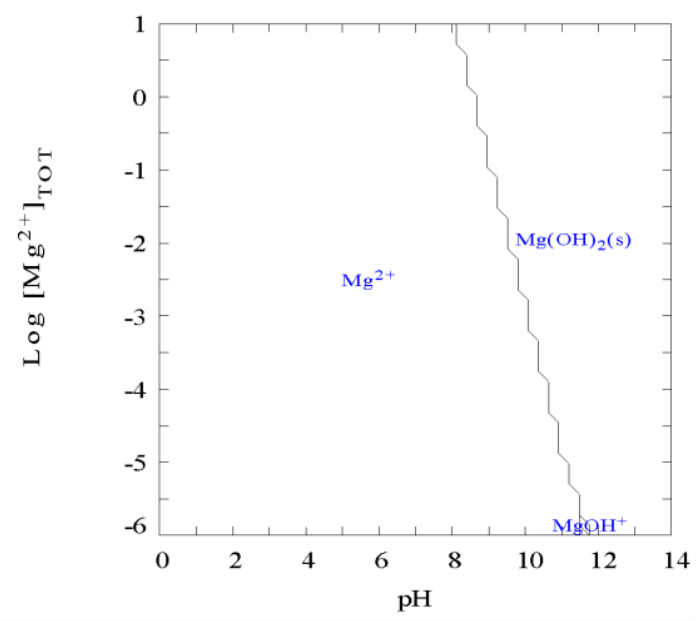

(c)

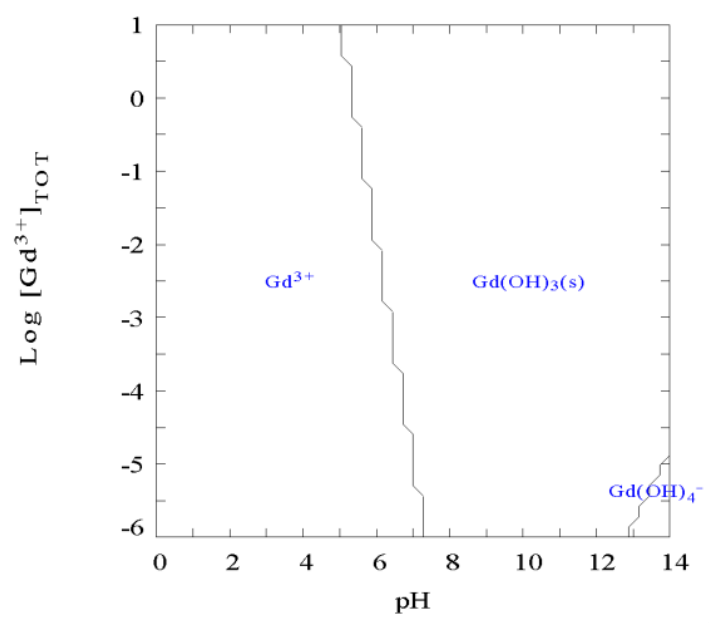

(b)

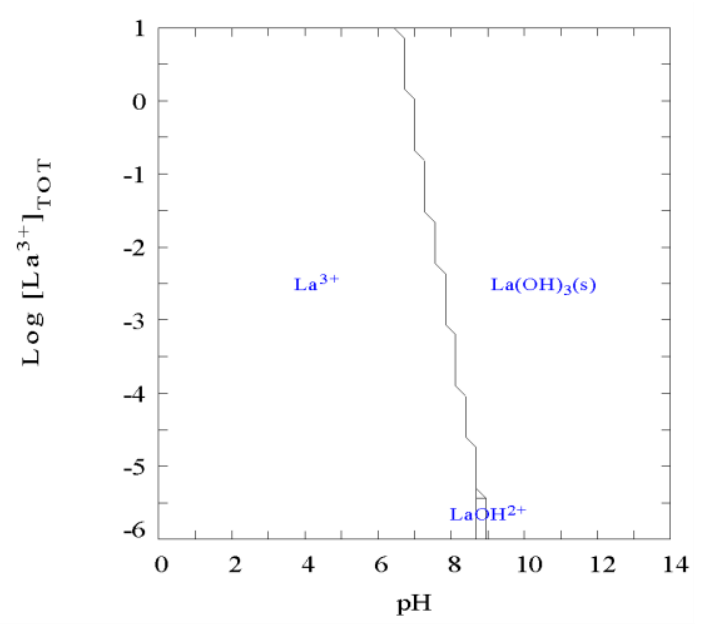

Figure 5.1. Predominance area diagrams for (a) $\mathrm{Mg}$, (b) La, and (c) Gd systems. These were calculated using the MEDUSA software package. 
This chapter will study the effect of varying $\mathrm{La}^{3+}$ or $\mathrm{Gd}^{3+}$ ion concentration on the corrosion behavior of AZ31B-H24 in $\mathrm{NaCl}$. To perform this, the total concentration of $\mathrm{Cl}^{-}$was fixed to 0.6 $\mathrm{M}$ and the concentration of inhibiting ion was varied between $10^{-4} \mathrm{M}$ to $10^{-1} \mathrm{M}$ using either $\mathrm{LaCl}_{3}$ or $\mathrm{GdCl}_{3}$ in addition to when no $\mathrm{NaCl}$ was present (i.e. $0.2 \mathrm{M} \mathrm{LaCl}_{3}$ or $\mathrm{GdCl}_{3}$ ). The corrosion rate of AZ31B-H24 was measured via gravimetric mass loss measurements after 24 hours immersion. In addition, the anodic and cathodic potentiodynamic polarization was used to determine the effects of inhibitor anodic and cathodic processes as a function of immersion time. The enhanced cathodic kinetics of AZ31B-H24 after a period of corrosion with and without inhibitors was evaluated utilizing a cycle of anodic and cathodic pulses. Anodic galvanostatic polarization was performed at varying applied current densities while cathodic potentiostatic polarization was performed after each anodic pulse to track the changes in cathodic kinetics with dissolution. Finally, the ability of $\mathrm{La}^{3+}$ and $\mathrm{Gd}^{3+}$ ion to inhibit corrosion at varying degrees of anodic polarization was investigated with electrochemical impedance spectroscopy (EIS).

\subsection{Experimental Procedures}

\subsubsection{Materials}

AZ31B-H24 was used in all investigations in this dissertation as supplied by Magnesium Elektron (Table 2.1). AZ31B-H24 sheets were sheared into squares approximately $2 \mathrm{~cm} \times 2 \mathrm{~cm}$ for electrochemical testing. All samples for electrochemical testing were mechanically ground to a 1200 grit $\mathrm{SiC}$ finish using ethanol $\left(\mathrm{C}_{2} \mathrm{H}_{6} \mathrm{O}\right)$ as lubricant. Sample surfaces were cleaned with ethanol and dried using compressed air after each grinding step. 


\subsubsection{Electrochemical Testing}

Various electrochemical testing methods were used to evaluate inhibiting ability of $\mathrm{La}^{3+}$ and $\mathrm{Gd}^{3+}$ for their ability to inhibit corrosion of $\mathrm{AZ31B}-\mathrm{H} 24$ in $\mathrm{Cl}^{-}$environments. In this study, the total concentration of $\mathrm{Cl}^{-}$was kept constant at $0.6 \mathrm{M} \mathrm{Cl}^{-}$and the concentration $\mathrm{RE}^{3+}$ in solution was varied using $\mathrm{LaCl}_{3}$ and $\mathrm{GdCl}_{3}$ substitutions with $\mathrm{NaCl}$. The total $\mathrm{RE}^{3+}$ concentration was varied between $10^{-4} \mathrm{M}$ and $0.2 \mathrm{M}$.

AZ31B-H24 samples were placed in a 3 electrode vertical flat cell using a platinum counter electrode and saturated calomel reference electrode. This setup allowed for $1 \mathrm{~cm}^{2}$ surface to be exposed to $250 \mathrm{~mL}$ of solution. Samples were allowed to freely corrode at OCP for 24 hours and were cleaned with $\mathrm{CrO}_{3}$ after testing for gravimetric mass loss measurements. Gravimetric mass loss from for each sample with $\pm 0.01 \mathrm{mg}$ resolution was converted to consumed anodic charge density $\left(\mathrm{Q}_{\Delta \mathrm{m}}\right)$ via Equation 5.1:

$$
Q_{\Delta m}=\frac{z n F}{A}=\frac{z \Delta m F}{A a}
$$

Equation 5.1

where $\mathrm{z}$ is the equivalent electrons per mole of $\mathrm{Mg}$ oxidized, $\Delta \mathrm{m}$ is the change in mass, $\mathrm{F}$ is Faraday's constant, $\mathrm{A}$ is the electrode area, and a is the molar mass of $\mathrm{Mg}$. In this study, $\mathrm{z}$ is assumed to be 2 equivalent $\mathrm{e}^{-} /$mole following the half-cell reaction $\mathrm{Mg} \rightarrow \mathrm{Mg}^{2+}+2 \mathrm{e}^{-}$. Congruent dissolution was assumed for AZ31B-H24 which alters Equation 5.1 to:

$$
Q_{\Delta m}=\frac{N_{e q} \times \Delta m \times F}{A}
$$

where $N_{e q}$ is the weighted average equivalent number of electrons per molar mass of the $i_{t h}$ element being dissolved or the reciprocal of the equivalent weight (EW) with units of g/eq: 


$$
N_{e q}=\sum \frac{f_{i} \times z_{i}}{a_{i}}
$$

$\mathrm{Al}^{3+}, \mathrm{Mg}^{2+}, \mathrm{Mn}^{2+}$, and $\mathrm{Zn}^{2+}$ are assumed to be dissolving for $\mathrm{AZ31B}$ in this equation where $f$ is the mass fraction of each element yielding a value of $N_{e q}=0.0787$ or EW $=12.71 \mathrm{~g} / \mathrm{eq}$. Hydrogen capture was not preformed due to precipitate formation in the burette. In additional tests, anodic potentiodynamic polarization was performed after 24 hours immersion at OCP with scans being measured from OCP to $+0.5 \mathrm{~V}$ above OCP at a scan rate of $1 \mathrm{mV} / \mathrm{s}$ after each OCP while cathodic potentiodynamic polarization was performed from OCP to $-3 \mathrm{~V}_{\mathrm{SCE}}$ at a scan rate of 2,500 $\mathrm{mV} / \mathrm{s}$. The $\mathrm{pH}$ was measured before and after 24 hour immersion testing.

To provide insight on the enhanced cathodic kinetics of AZ31B-H24 in each solution, a cycle of alternating anodic galvanostatic pulses followed by cathodic potentiostatic polarization in $0.6 \mathrm{M} \mathrm{NaCl}$. The anodic pulses were performed for 2 minutes at increasing anodic current densities from $0.5 \mathrm{~mA} / \mathrm{cm}^{2}, 1 \mathrm{~mA} / \mathrm{cm}^{2}, 5 \mathrm{~mA} / \mathrm{cm}^{2}, 10 \mathrm{~mA} / \mathrm{cm}^{2}$, and $20 \mathrm{~mA} / \mathrm{cm}^{2}$ while potentiostatic polarization was performed for one minute at $-2 \mathrm{~V}_{\mathrm{SCE}}$. This potential was deemed far enough away from OCP for evaluation of the predominantly true cathodic kinetics without the complicating effects of the anodic reaction. Anodic galvanostatic pulses were used to ensure the same anodic charge was obtained on each alloy.

To test the ability of RE ions in solution to inhibit corrosion at varying degrees of dissolution, anodic galvanostatic polarization was performed for 24 hours at applied current densities of $0.1 \mathrm{~mA} / \mathrm{cm}^{2}, 1 \mathrm{~mA} / \mathrm{cm}^{2}$, and $10 \mathrm{~mA} / \mathrm{cm}^{2}$ and were allowed to stabilize at OCP for 10 minutes prior to electrochemical impedance spectroscopy (EIS). EIS measurements were performed over a frequency of $10^{5} \mathrm{~Hz}$ to $0.005 \mathrm{~Hz}$ at 6 points per decade with an amplitude of \pm $10 \mathrm{mV}$. EIS spectra were analyzed and fit utilizing the ZView software and the equivalent circuit in Figure 5.2 which has been shown to most accurately calculate Mg corrosion rates [13,14]. In 
this circuit, $R_{S}$ is the solution resistance of the test environment and $R_{1}, R_{2}$, and $R_{3}$ represent the resistances of the anodic and cathodic reactions on the surface as well as the resistances of the oxides/hydroxides which form on the surface during corrosion. The capacitor $\mathrm{C}_{1}$ represents the charge separation at the sample surface of the oxide/hydroxide while $\mathrm{C}_{2}$ represents the double layer capacitance. Finally, the inductor, L, represents the relaxation of the coverage of adsorbed intermediates in corroding areas of the $\mathrm{Mg}$ surface where a dark corrosion product is often observed to appear. $\mathrm{R}_{\mathrm{p}}$ was calculated following Equation 5.4 derived from this circuit:

$$
\frac{1}{R_{p}}=\frac{1}{R_{1}+R_{2}}+\frac{1}{R_{3}}
$$

Here, large values of $\mathrm{R}_{\mathrm{p}}$ are indicative of a low corrosion current as $i \propto \frac{1}{R_{p}}$ according to the SternGeary relationship [13]. In addition, cathodic potentiodynamic polarization was completed after 24 hours immersion from OCP to $-3 \mathrm{~V}_{\mathrm{SCE}}$ at a scan rate of $2,500 \mathrm{mV} / \mathrm{s}$ and compared to scans performed after $10 \mathrm{~min}$ at OCP. Such a high scan rate was used to minimize changes in the surface condition after testing. In situ optical microscopy was performed to study changes in the surface of each alloy as a function of time to correlate with changes in $\mathrm{R}_{\mathrm{p}}$. The $\mathrm{pH}$ was measured before and after testing.

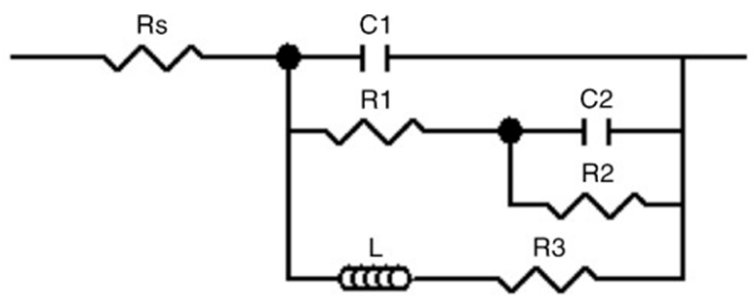

Figure 5.2. Equivalent circuit used to fit EIS spectra in this investigation 


\subsubsection{Raman Spectroscopy of Mg Surfaces}

Raman Spectroscopy was performed on sample surfaces after completion of OCP-EIS testing and ZRA testing with corrosion products intact using an i-Raman ${ }^{\circledR}$ high resolution spectrometer. Scans were performed from 150 to $4000 \mathrm{~cm}^{-1}$ utilizing a $532.06 \mathrm{~nm}$ diode laser at $100 \%$ power. Scans were accumulated using an integration time of 125 seconds. Peak identification was performed using standard samples in the RRUFFTM project database [15].

\subsection{Results}

\subsubsection{Potentiodynamic Polarization of AZ31B-H24}

The typical OCP vs. time behavior for AZ31B-H24 immersed in varying concentrations of $\mathrm{La}^{3+}$ and $\mathrm{Gd}^{3+}$ at a fixed total chloride concentration of $0.6 \mathrm{M}$ for 24 hours is shown in Figure 5.3. For $\mathrm{La}^{3+}$, there was a breakdown potential identified where the potentials dropped sharply at about $-1.6 \mathrm{~V}^{\mathrm{SCE}}$ for $\left[\mathrm{La}^{3+}\right] \leq 10^{-2} \mathrm{M}$ between $100-300$ seconds which is similar to that typically observed in $0.6 \mathrm{M} \mathrm{NaCl}$. The potential was then stable before increasing to a stable value between -1.56 $\mathrm{V}_{\mathrm{SCE}}$ and $-1.58 \mathrm{~V}_{\mathrm{SCE}}$. This increase in potential shift occurred at shorter times with increasing $\left[\mathrm{La}^{3+}\right]$ for $\left[\mathrm{La}^{3+}\right] \leq 10^{-2} \mathrm{M}$. In contrast, the potential vs. time for $\left[\mathrm{La}^{3+}\right] \geq 10^{-1} \mathrm{M}$ continuously increased before stabilizing at approximately $-1.56 \mathrm{~V}_{\mathrm{SCE}}$ after immersion for about 2,000 seconds. The potential vs time behavior as a function of $\left[\mathrm{Gd}^{3+}\right]$ was nearly identical to the trends observed with varying $\left[\mathrm{La}^{3+}\right]$, Figure 5.3b.

The similarity in corrosion behavior between $\left[\mathrm{La}^{3+}\right]$ and $\left[\mathrm{Gd}^{3+}\right]$ is also evident in the anodic potentiodynamic polarization curves shown in the E vs. log i plots in Figure 5.4. Here, the anodic kinetics are observed to increase with increasing $\left[\mathrm{La}^{3+}\right]$ or $\left[\mathrm{Gd}^{3+}\right]$ both after 10 minutes and after 24 hours immersion. In addition, AZ31B-H24 does not develop a passive current density with 
increasing immersion time and increasing $\left[\mathrm{La}^{3+}\right]$ or $\left[\mathrm{Gd}^{3+}\right]$ which indicates that a passive film does not form in the presence of $\mathrm{La}^{3+}$ or $\mathrm{Gd}^{3+}$ at the concentrations tested. Furthermore, the anodic measured kinetics were faster than that measured in $0.6 \mathrm{M} \mathrm{NaCl}$ with exception to $\left.10^{-4} \mathrm{M}^{\left[\mathrm{La}^{3+}\right.}\right]$ or $\left[\mathrm{Gd}^{3+}\right]$. The measured E vs. $\log \mathrm{i}$ behavior for $10^{-4} \mathrm{M}\left[\mathrm{La}^{3+}\right]$ and $\left[\mathrm{Gd}^{3+}\right]$ was similar to that of $0.6 \mathrm{M} \mathrm{NaCl}$ after 10 minute immersion and revealed an increase the anodic slope of AZ31B-H24 relative to higher concentrations of $\mathrm{La}^{3+}$ and $\mathrm{Gd}^{3+}$ approximately $+150 \mathrm{mV}$ above OCP ${ }^{8}$. This slope decreased with increasing concentration of $\mathrm{La}^{3+}$ and $\mathrm{Gd}^{3+}$ which indicates faster anodic dissolution kinetics. In addition, the cathodic potentiodynamic polarization scans in Figure 5.5 showed that the cathodic kinetics increased with increasing concentrations of $\mathrm{La}^{3+}$ and $\mathrm{Gd}^{3+}$ and the cathodic kinetics of $\mathrm{La}^{3+}$ and $\mathrm{Gd}^{3+}$ containing solution were faster on AZ31B-H24 than that measured in $0.6 \mathrm{M} \mathrm{NaCl}$ after both 10 minutes and 24 hours immersion.

\footnotetext{
${ }^{8}$ Note that at applied current densities above approximately $10^{-3} \mathrm{~A} / \mathrm{cm}^{2}$, the ohmic resistance contribution to the measured E vs log i behavior due to IR drop in solution becomes large and dominates the measured potential. Thus, trends in the data should be made below this current density.
} 
(a)

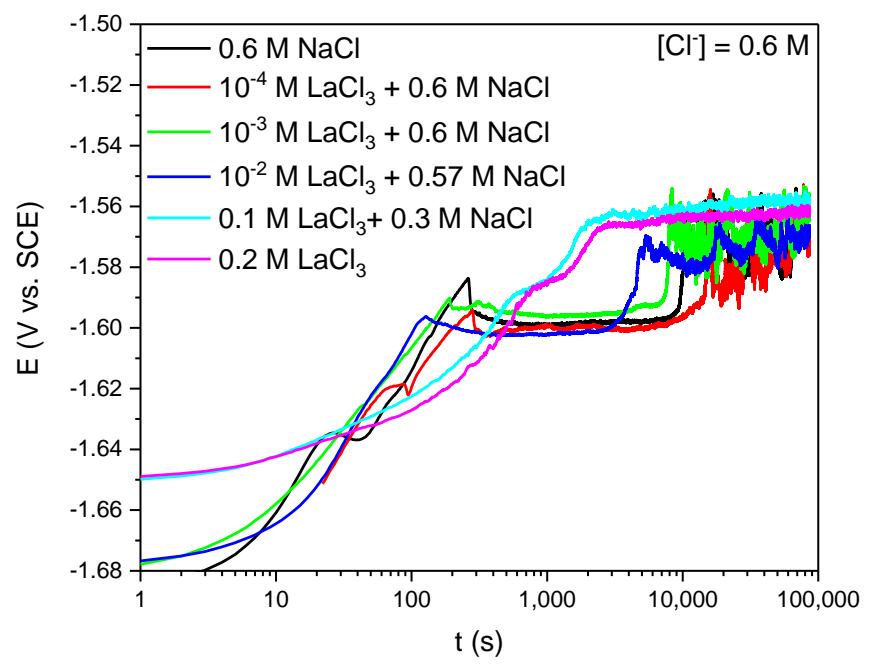

(b)

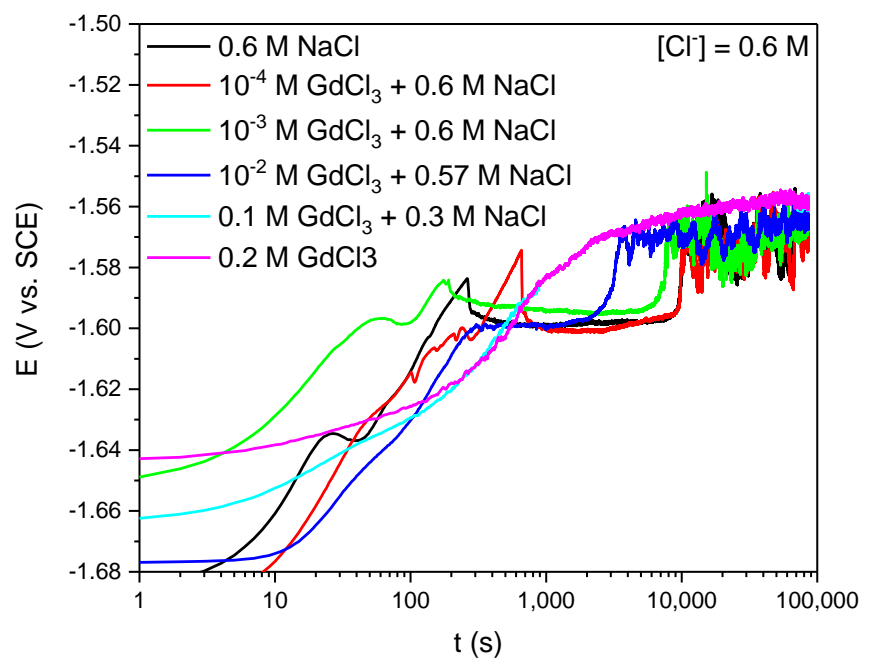

Figure 5.3. OCP vs. time behavior of AZ31B-H24 immersed in (a) $\mathrm{LaCl}_{3}$ and (b) $\mathrm{GdCl}_{3}$ for 24 hours. 
(a)

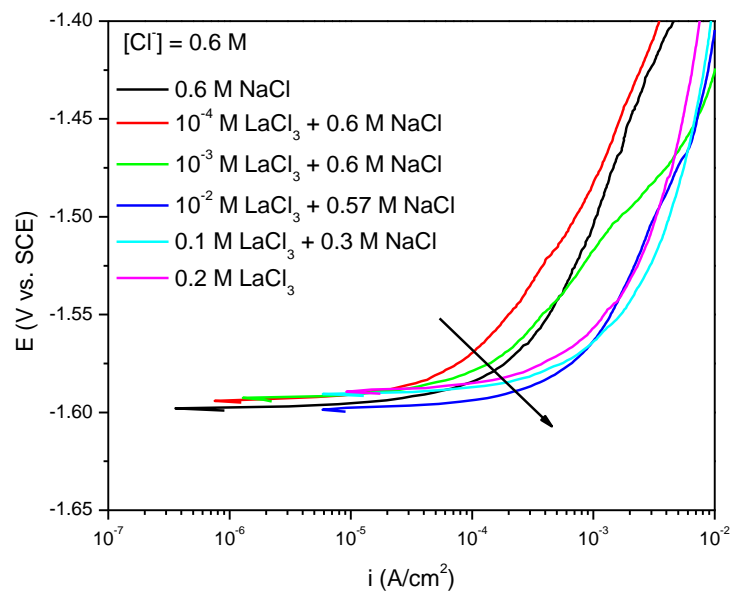

(c)

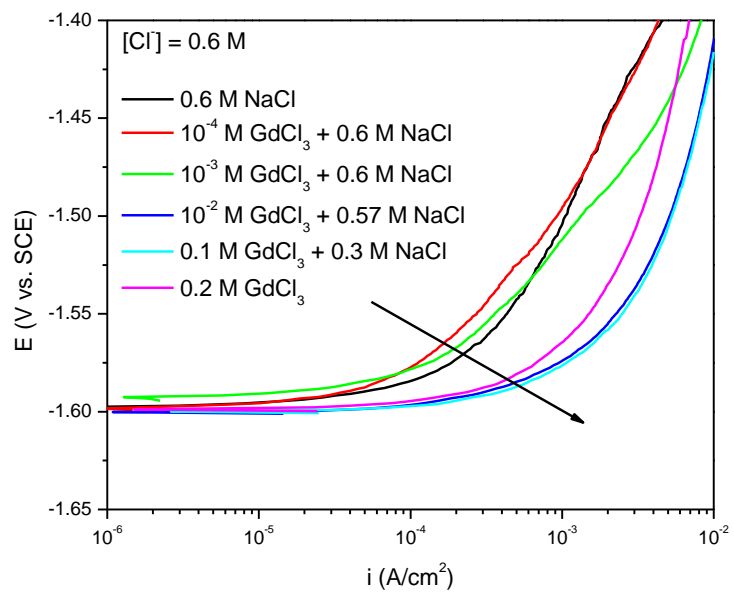

(b)

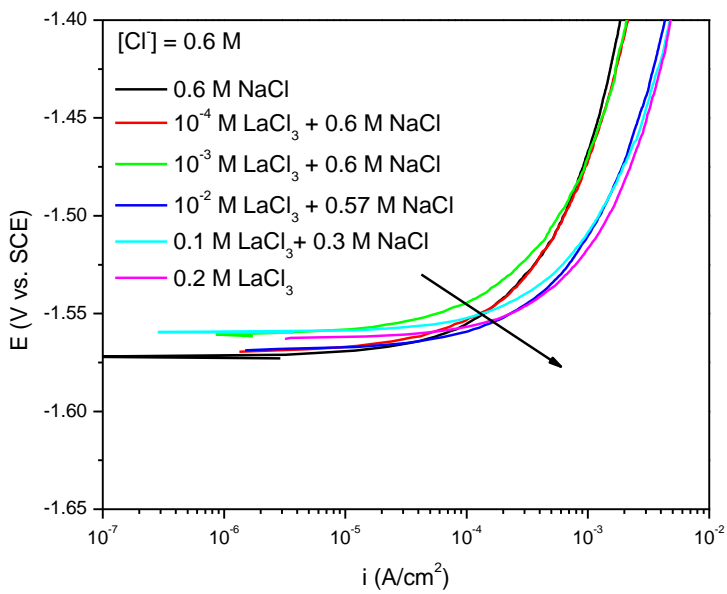

(d)

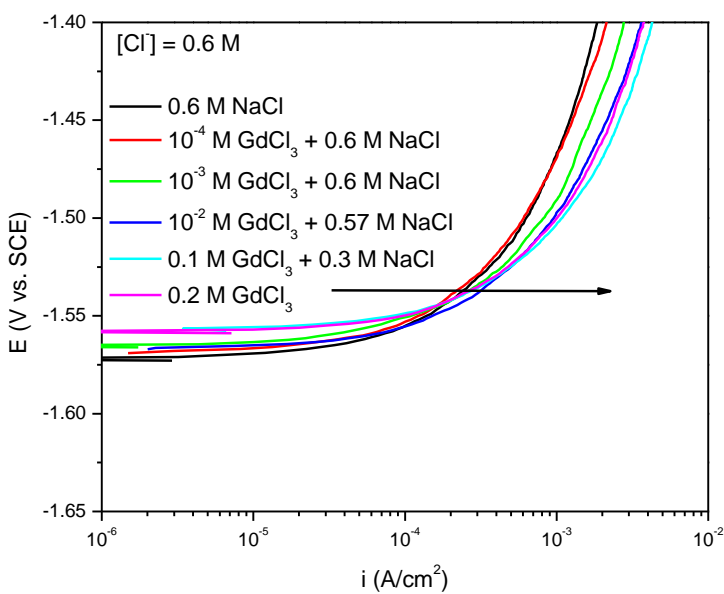

Figure 5.4. E vs. log i plots for IR-corrected anodic polarization of AZ31B-H24 after immersion in varying concentrations of $\mathrm{La}^{3+}$ for (a) 10 minutes and (b) 24 hours; (c) and (d) display the respective behavior in varying concentrations of $\mathrm{Gd}^{3+}$ after 10 minutes and 24 hours respectively. The scan rate was $1 \mathrm{mV} / \mathrm{s}$. 
(a)

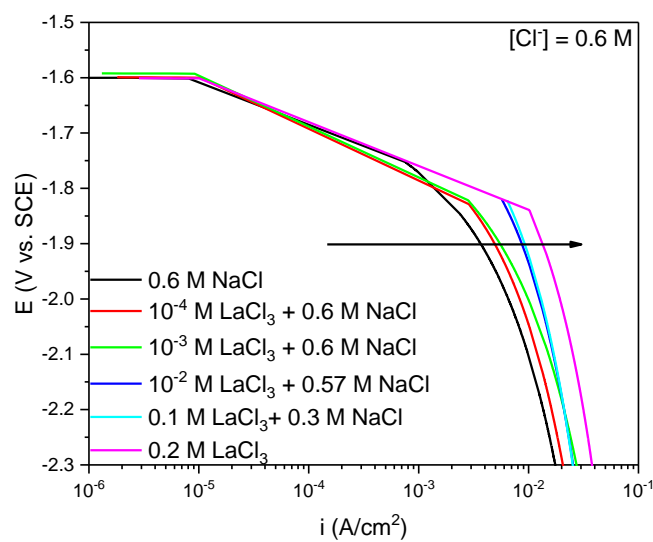

(c)

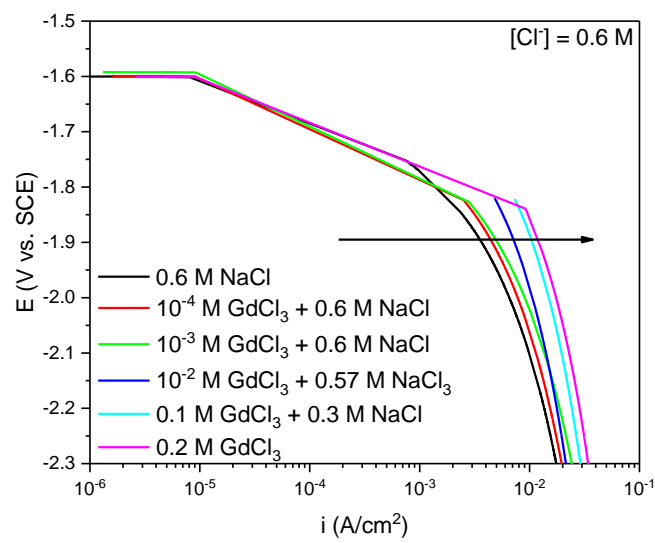

(b)

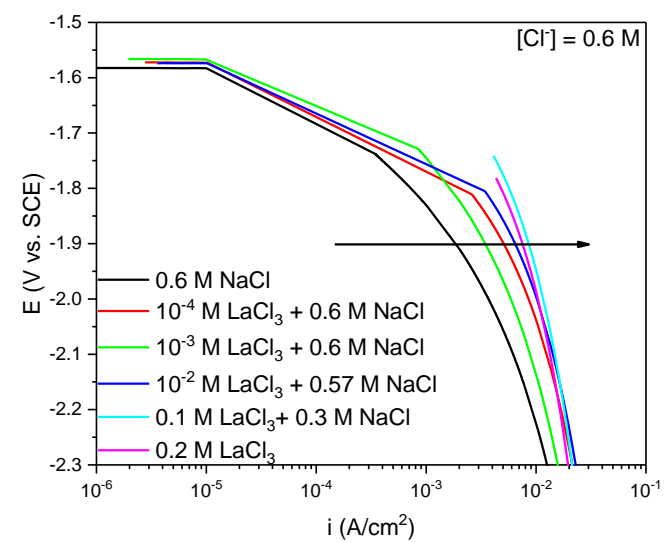

(d)

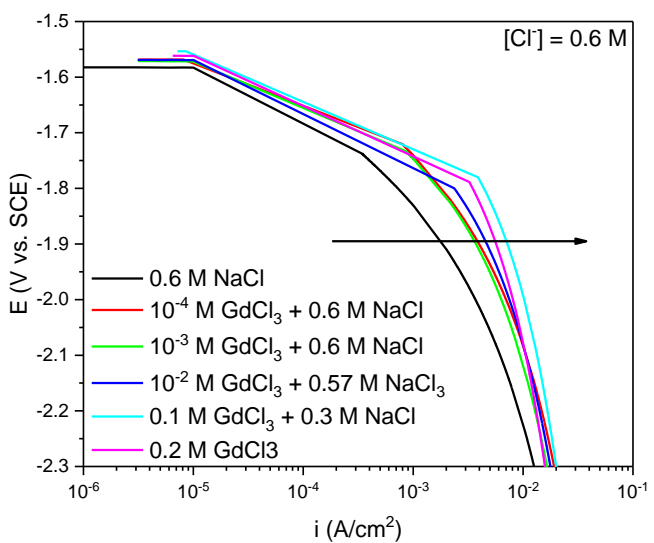

Figure 5.5. E vs. log i plots for cathodic polarization of AZ31B-H24 after immersion in varying concentrations of $\mathrm{La}^{3+}$ for (a) 10 minutes and (b) 24 hours; (c) and (d) display the respective behavior in varying concentrations of $\mathrm{Gd}^{3+}$ after 10 minutes and 24 hours respectively. The scan rate was $2,500 \mathrm{mV} / \mathrm{s}$. 


\subsubsection{Gravimetric Mass Loss Measurements as a Function of $\mathbf{R E}^{3+}$ Concentration}

The net anodic charge calculated from gravimetric mass loss after 24 hours immersion as a function of $\left[\mathrm{La}^{3+}\right]$ or $\left[\mathrm{Gd}^{3+}\right]$ is shown in Figure 5.6. For both electrolytes, the mass loss of AZ31B$\mathrm{H} 24$ increased with increasing $\mathrm{La}^{3+}$ or $\mathrm{Gd}^{3+}$. However, the mass loss measured for $10^{-4} \mathrm{M}$ and $10^{-}$ ${ }^{3} \mathrm{M} \mathrm{La}^{3+}$ or $\mathrm{Gd}^{3+}$ were similar in value to each other at about $13 \mathrm{C} / \mathrm{cm}^{2}$ which was nearly half the measured mass loss of AZ31B-H24 in $0.6 \mathrm{M} \mathrm{NaCl}$. Optical macro images of the typical corroded surface with the corrosion film intact in shown in Figure 5.7. The images for both $\mathrm{La}^{3+}$ (Figure 5.7a) and $\mathrm{Gd}^{3+}$ (Figure 5.7b) reveal a black corrosion product characteristic of Mg alloy corrosion with some white corrosion product formation. The coverage of corrosion product on the surface increased with increasing $\left[\mathrm{La}^{3+}\right]$ or $\left[\mathrm{Gd}^{3+}\right]$ as expected from gravimetric mass loss measurements. The surfaces for $10^{-4} \mathrm{M}$ and $10^{-3} \mathrm{M} \mathrm{La}^{3+}$ and $\mathrm{Gd}^{3+}$ were similar and did not become completely covered with corrosion product as indicated by areas of bare metal in the exposed area. For all samples, the white corrosion product was observed to form on top of the surface while the black corrosion product penetrated into the metal surface. A typical higher magnification image of this corrosion product formation is shown in Figure 5.8 for AZ31B-H24 immersed in $0.1 \mathrm{M} \mathrm{GdCl}_{3}$ $+0.3 \mathrm{M} \mathrm{NaCl}$ for 24 hours.

The change in $\mathrm{pH}$ for 24 hours immersion testing in $\mathrm{La}^{3+}$ and $\mathrm{Gd}^{3+}$ is shown in Figure 5.9. The initial $\mathrm{pH}$ of each solution was observed to decrease with an increase in $\left[\mathrm{La}^{3+}\right]$ or $\left[\mathrm{Gd}^{3+}\right]$ and an increase in $\mathrm{pH}$ is observed in each electrolyte tested in this investigation relative to its initial measured $\mathrm{pH}$. A large increase in $\mathrm{pH}$ is observed for AZ31B-H24 immersed in $0.6 \mathrm{M} \mathrm{NaCl}$ with the $\mathrm{pH}$ increasing from approximately 5.6 to 8.5 . The only other electrolyte which experienced a $\mathrm{pH}$ increase this large was $10^{-4} \mathrm{M} \mathrm{LaCl}_{3}+0.6 \mathrm{M} \mathrm{NaCl}$ which increased from 5.8 to 8.6. In all other solutions, the final $\mathrm{pH}$ was measured to be below 7.5. 
(a)

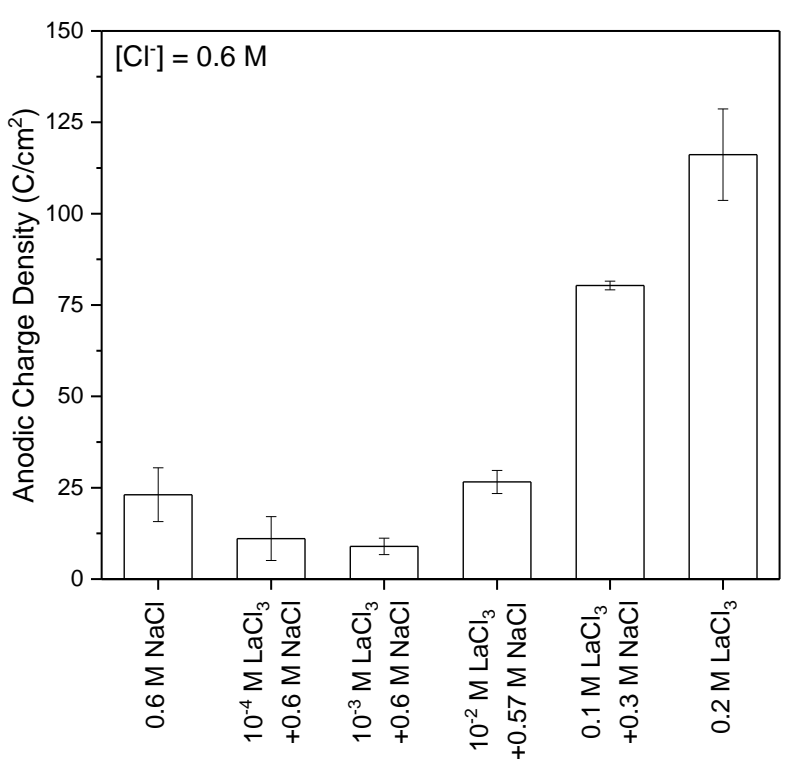

(b)

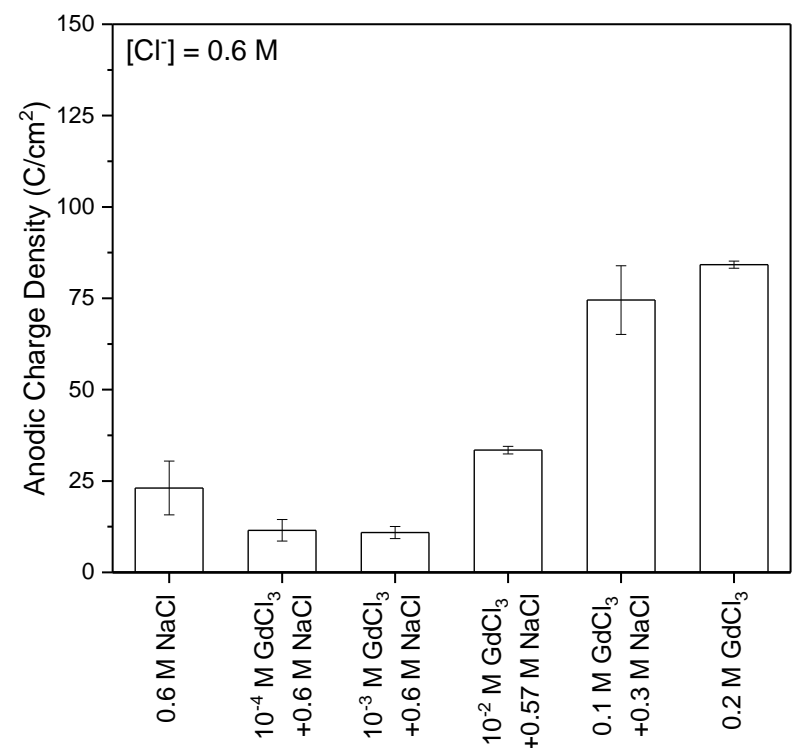

Figure 5.6. Gravimetric mass loss converted to anodic charge for AZ31B-H24 immersed in varying concentrations of (a) $\mathrm{La}^{3+}$ and (b) $\mathrm{Gd}^{3+}$ at OCP for 24 hours. 
(a)
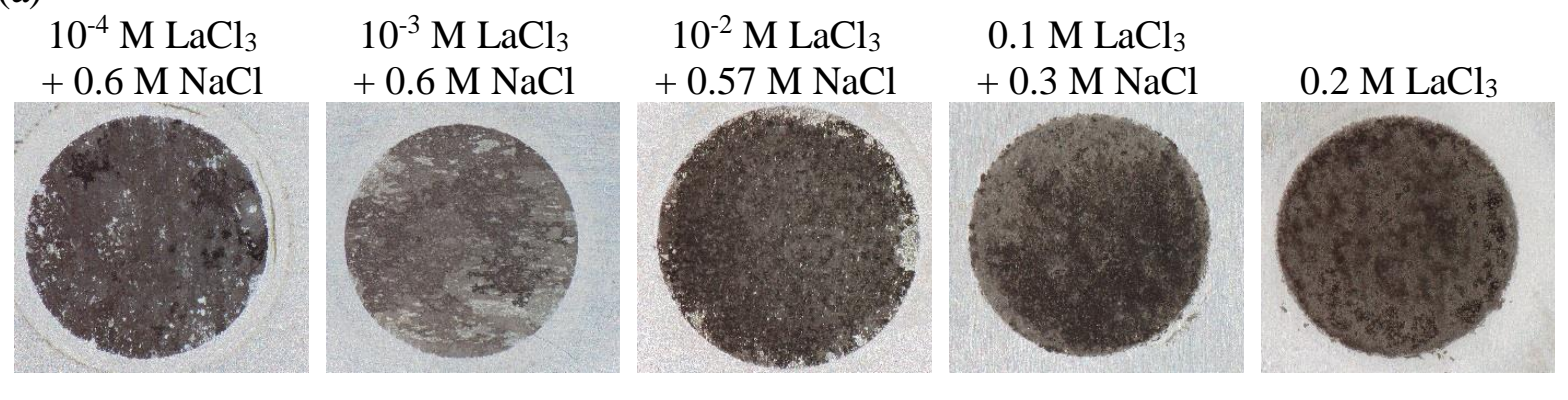

(b)
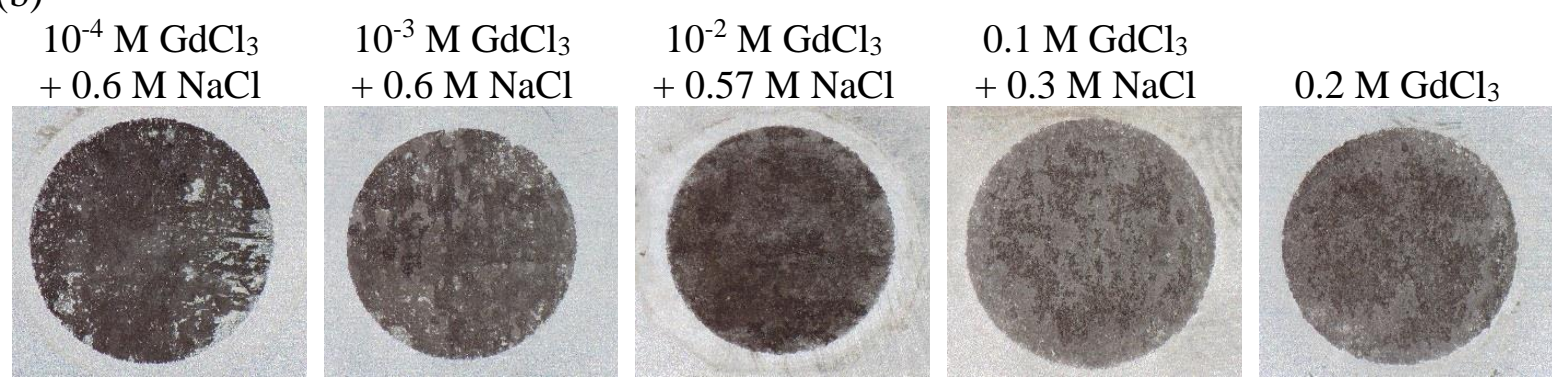

Figure 5.7. Optical macro images of AZ31B-H24 after 24 hour exposure to various concentrations of (a) $\mathrm{La}^{3+}$ and (b) $\mathrm{Gd}^{3+}$ revealing the corrosion films formed on the sample surface. The exposure area was $1 \mathrm{~cm}^{2}$.

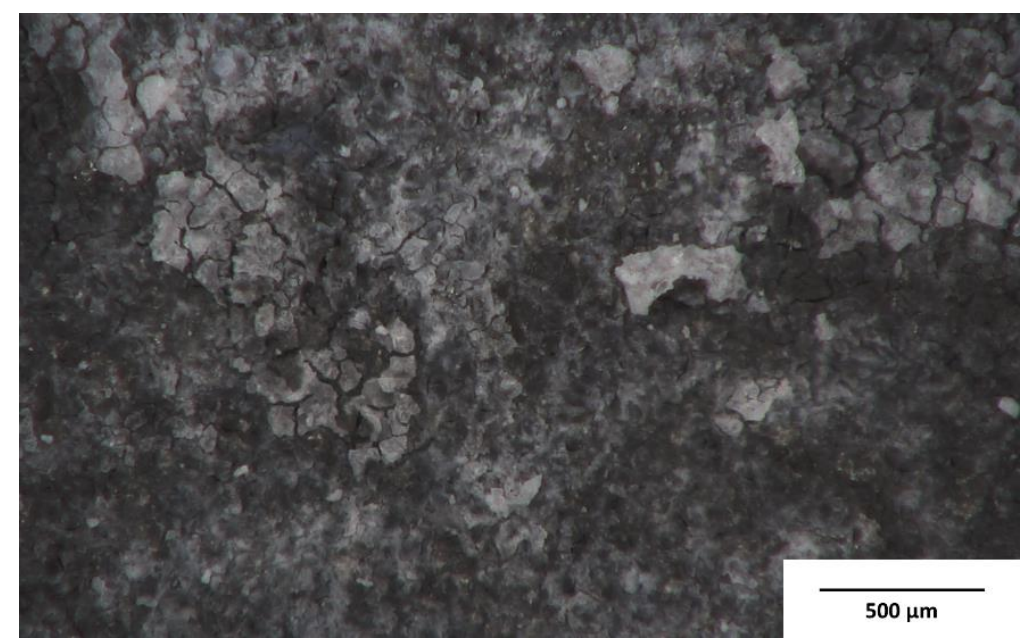

Figure 5.8. Higher magnification image revealing the corrosion surface of AZ31B-H24 immersed in $0.1 \mathrm{M} \mathrm{GdCl}_{3}+0.3 \mathrm{M} \mathrm{NaCl}$ for 24 hours. 
(a)

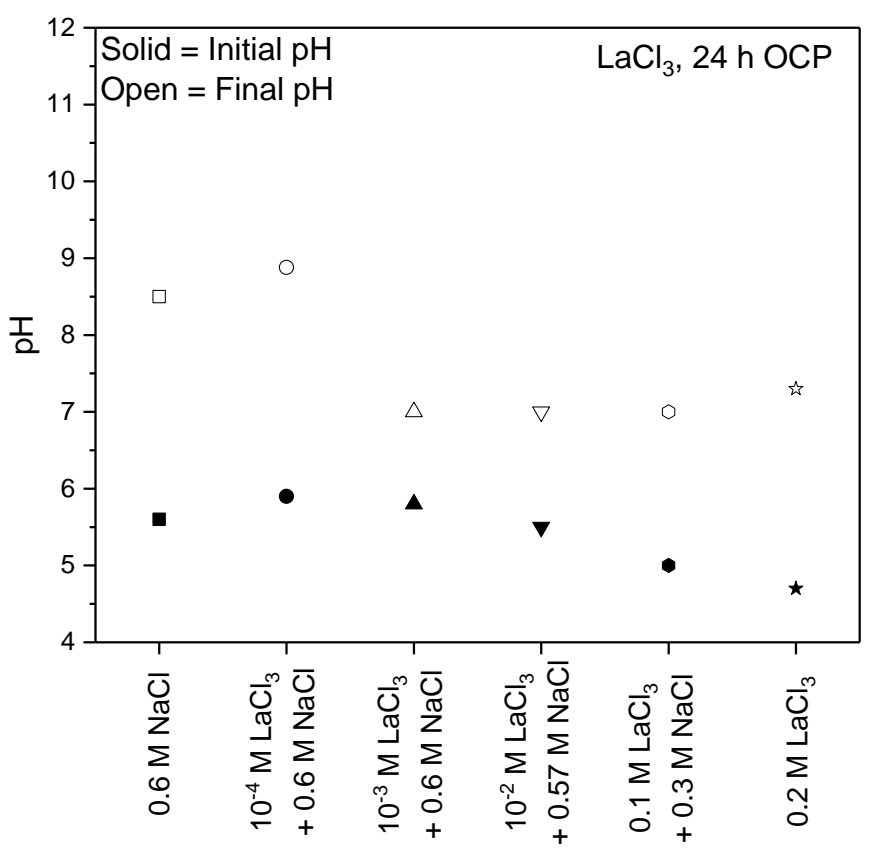

(b)

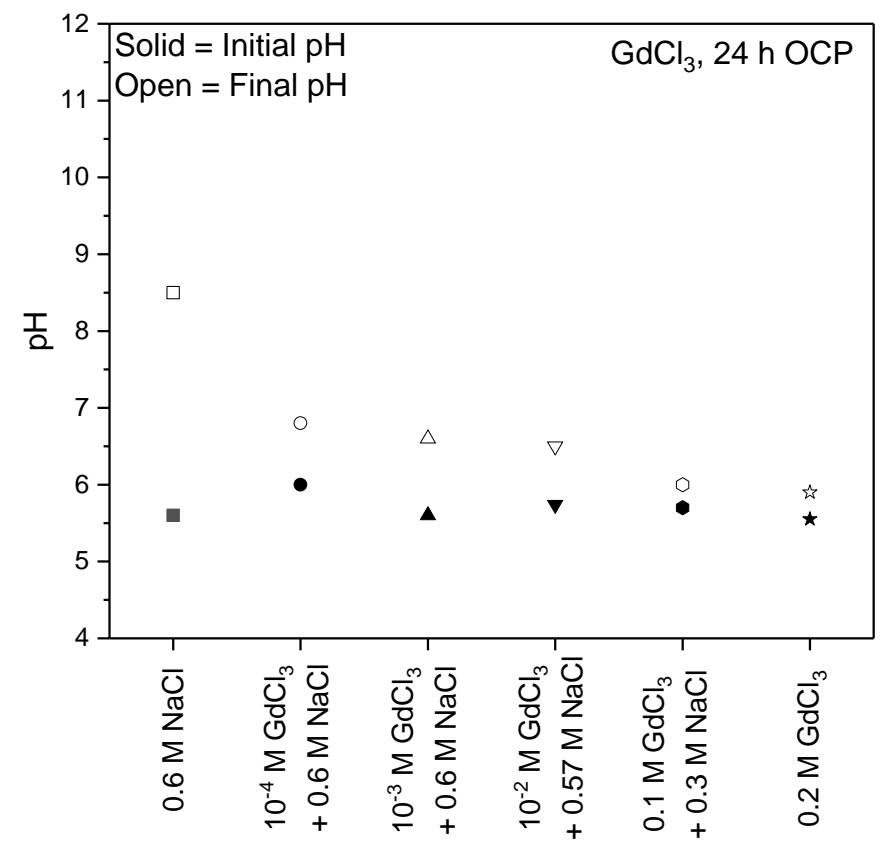

Figure 5.9. The average $\mathrm{pH}$ of the bulk solution for AZ31B-H24 freely corroding at OCP for 24 hours in varying concentrations of (a) $\mathrm{La}^{3+}$ and (b) $\mathrm{Gd}^{3+}$ compared to $0.6 \mathrm{M} \mathrm{NaCl}$. The chloride concentration was constant at $0.6 \mathrm{M} \mathrm{Cl}^{-}$. 


\subsubsection{Galvanostatic-Potentiostatic Cycle Testing}

The enhancement in cathodic kinetics as a function of anodic polarization was measured through a cycle of increasing anodic galvanostatic pulses followed by cathodic potentiostatic polarization at $-2 \mathrm{~V}_{\mathrm{SCE}}$ is shown in Figure 5.10 for varying concentration of $\mathrm{La}^{3+}$ with reference to $0.6 \mathrm{M} \mathrm{NaCl}$. The measured potential during anodic galvanostatic polarization, Figure 5.10b, was observed to be stable during each pulse after a brief induction period. Furthermore, the change in potential with increasing anodic polarization was nearly identical for each electrolyte with small variations. The cathodic pulses in Figure 5.10b reveal that the cathodic kinetics are the slowest for AZ31B-H24 immersed in $0.6 \mathrm{M} \mathrm{NaCl}$ during the first pulse while the cathodic kinetics increased with increasing $\left[\mathrm{La}^{3+}\right]$ as expected from the cathodic potentiodynamic curves in Figure 5.5. It was further observed that the cathodic kinetics increased with each anodic pulse for each solution and total enhancement in cathodic kinetics using the final data point of each pulse was approximately $4 \mathrm{~mA} / \mathrm{cm}^{2}$ with exception to $0.1 \mathrm{M} \mathrm{LaCl}_{3}+0.3 \mathrm{M} \mathrm{NaCl}$ which only increased about $2 \mathrm{~mA} / \mathrm{cm}^{2}$. The data for $\mathrm{LaCl}_{3}$ are summarized in Figure 5.11 where the measured potential at the end of each galvanostatic pulse is plotted is compared to the potentiodynamic polarization curves measured after 10 min immersion at OCP in Figure 5.11a and the current density of the last data point measured during cathodic polarization is plotted vs. the current density of the anodic pulse which occurred immediately before cathodic polarization at $-2 \mathrm{~V}_{\text {SCE. }}$. Figure 5.11 a shows that the change in potential with current density during galvanostatic pulses resembles that of the anodic polarization curves but the galvanostatic potentials are shifted to higher anodic current densities. These trends would be expected based off the change in applied current density. In Figure 5.11b, it is observed that the relative enhancement in cathodic kinetics given by the slope of the data is similar for AZ31B-H24 immersed in each solution. 
(a)

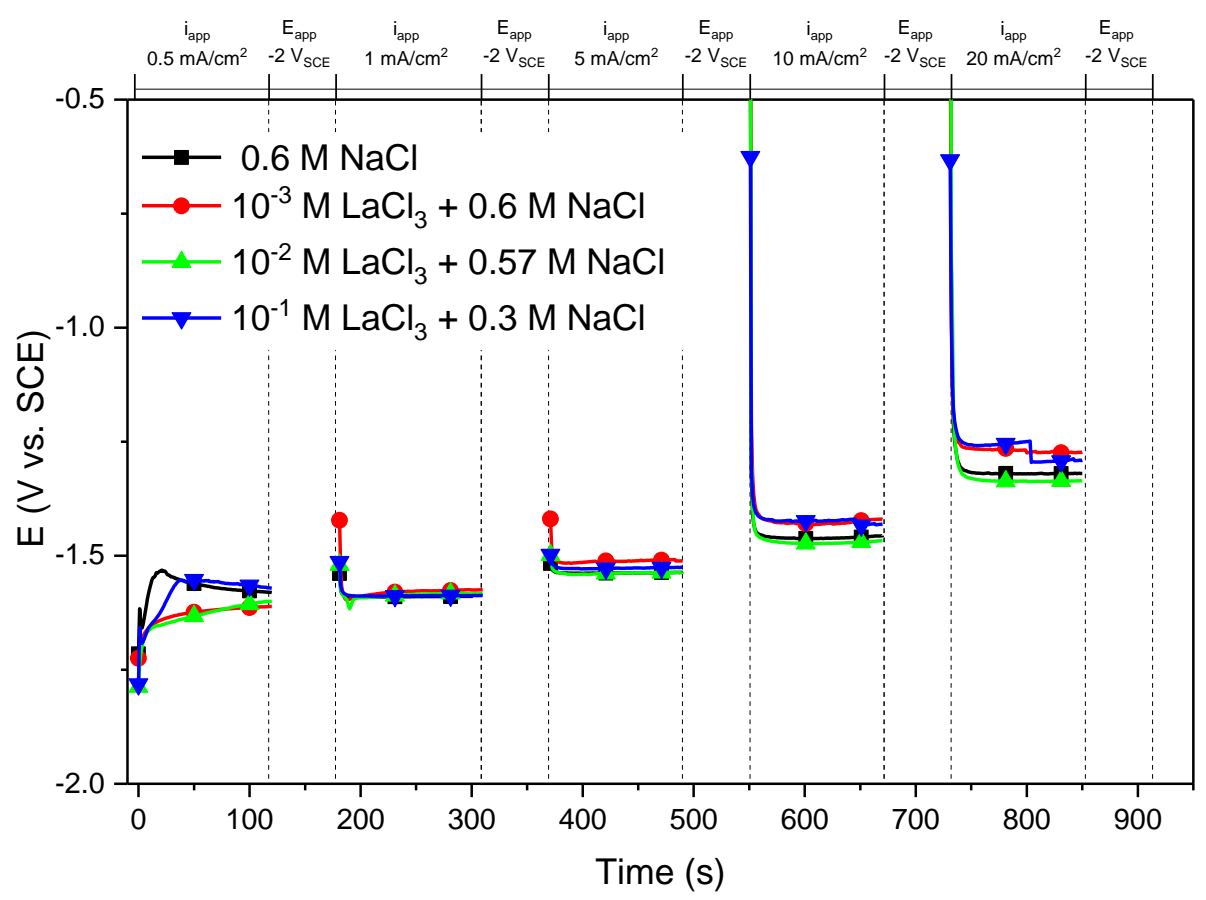

(b)

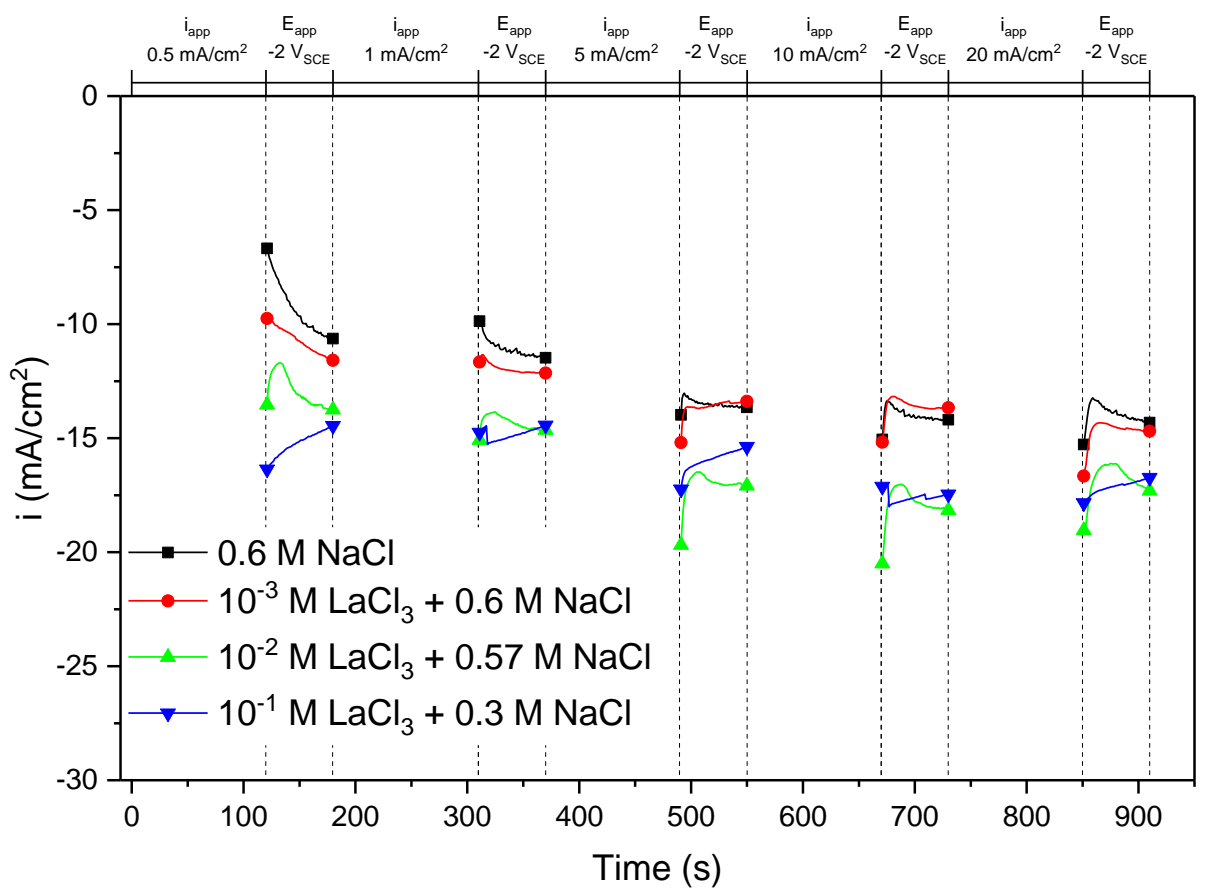

Figure 5.10. The typical data measured during galvanostatic-cycling test for AZ31B-H24 in varying concentrations of $\mathrm{La}^{3+}$ compared to $0.6 \mathrm{M} \mathrm{NaCl}$. (a) shows the potential vs. time and (b) shows the cathodic current vs. time for each respective galvanostatic and potentiostatic pulse. 
(a)

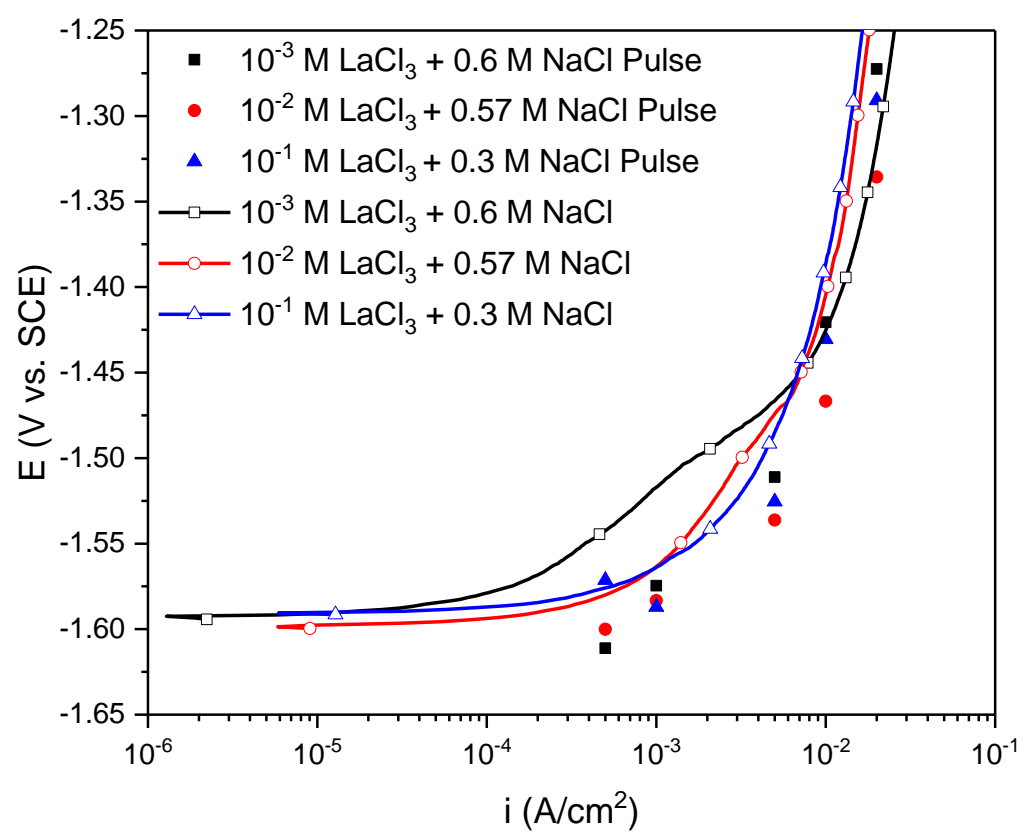

(b)

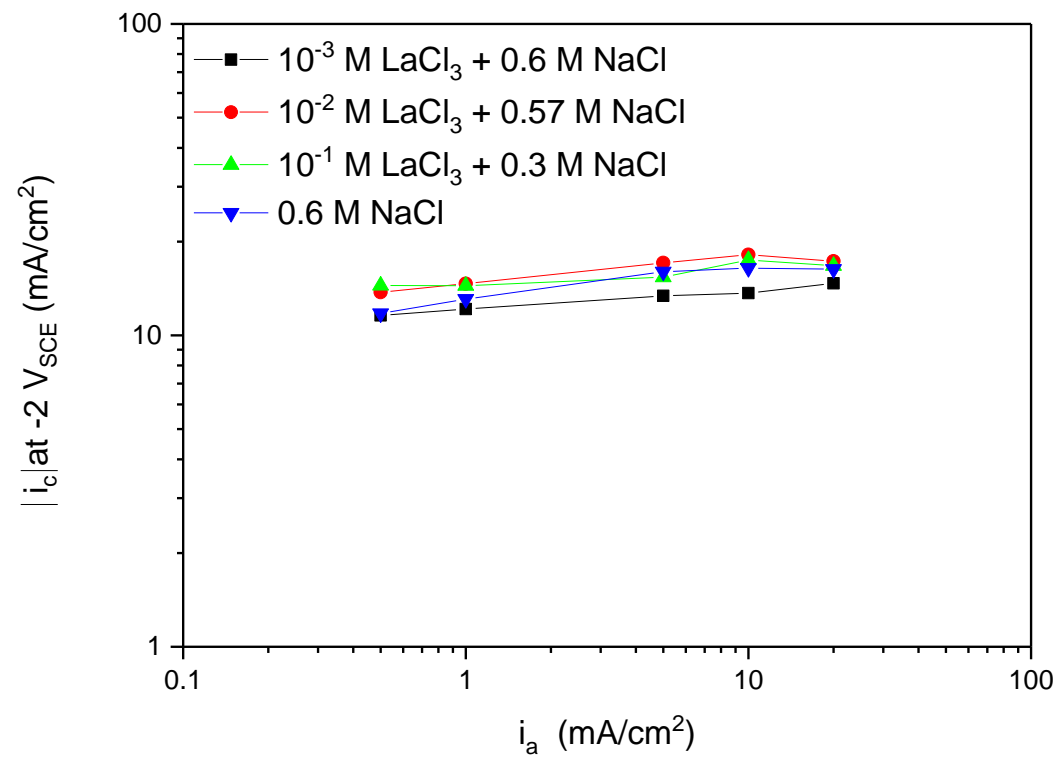

Figure 5.11. Summary of cycle testing in $\mathrm{LaCl}_{3}$. The average potential measured at the end of each anodic galvanostatic step is shown in by the solid symbols in (a) and compared to anodic potentiodynamic polarization curves. The average cathodic current density measured at the end of potentiostatic pulses at $-2 V_{S C E}$ is shown in (b) where $i_{a}$ is the applied anodic current density and $i_{c}$ is the cathodic current density measured after the respective anodic pulse. 
The galvanostatic-potentiostatic cycle behavior for $\mathrm{Gd}^{3+}$ (Figure 5.12) was similar to that measured on AZ31B-H24 electrodes in $\mathrm{La}^{3+}$. During each anodic galvanostatic pulse in Figure 5.12a, the stable measured potential of AZ31B-H24 in each electrolyte was approximately the same during each anodic pulse. The measured cathodic current density during cathodic pulses (Figure 5.12b) was slowest after the first pulse for $0.6 \mathrm{M} \mathrm{NaCl}$ while the cathodic kinetics were fastest for $0.1 \mathrm{M} \mathrm{GdCl}_{3}+0.3 \mathrm{M} \mathrm{NaCl}$. Interestingly, the cathodic kinetics measured for $10^{-2} \mathrm{M}$ $\mathrm{GdCl}_{3}+0.57 \mathrm{M} \mathrm{NaCl}$ were nearly identical to $0.6 \mathrm{M} \mathrm{NaCl}$ at the end of each cathodic pulse but was much greater at the beginning of each pulse than $0.6 \mathrm{M} \mathrm{NaCl}$. The enhancement in cathodic current density using the final data point of each pulse was approximately $4 \mathrm{~mA} / \mathrm{cm}^{2}$ for $0.6 \mathrm{M}$ $\mathrm{NaCl}$ and $10^{-2} \mathrm{M} \mathrm{GdCl}_{3}+0.57 \mathrm{M} \mathrm{NaCl}$ while the enhancement was $3 \mathrm{~mA} / \mathrm{cm}^{2}$ for $10^{-3} \mathrm{M} \mathrm{GdCl}_{3}$ $+0.6 \mathrm{M} \mathrm{NaCl}$ and $0.1 \mathrm{M} \mathrm{GdCl}_{3}+0.3 \mathrm{M} \mathrm{NaCl}$. The data for $\mathrm{GdCl}_{3}$ are summarized in Figure 5.13 where the measured potential at the end of each galvanostatic pulse is plotted is compared to the potentiodynamic polarization curves measured after $10 \mathrm{~min}$ immersion at OCP in Figure 5.13a and the current density of the last data point measured during cathodic polarization is plotted vs. the current density of the anodic pulse which occurred immediately before cathodic polarization at -2 VSCE. Similarily to $\mathrm{LaCl}_{3}$, the results for $\mathrm{GdCl}_{3}$ in Figure 5.13a shows that the change in current density with potential during galvanostatic pulses resembles that of the anodic polarization curves but the galvanostatic potentials are shifted to higher anodic current densities. In Figure 5.13b, it is observed that the relative enhancement in cathodic kinetics given by the slope of the data is similar for AZ31B-H24 immersed in each solution. 
(a)

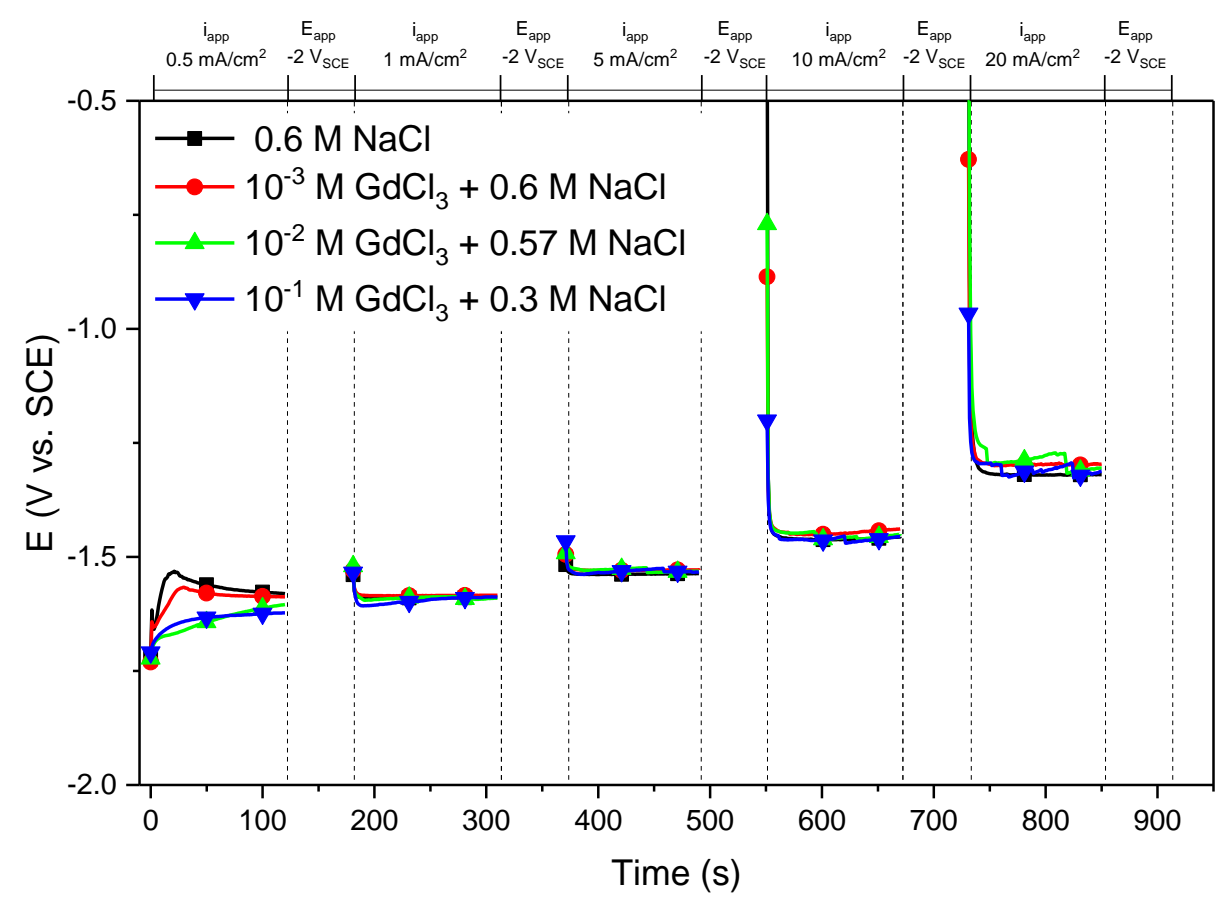

(b)

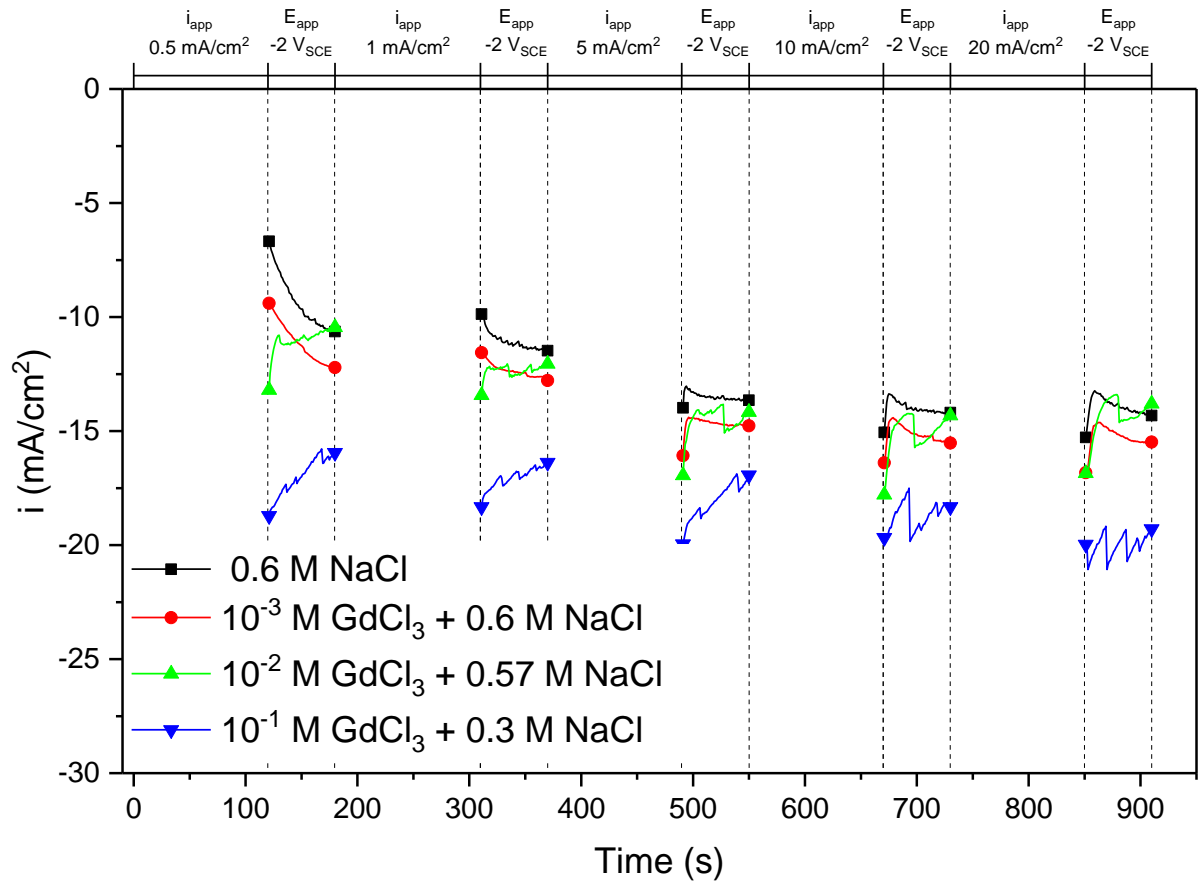

Figure 5.12. The typical data measured during galvanostatic-cycling test for AZ31B-H24 in varying concentrations of $\mathrm{Gd}^{3+}$ compared to $0.6 \mathrm{M} \mathrm{NaCl}$. (a) shows the potential vs. time and (b) shows the cathodic current vs. time for each respective galvanostatic and potentiostatic pulse. 
(a)

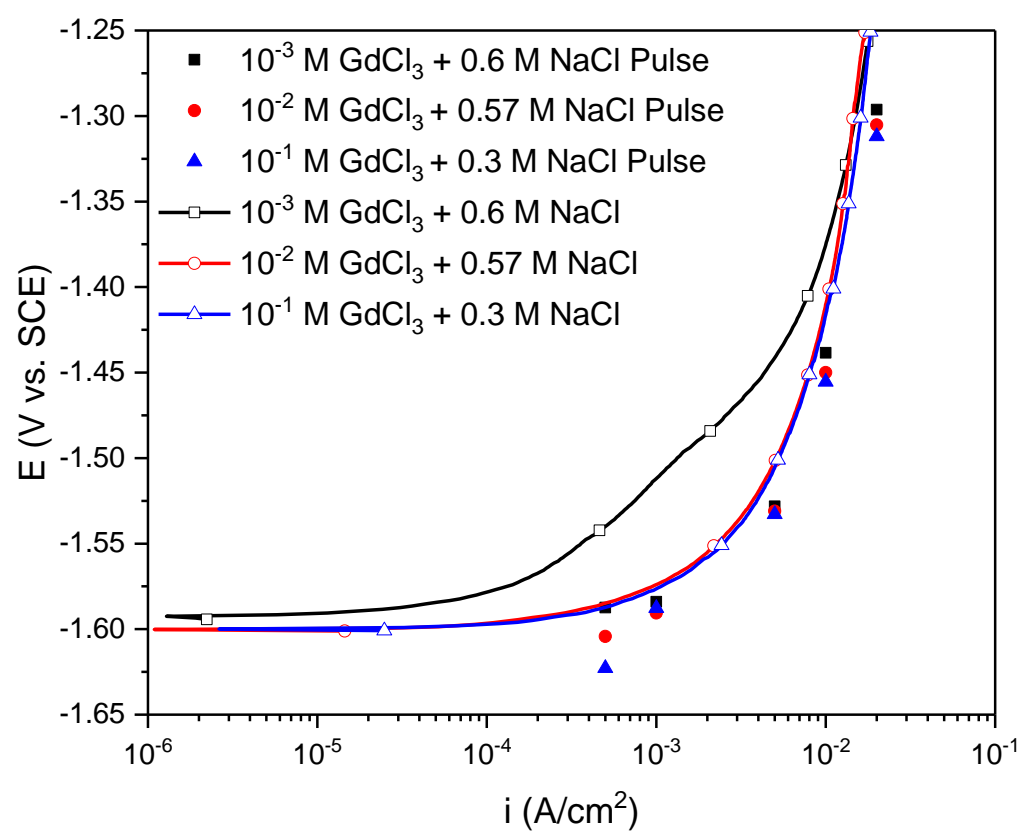

(b)

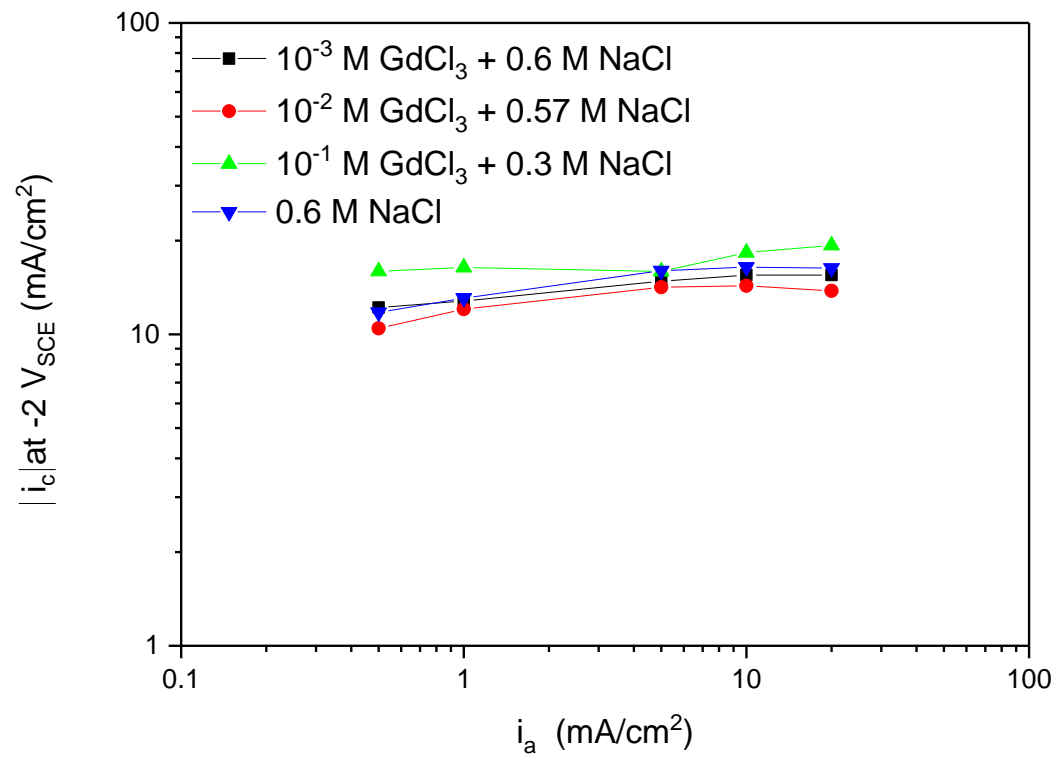

Figure 5.13. Summary of cycle testing in $\mathrm{GdCl}_{3}$. The average potential measured at the end of each anodic galvanostatic step is shown in by the solid symbols in (a) and compared to anodic potentiodynamic polarization curves. The average cathodic current density measured at the end of potentiostatic pulses at $-2 V_{S C E}$ is shown in (b) where $i_{a}$ is the applied anodic current density and $i_{c}$ is the cathodic current density measured after the respective anodic pulse. 


\subsubsection{EIS Testing after Varying Anodic Galvanostatic Polarization}

The typical EIS spectra of AZ31B-H24 immersed in varying $\left[\mathrm{La}^{3+}\right]$ after 24 hour anodic galvanostatic polarization at $0.1 \mathrm{~mA} / \mathrm{cm}^{2}$ is shown in Figure 5.14. The Bode magnitude plot in Figure 5.14a shows that the modulus at intermediate and low frequencies decreases with increasing $\left[\mathrm{La}^{3+}\right]$. This indicates that the polarization resistance of AZ31B-H24 decreases with increasing $\left[\mathrm{La}^{3+}\right]$. This is further shown by the decrease in negative phase angle at intermediate frequencies in the Bode phase plot in Figure 5.14b and the decrease in loop size with increasing $\left[\mathrm{La}^{3+}\right]$ in the Nyquist plot in Figure 5.14c. The same trend of decreasing polarization resistance with increasing $\left[\mathrm{La}^{3+}\right]$ is observed after galvanostatic anodic polarization at $1 \mathrm{~mA} / \mathrm{cm}^{2}$ as shown in Figure 5.15 but there did not appear to be any difference in the polarization resistance after applying $10 \mathrm{~mA} / \mathrm{cm}^{2}$ for 24 hours (Figure 5.16). The average EIS estimated $R_{p}$ of each solution as a function applied anodic current density is shown in Figure 5.17a while the change in $\mathrm{pH}$ is shown in Figure 5.17b. This figure shows that the value for $\mathrm{R}_{\mathrm{p}}$ decreased with increasing $\left[\mathrm{La}^{3+}\right]$ and increasing applied anodic current density. In addition, the final bulk $\mathrm{pH}$ was observed in increase with increasing anodic current density and decreased $\left[\mathrm{La}^{3+}\right]$.

The typical EIS spectra of AZ31B-H24 immersed in varying $\left[\mathrm{Gd}^{3+}\right]$ after 24 hour anodic galvanostatic polarization at $0.1 \mathrm{~mA} / \mathrm{cm}^{2}, 1 \mathrm{~mA} / \mathrm{cm}^{2}$, and $10 \mathrm{~mA} / \mathrm{cm}^{2}$ are shown in Figure 5.18, Figure 5.19, and Figure 5.20 respectively. As with $\mathrm{La}^{3+}$ the EIS estimated $\mathrm{R}_{\mathrm{p}}$ in Figure 5.21a show that the polarization resistance decreased with increasing $\left[\mathrm{Gd}^{3+}\right]$. However, the polarization resistance was observed to be greater than that of $0.6 \mathrm{M} \mathrm{NaCl}$ for $10^{-3} \mathrm{M} \mathrm{Gd}^{3+}$ and $10^{-2} \mathrm{Gd}^{3+}$ after anodic polarization at $10 \mathrm{~mA} / \mathrm{cm}^{2}$ with $\mathrm{R}_{\mathrm{p}}$ being the greatest for $10^{-3} \mathrm{M} \mathrm{Gd}^{3+}$. In addition, the change in $\mathrm{pH}$ as a function of anodic polarization, Figure $5.21 \mathrm{~b}$, reveals that the bulk $\mathrm{pH}$ increases in each solution with increasing anodic polarization. 
(a)

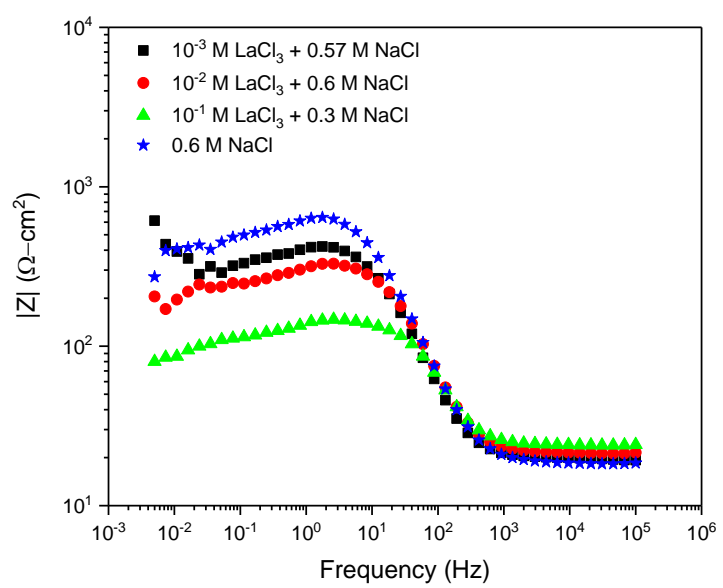

(c)

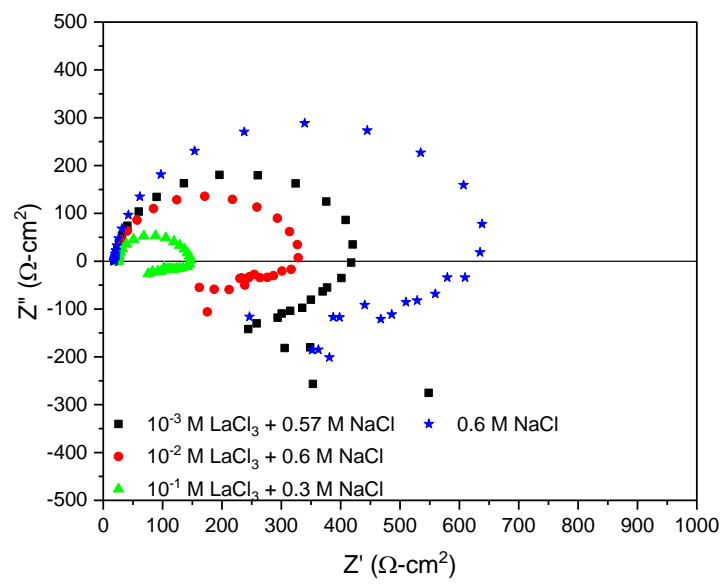

(b)

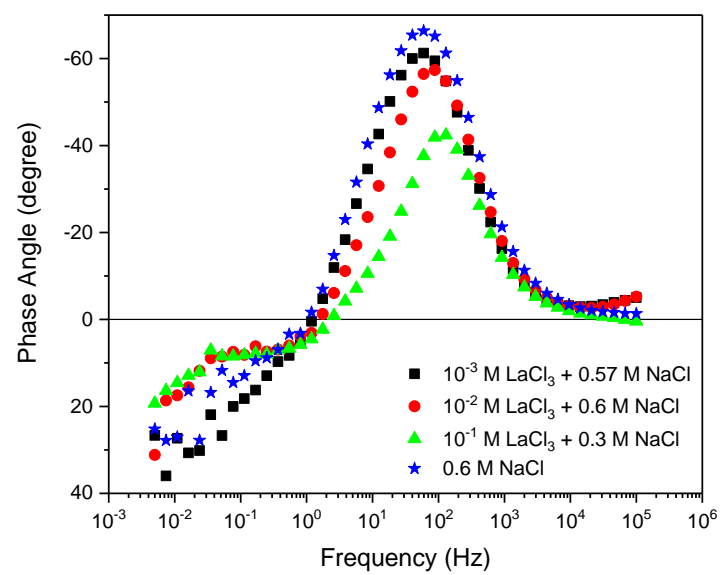

Figure 5.14. EIS measurements with varying $\left[\mathrm{La}^{3+}\right]$ at a constant total chloride concentration of $0.6 \mathrm{M}$ after anodic galvanostatic polarization at $0.1 \mathrm{~mA} / \mathrm{cm}^{2}$. (a) shows Bode magnitude plot, (b) shows the Bode phase plot, and (c) shows the Nyquist plot. 
(a)

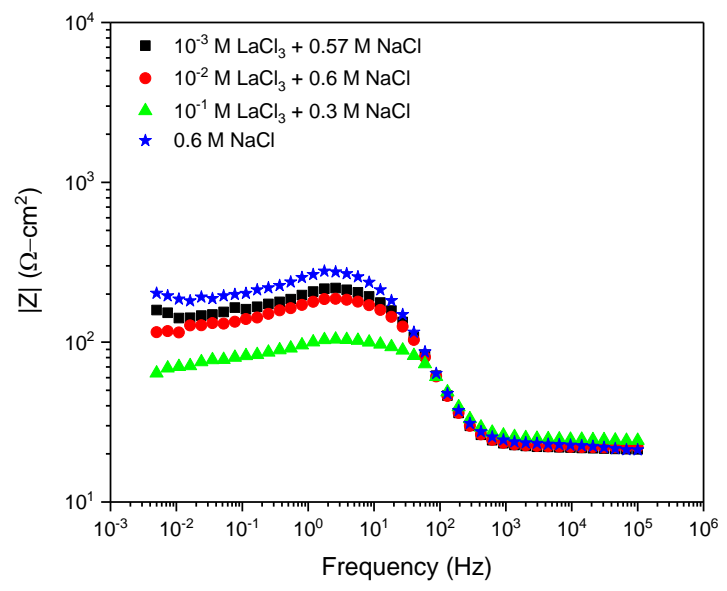

(c)

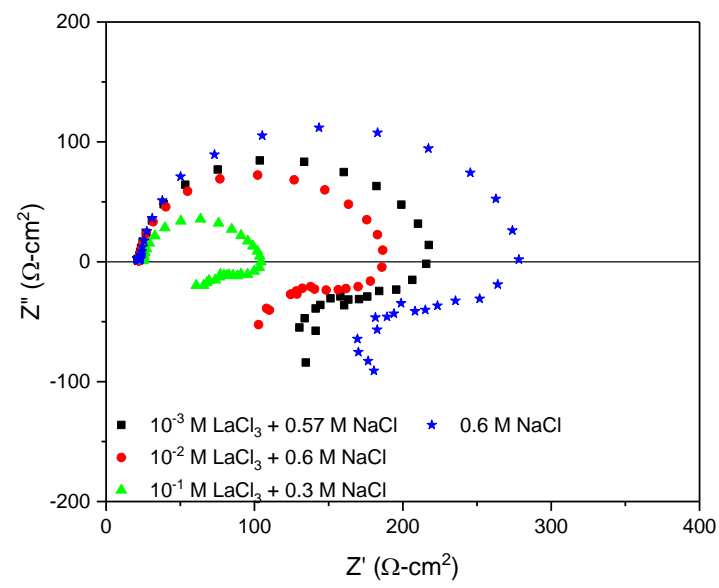

(b)

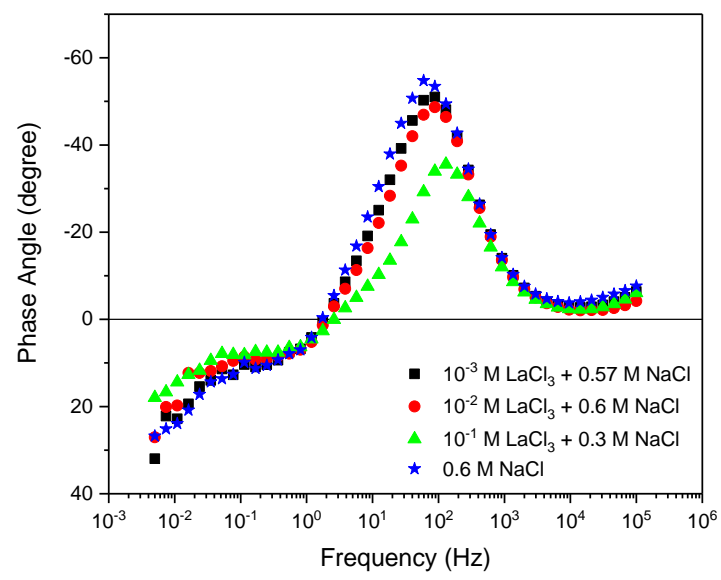

Figure 5.15. EIS measurements with varying $\left[\mathrm{La}^{3+}\right]$ at a constant total chloride concentration of $0.6 \mathrm{M}$ after anodic galvanostatic polarization at $1 \mathrm{~mA} / \mathrm{cm}^{2}$. (a) shows Bode magnitude plot, (b) shows the Bode phase plot, and (c) shows the Nyquist plot. 
(a)

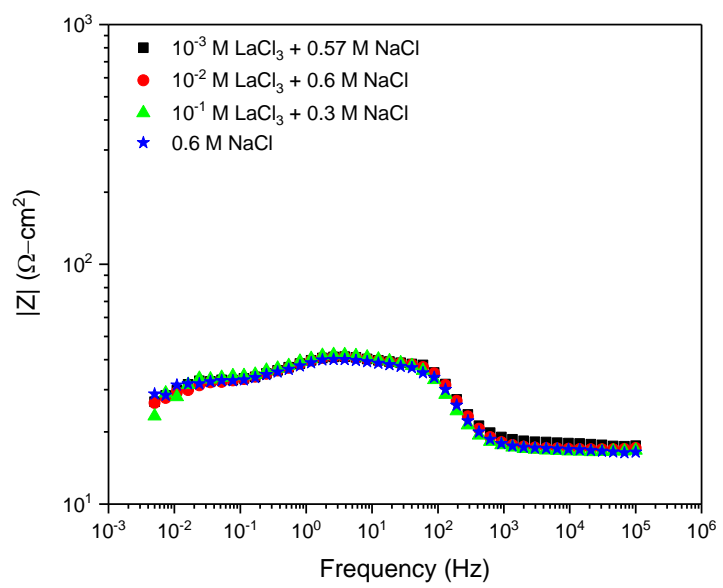

(c)

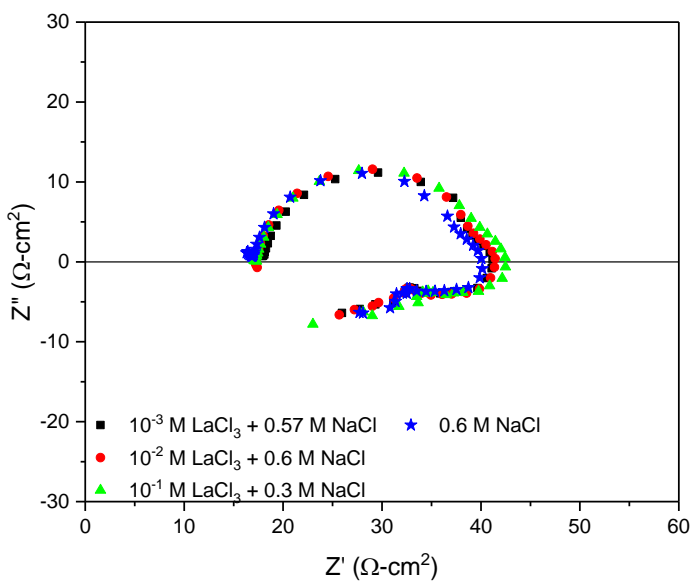

(b)

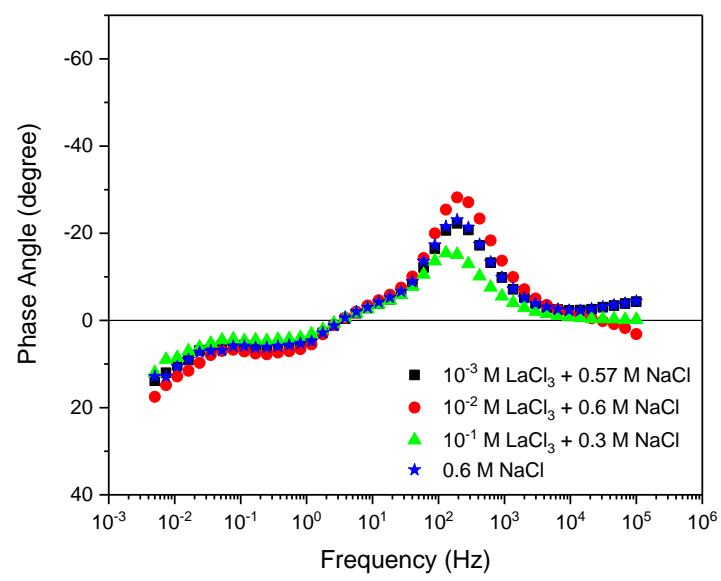

Figure 5.16. EIS measurements with varying $\left[\mathrm{La}^{3+}\right]$ at a constant total chloride concentration of $0.6 \mathrm{M}$ after anodic galvanostatic polarization at $10 \mathrm{~mA} / \mathrm{cm}^{2}$. (a) shows Bode magnitude plot, (b) shows the Bode phase plot, and (c) shows the Nyquist plot. 
(a)

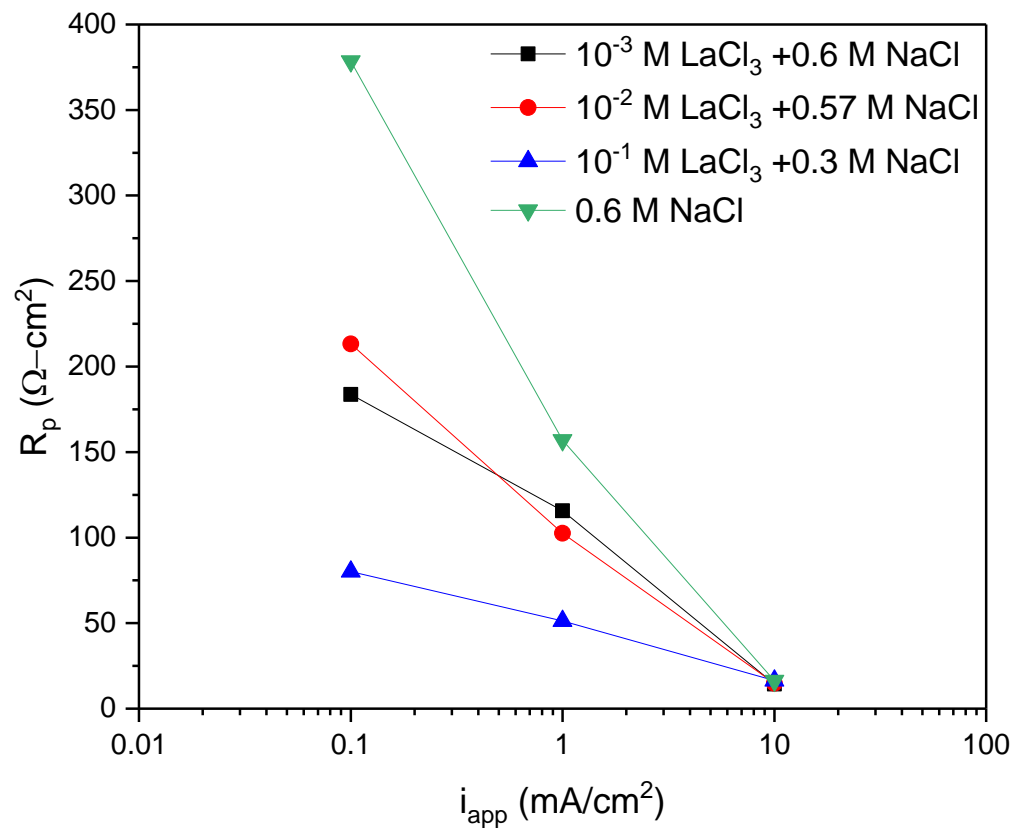

(b)

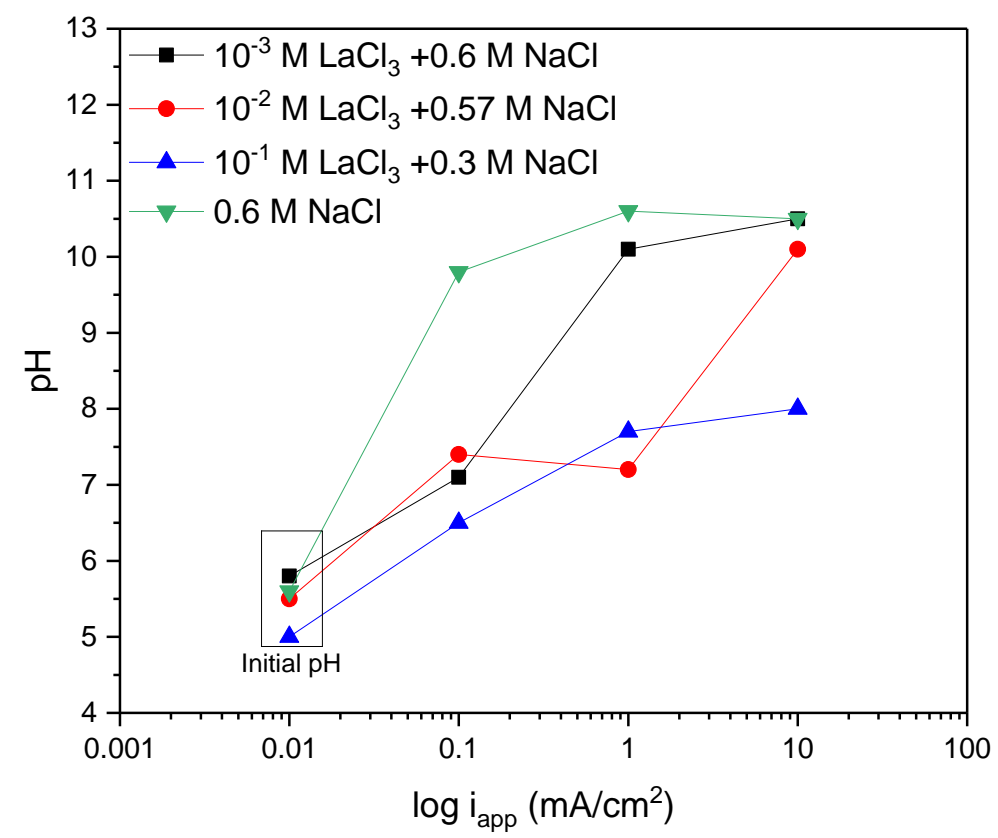

Figure 5.17. (a) The change in average polarization resistance of AZ31B-H24 with varying $\left[\mathrm{La}^{3+}\right]$ as a function of applied anodic current density (b) the change in $\mathrm{pH}$ as a function of applied current density. The initial $\mathrm{pH}$ of each solution is plotted at $0.01 \mathrm{~mA} / \mathrm{cm}^{2}$. 
(a)

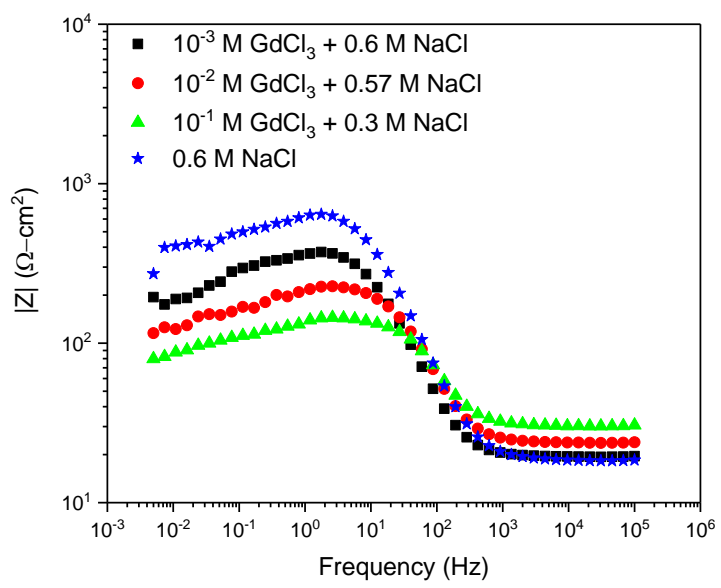

(c)

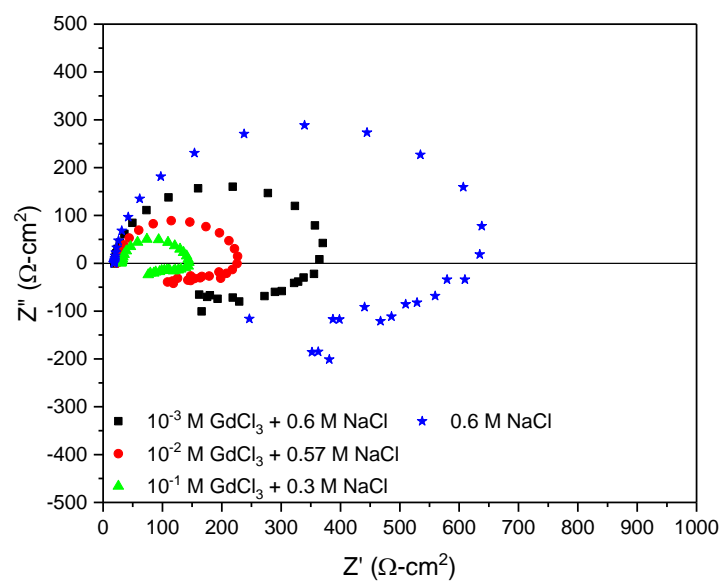

(b)

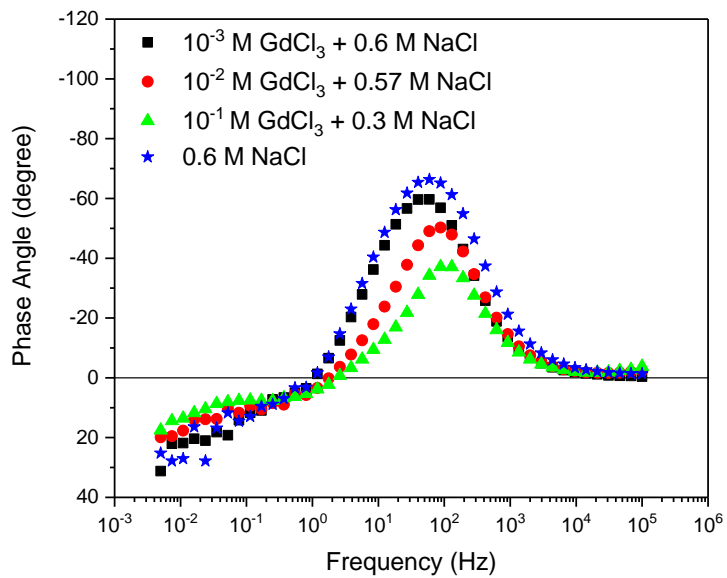

Figure 5.18. EIS measurements with varying $\left[\mathrm{Gd}^{3+}\right]$ at a constant total chloride concentration of $0.6 \mathrm{M}$ after anodic galvanostatic polarization at $0.1 \mathrm{~mA} / \mathrm{cm}^{2}$. (a) shows Bode magnitude plot, (b) shows the Bode phase plot, and (c) shows the Nyquist plot. 
(a)

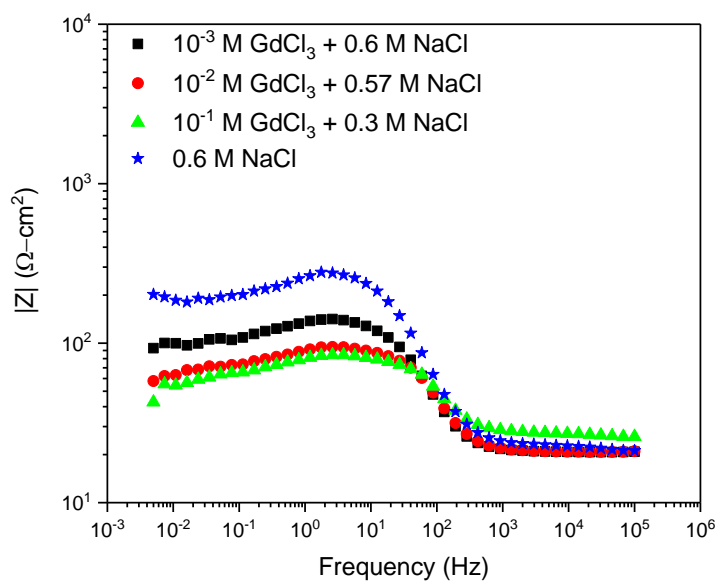

(c)

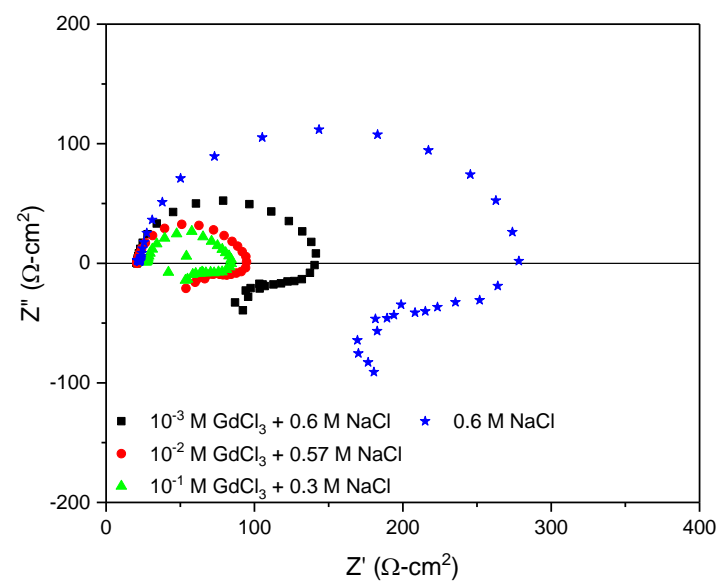

(b)

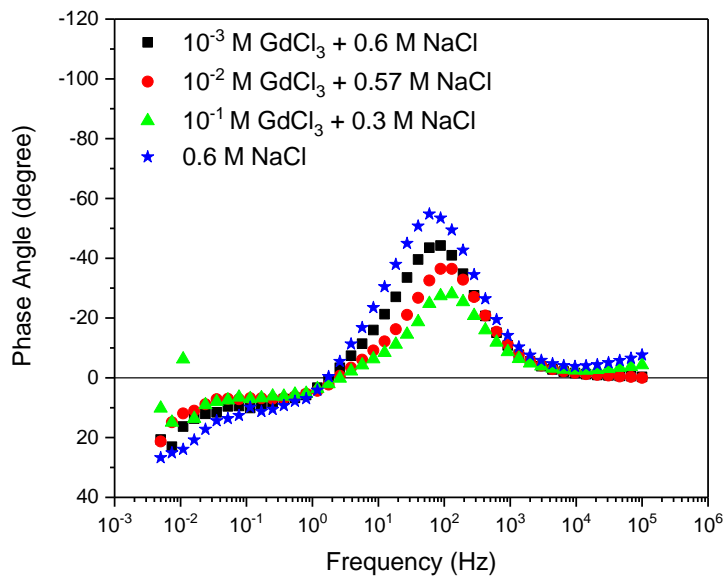

Figure 5.19. EIS measurements with varying $\left[\mathrm{Gd}^{3+}\right]$ at a constant total chloride concentration of $0.6 \mathrm{M}$ after anodic galvanostatic polarization at $1 \mathrm{~mA} / \mathrm{cm}^{2}$. (a) shows Bode magnitude plot, (b) shows the Bode phase plot, and (c) shows the Nyquist plot. 
(a)

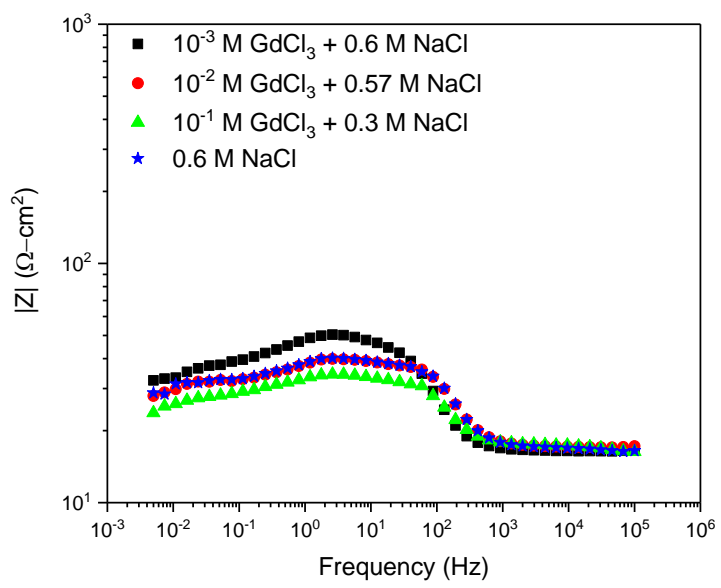

(c)

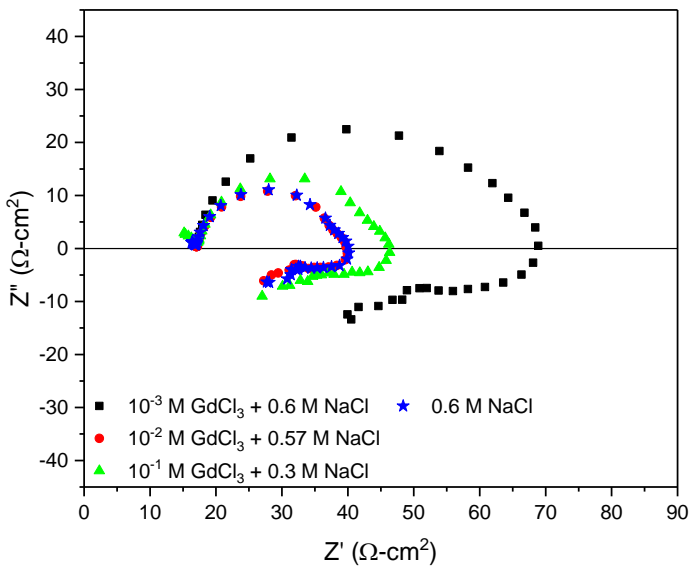

(b)

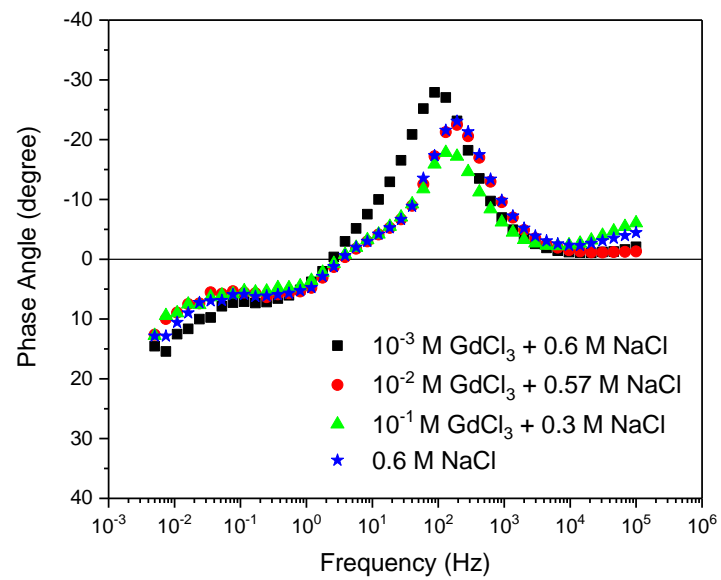

Figure 5.20. EIS measurements with varying $\left[\mathrm{Gd}^{3+}\right]$ at a constant total chloride concentration of $0.6 \mathrm{M}$ after anodic galvanostatic polarization at $10 \mathrm{~mA} / \mathrm{cm}^{2}$. (a) shows Bode magnitude plot, (b) shows the Bode phase plot, and (c) shows the Nyquist plot. 
(a)

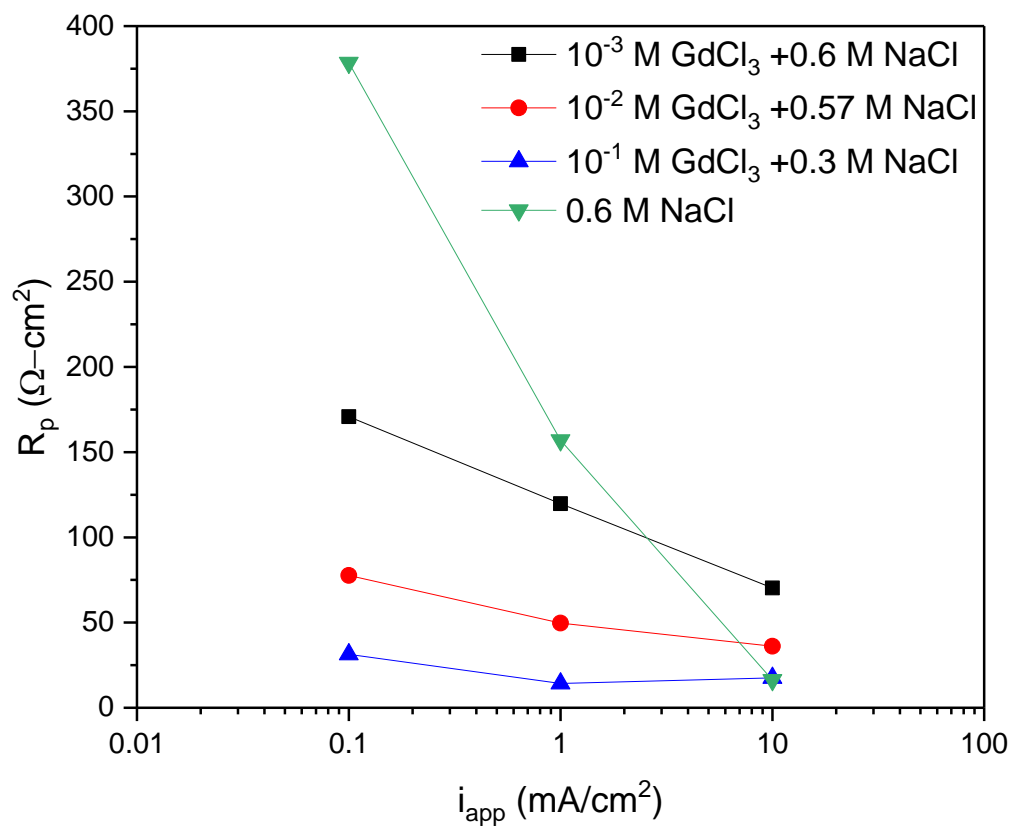

(b)

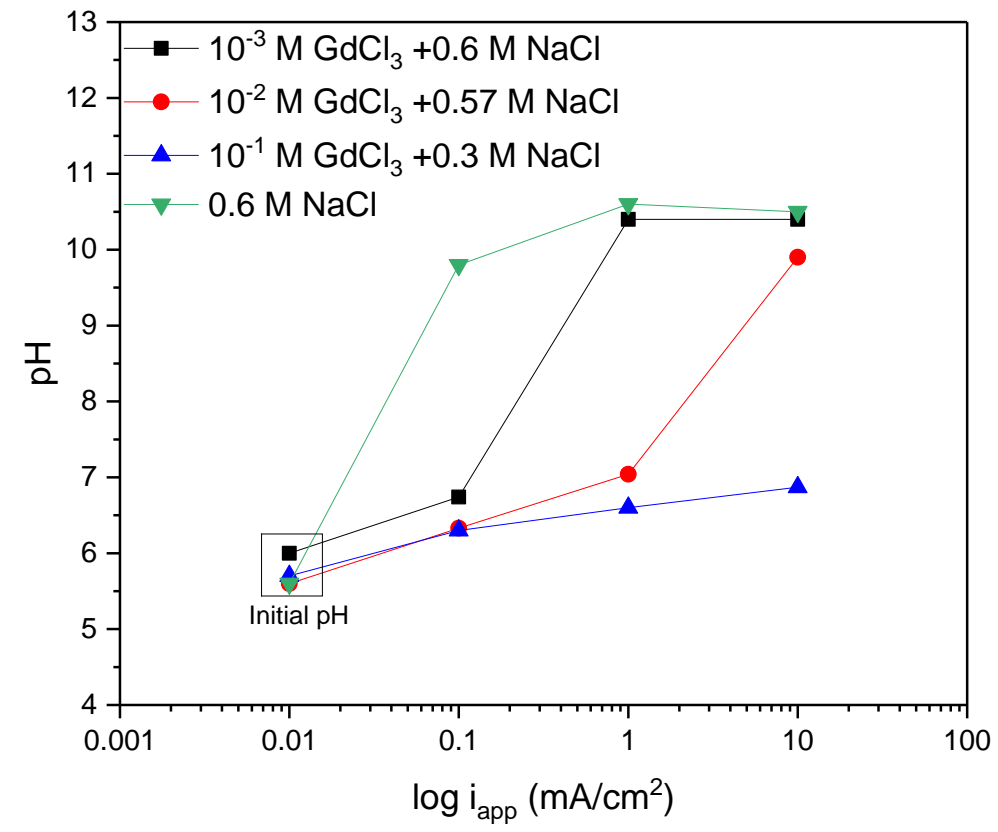

Figure 5.21. (a) The change in average polarization resistance of AZ31B-H24 with varying $\left[\mathrm{Gd}^{3+}\right]$ as a function of applied anodic current density and (b) the change in $\mathrm{pH}$ as a function of applied current density. The initial $\mathrm{pH}$ of each solution is plotted at $0.01 \mathrm{~mA} / \mathrm{cm}^{2}$. 
Optical macro images of AZ31B-H24 after anodic galvanostatic polarization with the dissolution film intact is shown in Figure 5.22 for varying $\mathrm{La}^{3+}$ and Figure 5.23 for varying $\mathrm{Gd}^{3+}$. These figures shows both black and white dissolution products forming on the surface and that the dissolution damage to the surface increases with increasing applied anodic current density. The dissolution film formation was similar to that observed at OCP in that the white film formed on the surface of AZ31B-H24 while the black film penetrated into the sample. This is shown more clearly in a high magnification image of $10^{-2} \mathrm{M} \mathrm{GdCl}_{3}+0.57 \mathrm{M} \mathrm{NaCl}$ after an applied current density of $1 \mathrm{~mA} / \mathrm{cm}^{2}$.

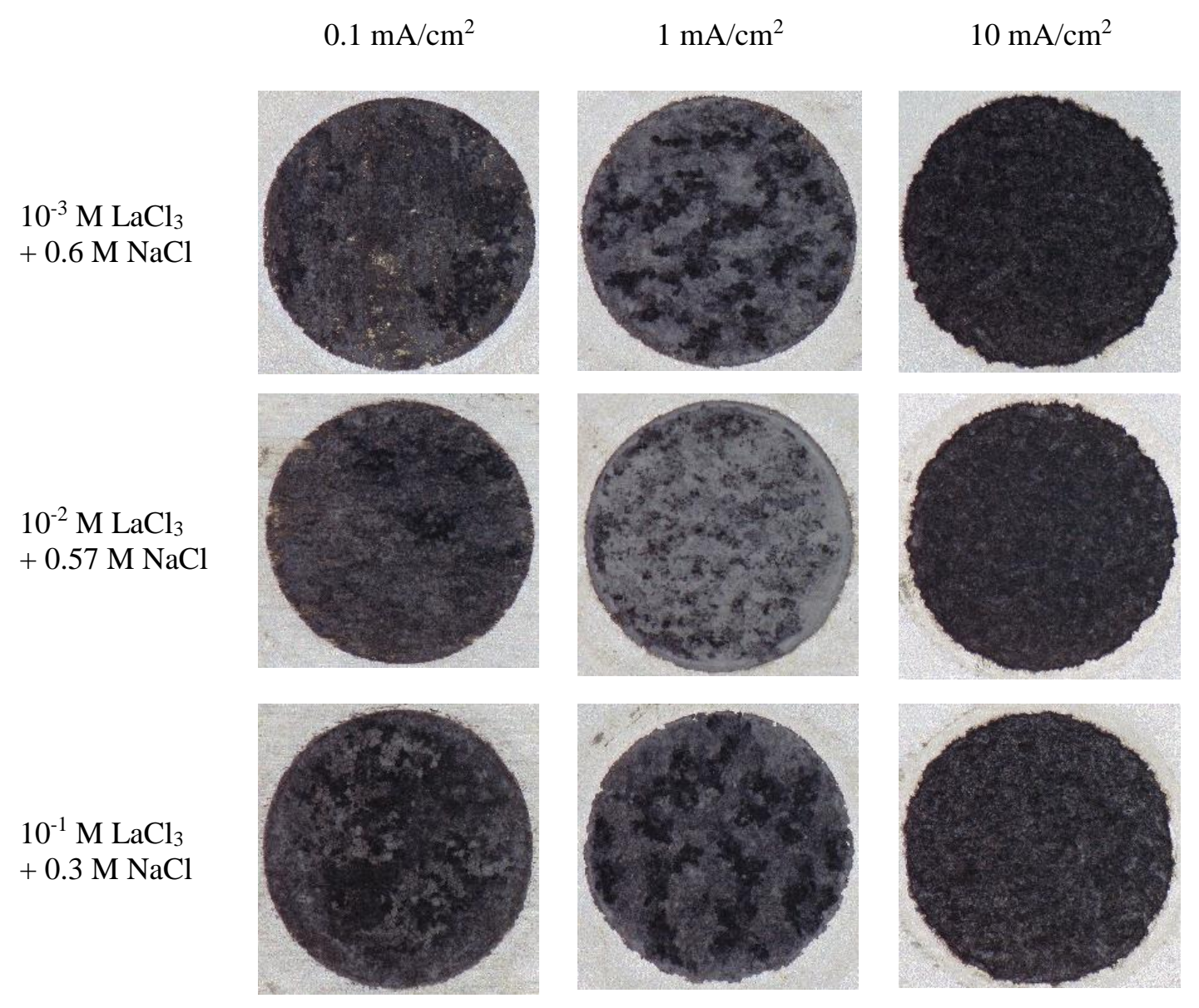

Figure 5.22. Optical macro images of corroded AZ31B-H24 surfaces after different anodic galvanostatic pulses as a function with varying $\left[\mathrm{La}^{3+}\right]$. The sample exposure area was $1 \mathrm{~cm}^{2}$. 
$0.1 \mathrm{~mA} / \mathrm{cm}^{2}$
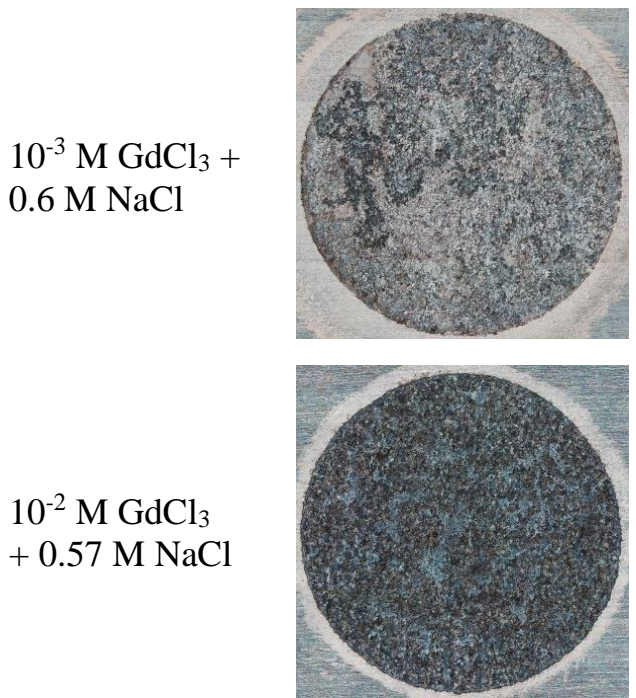

$10^{-2} \mathrm{M} \mathrm{GdCl}_{3}$ $+0.57 \mathrm{M} \mathrm{NaCl}$

$10^{-1} \mathrm{M} \mathrm{GdCl}_{3}$ $+0.3 \mathrm{M} \mathrm{NaCl}$

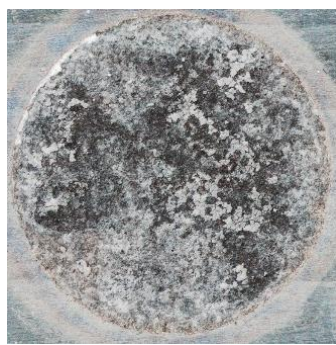

$1 \mathrm{~mA} / \mathrm{cm}^{2}$
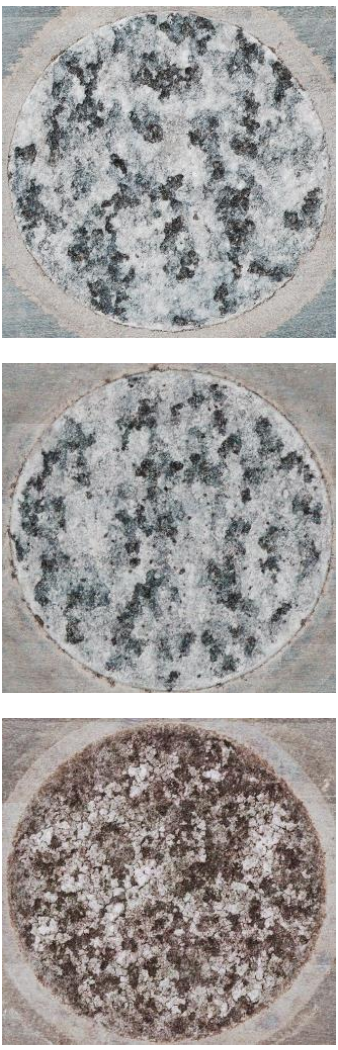

$10 \mathrm{~mA} / \mathrm{cm}^{2}$
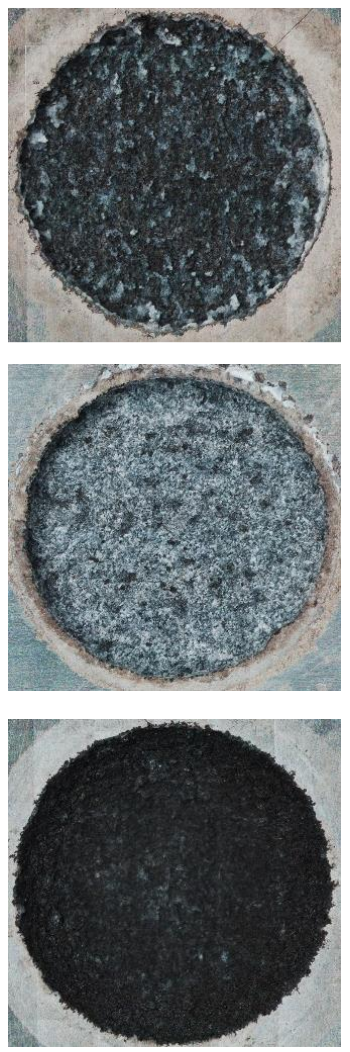

Figure 5.23. Optical macro images of corroded AZ31B-H24 surfaces after different anodic galvanostatic pulses as a function with varying $\left[\mathrm{Gd}^{3+}\right]$. The sample exposure area was $1 \mathrm{~cm}^{2}$.

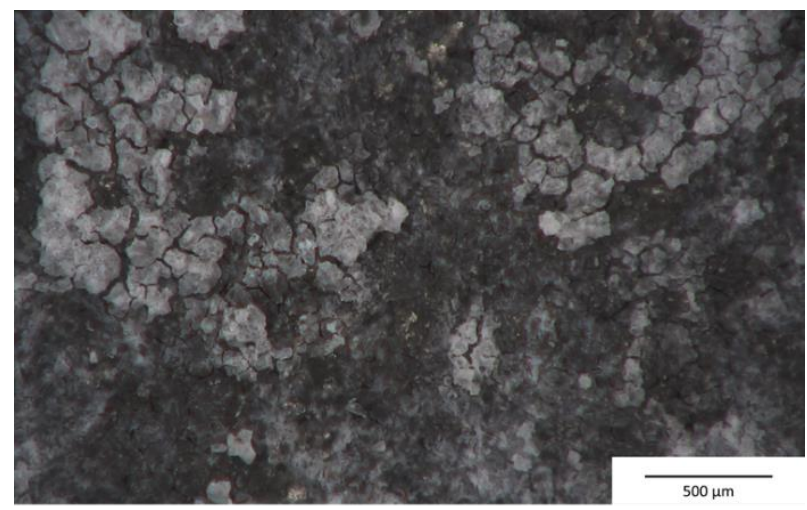

Figure 5.24. Higher magnification optical image showing the dissolution surface of AZ31B-H24 after anodic polarization at $1 \mathrm{~mA} / \mathrm{cm}^{2}$ for 24 hours in in $10^{-2} \mathrm{M} \mathrm{GdCl}_{3}+0.57 \mathrm{M} \mathrm{NaCl}$. 


\subsubsection{Raman Spectroscopy}

Raman spectroscopy was performed on samples in an attempt to identify the dissolution products forming on AZ31B-H24 surfaces during exposure to $\mathrm{La}^{3+}$ and $\mathrm{Gd}^{3+}$ as a function of anodic galvanostatic polarization and the measured $\mathrm{pH}$ from Section 5.3.4. Figure 5.25a indicates that $\mathrm{Mg}(\mathrm{OH})_{2}$ is the primary dissolution product forming on the AZ31B-H24 surface at $10^{-3} \mathrm{M}$ $\mathrm{La}^{3+}$ and $10^{-2} \mathrm{La}^{3+}$ regardless of the applied anodic current density. However, there appears to be another species present on during immersion in $10^{-1} \mathrm{M} \mathrm{La}^{3+}$. This species could not be identified from RRUFF database [15] or in the literature but maybe related to $\mathrm{La}(\mathrm{OH})_{3}$ or $\mathrm{La}(\mathrm{CO})_{3}(\mathrm{OH})$. For $\mathrm{Gd}^{3+}$, only $\mathrm{Mg}(\mathrm{OH})_{2}$ was determined to be forming as shown in Figure $5.25 \mathrm{~b}$ for $10^{-3} \mathrm{M} \mathrm{Gd}^{3+}$ and $10^{-2} \mathrm{M} \mathrm{Gd}^{3+}$ while the formation of $\mathrm{Gd}(\mathrm{OH})_{3}$ or a $\mathrm{Gd}$ carbonate species is apparent in $10^{-1} \mathrm{M} \mathrm{Gd}^{3+}$ based on the similarities to $\mathrm{La}(\mathrm{CO})_{3}(\mathrm{OH})$. 
(a)

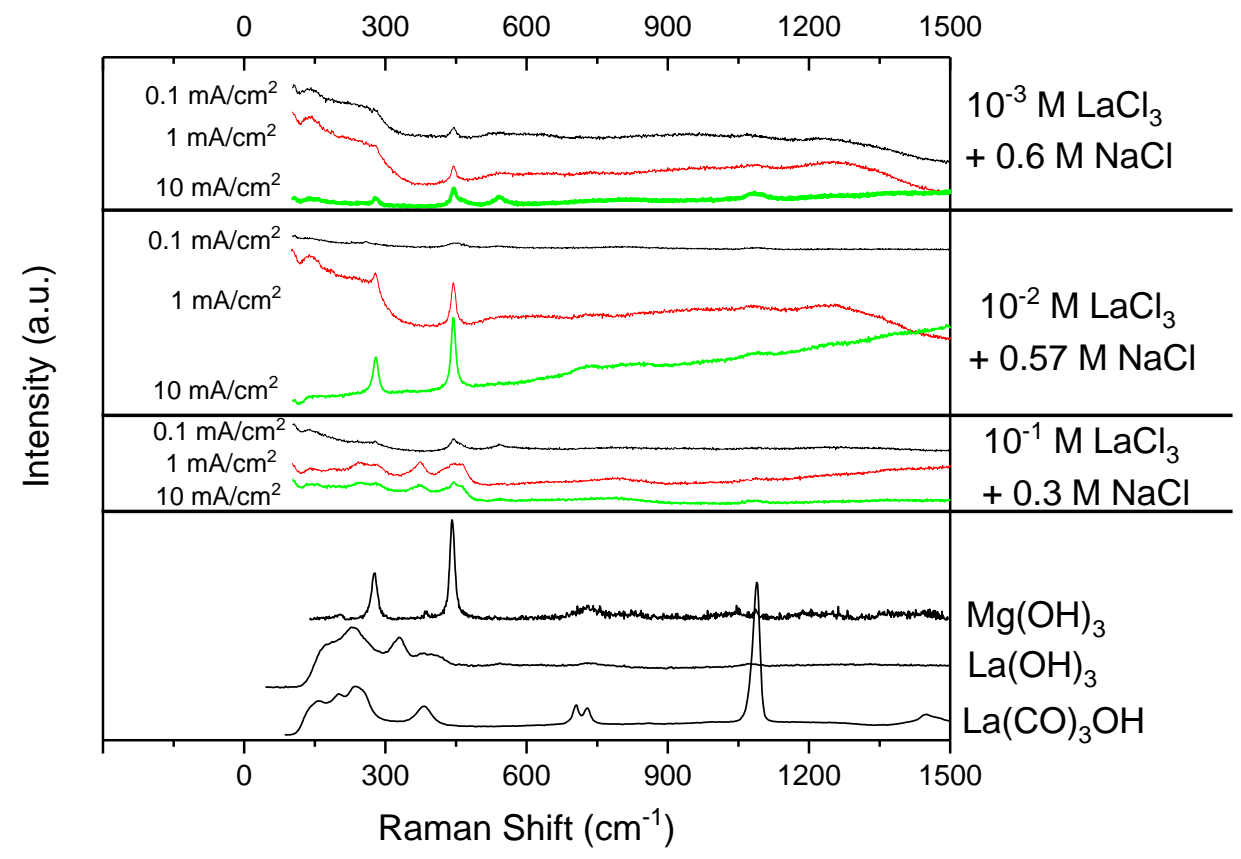

(b)

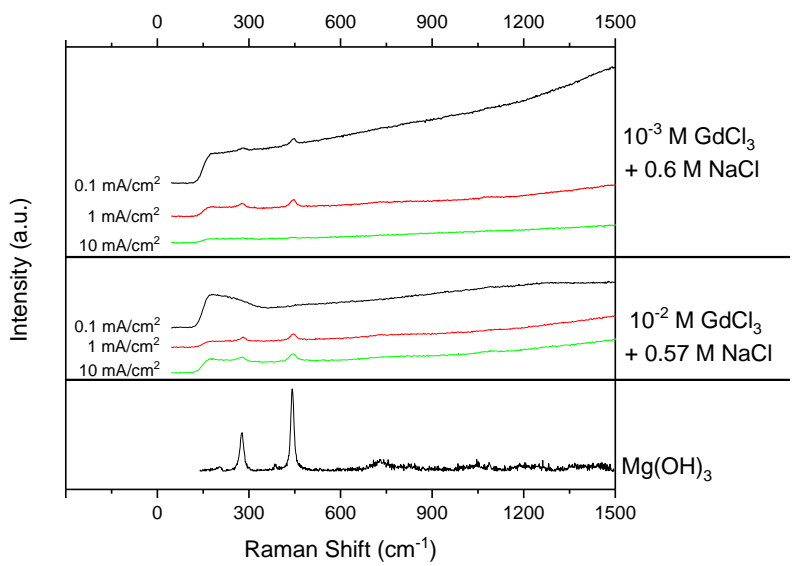

(c)

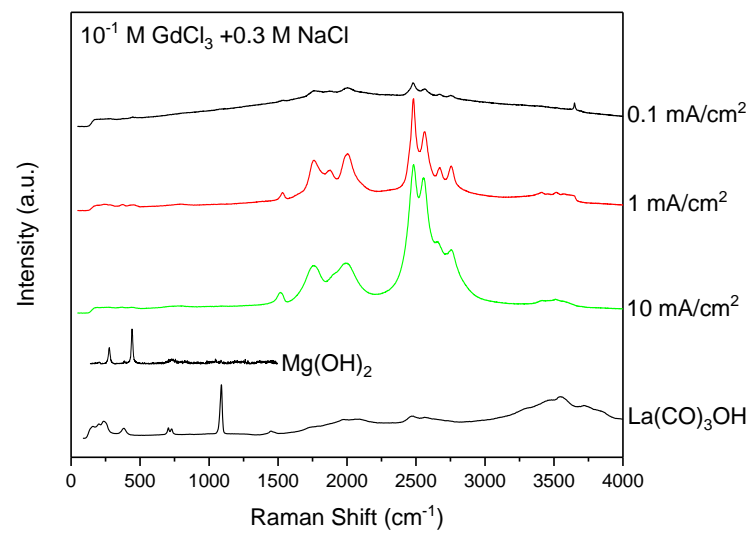

Figure 5.25. Raman spectra measured on AZ31B-H24 after 24 hour anodic galvanostatic polarization in each solution tested in Section 5.3.4. (a) shows the results for conditions with $\mathrm{La}^{3+}$ compared to $\mathrm{Mg}(\mathrm{OH})_{2}, \mathrm{La}(\mathrm{OH})_{3}$, and $\mathrm{La}(\mathrm{CO})_{3} \mathrm{OH}$ standards while (b) shows the results for $10^{-3} \mathrm{M} \mathrm{Gd}^{3+}$ and $10^{-2} \mathrm{M} \mathrm{Gd}^{3+}$ compared to $\mathrm{Mg}(\mathrm{OH})_{2}$ standard and (c) shows the results for $10^{-1}$ $\mathrm{M} \mathrm{Gd}^{3+}$ compared to $\mathrm{Mg}(\mathrm{OH})_{2}$ standard and the standard for $\mathrm{La}(\mathrm{CO})_{3} \mathrm{OH}$ used as a proxy to $\mathrm{Gd}$ species as no standards for Gd were available. 


\subsection{Discussion}

\subsubsection{Role of Inhibitor on AZ31B-H24 Corrosion Kinetics}

The results presented here demonstrate that the corrosion resistance of AZ31B-H24 can be increased under freely corroding conditions in $\mathrm{Cl}^{-}$environments in the presence of $\mathrm{La}^{3+}$ and $\mathrm{Gd}^{3+}$ ions provided the concentration was low enough. This was shown through gravimetric mass loss measurements for $\left[\mathrm{RE}^{3+}\right]$ less than $10^{-2} \mathrm{M}$ as show in Figure 5.6. This is likely due to the small decrease in anodic kinetics observed at $10^{-4} \mathrm{M}$ and $10^{-3} \mathrm{M} \mathrm{La}^{3+}$ and $\mathrm{Gd}^{3+}$ within approximately $+150 \mathrm{mV}$ above OCP compared to $0.6 \mathrm{M} \mathrm{NaCl}$ in the $\mathrm{E}$ vs. $\log \mathrm{i}$ behavior observed in Figure 5.4 after 10 minutes immersion compared to high concentrations of inhibitor ion which saw a decrease in anodic slope and shift to higher anodic current densities. Thus, $\mathrm{La}^{3+}$ and $\mathrm{Gd}^{3+}$ may function as anodic inhibitors as the cathodic $\mathrm{E}$ vs. $\log \mathrm{i}$ did not indicate a reduction in the cathodic kinetics with respect to AZ31B-H24 exposed in $0.6 \mathrm{M} \mathrm{NaCl}$ with no inhibitor ion. Furthermore, the cathodic HER kinetics of inhibitor containing solutions increased with increasing inhibitor concentration during cyclic anodic-cathodic polarization testing in Section 5.3.3. However, this decrease in anodic kinetics was not present with or without inhibitor present after 24 hours immersion which indicates that that any passive film which may have formed broke down in the aggressive chloride environment and did not provide additional corrosion protection as AZ31BH24 dissolution progressed. The optical micrographs presented in this chapter shows that the dissolution film did indeed breakdown and was often cracked which allows for the ingress of chloride ions through the film to react with exposed Mg surface. Furthermore, the films formed were not continuous as noted by the black and white corroded areas. These two separate areas are related to two types of filiform corrosion (FFC) which occurs on AZ31B-H24 in chloride [16,17]. The white dissolution film formed is related to the first breakdown potential observed during OCP 
measurements in Figure 5.3 and is characteristic of the formation of a thin corrosion product. The second breakdown potential observed at later times coincides with a much deeper corrosion product layer. The inhibitors tested here did not delay the onset of the first form of FFC but a delay in the onset of the second form of FFC was observed with $10^{-4} \mathrm{M} \mathrm{La}^{3+}$ and $\mathrm{Gd}^{3+}$ which may attribute to the lower measured mass loss after 24 hours immersion.

\subsubsection{Influence of pH on Dissolution Film Formation and Polarization Resistance}

In this investigation, the final bulk $\mathrm{pH}$ measured in solution was observed to occur in two different regimes; below approximately $\mathrm{pH}=7$ and near $\mathrm{pH}=10$. These two regimes of $\mathrm{pH}$ exist due to buffering of the solution as $\mathrm{La}^{3+}$ or $\mathrm{Gd}^{3+}$ ions in solution are consumed over time with $\mathrm{Mg}$ corrosion at their respective equilibrium values of $\mathrm{pH}$ between the soluble ion and the solid hydroxide product. This is shown in Figure 5.26 where the dissolution trajectory of $\mathrm{Mg}$ is shown with respect to the equilibrium lines for $\mathrm{La}^{3+} / \mathrm{La}(\mathrm{OH})_{3}, \mathrm{Gd}^{3+} / \mathrm{Gd}(\mathrm{OH})_{3}$, and $\mathrm{Mg}^{2+} / \mathrm{Mg}(\mathrm{HO})_{2}$. A full derivation of the complex construction of these diagrams is given in the appendix in the appendix in Section 5.7. The dissolution trajectory of $\mathrm{Mg}$ in solution follows the blue dashed line in water with no inhibitor ion present whereas the black, red, and green dashed lines correspond to the dissolution trajectory of $\mathrm{Mg}$ in water with $10^{-3} \mathrm{M} \mathrm{La}^{3+}$ or $\mathrm{Gd}^{3+}$ (black), $10^{-2} \mathrm{M} \mathrm{La}^{3+}$ or $\mathrm{Gd}^{3+}$ (red), and $10^{-1} \mathrm{M} \mathrm{La}^{3+}$ or $\mathrm{Gd}^{3+}$ (green), respectively. As Mg dissolves in solution, the concentration of $\mathrm{Mg}^{2+}$ in solution will increase and the $\mathrm{pH}$ will increase as $\mathrm{Mg}$ dissolution produces $\mathrm{OH}^{-}$ions during HER. This rise in $\mathrm{pH}$ with addition of $\mathrm{Mg}^{2+}$ in solution will occur up to the point labelled by the stars on each $\mathrm{Mg}$ dissolution trajectory curve. It is at this point that the solution $\mathrm{pH}$ becomes high enough to begin precipitating $\mathrm{La}(\mathrm{OH})_{3}$ or $\mathrm{Gd}(\mathrm{OH})_{3}$ from the concentration of $\mathrm{La}^{3+}$ and $\mathrm{Gd}^{3+}$ in solution as governed by Equation 5.6 and Equation 5.7. The change in $\mathrm{pH}$ with further $\mathrm{Mg}$ dissolution after the stars becomes very small with large increases of $\mathrm{Mg}^{2+}$ in solution. This means 
that the $\mathrm{pH}$ is being buffered as $\mathrm{La}^{3+}$ or $\mathrm{Gd}^{3+}$ is being consumed by the formation of their respective hydroxides. Furthermore, the dissolution trajectory of Mg after the stars accounts for the decrease in $\mathrm{La}^{3+}$ or $\mathrm{Gd}^{3+}$ present in solution and after a certain level of dissolution (i.e., high production of $\mathrm{Mg}^{2+}$ and $\mathrm{OH}^{-}$in solution) all of the soluble $\mathrm{La}^{3+}$ or $\mathrm{Gd}^{3+}$ in solution will be consumed and the dissolution trajectory of $\mathrm{Mg}$ will be governed by only the increase in $\mathrm{Mg}^{2+}$ and production of $\mathrm{OH}^{-}$ with further $\mathrm{Mg}$ dissolution until the equilibrium condition for precipitation of $\mathrm{Mg}(\mathrm{OH})_{2}$ is satisfied. Thus, the final bulk $\mathrm{pH}$ in solution can be predicted with knowledge of the total $\mathrm{Mg}^{2+}$ in solution.

The final concentration of $\mathrm{Mg}^{2+}$ in solution was calculated based on the total anodic charge and assuming all of $\mathrm{Mg}^{2+}$ produced was equivalent to that charge. This is of course not the case due to the NDE but it works as a simple approximation for this calculation. The lines for the final $\left[\mathrm{Mg}^{2+}\right]$ in solution are labelled with the dotted lines for each applied galvanostatic current density. The final bulk $\mathrm{pH}$ measured will then occur at the intersection of these concentration lines and the curves for the $\mathrm{Mg}$ dissolution trajectory. However, this is only valid if the concentration of $\mathrm{Mg}^{2+}$ at intersection point occurs before the $\mathrm{Mg}^{2+} / \mathrm{Mg}(\mathrm{OH})_{2}$ stability line. If the intersection of the $\mathrm{Mg}$ dissolution trajectory and the $\mathrm{Mg}^{2+} / \mathrm{Mg}(\mathrm{OH})_{2}$ stability line occurs at a concentration below the total concentration of $\mathrm{Mg}^{2+}$ in solution, then the condition for equilibrium for precipitation of $\mathrm{Mg}(\mathrm{OH})_{2}$ is met and equilibrium will beachieved at this $\mathrm{pH}$. Further changes in $\mathrm{pH}$ will then depend on the precipitation kinetics of $\mathrm{Mg}(\mathrm{OH})_{2}$ vs. the dissolution kinetics of $\mathrm{Mg}$ oxidation to $\mathrm{Mg}^{2+}$. If the precipitation of $\mathrm{Mg}(\mathrm{OH})_{2}$ is faster than the production of $\mathrm{Mg}^{2+}$ in solution, then the concentration of $\mathrm{Mg}^{2+}$ in solution will decrease and the $\mathrm{pH}$ will be able to increase along the $\mathrm{Mg}^{2+} / \mathrm{Mg}(\mathrm{OH})_{2}$ stability line. 
The calculated final $\mathrm{pH}$ using this framework for each dissolution trajectory is labelled 1 for an applied current density of $0.1 \mathrm{~mA} / \mathrm{cm}^{2}, 2$ for $1 \mathrm{~mA} / \mathrm{cm}^{2}$, and 3 for $10 \mathrm{~mA} / \mathrm{cm}^{2}$. These results are shown in Figure 5.27 and show excellent agreement with the measured final values of bulk pH for both La and Gd given the simplified assumptions used. This also helps explain in part the dissolution films which form on the dissolving AZ31B-H24 surfaces during galvanostatic polarization. For example, the dissolution trajectory and final $\mathrm{pH}$ measured would only predict the formation of $\mathrm{La}(\mathrm{OH})_{3}$ and $\mathrm{Gd}(\mathrm{OH})_{3}$ at $10^{-1} \mathrm{M}$ inhibitor and the results of Raman spectroscopy suggest that species of this nature precipitates on AZ31B-H24 surfaces. However, this species was not observed in $10^{-2}$ and $10^{-3} \mathrm{M}$ inhibitor and only $\mathrm{Mg}(\mathrm{OH})_{2}$ could be identified. The $\mathrm{Mg}$ dissolution trajectory plots only considered the chemical formation of $\mathrm{La}(\mathrm{OH})_{3}, \mathrm{Gd}(\mathrm{OH})_{3}$, and $\mathrm{Mg}(\mathrm{OH})_{2}$ in solution. It is possible that the lack of presence of $\mathrm{La}(\mathrm{OH})_{3}$ and $\mathrm{Gd}(\mathrm{OH})_{3}$ type species on the $\mathrm{Mg}$ surface is due to direct electrochemical formation of $\mathrm{Mg}(\mathrm{OH})_{2}$ occurred via:

$$
\mathrm{Mg}+2 \mathrm{H}_{2} \mathrm{O} \rightarrow \mathrm{Mg}(\mathrm{OH})_{2}+\mathrm{H}_{2} \quad \text { Equation } 5.5
$$

Any $\mathrm{La}(\mathrm{OH})_{3}$ or $\mathrm{Gd}(\mathrm{OH})_{3}$ may form in solution but may not be precipitated out on the AZ31BH24 surfaces and would not be found via Raman spectroscopy. 
(a)

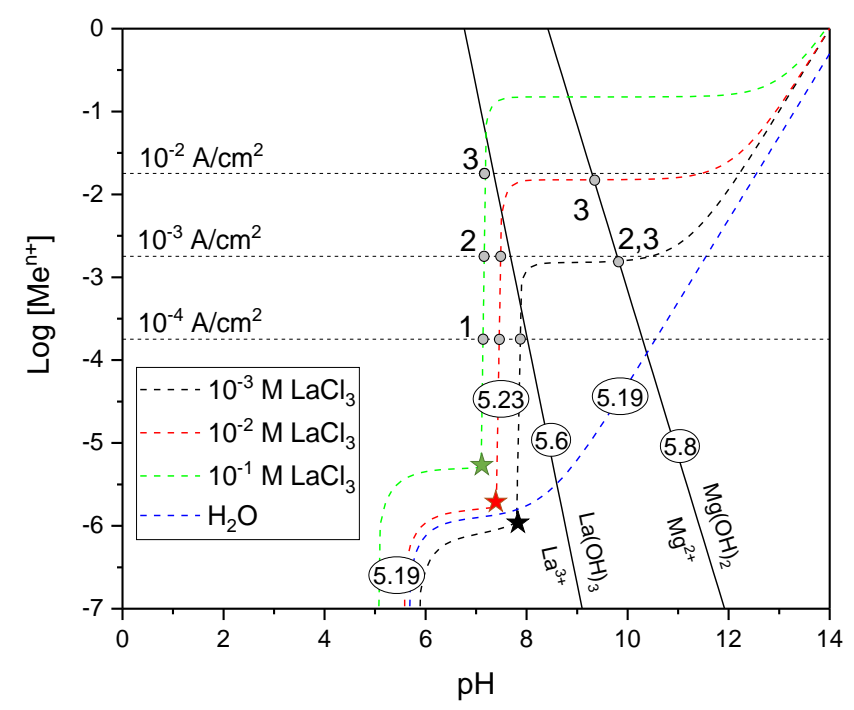

(b)

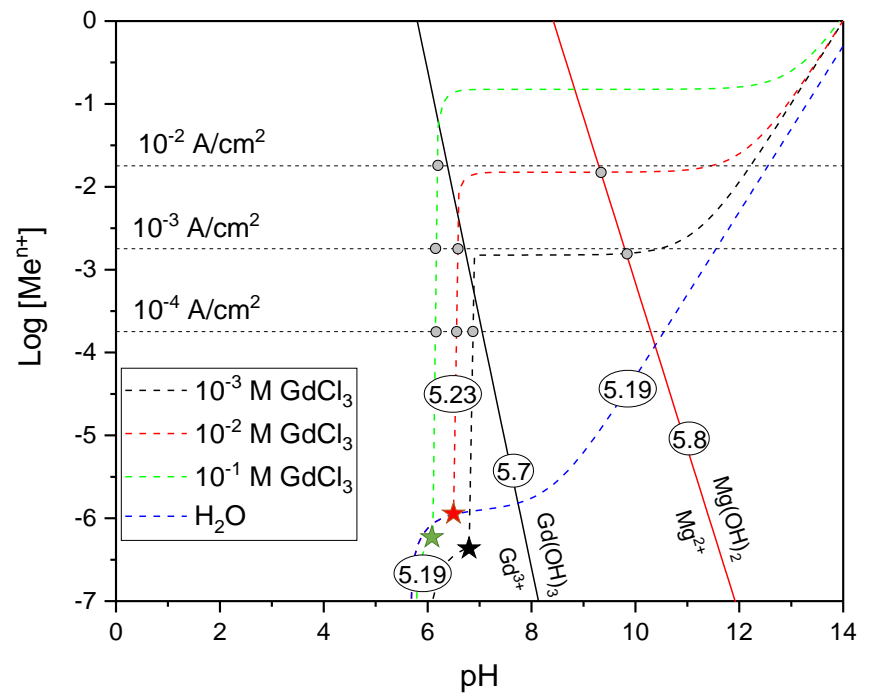

Figure 5.26. Chemical stability diagram for (a) $\mathrm{La}^{3+}$ and (b) $\mathrm{Gd}^{3+}$ systems showing the dissolution trajectory of $\mathrm{Mg}$ during corrosion. The dissolution trajectories for different levels of $\mathrm{La}^{3+}$ or $\mathrm{Gd}^{3+}$ and the case of no inhibitor ion (blue) are shown by the dashed lines. The horizontal dotted lines indicate what the theoretical concentration of $\mathrm{Mg}^{2+}$ would be in solution at the end of each galvanostatic hold. The intersection of the dissolution trajectory with either the theoretical $\left[\mathrm{Mg}^{2+}\right]$ or the chemical stability lines are indicated by the grey dots and indicate the theoretical final $\mathrm{pH}$. The dots labelled 1 are after an applied current density of $0.1 \mathrm{~mA} / \mathrm{cm}^{2}$ for 24 hours, the dots labelled 2 for $1 \mathrm{~mA} / \mathrm{cm}^{2}$ and the dots labelled 3 for $10 \mathrm{~mA} / \mathrm{cm}^{2}$. 
(a)

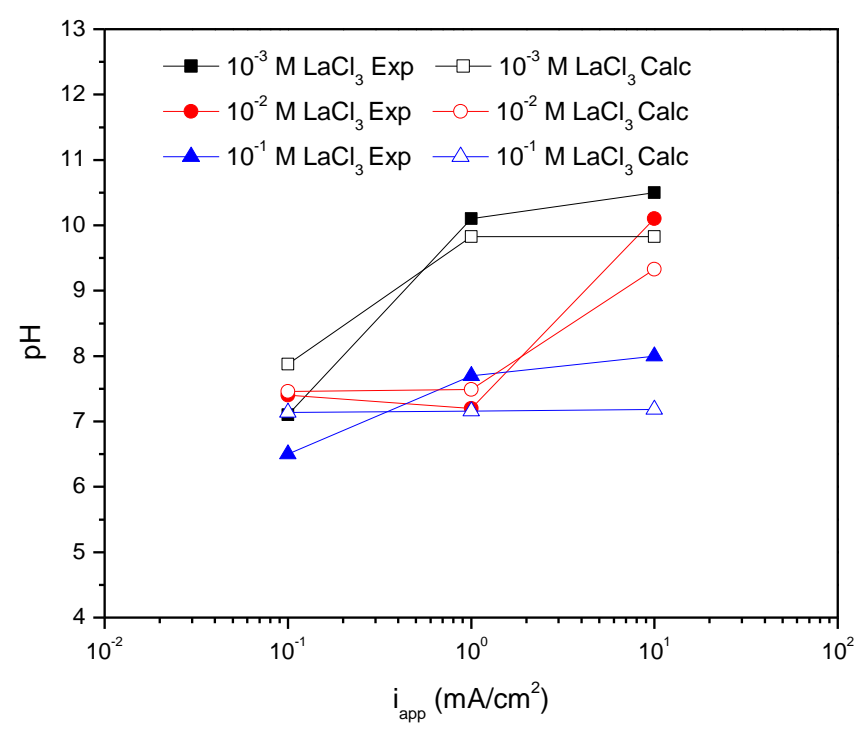

(b)

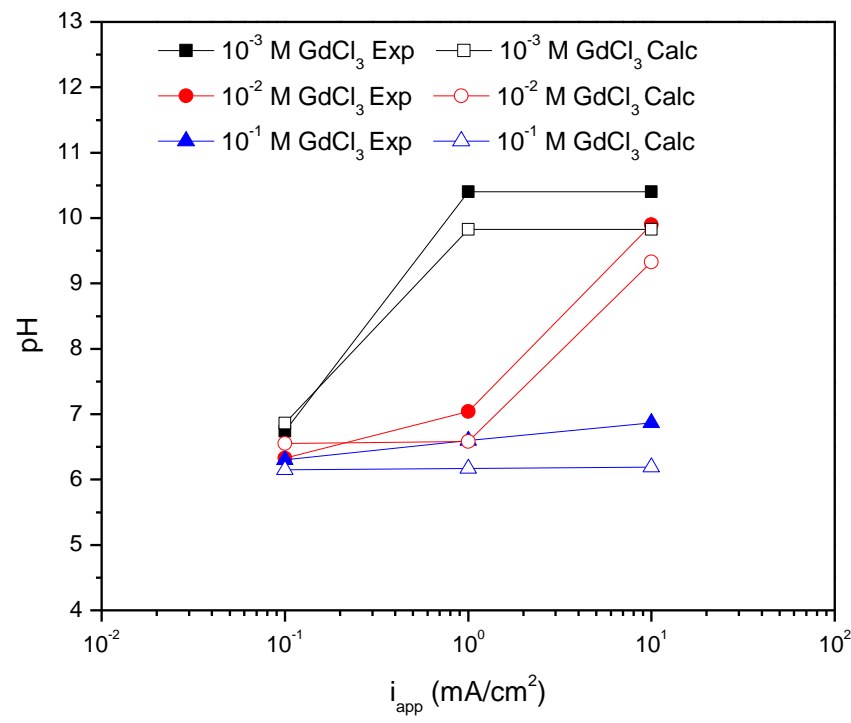

Figure 5.27. Comparison of the calculated final $\mathrm{pH}$ using the $\mathrm{Mg}$ dissolution trajectory and chemical stability diagram in Figure 5.26 compared to the measured final $\mathrm{pH}$ after anodic galvanostatic polarization experiments in Section 5.3.4 for (a) $\mathrm{LaCl}_{3}$ and (b) $\mathrm{GdCl}_{3}$. Excellent agreement between the calculated and measured values of $\mathrm{pH}$ is observed. 


\subsubsection{Implications on Design Multifunctional Coatings for AZ31B-H24}

The results of this chapter suggest that large alloy contents of La and Gd should be avoided in $\mathrm{Mg}$ as increases in $\mathrm{La}^{3+}$ and $\mathrm{Gd}^{3+}$ ion concentration in solution leads to increased corrosion rates via enhanced anodic and cathodic kinetics and lack of passive film formation. However, there may be some benefit to small additions of either RE element in a sacrificial alloy but it is unclear what concentration of La or Gd in an alloy would be able to achieve the decrease in corrosion rate found with respect to AZ31B-H24 immersed in $0.6 \mathrm{M} \mathrm{NaCl}$. The large enhancement in cathodic kinetics is also a concern with respect to galvanic coupling as reduction of cathodic kinetics and suppression of enhanced cathodic kinetics is required to improve sacrificial cathodic protection of AZ31B-H24. The observations of increasing cathodic kinetics with increasing concentration of La or $\mathrm{Gd}$ are in agreement with experimental results of pure $\mathrm{La}$ and $\mathrm{Gd}$ in $0.1 \mathrm{M} \mathrm{NaCl}$ which showed large enhanced cathodic kinetics [18]. 


\subsection{Conclusions}

Based on the results of this chapter, the following can be concluded:

- The corrosion inhibition of AZ31B-H24 was limited in the presence of $\mathrm{La}^{3+}$ and $\mathrm{Gd}^{3+}$ ions. Almost a 2x decrease in mass loss was observed at inhibitor ion concentrations less than $10^{-2} \mathrm{M}$ in comparison to no inhibitor but mass loss rapidly increased at inhibitor ion greater than $10^{-2} \mathrm{M}$ due to increases in the anodic and cathodic reaction rates.

- Novel chemical stability diagrams constructed for the dissolution trajectory of $\mathrm{Mg}$ in $\mathrm{La}^{3+}$ and $\mathrm{Gd}^{3+}$ environments were found to accurately predict the behavior of $\mathrm{pH}$ as a function of $\mathrm{Mg}$ dissolution.

- $\mathrm{Mg}(\mathrm{OH})_{2}$ primarily formed on AZ31B-H24 surface except at inhibitor concentrations greater than $0.1 \mathrm{M}$ where precipitation of species related to the respective inhibitor ion formed on the AZ31B-H24 surface. Precipitation of these species provided little benefit to increase the corrosion resistance of AZ31B-H24.

- The use of $\mathrm{La}$ and $\mathrm{Gd}$ as alloying additions for a multifunctional Mg-based sacrificial coating is cautioned based on the rapid increase in anodic and cathodic kinetics with increasing $\mathrm{La}^{3+}$ and $\mathrm{Gd}^{3+}$ in solution and the limited ability to inhibit $\mathrm{Mg}$ corrosion in the presence of $\mathrm{Cl}^{-}$. 


\subsection{References}

[1] M. Forsyth, B. Hinton, eds., Rare Earth-Based Corrosion Inhibitors, Woodhead Publishing, 2014.

[2] X.-B. Chen, T. Cain, J.R. Scully, N. Birbilis, "Technical Note: Experimental Survey of Corrosion Potentials for Rare Earth Metals Ce, Er, Gd, La, and $\mathrm{Nd}$ as a Function of $\mathrm{pH}$ and Chloride Concentration," CORROSION. 70 (4) , 323-328, 2014.

[3] J.R. Scully, F. Presuel-Moreno, M. Goldman, R.G. Kelly, N. Tailleart, "User-selectable barrier, sacrificial anode, and active corrosion inhibiting properties of Al-Co-Ce alloys for coating applications," Corrosion. 64 (3) , 210-229, 2008.

[4] F. Presuel-Moreno, M.A. Jakab, N. Tailleart, M. Goldman, J.R. Scully, "Corrosion-resistant metallic coatings," Mater. Today. 11 (10) , 14-23, 2008.

[5] M.A. Jakab, J.R. Scully, "On-demand release of corrosion-inhibiting ions from amorphous Al-Co-Ce alloys," Nat. Mater. 4 (9) , 667-670, 2005.

[6] H. Horikiri, A. Kato, A. Inoue, T. Masumoto, "New Mg-based amorphous alloys in Mg- Ymisch metal systems,” Mater. Sci. Eng. A. 179, 702-706, 1994.

[7] A.L. Rudd, C.B. Breslin, F. Mansfeld, "The corrosion protection afforded by rare earth conversion coatings applied to magnesium," Corros. Sci. 42 (2), 275-288, 2000.

[8] M.F. Montemor, A.M. Simões, M.J. Carmezim, "Characterization of rare-earth conversion films formed on the AZ31 magnesium alloy and its relation with corrosion protection," Appl. Surf. Sci. 253 (16) , 6922-6931, 2007.

[9] F.E.-T. Heakal, O.S. Shehata, N.S. Tantawy, "Enhanced corrosion resistance of magnesium alloy AM60 by cerium(III) in chloride solution," Corros. Sci. 56 , 86-95, 2012.

[10] G. Jin, Y. Yang, X. Cui, E. Liu, Z. Wang, Q. Li, "Chrome-free neodymium-based protective coatings for magnesium alloys," Mater. Lett. 65 (8) , 1145-1147, 2011.

[11] O.V. Karavai, A.C. Bastos, M.L. Zheludkevich, M.G. Taryba, S.V. Lamaka, M.G.S. Ferreira, "Localized electrochemical study of corrosion inhibition in microdefects on coated AZ31 magnesium alloy," Electrochimica Acta. 55 (19) , 5401-5406, 2010.

[12] L. Li, Q. Qu, Z.W. Fang, L. Wang, Y. He, R. Yuan, Z. Ding, "Enhanced corrosion resistance of AZ31B magnesium alloy by cooperation of rare earth cerium and stannate conversion coating,” Int J Electrochem Sci. 7 , 12690-12705, 2012.

[13] A.D. King, N. Birbilis, J.R. Scully, "Accurate Electrochemical Measurement of Magnesium Corrosion Rates; a Combined Impedance, Mass-Loss and Hydrogen Collection Study," Electrochimica Acta. 121 , 394-406, 2014.

[14] L.G. Bland, A.D. King, N. Birbilis, J.R. Scully, "Assessing the Corrosion of Commercially Pure Magnesium and Commercial AZ31B by Electrochemical Impedance, Mass-Loss, Hydrogen Collection, and Inductively Coupled Plasma Optical Emission Spectrometry Solution Analysis," CORROSION. 71 (2) , 128-145, 2015.

[15] B. Lafuente, R.T. Downs, H. Yang, N. Stone, 2015 Power Databases RRUFF Proj. Highlights Mineral. Crystallogr. T Armbruster R M Danisi Eds Berl. Ger. W Gruyter Pp 1-30. n.d.

[16] M.A. Melia, T.W. Cain, B.F. Briglia, J.R. Scully, J.M. Fitz-Gerald, "Evolution of the Corrosion Morphology on AZ31B Tracked Electrochemically and by In Situ Microscopy in Chloride-Containing Media," JOM. 69 (11) , 2322-2327, 2017.

[17] H.M. Krebs, A. Chiraz, L. Lechnar, J. Gleb, X. Zhou, G.E. Thompson, P.J. Withers, TimeEvolved Correlative Imaging Applied to the Corrosion Study of Mg Alloys in Alkali Environment, in: Hyerdabad, India, 2015. 
[18] R.L. Liu, S. Thomas, J.R. Scully, G. Williams, N. Birbilis, "An Experimental Survey of the Cathodic Activation of Metals Including $\mathrm{Mg}, \mathrm{Sc}, \mathrm{Gd}, \mathrm{La}, \mathrm{Al}, \mathrm{Sn}, \mathrm{Pb}$, and $\mathrm{Ge}$ in Dilute Chloride Solutions of Varying pH," CORROSION. 73 (5) , 494-505, 2017.

[19] C. Ekberg, P.L. Brown, Hydrolysis of Metal Ions, Wiley-VCH, Weinheim, Germany, 2016. 


\subsection{Appendix- Construction of Chemical Stability Diagrams and Mg Dissolution Trajectory}

\subsubsection{Plotting Equilibrium Stability Boundaries}

Construction of the chemical stability diagrams presented in this chapter begins with plotting the equilibrium reaction boundaries for $\mathrm{La}^{3+}, \mathrm{Gd}^{3+}$, and $\mathrm{Mg}^{2+}$ precipitation to their respective hydroxides. The chemical reaction for these equilibrium reaction is given below:

$$
\begin{array}{lr}
\mathrm{La}^{3+}+3 \mathrm{OH}^{-} \rightleftharpoons \mathrm{La}(\mathrm{OH})_{3}, \mathrm{~K}_{\mathrm{sp}}=19.6 & \text { Equation } 5.6 \\
\mathrm{Gd}^{3+}+3 \mathrm{OH}^{-} \rightleftharpoons \mathrm{Gd}(\mathrm{OH})_{3}, \mathrm{~K}_{\mathrm{sp}}=17.4 & \text { Equation } 5.7 \\
\mathrm{Mg}^{2+}+2 \mathrm{OH}^{-} \rightleftharpoons \mathrm{Mg}(\mathrm{OH})_{2}, \mathrm{~K}_{\mathrm{sp}}=17.1 & \text { Equation } 5.8
\end{array}
$$

where solubility products were taken from [19]. The equilibrium boundaries can then be plotted as a function of soluble ion concentration and $\mathrm{pH}$ via:

$$
\begin{aligned}
& \log \left[L a^{3+}\right]=19.6-3 p H \\
& \text { Equation 5.9 } \\
& \log \left[G d^{3+}\right]=17.4-3 p H \\
& \text { Equation } 5.10 \\
& \log \left[M g^{2+}\right]=17.1-2 p H
\end{aligned}
$$

These boundaries are plotted for treatment here without considering complexation of $\mathrm{Cl}^{-}$or other species with chemical equilibrium boundaries and also do not consider the ionic strength which adds additional complexities.

\subsubsection{Plotting the Mg Dissolution Trajectory}

To plot the Mg dissolution trajectory during Mg dissolution, we begin with the dissolution of $\mathrm{Mg}$ where the anodic reaction is given by:

$$
M g \rightarrow M g^{2+}+2 e^{-}
$$

Equation 5.12

and the cathodic reaction is given by:

$$
2 \mathrm{H}^{+}+2 e^{-} \rightarrow \mathrm{H}_{2}
$$

Equation 5.13 


$$
\begin{aligned}
& \text { or } \\
& \mathrm{H}_{2} \mathrm{O}+2 e^{-} \rightarrow 2 \mathrm{OH}^{-}+2 \mathrm{H}_{2} \quad \text { Equation } 5.14
\end{aligned}
$$

where $2 \mathrm{H}^{+}$ions are consuming the $2 \mathrm{e}^{-}$to form $\mathrm{H}_{2}$ gas which creates a deficit of $\mathrm{H}^{+}$in solution compared to the initial concentration of $\mathrm{H}^{+}$or $\mathrm{OH}^{-}$is being produced which also decreases the concentration of $\mathrm{H}^{+}$in solution. Thus, at during electrochemical dissolution of $\mathrm{Mg}$ at $\mathrm{OCP}$, there for every mol of $\mathrm{Mg}$ dissolved, $2 \mathrm{H}^{+}$are, in effect, being consumed. This ratio of $\mathrm{Mg}^{2+}: \mathrm{H}^{+}$will be assumed for simplicity for anodic dissolution of $\mathrm{Mg}$. This of course is not true due to manifestation of the NDE difference effect where the ratio of $\mathrm{Mg}^{2+}: \mathrm{H}^{+}$is greater than 1:2 (Chapter 3) but determination of the exact ratio of $\mathrm{Mg}^{2+}: \mathrm{H}^{+}$would involve a large amount of experimental work for each solution and applied current density. Nonetheless, it works as a good approximation for treatment here. Similar to the deficit of $\mathrm{H}^{+}$, an excess of $\left[\mathrm{Mg}^{2+}\right]$ relative to the initial $\left[\mathrm{Mg}^{2+}\right]$ in solution occurs with increased $\mathrm{Mg}$ dissolution.

The relationship between excess $\mathrm{Mg}^{2+}$ and deficit of $\mathrm{H}^{+}$due to dissolution is given by:

$$
\left[\mathrm{Mg}^{2+}\right]_{\text {excess }}=\frac{1}{2}\left(\left[\mathrm{H}^{+}\right]_{\text {init }}-\left[\mathrm{H}^{+}\right]_{\text {inst }}\right)
$$

here $\left[\mathrm{H}^{+}\right]_{\text {init }}$ is the initial concentration of $\mathrm{H}^{+}$in solution while $\left[\mathrm{H}^{+}\right]_{\text {inst }}$ is the instantaneous concentration $\mathrm{H}^{+}$produced after production of excess $\mathrm{Mg}^{2+}$. Likewise, the relationship of excess $\mathrm{Mg}^{2+}$ production to excess production of $\mathrm{OH}^{-}$is:

$$
\left[\mathrm{Mg}^{2+}\right]_{\text {excess }}=\frac{1}{2}\left(\left[\mathrm{OH}^{-}\right]_{\text {inst }}-\left[\mathrm{OH}^{-}\right]_{\text {init }}\right)
$$

Both of these relations need to be considered across the entire spectrum of $\mathrm{pH}$ as $\mathrm{H}^{+}$dominates at $\mathrm{pH}$ below 7 and $\mathrm{OH}^{-}$dominates at $\mathrm{pH}$ greater than 7. The concentration of $\mathrm{H}^{+}$and $\mathrm{OH}^{-}$can be described by the $\mathrm{pH}$ where:

$$
p H=-\log \left[H^{+}\right]
$$




$$
\begin{gathered}
\text { or } \\
p H=14+\log \left[\mathrm{OH}^{-}\right]
\end{gathered}
$$

When the initial concentration of $\mathrm{Mg}^{2+}$ is considered, the following can be derived to explain the relationship between $\left[\mathrm{Mg}^{2+}\right]$ and $\mathrm{pH}$ :

$$
\begin{aligned}
\log \left[\mathrm{Mg}^{2+}\right]_{\text {inst }} & =\log \left(\left[\mathrm{Mg}^{2+}{ }_{\text {init }}\right]+\frac{1}{n}\left[10^{-p H_{\text {init }}}-10^{-p H_{\text {inst }}}\right]\right. \\
& \left.+\frac{1}{n}\left[10^{p H_{\text {inst }}-14}-10^{p H_{\text {init }}-14}\right]\right)
\end{aligned}
$$

Equation 5.19

where $\mathrm{n}=2$ for $\mathrm{Mg}^{2+}$. This relationship is valid for just $\mathrm{Mg}^{2+}$ and water and does not consider the buffering effects of chemical conversion of $\mathrm{La}^{3+}$ and $\mathrm{Gd}^{3+}$ to their respective hydroxides in solution. Thus, the Mg dissolution trajectory described in Equation 5.19 is only valid up to the equilibrium pH governed by Equation 5.9 and Equation 5.10 for La and Gd, respectively. At this $\mathrm{pH}$, further changes in $\mathrm{pH}$ with increasing $\left[\mathrm{Mg}^{2+}\right]$ in solution must include the deficit of $\mathrm{La}^{3+}$ and $\mathrm{Gd}^{3+}$ with $\mathrm{Mg}$ dissolution.

To account for buffer of $\mathrm{La}^{3+}$ and $\mathrm{Gd}^{3+}$ a new balanced equilibrium expression needs to be made. As both La and Gd have a valence state of +3 , the derivation will be the same and we will proceed using La. The balanced equation for dissolution of $\mathrm{Mg}$ and precipitation of $\mathrm{La}(\mathrm{OH})_{3}$ is given by:

$$
\mathrm{Mg}+\frac{2}{3} \mathrm{La}^{3+}+2 \mathrm{H}_{2} \mathrm{O}=\mathrm{Mg}^{2+}+\frac{2}{3} \mathrm{La}(\mathrm{OH})_{3}+\mathrm{H}_{2}
$$

It is evident that higher production of $\mathrm{Mg}^{2+}$ is required to change the $\mathrm{pH}$ as $\mathrm{La}^{3+}$ is consuming the $\mathrm{OH}^{-}$produced. Thus, the excess $\mathrm{Mg}^{2+}$ required is proportional to 2/3 excess of $\mathrm{La}(\mathrm{OH})_{3}$ produced.

$$
\left[\mathrm{Mg}^{2+}\right]_{\text {excess }}=\frac{3}{2}\left[\mathrm{La}(\mathrm{OH})_{3}\right]_{\text {excess }}
$$

where 


$$
\left[\mathrm{La}(\mathrm{OH})_{3}\right]_{\text {excess }}=\left[\mathrm{La}^{3+}\right]_{\text {init }}-10^{19.6-3 p H}
$$

Equation 5.22

Thus, the excess $\mathrm{Mg}^{2+}$ needed is given by the combination of Equation 5.21 and Equation 5.22 into Equation 5.19 yielding:

$$
\begin{aligned}
\log \left[\mathrm{Mg}^{2+}\right]= & \log \left(\frac{3}{2}\left(\left[\mathrm{La}^{3+}\right]_{\text {init }}-10^{19.6-3 p H}\right)+\left[\mathrm{Mg}^{2+}{ }_{\text {init }}\right]\right. \\
& \left.+\frac{1}{1}\left[10^{-p H_{\text {init }}}-10^{-p H_{\text {inst }}}\right]+\frac{1}{1}\left[10^{p H_{\text {inst }}-14}-10^{p H_{\text {init }}-14}\right]\right)
\end{aligned}
$$

where the initial $\mathrm{pH}$ is the equilibrium $\mathrm{pH}$ given by Equation 5.9.

To perform the calculations, the initial $\mathrm{pH}$ for Equation 5.19 was taken as the measured initial $\mathrm{pH}$ during experimental testing and the initial $\left[\mathrm{Mg}^{2+}\right]$ is taken to be $10^{-10} \mathrm{M}$ which is sufficiently small to produce $\mathrm{Mg}$ dissolution trajectory prior to rare earth buffering in the $\mathrm{pH}$ range of interest. 


\section{Assessment of Mg-Sn Surface Alloys for the Sacrificial Cathodic Protection of Mg Alloy AZ31B}

\subsection{Introduction}

Sn has become a popular Mg alloying element for corrosion studies based on the low hydrogen evolution reaction (HER) exchange current density in addition to the ability to form an improved passive film in aqueous environments compared to pure $\mathrm{Mg}$ [1-5]. Furthermore, pure Sn has been shown to be an element which does not produce anodically enhanced cathodic kinetics [6]. These electrochemical properties limit the detrimental effects of the negative difference effect (NDE, i.e. the increase in HER rate with increasing anodic polarization) which makes $\mathrm{Mg}-\mathrm{Sn}$ an ideal candidate as a sacrificial alloy. Moreover, $\mathrm{Sn}$ has good solubility in $\mathrm{Mg}$ with a maximum equilibrium solid solubility of $14.48 \mathrm{wt} \%$ as shown in Figure 6.1 [7]. This enables for a wide range of composition to be explored without complications of micro-galvanic coupling due to the precipitation of secondary phases. This wide range of compositional solid solubility presents the opportunity for determination of a tuneable alloy system for cathodic protection meaning that the electrochemical properties such as the OCP, corrosion current density, passive current density, passive potential range, breakdown potential of $\mathrm{Mg}-\mathrm{Sn}$ anodes can be regulated and subsequently modeled as a function of $\mathrm{Sn}$ alloy content. Such factors can then be used to predict the galvanic couple potential and current for a given sacrificial system such that the optimized cathodic protection can be supplied as has been performed for Al-Co-Ce alloys for AA2024 [8,9]. However, this may be complicated by the lack of stability of dissolving Mg electrodes due to enhanced cathodic activity as well as rapid dissolution kinetics and dissolution film formation.

In this study, the corrosion behavior of solid solution $\mathrm{Mg}-\mathrm{xSn}(\mathrm{x}=1,5,10 \mathrm{wt} \%)$ alloys were studied under freely corroding conditions in $0.6 \mathrm{M} \mathrm{NaCl}$ utilizing electrochemical impedance 
spectroscopy (EIS) combined with in situ optical video. The cathodic activation of $\mathrm{Mg}$-Sn alloys was characterized by using a cycle of anodic galvanostatic pulses followed by cathodic potentiostatic polarization at $-2 \mathrm{~V}_{\mathrm{SCE}}$ as in Chapter 5. In addition, simulated galvanic couples between $\mathrm{Mg}$-Sn alloys and AZ31B were made using zero resistance ammeter testing to evaluate the sacrificial cathodic protection performance of each alloy. Finally, deposition of $\mathrm{Mg}$-Sn alloys on AZ31B alloys surfaces was attempted through the use of pulsed laser deposition (PLD) and evaluated for sacrificial cathodic protection. PLD was used for its excellent ability to maintain the stoichiometry of the target on the substrate during deposition.

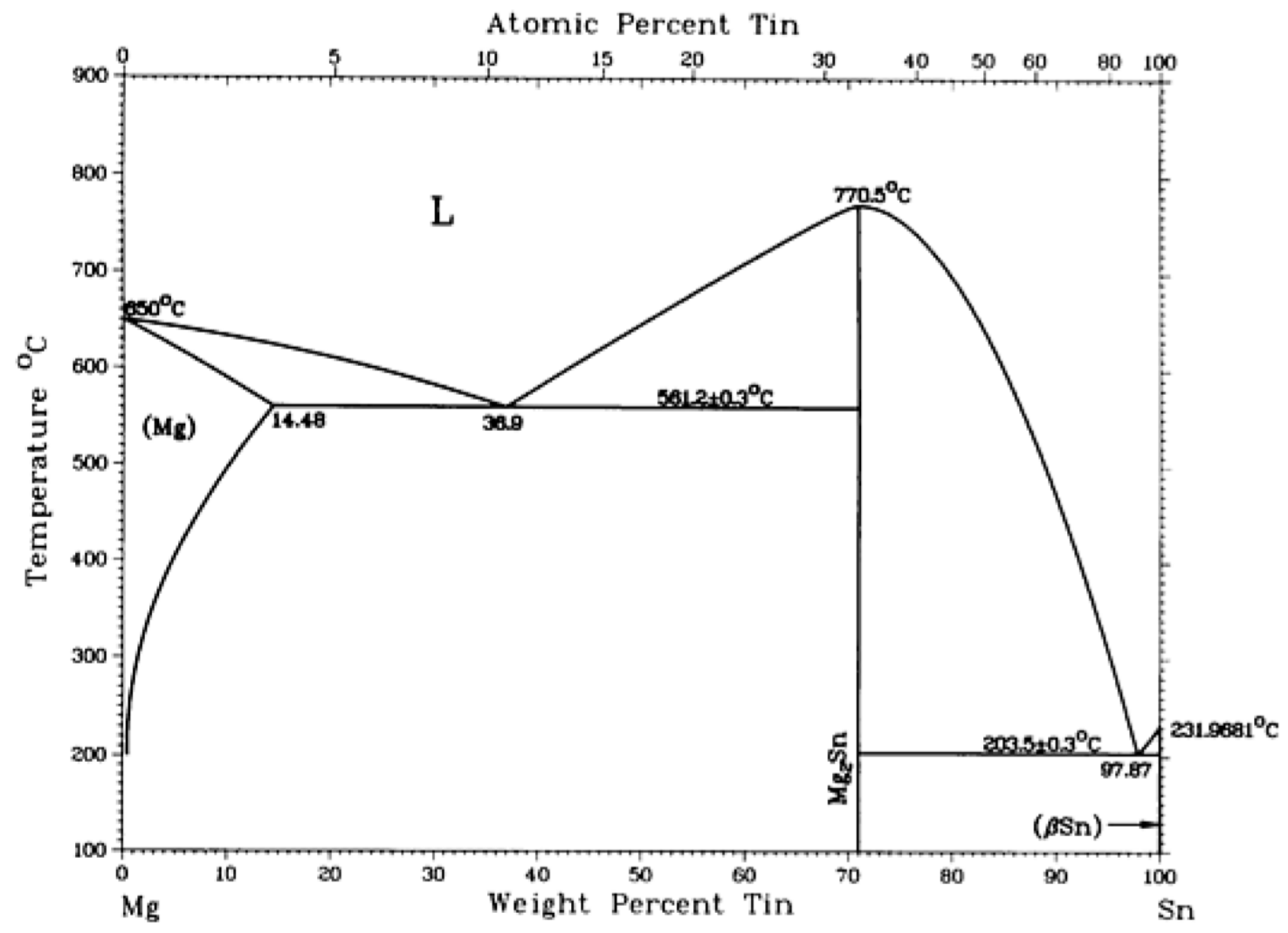

Figure 6.1. Equilibrium binary phase diagram for the Mg-Sn system [7]. 


\subsection{Experimental Procedures}

\subsubsection{Materials and Alloy Preparation}

High purity (HP) Mg (Alfa Aesar), Mg alloy AZ31B-H24 (Magnesium Elektron), and custom Mg-Sn alloys were used in this investigation. The compositions of these are found in Table 6.1. Mg-Sn alloys were prepared using pellets formed from the same lot of HP Mg used for electrochemical testing and 99.99\% pure Sn flakes containing <1 ppm As, <20 ppm Cu, 20 ppm $\mathrm{Fe}$, and $30 \mathrm{ppm} \mathrm{Pb}$. The appropriate weight of $\mathrm{Mg}$ and $\mathrm{Sn}$ were measured to create nominal $\mathrm{Mg}$ $1,5,10 \mathrm{wt} \%$ alloys by melting in a custom-built induction melting furnace. Prior to melting, materials were placed in a stainless steel crucible coated with BN. The induction melting furnace was backfilled with Ar and pumped below 50 mTorr three times to reduce the amount of oxygen in the chamber. Final melting was performed at a slightly positive pressure under Ar atmosphere to help prevent $\mathrm{Mg}$ vaporization during melting. After melting, the $\mathrm{Mg}$-Sn alloys were immediately cast into a stainless steel crucible coated in $\mathrm{BN}$ to produce buttons roughly 1.5 " in diameter and $1 / 8$ " thickness; one sample of each composition was made. The buttons were then hot rolled at $350^{\circ} \mathrm{C}$ to produce flat disks and homogenized for 24 hours at $525^{\circ} \mathrm{C}$ under $\mathrm{Ar}$ at atmospheric pressure and allowed to air cool. Finally, the $\mathrm{Mg}$-Sn alloys were solution treated at $525^{\circ} \mathrm{C}$ for 2 hours and water quenched to retain a solid solution. Scanning electron microscopy (SEM) operated in the backscattered electron mode (BSE) and X-ray diffraction (XRD) was performed to assess the microstructure of each Mg-Sn alloy. Powder XRD measurements employed $\mathrm{Cu}_{\alpha}$. radiation using a PANalytical X'pert Pro multipurpose diffractometer at $45 \mathrm{kV}$ and $40 \mathrm{~mA}$ in a BraggBrentano $\theta-2 \theta$ geometry and scanned from $15-70^{\circ} 2 \theta$. The PANalytical HighScore software package was used to perform peak matching. 
Table 6.1. Composition (wt\%) of materials used in this investigation. Analysis of HP Mg and AZ31B-H24 performed by Quantitative Testing Corporation (QUANT) using ICP-OES. MgSn alloys were quantified by X-ray fluorescence.

\begin{tabular}{|c|c|c|c|c|c|c|c|c|c|c|}
\hline Alloy & UNS\# & $\mathrm{Mg}$ & $\mathrm{Sn}$ & $\mathrm{Al}$ & $\mathrm{Zn}$ & $\mathrm{Mn}$ & $\mathrm{Fe}$ & $\mathrm{Ni}$ & $\mathrm{Cu}$ & $\mathrm{Pb}$ \\
\hline Mg-1Sn & & $\mathrm{Bal}$ & 1.23 & 0.02 & 0.005 & 0.002 & 0.002 & $<0.001$ & 0.002 & 0.002 \\
\hline Mg-5Sn & & Bal & 5.48 & 0.03 & 0.005 & 0.004 & 0.007 & $<0.001$ & 0.003 & 0.005 \\
\hline Mg-10Sn & & Bal & 10.65 & 0.02 & 0.004 & 0.002 & 0.001 & $<0.001$ & 0.003 & 0.002 \\
\hline HP Mg & & Bal & -- & 0.02 & 0.03 & $<0.01$ & 0.008 & $<0.001$ & 0.003 & -- \\
\hline AZ31B-H24 & M11311 & Bal & -- & 3.02 & 0.99 & 0.33 & 0.005 & 0.002 & 0.005 & -- \\
\hline
\end{tabular}

\subsubsection{Pulsed Laser Deposition of Mg-Sn Alloys on AZ31B}

Pulsed laser deposition (PLD) was performed at $1.5 \times 10^{-1}$ Torr of He, after reaching an ultimate pressure of $1.0 \times 10^{-5}$ Torr. The fluence of the laser was held at $2.0 \mathrm{~J} / \mathrm{cm}^{2}$ and pulsed at a rate of $10 \mathrm{~Hz}$. All films used in corrosion experiments were deposited using the above conditions for 20 minutes, yielding a thickness of $\approx 225 \mathrm{~nm}$ as determined by SEM (Figure 6.14d). In this investigation, the Mg-Sn alloys produced were used as the targets for coating on to AZ31B.

\subsubsection{Electrochemical testing}

Numerous electrochemical methods were utilized during this investigation to characterize the corrosion behavior of bulk Mg-Sn alloys as well as PLD coated AZ31B. All experiments were permed under full immersion conditions in $250 \mathrm{~mL}$ of quiescent $0.6 \mathrm{M} \mathrm{NaCl}$ solution with a starting $\mathrm{pH}$ of about 5.6. All bulk samples for electrochemical testing were ground to a 1200 grit finish using $\mathrm{SiC}$ paper and ethanol as a lubricant. Samples were cleaned with ethanol and dried with a jet of compressed air after each grinding step. All electrochemical tests were performed at least twice on each sample.

The corrosion behavior of bulk Mg-Sn alloys was assessed under freely corroding conditions using a three electrode cell with $\mathrm{Mg}$-Sn working electrode, platinum mesh counter electrode, and a saturated calomel reference electrode at their open circuit potential (OCP) for 24 
hours. The polarization resistance $\left(\mathrm{R}_{\mathrm{p}}\right)$ was calculated at intervals of $0.5,3,6,12,18$, and 24 hours using electrochemical impedance spectroscopy (EIS). Measurements were performed over a frequency of $10^{5} \mathrm{~Hz}$ to $0.005 \mathrm{~Hz}$ at 6 points per decade with an amplitude of $\pm 10 \mathrm{mV}$. EIS spectra were analyzed and fit utilizing the ZView software and the equivalent circuit in Figure 5.2 which has been shown to most accurately calculate $\mathrm{Mg}$ corrosion rates $[10,11]$. In this circuit, $\mathrm{R}_{\mathrm{s}}$ is the solution resistance of the test environment and $\mathrm{R}_{1}, \mathrm{R}_{2}$, and $\mathrm{R}_{3}$ represent the resistances of the anodic and cathodic reactions on the surface as well as the resistances of the oxides/hydroxides which form on the surface during corrosion. The capacitor $C_{1}$ represents the charge separation at the sample surface of the oxide/hydroxide while $\mathrm{C}_{2}$ represents the double layer capacitance. Finally, the inductor, L, represents the relaxation of the coverage of adsorbed intermediates in corroding areas of the $\mathrm{Mg}$ surface where a dark corrosion product is often observed to appear. $\mathrm{R}_{\mathrm{p}}$ was calculated following Equation 6.1 derived from this circuit:

$$
\frac{1}{R_{p}}=\frac{1}{R_{1}+R_{2}}+\frac{1}{R_{3}}
$$

Here, large values of $\mathrm{R}_{\mathrm{p}}$ are indicative of a low corrosion current as $i \propto \frac{1}{R_{p}}$ according to the SternGeary relationship [10]. In addition, cathodic potentiodynamic polarization was completed after 24 hours immersion from OCP to $-3 \mathrm{~V}_{\mathrm{SCE}}$ at a scan rate of $2,500 \mathrm{mV} / \mathrm{s}$ and compared to scans performed after $10 \mathrm{~min}$ at OCP. Such a high scan rate was used to minimize changes in the surface condition after testing. In situ optical microscopy was performed to study changes in the surface of each alloy as a function of time to correlate with changes in $R_{p}$.

Anodically induced cathodic activation of $\mathrm{Mg}$-Sn alloys was evaluated using a cycle of alternating anodic galvanostatic pulses followed by cathodic potentiostatic polarization in $0.6 \mathrm{M}$ $\mathrm{NaCl}$. The anodic pulses were performed for 2 minutes at increasing anodic current densities from 
$0.5 \mathrm{~mA} / \mathrm{cm}^{2}, 1 \mathrm{~mA} / \mathrm{cm}^{2}, 5 \mathrm{~mA} / \mathrm{cm}^{2}, 10 \mathrm{~mA} / \mathrm{cm}^{2}$, and $20 \mathrm{~mA} / \mathrm{cm}^{2}$ while potentiostatic polarization was performed for one minute at $-2 \mathrm{~V}_{\text {SCE}}$. This potential was deemed far enough away from OCP for evaluation of the predominantly true cathodic kinetics without the complicating effects of the anodic reaction. Anodic galvanostatic pulses were used to ensure the same anodic charge was obtained on each alloy.

To test whether or not the bulk Mg-Sn alloys would be able to provide sacrificial cathodic protection to AZ31B, zero resistance ammeter (ZRA) testing was performed for 24 hours in an electrochemical flat cell using Mg-Sn as the working electrode and AZ31B as the counter electrode with an SCE reference electrode. Each window of the flat cell provided an area of $1 \mathrm{~cm}^{2}$ to give a 1:1 anode to cathode ratio. The OCP was measured 10 minutes before and after ZRA testing to measure changes in the corrosion potential of each alloy. In addition, cathodic potentiodynamic polarization was performed on each electrode immediately after completion of the galvanic couple experiment to check for enhanced cathodic kinetics after galvanic coupling. Gravimetric mass loss of each sample with $\pm 0.01 \mathrm{mg}$ resolution was converted to consumed anodic charge density $\left(\mathrm{Q}_{\Delta \mathrm{m}}\right)$ via Equation 6.2:

$$
Q_{\Delta m}=\frac{z n F}{A}=\frac{z \Delta m F}{A a}
$$

Equation 6.2

where $\mathrm{z}$ is the equivalent electrons per mole of $\mathrm{Mg}$ oxidized, $\Delta \mathrm{m}$ is the change in mass, $\mathrm{F}$ is Faraday's constant, A is the electrode area, and a is the molar mass of Mg. In this study, $\mathrm{z}$ is assumed to be 2 equivalent $\mathrm{e}^{-} /$mole following the half-cell reaction $\mathrm{Mg} \rightarrow \mathrm{Mg}^{2+}+2 \mathrm{e}^{-}$. Congruent dissolution is assumed for AZ31B-H24 which alters Equation 6.2 to:

$$
Q_{\Delta m}=\frac{N_{e q} \times \Delta m \times F}{A}
$$


where $N_{e q}$ is the weighted average equivalent number of electrons per molar mass of the $i_{t h}$ element being dissolved or the reciprocal of the equivalent weight (EW) with units of g/eq:

$$
N_{e q}=\sum \frac{f_{i} \times z_{i}}{a_{i}}
$$

Equation 6.4

$\mathrm{Al}^{3+}, \mathrm{Mg}^{2+}, \mathrm{Mn}^{2+}$, and $\mathrm{Zn}^{2+}$ are assumed to be dissolving for AZ31B in this equation where $f$ is the mass fraction of each element yielding a value of $N_{e q}=0.0787$ or EW $=12.71 \mathrm{~g} / \mathrm{eq}$. For $\mathrm{Mg}-\mathrm{Sn}$ alloys, only $\mathrm{Mg}^{2+}$ was assumed to be dissolving yielding $N_{e q}=0.0822$ or EW $=12.155 \mathrm{~g} / \mathrm{eq}$.

\subsubsection{Raman Spectroscopy}

Raman Spectroscopy was performed on sample surfaces after completion of OCP-EIS testing and ZRA testing with corrosion products intact using an i-Raman ${ }^{\circledR}$ high resolution spectrometer. Scans were performed from 150 to $4000 \mathrm{~cm}^{-1}$ utilizing a $532.06 \mathrm{~nm}$ diode laser at $100 \%$ power. Scans were accumulated using an integration time of 125 seconds. Peak identification was performed using standard samples in the RRUFFTM project database [25] and in-house standards.

\subsection{Results}

\subsubsection{As Quenched Microstructure of Mg-Sn Alloys}

The results of XRD testing of the as quenched $\mathrm{Mg}-\mathrm{Sn}$ alloys is shown in Figure 6.2. In Figure $6.2 \mathrm{a}$, the measured intensity vs. $2 \theta$ revealed peaks corresponding to $\alpha-\mathrm{Mg}$ while there no peaks were found corresponding to other phases. This is shown more clearly in Figure $6.2 \mathrm{~b}$ where the log of intensity revealed no other peaks in the background signal besides $\alpha-\mathrm{Mg}$. Backscattered electron SEM images of each Mg-Sn alloy are shown in Figure 6.3 and reveal a single phase microstructure. If there were any $\mathrm{Mg}_{2} \mathrm{Sn}$ or other secondary phase precipitates present, they would be noted by a bright white contrast relative to the $\alpha-\mathrm{Mg}$ matrix due to $\mathrm{Sn}$ possessing a higher atomic number than $\mathrm{Mg}$. 
(a)

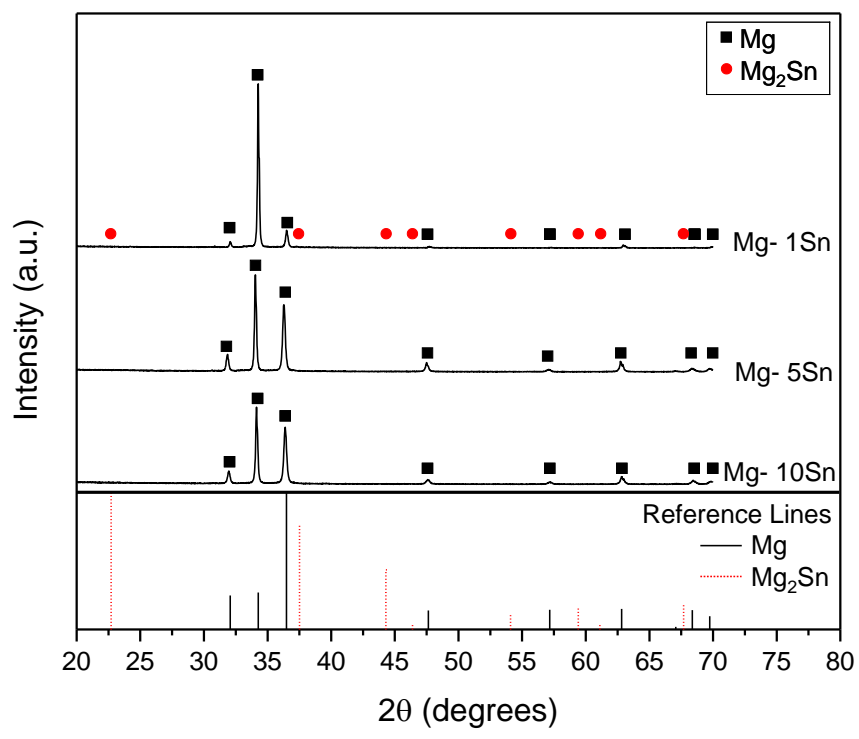

(b)

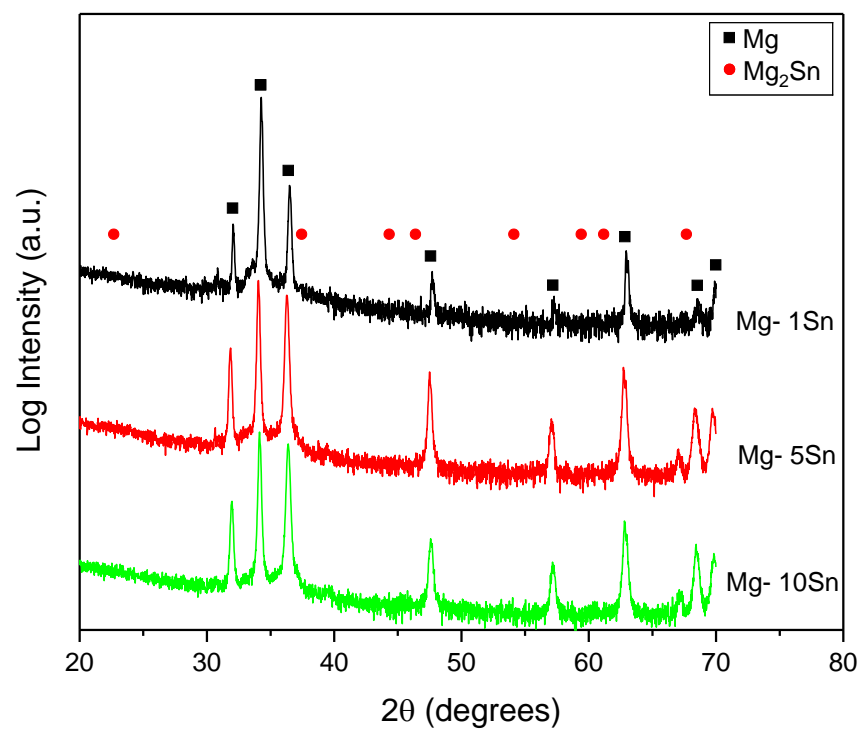

Figure 6.2. Powder X-ray diffraction pattern for Mg-Sn alloys. (a) shows the measured intensity vs. $2 \theta$ with corresponding reference spectra. The black solid line reference lines correspond to $\mathrm{Mg}$ while the red dotted reference line correspond to $\mathrm{Mg}_{2} \mathrm{Sn}$. (b) shows the log of the intensity. 

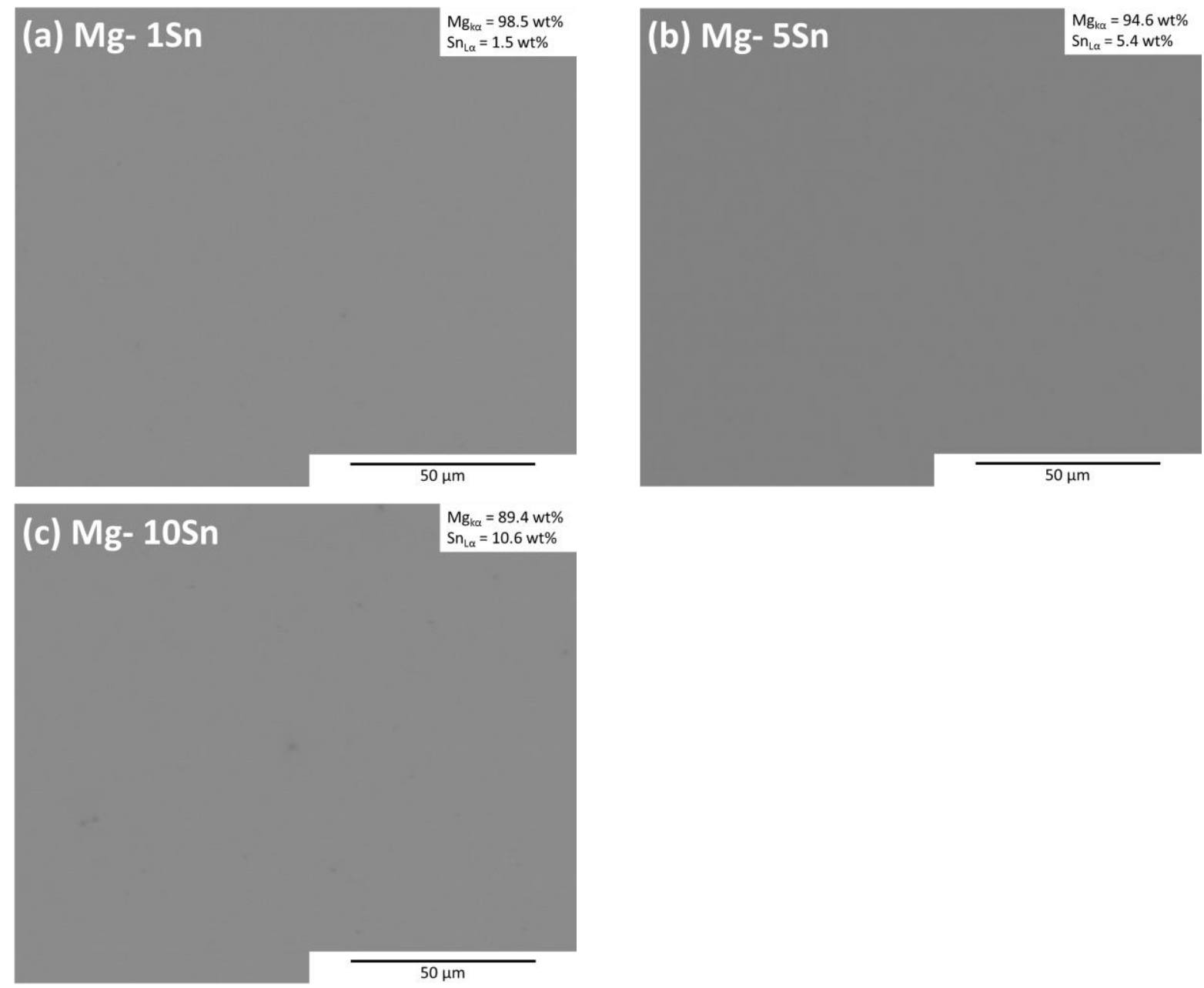

Figure 6.3. Backscattered SEM images showing a single phase for (a) Mg-1Sn, (b) Mg-5Sn, and (c) Mg-10Sn. Samples were polished to a $1 \mu \mathrm{m}$ diamond finish.

\subsubsection{Polarization and Corrosion Behavior of Bulk Mg-Sn Alloys at OCP}

Figure 6.4 shows measurements of OCP after 10 minutes followed by anodic or cathodic polarization scans in $0.6 \mathrm{M} \mathrm{NaCl}$. The plots of $\mathrm{OCP}$ vs. time in Figure $6.4 \mathrm{a}, \mathrm{b}$ reveal that the $\mathrm{Mg}$ Sn alloys possess an OCP more negative than that of AZ31B which shows that sacrificial cathodic protection can be achieved for as much as 10 minutes but there was some variance in the OCP behavior in each alloy. For example, the OCP of Mg-10Sn after 10 minutes is the least noble of the Mg-Sn alloys during the anodic scan (Figure 6.4a) while it is the most noble in the cathodic scan (Figure 6.4b). The anodic and cathodic polarization behavior of $\mathrm{Mg}$-Sn alloys are shown in 
Figure $6.4 \mathrm{c}$,d,e after 10 minutes immersion in $0.6 \mathrm{M} \mathrm{NaCl}$ at $\mathrm{OCP}$. The anodic polarization curves in Figure 6.4c show that Mg-10Sn may have some ability to pseudo passivate up to about -1.6 $\mathrm{V}_{\text {SCE }}$ while Mg-1Sn and Mg-5Sn revealed limited ability for passivation. However, IR correction ${ }^{9}$ of the anodic E vs $\log \mathrm{i}$ behavior in Figure $6.4 \mathrm{~d}$ shows that this is not true passive behavior. The behavior is linear on E-log i scale between approximately $-1.7 \mathrm{~V}_{\mathrm{SCE}}$ to $-1.6 \mathrm{~V}_{\mathrm{SCE}}$ before the current density increased rapidly with increasing potential. The slope in this region is approximately 120 $\mathrm{mV} /$ dec. Similarly, the slope measured in the linear regions for $\mathrm{Mg}-1 \mathrm{Sn}$ and $\mathrm{Mg}-5 \mathrm{Sn}$ yielded values of approximately $66 \mathrm{mV} / \mathrm{dec}$ and $72 \mathrm{mV} / \mathrm{dec}$ respectively; for reference, the anodic Tafel slope for pure Mg is typically cited between 30-60 mV/dec. This increase in anodic slope (increase in polarizabiliy) with increasing wt $\%$ Sn indicates that polarity reversal may be of a concern as the galvanic couple potential may be near the OCP of AZ31B-H24 which is not desired for sacrificial cathodic protection. In addition, the anodic kinetics were increased with increasing wt\% $\mathrm{Sn}$ at small anodic overpotentials after $10 \mathrm{~min}$ immersion at OCP. The cathodic potentiodynamic polarization curves in Figure 6.4e indicate that $\mathrm{Mg}$-10Sn has the fastest cathodic kinetics after immersion at OCP for 10 minutes with $\mathrm{Mg}$-1Sn possessing the slowest cathodic kinetics. However, all $\mathrm{Mg}-\mathrm{Sn}$ alloys showed a decrease relative to $\mathrm{HP} \mathrm{Mg}$. It should be noted that there is no breakdown/film formation on the alloy surface before these scans were taken. In light of these observations at short times, the OCP behavior was investigated for 24 hours to better understand longer term corrosion behavior.

\footnotetext{
${ }^{9}$ IR correction at high current densities resulted in overcompensation of the potential which resulted in the decrease in potential with increasing anodic polarization noted by the curves for AZ31B and Mg-5Sn.
} 
(a)

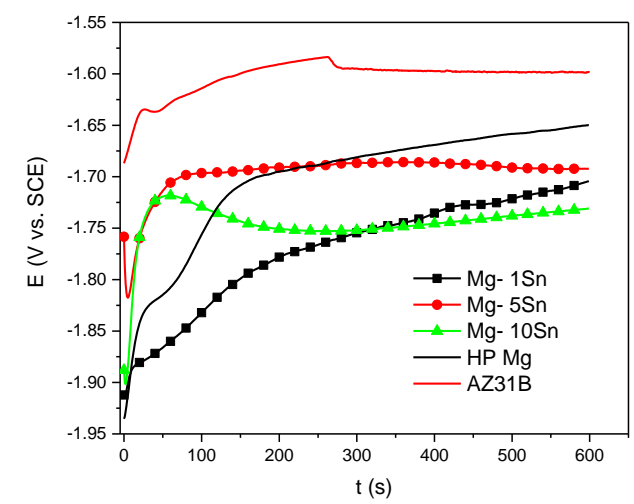

(c)

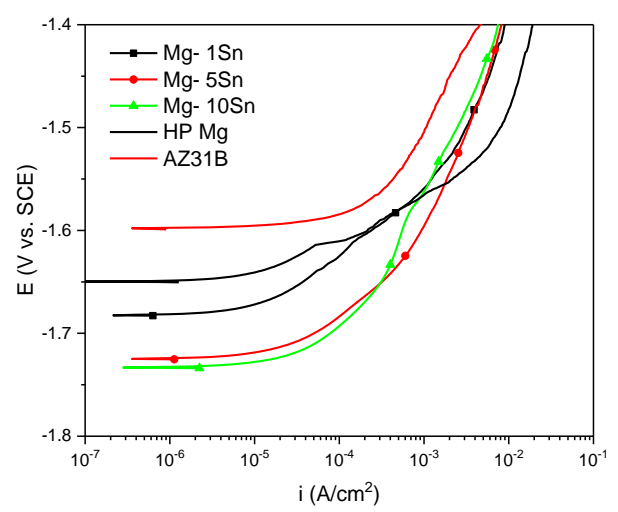

(e)

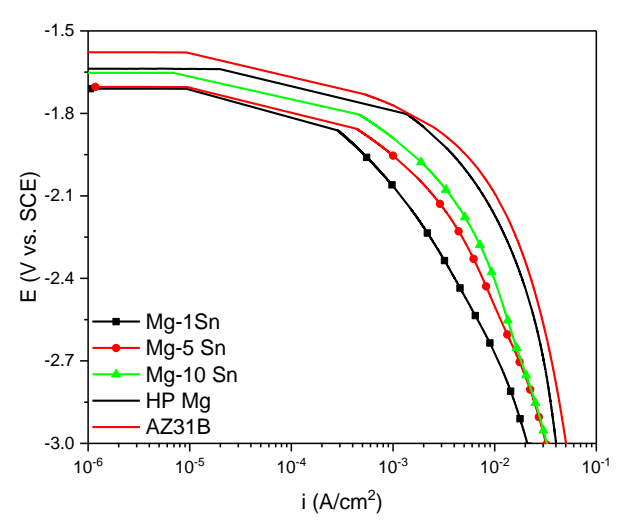

(b)

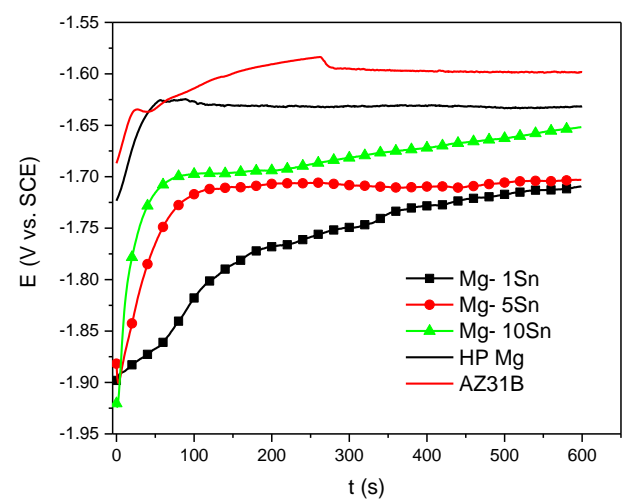

(d)

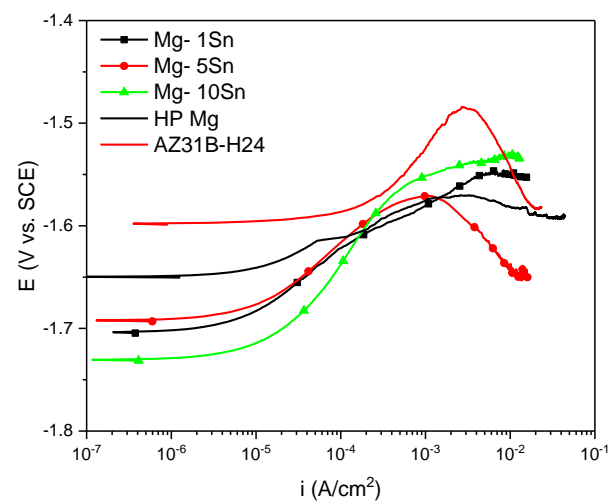

Figure 6.4. Plots of OCP vs. time with corresponding anodic (a,b) and cathodic (c,d) polarization scans taken after 10 minutes at OCP. Anodic scans were performed at $1 \mathrm{mV} / \mathrm{s}$ while cathodic scans were conducted at $2500 \mathrm{mV} / \mathrm{s}$. (e) Shows the anodic polarization curves after performing IR correction. Overcompensation is seen at high current densities due to additional ohmic resistance of anodic hydrogen evolution. 
The change in OCP with time for Mg-Sn alloys and AZ31B for 24 hours in $0.6 \mathrm{M} \mathrm{NaCl}$ is shown in Figure 6.5a. This plot shows that the variation of OCP with time of $\mathrm{Mg}-1 \mathrm{Sn}$ is constant throughout the 24 hours measurement at about $-1.64 \mathrm{~V}_{\mathrm{SCE}}$. In contrast, the OCP of Mg-5Sn is constant in the range of $-1.58 \mathrm{~V}_{\mathrm{SCE}}$ to $-1.60 \mathrm{~V}_{\mathrm{SCE}}$ for about 16.5 hours $(60,000 \mathrm{~s})$ before decreasing to an ultimate potential of about $-1.67 \mathrm{~V}_{\mathrm{SCE}}$. Mg-10Sn displayed a similar behavior as Mg-5Sn but was stable for a much shorter time of about 5.5 hours $(20,000 \mathrm{~s})$ at $-1.6 \mathrm{~V}_{\mathrm{SCE}}$ before decreasing and stabilizing between $-1.63 \mathrm{~V}_{\mathrm{SCE}}$ to $-1.65 \mathrm{~V}_{\mathrm{SCE}}$ (note that breaks in the potential vs. time data occur when EIS measurements were taken). The stability of potential for $\mathrm{Mg}-5$ and $\mathrm{Mg}-10 \mathrm{Sn}$ at -1.6 $\mathrm{V}_{\text {SCE }}$ up to 4 hours is similar to that of AZ31B which indicates that polarity reversal may occur with these two alloys when coupled to AZ31B but not at times longer times after 4 hours as indicated by the increase in OCP of AZ31B. Figure $6.5 \mathrm{~b}$ shows that a large increase in cathodic kinetics was observed with $\mathrm{Mg}$-1Sn after 24 hours immersion while a small increase in cathodic kinetics occurred with Mg-5Sn. In contrast, the cathodic kinetics decreased for Mg-10Sn. Despite the enhanced cathodic kinetics observed on Mg-1Sn and Mg-5Sn, each Mg-Sn alloy possessed cathodic kinetics slower than that of AZ31B which indicates an increased corrosion resistance as the corrosion of $\mathrm{Mg}$ is controlled by cathodic HER [12].

During the 24 hour OCP measurements, EIS was performed at 0.5, 3, 6, 12, 18, and 24 hours from initiation of testing to track the change in polarization resistance with time as shown in Figure 6.6; the measurements of $\mathrm{R}_{\mathrm{p}}$ can be correlated with In situ optical images in Figure 6.7. Of the Mg-Sn Alloys, Mg-10Sn was the only stable alloy with $\mathrm{R}_{\mathrm{p}} \approx 1100 \Omega-\mathrm{cm}^{2}$. This was noted with a thin black film (1200 grit grind marks can still be seen, Figure 6.8d) that formed on the surface after 30 minutes and remained with no breakdown after 24 hours and was about an order of magnitude greater than that of AZ31B. The Mg-1Sn and $\mathrm{Mg}-5 \mathrm{Sn}$ alloys possessed an $\mathrm{R}_{\mathrm{p}}$ value 
(a)

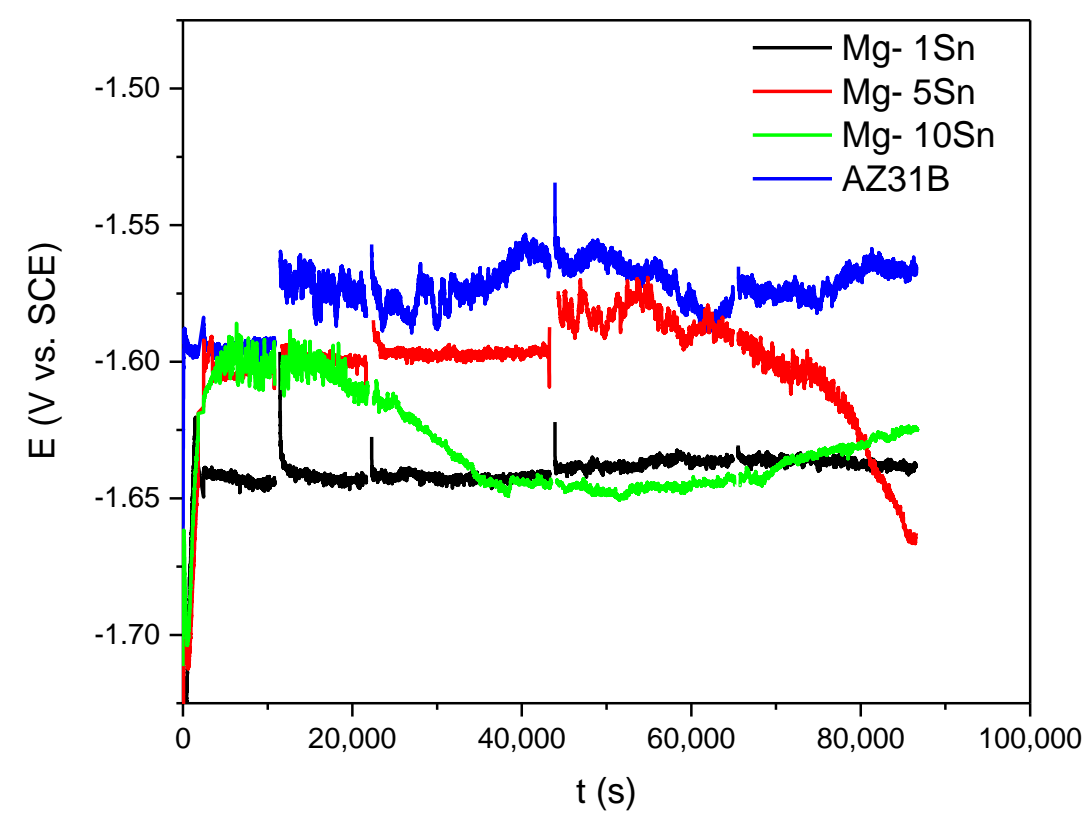

(b)

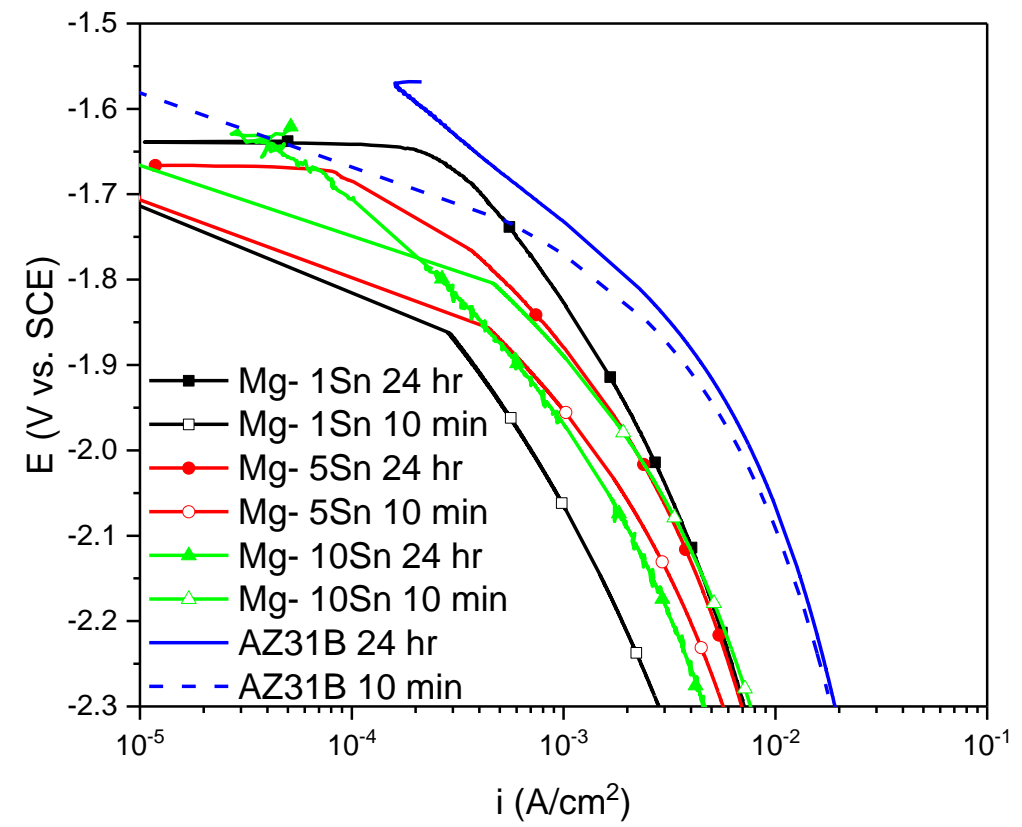

Figure 6.5. (a) OCP vs time behavior for Mg-Sn alloys for 24 hours and (b) corresponding cathodic potentiodynamic polarization scans taken after 24 hours in $0.6 \mathrm{M} \mathrm{NaCl}$. The peaks present in (a) are breaks in the potential when EIS was performed. 
of greater than that of AZ31B for 3 hours and 6 hours respectively before becoming less than that of $A Z 31 B$. This decrease in $R_{p}$ is noted by the initiation and propagation of filiform corrosion on the respective surfaces. However, the surface of the $\mathrm{Mg}-5 \mathrm{Sn}$ alloy darkened in areas where filiform corrosion did not occur similarly to the surface of the Mg-10Sn alloy. Indeed, filiform corrosion ceased for Mg-5Sn after 12 hours and the $\mathrm{R}_{\mathrm{p}}$ increased to become greater than AZ31B after 24 hours. In contrast, the $\mathrm{R}_{\mathrm{p}}$ of $\mathrm{Mg}-1 \mathrm{Sn}$ increased after 6 hours with the propagation and increased surface coverage of filiform corrosion similarly to AZ31B.

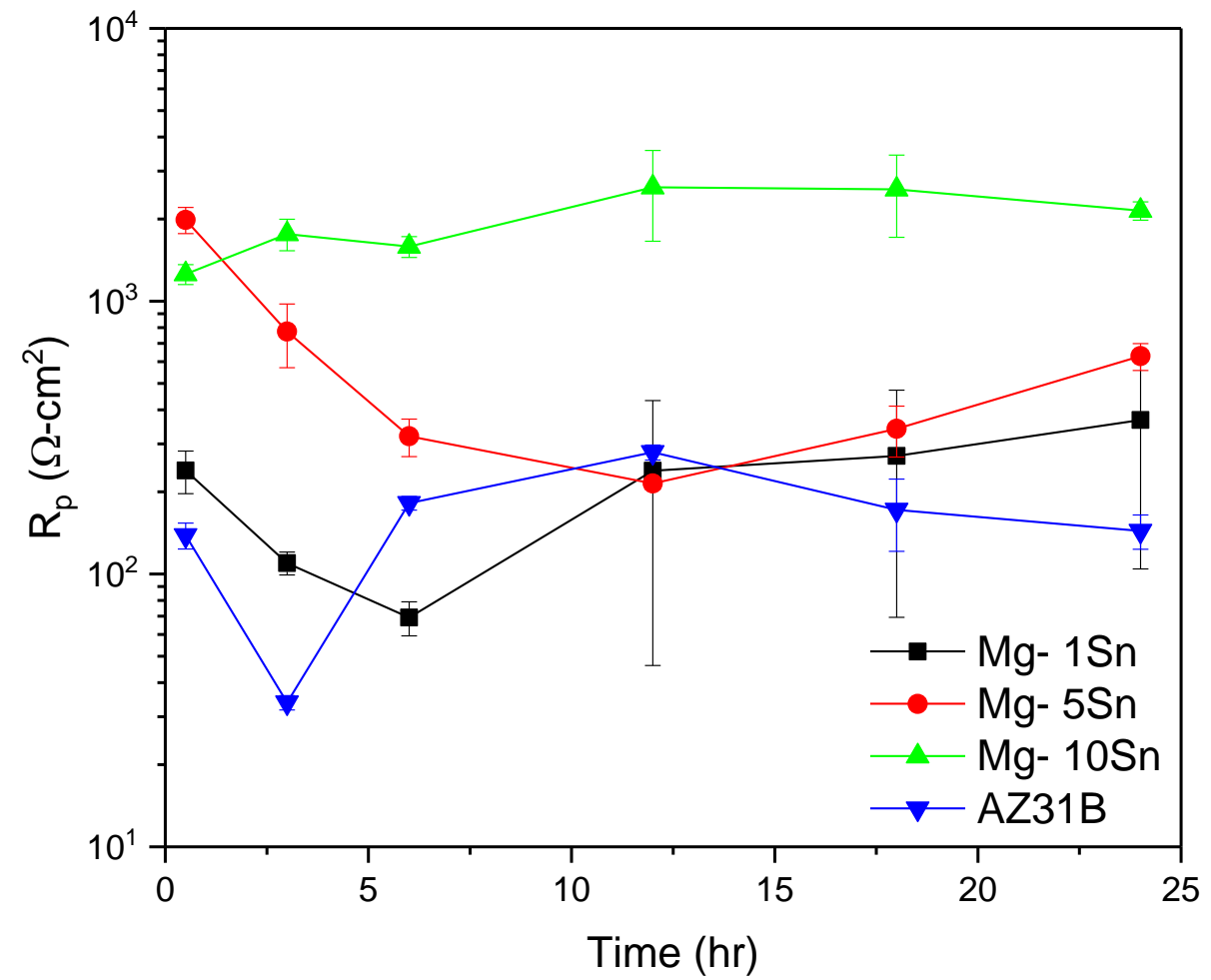

Figure 6.6. Variation of polarization resistance of $\mathrm{Mg}$-Sn alloys with time immersed in $0.6 \mathrm{M}$ $\mathrm{NaCl}$ at $\mathrm{OCP}$ compared to AZ31B. 


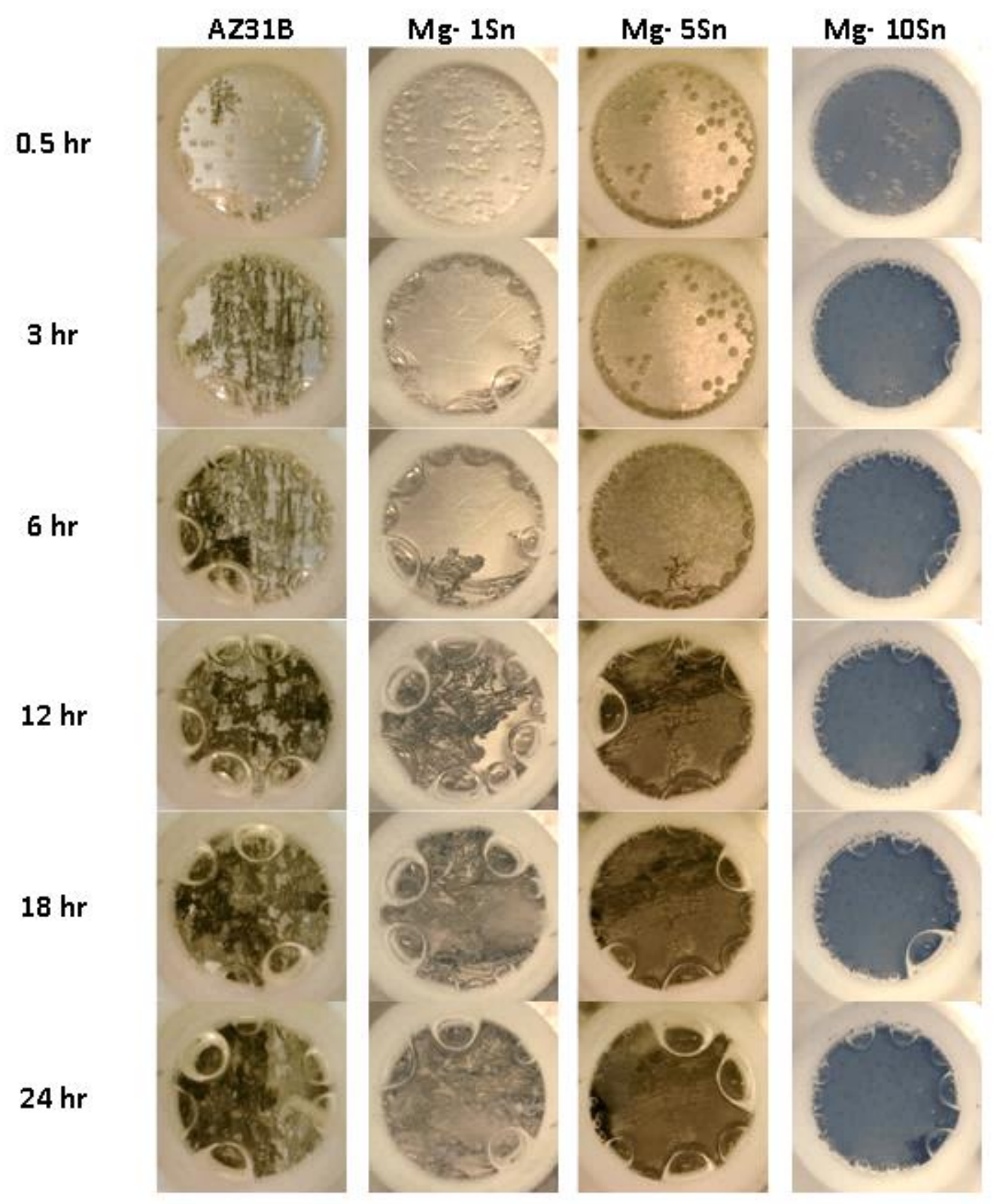

Figure 6.7. In situ optical images of Mg-Sn alloys compared to AZ31B under immersion in 0.6 $\mathrm{M} \mathrm{NaCl}$ at $\mathrm{OCP}$ at intervals when EIS was performed. The exposed sample area is $1 \mathrm{~cm}^{2}$.

Raman spectroscopy was performed on the various corrosion films which formed on $\mathrm{Mg}$ Sn alloys during 24-hour immersion testing. The results in Figure 6.8 tested the three different colored dissolution films which occurred on each alloy. The white film formed on $\mathrm{Mg}-1 \mathrm{Sn}$ and 
$\mathrm{Mg}-5 \mathrm{Sn}$ is characteristic of $\mathrm{Mg}(\mathrm{OH})_{2}$ while gold and black films are similar to $\mathrm{SnO}$ and may even be a dehydrated $\mathrm{Sn}(\mathrm{OH})_{2}$ film. The black films formed on $\mathrm{Mg}-10 \mathrm{Sn}$ was the same in character to the black dissolution film formed on $\mathrm{Mg}-5 \mathrm{Sn}$ and resembles the in-house standard $\mathrm{SnO}$ spectrum.

(a)

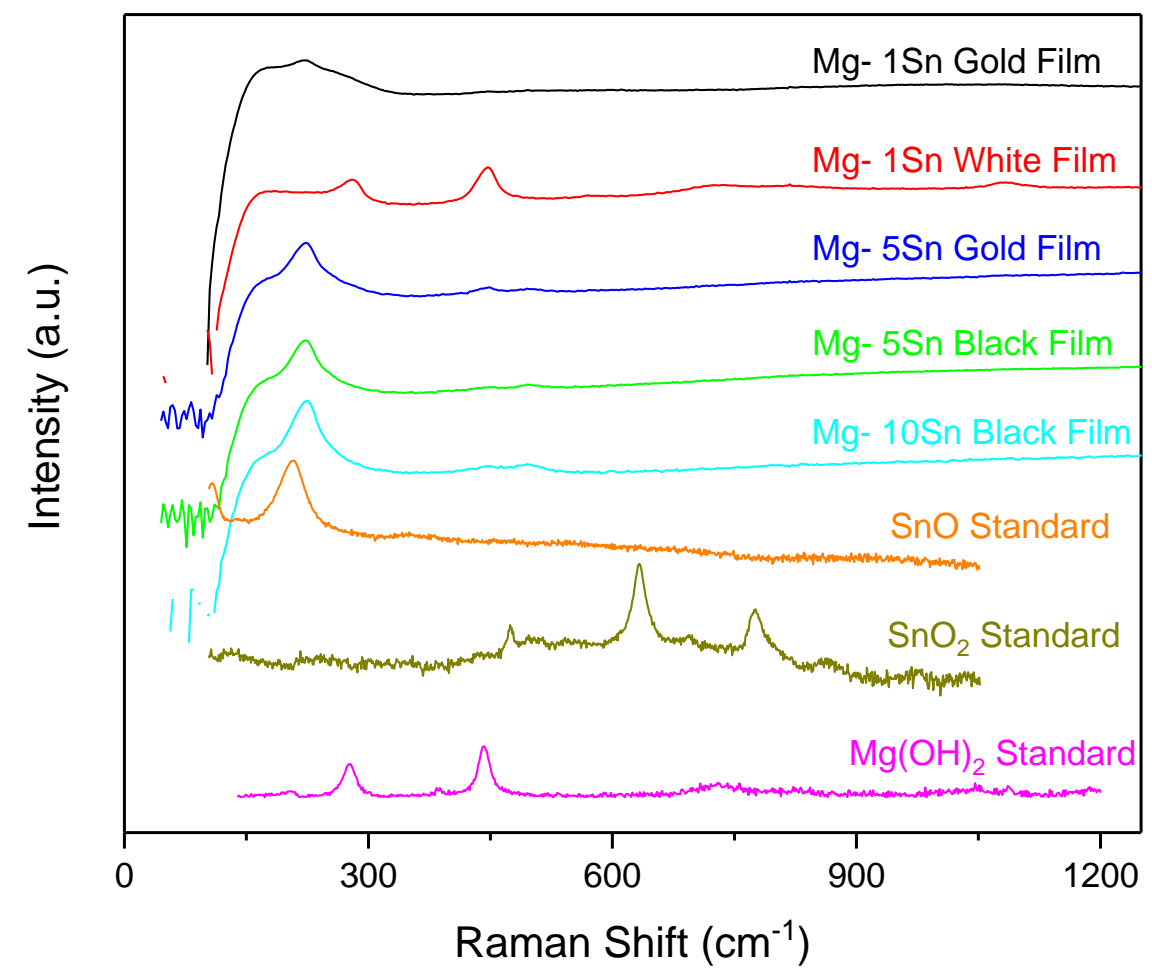

(b)

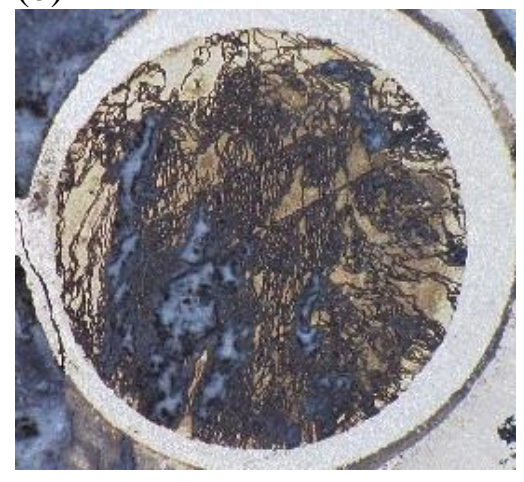

(c)

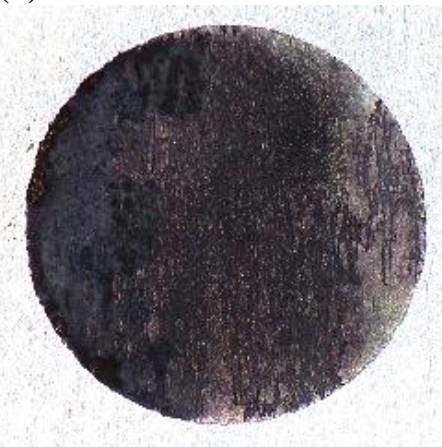

(d)

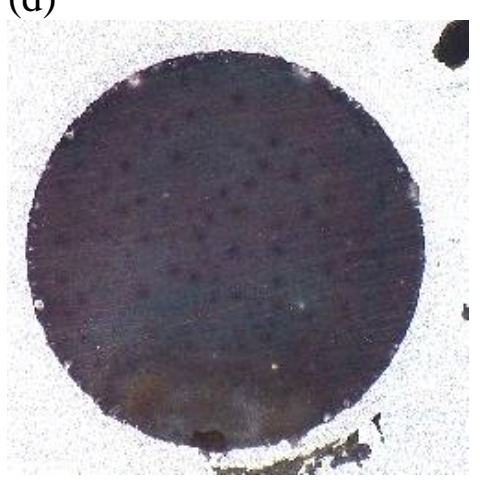

Figure 6.8. (a) Raman spectroscopy on the various corrosion films that formed during 24 hour immersion testing in 0.6 M NaCl. Optical images of (b) Mg-1Sn, (c) Mg-5Sn, and (d) Mg-10Sn after immersion corresponding to the film areas probed by Raman Spectroscopy. 


\subsubsection{Galvanostatic-Potentiostatic Cycle Testing}

Assessment of the enhancement in cathodic kinetics of each alloy is shown in Error! $\mathbf{R}$ eference source not found. via a unique cycle of anodic galvanostatic polarization followed by potentiostatic polarization at $-2 \mathrm{~V}_{\mathrm{SCE}}$ to measure changes in cathodic kinetics. Error! Reference s ource not found.a display the typical potential vs. time transients during anodic galvanostatic pulses while Error! Reference source not found.b shows the typical measured current density v s. time transients during cathodic potentiostatic pulses. The potential vs. time during anodic galvanostatic pulses reveal that the potential of $\mathrm{Mg}$ - $\mathrm{Sn}$ alloys were stable for the duration of the anodic pulse while the measured current density with time varied and did not always reach a stable current density during cathodic polarization. However, trends in the data can still be made. The average potential taken from the last data point measured during each anodic galvanostatic pulse vs. anodic current density is shown in Figure 6.9a while the average cathodic current density taken from the last data point measured during each cathodic potentiostatic pulse vs. the anodic galvanostatic current density prior to potentiostatic polarization is shown in Figure 6.9b. In general, the measured potential during anodic galvanostatic pulse, shown by the solid symbols, increased with increasing wt\% Sn which indicates a decrease in the anodic kinetics with increasing $\mathrm{wt} \% \mathrm{Sn}$. This is in agreement with the measured potentiodynamic polarization curves shown by the open symbols over the range of current densities tested. During cathodic pulses, the cathodic current density of Mg-Sn alloys was approximately an order of magnitude less than that of AZ31B$\mathrm{H} 24$ at each pulse while HP Mg began with a cathodic current density similar to that of the MgSn alloys but rapidly increased after increasing anodic dissolution. For the $\mathrm{Mg}-\mathrm{Sn}$ alloys, the relative enhancement in cathodic kinetics was greater than that of AZ31B-H24 and less than that 
of HP Mg. Furthermore, the relative enhancement in cathodic kinetics decreased with increasing wt $\% \mathrm{Sn}$. 
(a)

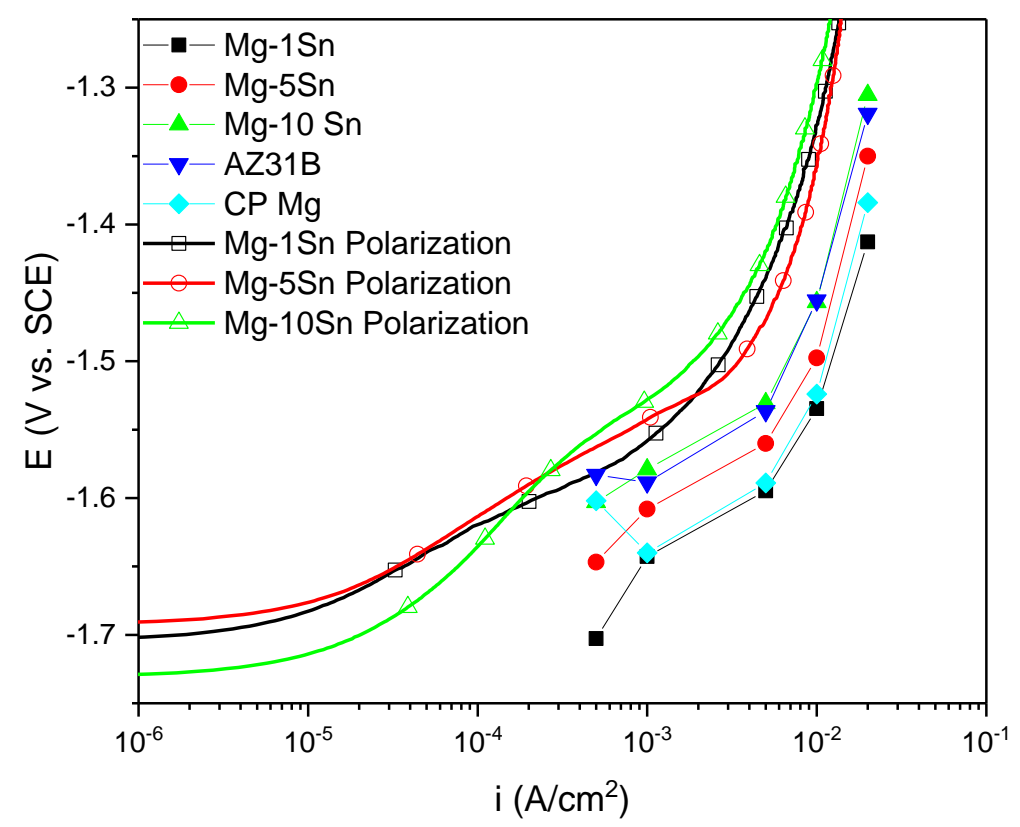

(b)

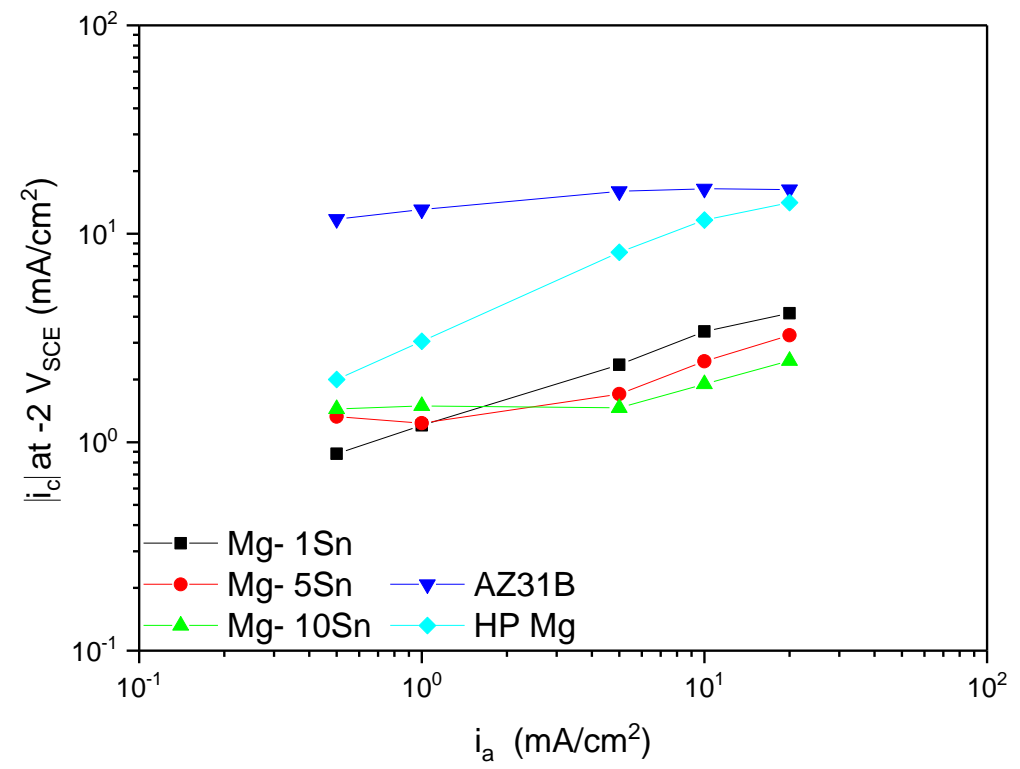

Figure 6.9. Summary of cycle testing. The average potential measured at the end of each anodic galvanostatic step is shown in by the solid symbols in (a) and compared to anodic potentiodynamic polarization curves. The average cathodic current density measured at the end of potentiostatic pulses at $-2 \mathrm{~V}_{\mathrm{SCE}}$ is shown in (b) where $\mathrm{i}_{\mathrm{a}}$ is the applied anodic current density and $i_{c}$ is the cathodic current density measured after the respective anodic pulse. 


\subsubsection{ZRA testing of Bulk Mg-Sn Alloys with AZ31B}

ZRA testing was performed on each Mg-Sn alloys for 24 hours immersion in $0.6 \mathrm{M} \mathrm{NaCl}$ two times to show reproducibility of galvanic couple behavior. The results for $\mathrm{Mg}-1 \mathrm{Sn}$ coupled to AZ31B-H24 is shown in Figure 6.10. The couple potential vs. time was plotted in Figure 6.10a and shows that the couple potential was stable for the duration of the ZRA test after about 20,000 seconds. Furthermore, the couple potential was closer to the OCP of Mg-1Sn than AZ31B-H24 with time which decreases the probability of polarity reversal. The galvanic couple current density plotted vs. time in Figure 6.10b reveals a constant current density after about 20,000 seconds in agreement with the measurement of galvanic couple potential.

The ZRA behavior for Mg-5Sn coupled to AZ31B-H24 is shown in Error! Reference s ource not found.. In contrast to $\mathrm{Mg}-1 \mathrm{Sn}$ coupled to AZ31B-H24, the galvanic couple potential behavior varied greatly between test runs. The first test revealed a stable galvanic couple potential of about 1.6 $\mathrm{V}_{\mathrm{SCE}}$ for the first 40,000 seconds of the test. The galvanic couple potential then decreased to a value of about $-1.66 \mathrm{~V}_{\mathrm{SCE}}$ after 60,000 seconds and remained stable around that potential for the remainder of the test. In contrast, the second ZRA test conducted possessed a relatively stable couple potential of about $-1.6 \mathrm{~V}_{\mathrm{SCE}}$ for the entire test. In both test runs, the galvanic couple potential was not more positive than the OCP of $\mathrm{Mg}-5 \mathrm{Sn}$ which would be expected. However, the galvanic couple potential was never more positive than the OCP of AZ31B-H24 and thus, desired anode-cathode polarity was maintained over the duration of the test as indicated by the galvanic couple potential in Error! Reference source not found.b.

The ZRA behavior for Mg-10Sn coupled to AZ31B-H24 is shown in Figure 6.11. The galvanic couple potential vs. time in Figure 6.11a shows that the galvanic couple potential becomes more noble than AZ31B-H24 within the first 3,000 seconds of the test as shown clearly in the inset 
(a)

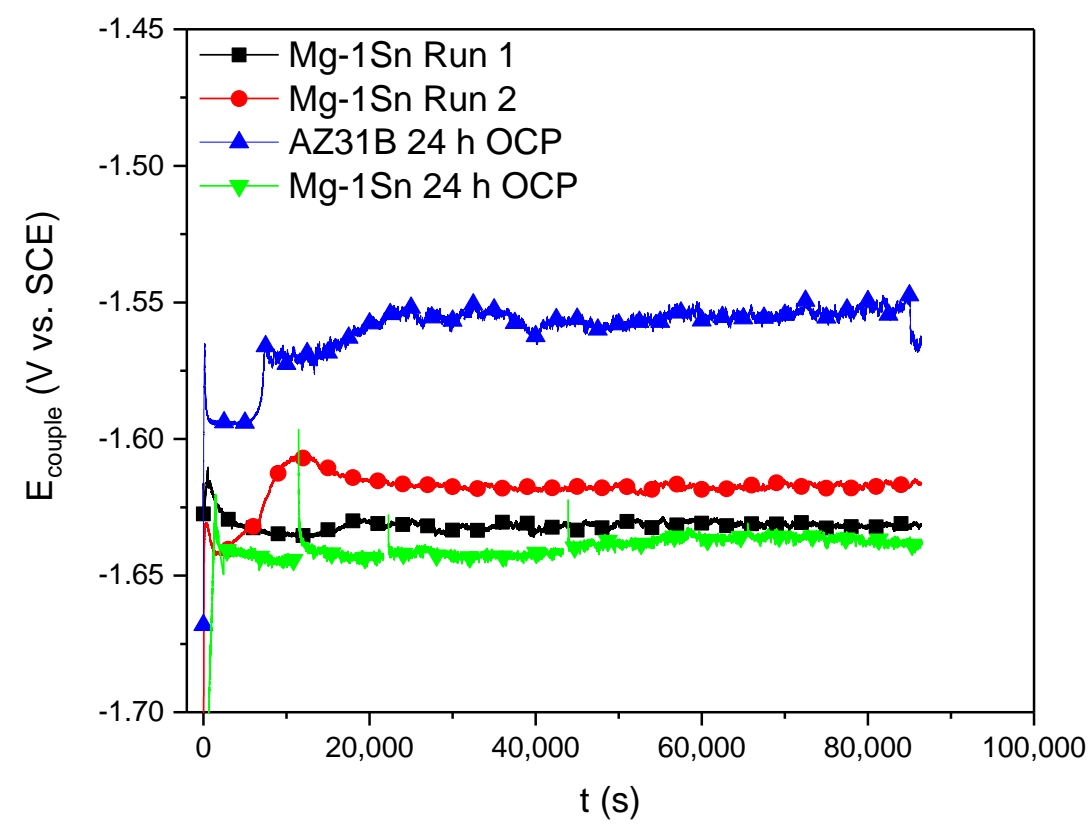

(b)

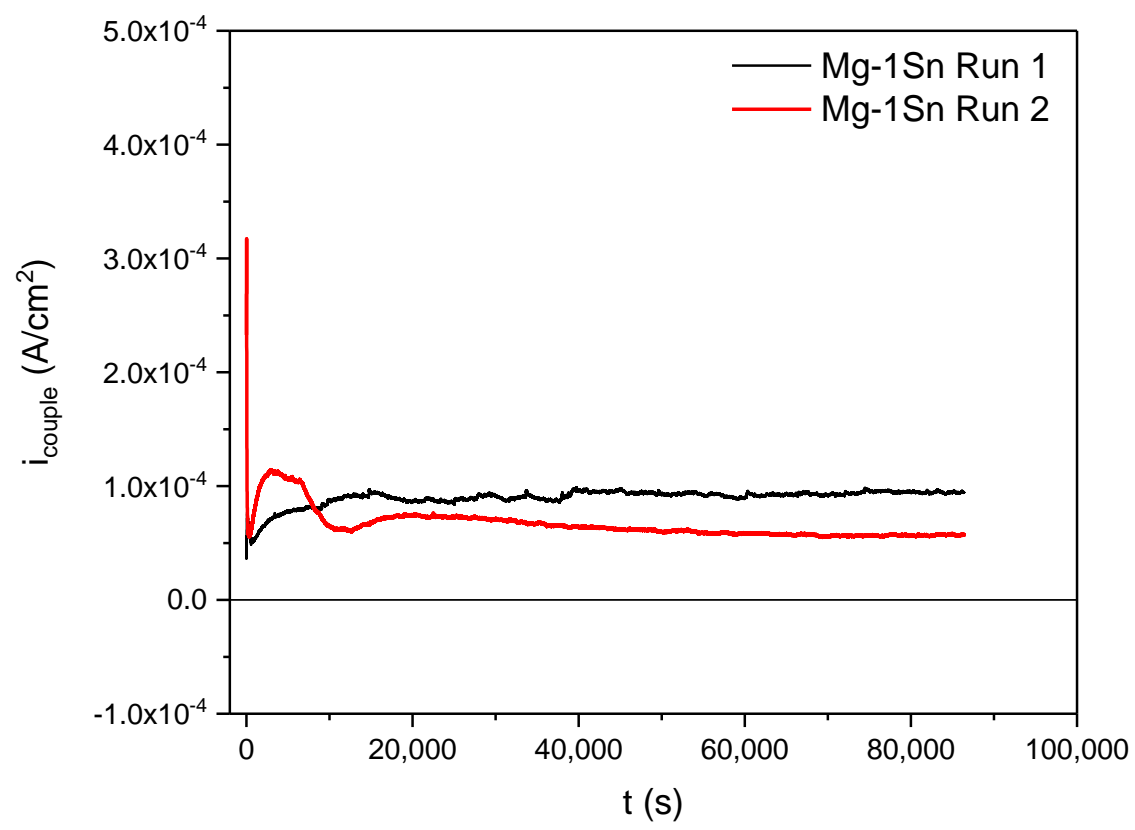

Figure 6.10. ZRA testing of Mg-1Sn with AZ31B in $0.6 \mathrm{M} \mathrm{NaCl}$. (a) Shows the change in couple potential with time while (b) shows the change in coupled current density with time. $\mathrm{Mg}-1 \mathrm{Sn}$ was placed as the working electrode with AZ31B-H24 being the counter electrode. 
(a)

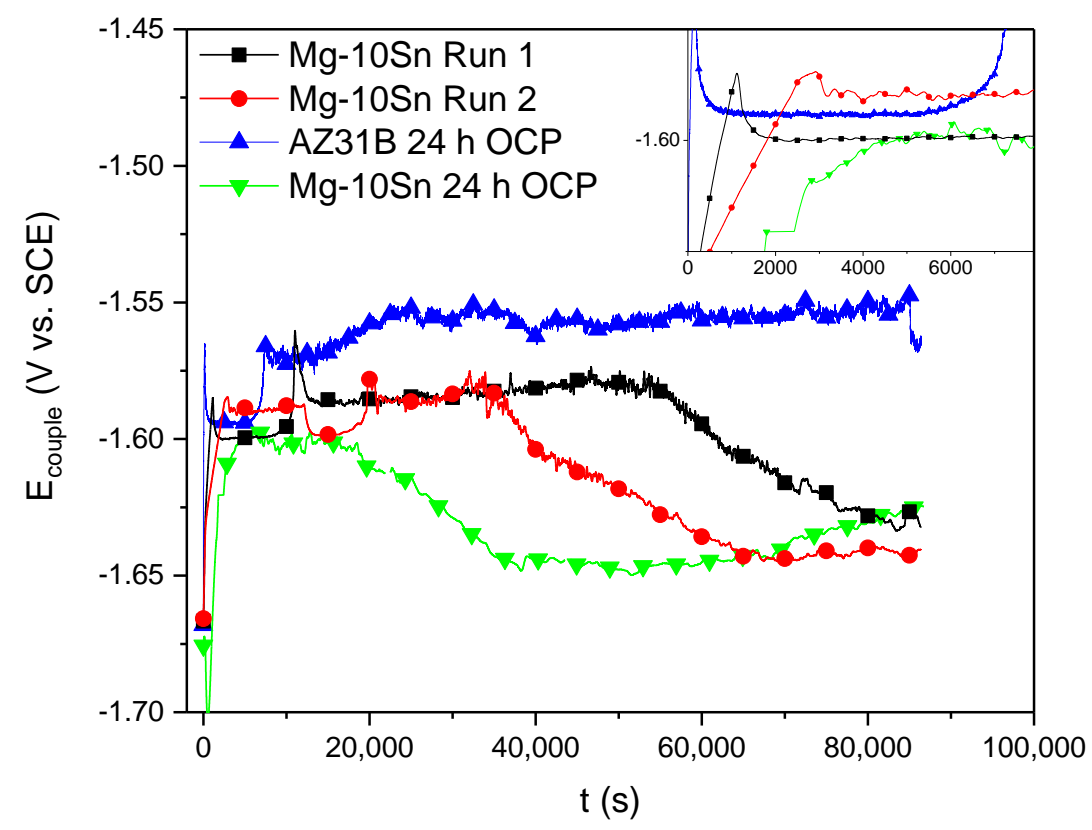

(b)

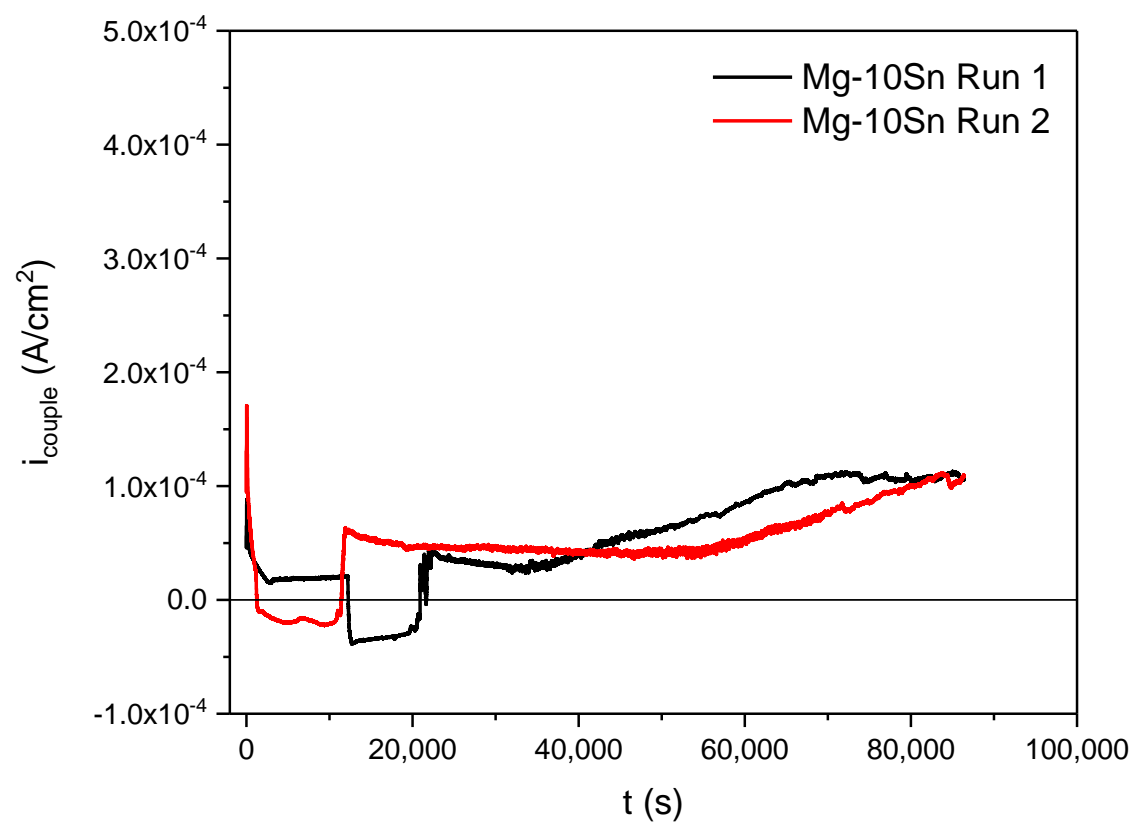

Figure 6.11. ZRA testing of $\mathrm{Mg}-10 \mathrm{Sn}$ with AZ31B in $0.6 \mathrm{M} \mathrm{NaCl}$. (a) Shows the change in couple potential with time while (b) shows the change in coupled current density with time. Mg-10Sn was placed as the working electrode with AZ31B-H24 being the counter electrode. 
graph. It is at this point that the polarity switched for Run 2 and the net current density became negative indicating the start of galvanically enhanced anodic dissolution of AZ31B-H24, Figure 6.11b. The polarity also switched for Run 1 albeit at a later time. Eventually, the polarity for both Run 1 and Run 2 switched back to being net anodic and both runs spent approximately the same amount of time being net cathodic. After the polarity switched back to being net anodic, the polarity remained net anodic for the remainder of the test period.

The optical images in Figure 6.12 taken after ZRA testing show that very little corrosion occurred on AZ31B when coupled with Mg-1Sn (Figure 6.12a) and Mg-5Sn (Figure 6.12b) as would be expected from the results of ZRA testing. However, there was more appreciable corrosion damage visually on AZ31B when coupled with Mg-10Sn due to the brief time period when the polarity reversed and AZ31B became the anode. The corrosion damage on the $\mathrm{Mg}-\mathrm{Sn}$ alloys during ZRA testing resembled that of OCP testing (see Figure 6.12).

The corresponding charge accumulated due to mass loss and the galvanic couple current is shown in Figure 6.13. In this figure, $\mathrm{Q}_{\mathrm{AZ31B}-\mathrm{H} 24, \mathrm{OCP}}$ is the charge accumulated from mass loss for

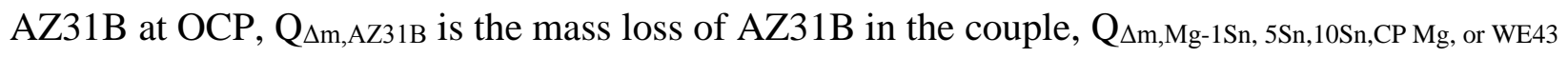
is the couple mass loss of the sacrificial anode, and $\mathrm{Q}_{\text {couple }}$ is the charge determined from the galvanic couple current. Figure 6.13a shows that mass loss was greatest for $\mathrm{Mg}-1 \mathrm{Sn}$ and lowest for $\mathrm{Mg}-10 \mathrm{Sn}$ as would be expected based on $\mathrm{R}_{\mathrm{p}}$ measurements at OCP. The mass loss of AZ31B decreased approximately $15 \mathrm{x}$ for $\mathrm{Mg}-1 \mathrm{Sn}$ and $\mathrm{Mg}-5 \mathrm{Sn}$ couples compared to mass loss of AZ31B at OCP while it decreased about $5 \mathrm{x}$ for $\mathrm{Mg}-10 \mathrm{Sn}$ couples. When compared to the couple behavior of CP Mg and WE43 coupled to AZ31B, Figure 6.13b, the coupled mass loss of AZ31B decreased about 2-3x while the mass loss of CP and WE43 were much greater than that of the Mg-Sn alloys. This is a positive finding regarding the prospects of $\mathrm{Mg}-\mathrm{Sn}$ as a sacrificial anode. 
(a)

(b)

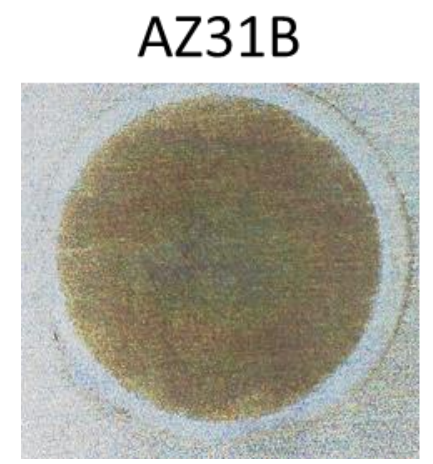

Mg- $1 S n$
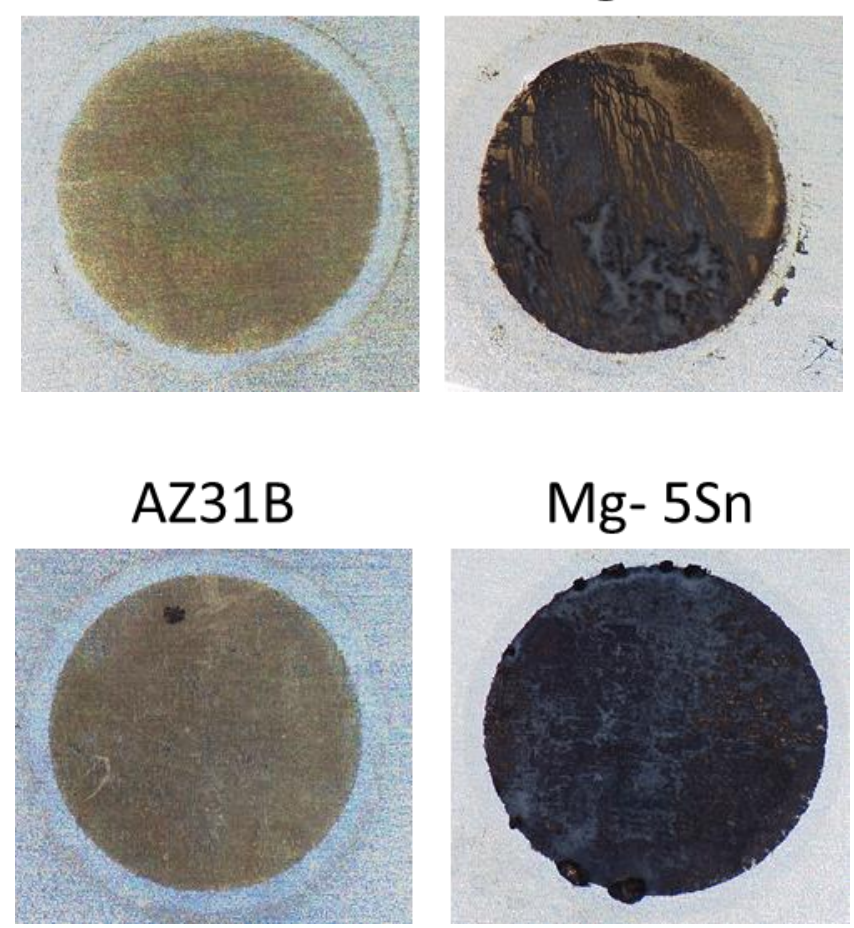

(c)

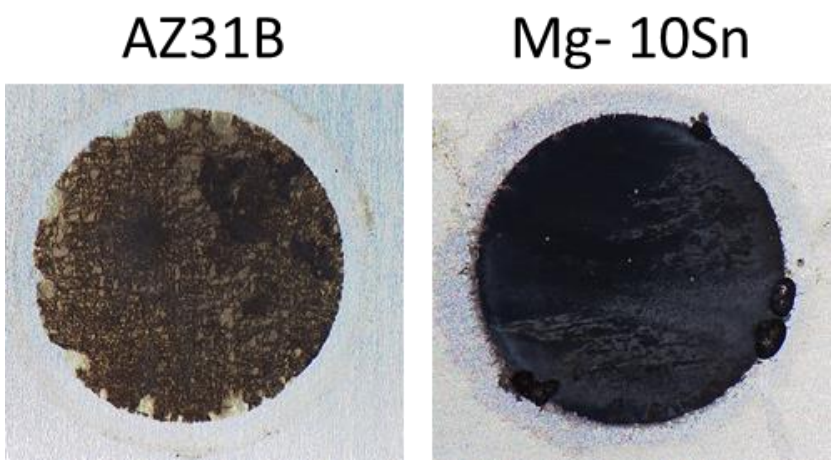

Figure 6.12. Optical images of sample surfaces after ZRA testing are shown in (c) for Mg-1Sn, (d) for Mg-5Sn, and (e) for Mg-10Sn. The exposed sample area is $1 \mathrm{~cm}^{2}$. 
(a)

(b)
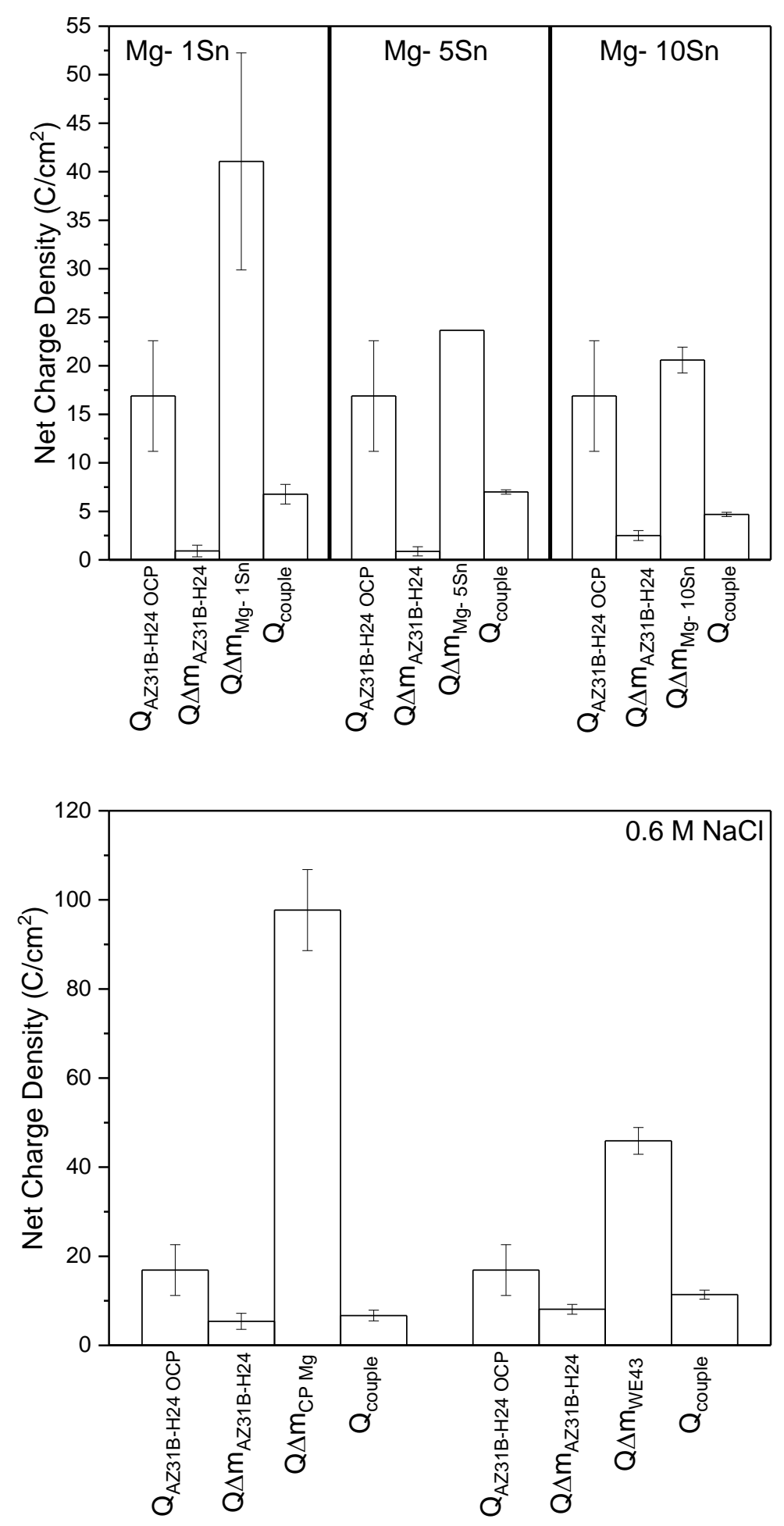

Figure 6.13. Charge accumulated due to mass loss and the galvanic couple current during ZRA testing for (a) $\mathrm{Mg}$-Sn alloys coupled to AZ31B compared to (b) commercially pure $\mathrm{Mg}$ and WE43 coupled to AZ31B from a previous investigation. 


\subsubsection{Characterization and ZRA Testing of Mg-Sn Alloys Deposited on AZ31B}

Thin films of deposited Mg-Sn alloys were attempted on AZ31B by PLD. Backscattered SEM images of the typical film for each alloy is shown in Figure 6.14. These images were performed after deposition on a Si wafer so that EDS analysis of the film and secondary phase particles could be performed without additional Mg intensity of Mg-based substrates due to the interaction depth of the electron beam. This figure shows that there are heavy element particles (bright contrast) forming on top of the film. Semi-quantitative EDS performed on the film matrix and the white particles indicate that the white particles are composed of $\mathrm{Mg}, \mathrm{O}$, and $\mathrm{Sn}$ while the matrix is primarily composed of $\mathrm{Mg}$ and $\mathrm{O}$ with no $\mathrm{Sn}$. A cross sectional backscattered SEM image of Mg-1Sn deposited on an Si wafer (Figure 6.14d) revealed approximately a $225 \mathrm{~nm}$ film which was typical for the deposition conditions.

To test whether or not PLD films of Mg-Sn alloys would provide sacrificial protection of AZ31B, ZRA testing was performed where PLD coated AZ31B was placed as the working electrode with non-coated AZ31B as the counter electrode. The results in Figure 6.15a show that the couple potential increased constantly throughout the duration of the test while the couple current for each coating is observed to change polarity multiple times for each alloy, Figure 6.15b. The optical images taken after ZRA testing in Figure 6.16a-c reveal heavy dissolution product formation and corrosion damage to both the PLD coated AZ31B and non-coated AZ31B which is to be expected from the polarity reversal. Thus, these films do not appear to provide adequate sacrificial cathodic protection. 

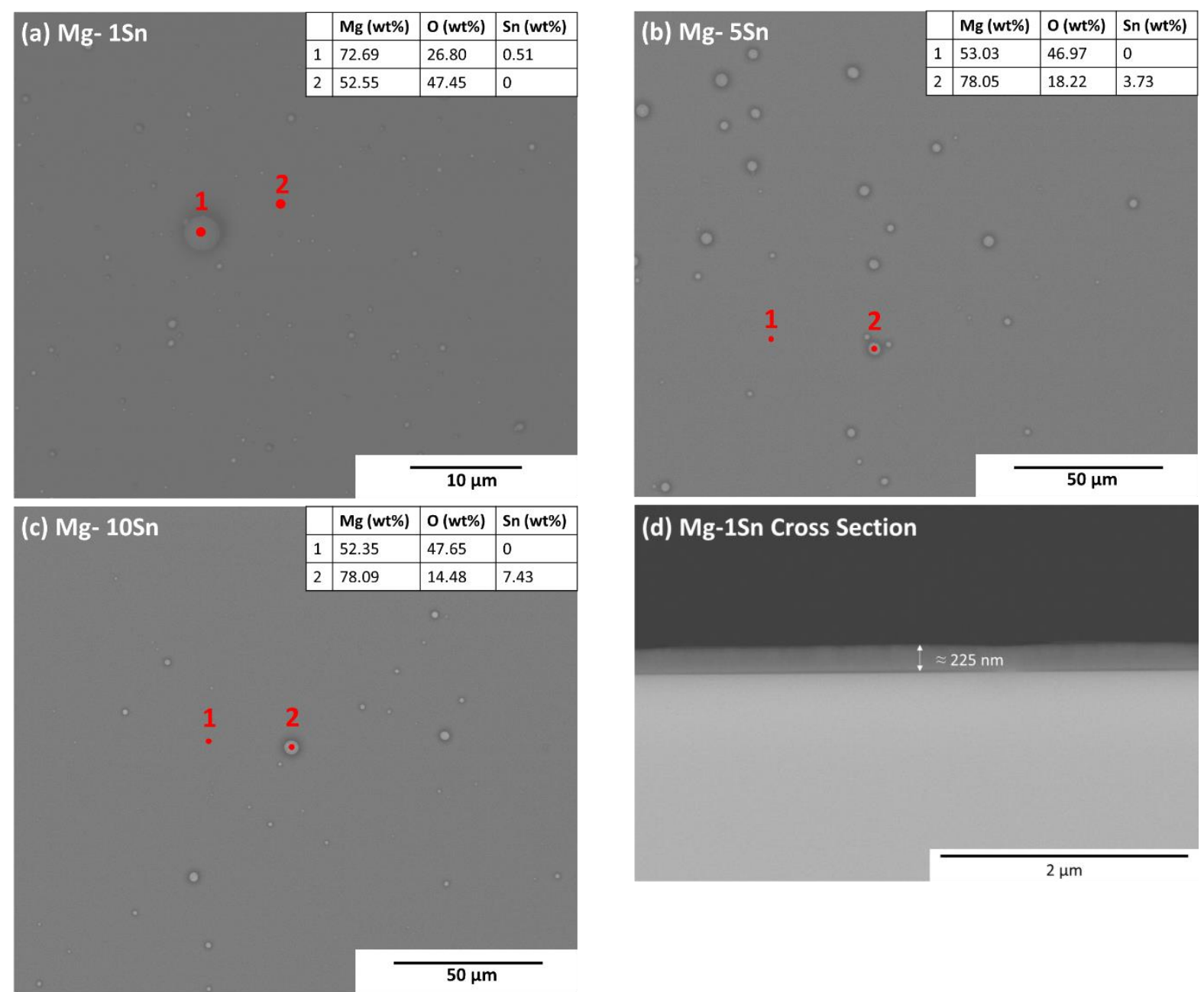

Figure 6.14. Backscattered SEM image of PLD coated Si wafers using (a) Mg-1Sn, (b) Mg-5Sn, and (c) Mg-10Sn targets. (d) shows the cross section of Mg-1Sn deposited on an Si wafer. The red circles indicate where point EDS analysis was performed. 
(a)

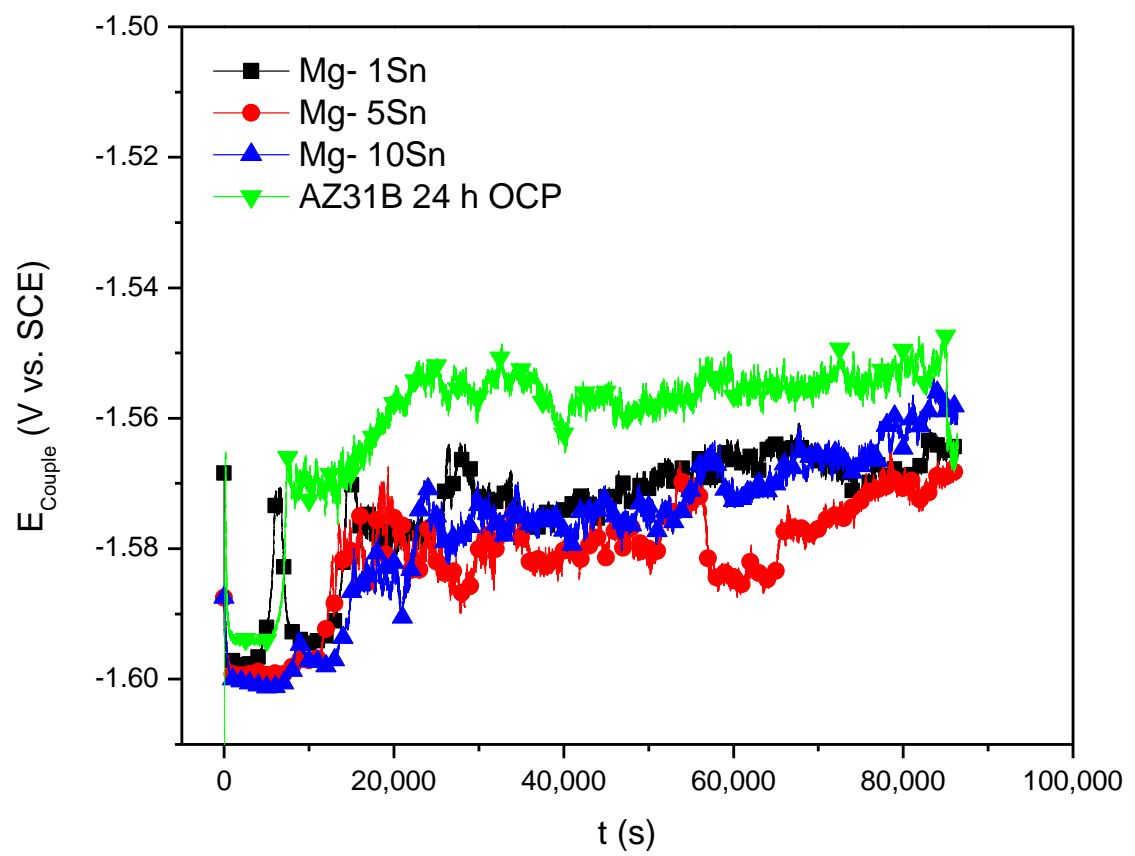

(b)

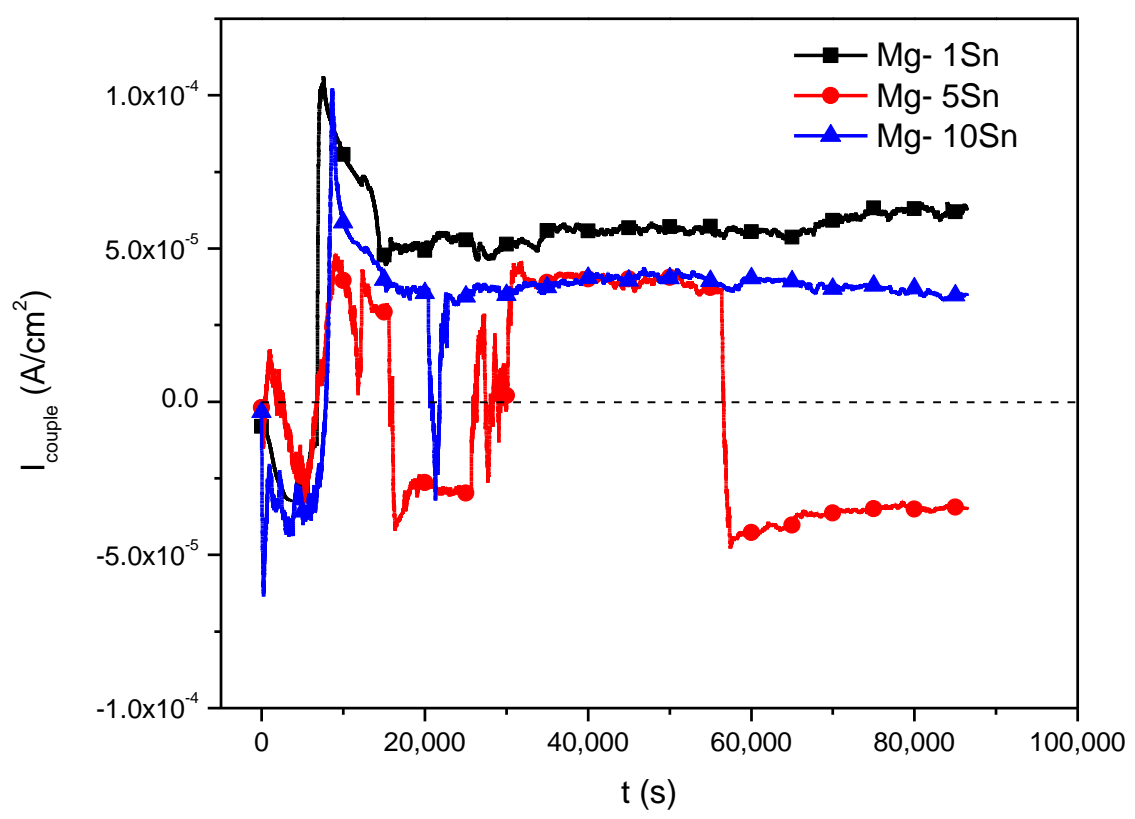

Figure 6.15. ZRA testing of AZ31B coated with Mg-Sn alloys coupled to non-coated AZ31B for 24 hours in $0.6 \mathrm{M} \mathrm{NaCl}$. (a) shows the change in couple potential with time while (b) shows the couple current with time. 
(a)

(b)
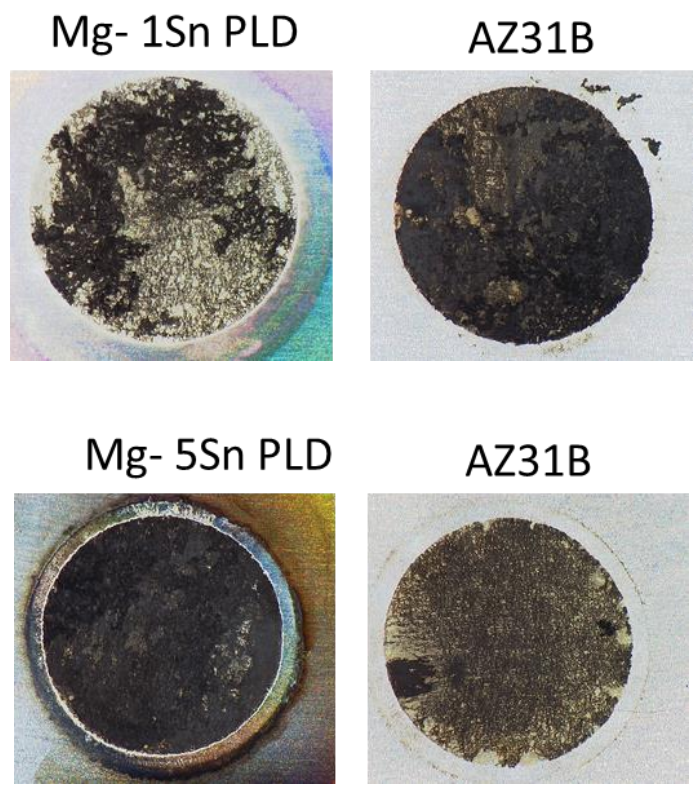

(c)
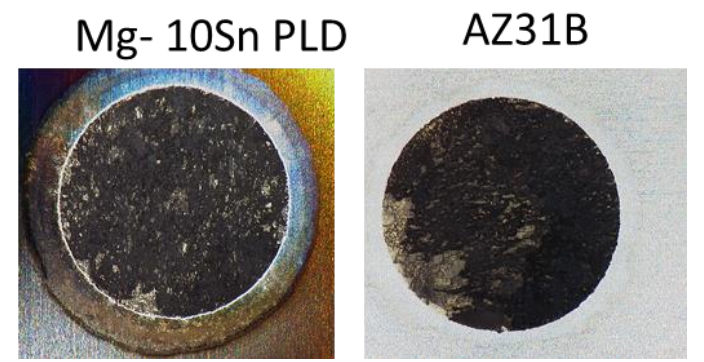

Figure 6.16. Optical images taken after ZRA testing are shown in (c) for Mg-1Sn coatings, (d) Mg-5Sn coatings, and (e) Mg-10Sn Coatings. The test area was $1 \mathrm{~cm}^{2}$ to provide a 1:1 anode to cathode ratio.

\subsection{Discussion}

\subsubsection{Improved Corrosion Resistance of Mg-Sn Alloys}

The results of this investigation show that Mg-Sn alloys have the ability to provide sacrificial cathodic protection to AZ31B while also having a low intrinsic corrosion rate. This low intrinsic corrosion rate is most notable for the $\mathrm{Mg}-10 \mathrm{Sn}$ alloy which formed a thin black film on the entire alloy surface. This film appeared to act as an improved corrosion resistant film compared to the typically porous thick $\mathrm{Mg}(\mathrm{OH})_{2}$ dissolution film which accompanies $\mathrm{Mg}$ dissolution in chlorides. This film aids in an increase in polarization resistance of more than an order of magnitude greater 
than that of AZ31B despite increased anodic kinetics of Mg-10Sn compared to AZ31B-H24 from polarization scans, Figure 6.4. However, the increased polarization resistance is likely due to a much slower HER rate of Mg-10Sn which dominated the corrosion rate with respect to the anodic reaction rate. Indeed, the cathodic kinetics of $\mathrm{Mg}$-10Sn decreased after 24 hours immersion in 0.6 $\mathrm{M} \mathrm{NaCl}$ which is not often observed with $\mathrm{Mg}$ alloys. The decrease in cathodic kinetics would also account for the decrease in the OCP with time shown in Figure 6.5a. This is likely due to the enrichment of Sn on the dissolving Mg surface. The hydrogen evolution reaction proceeds by two electron transfer reaction which follows either the Volmer-Tafel mechanism or the VolmerHeyrovsky mechanism [13]:

$$
\begin{array}{cc}
\text { Volmer step: } \mathrm{H}^{+}+\mathrm{e}^{-}+{ }^{*} \rightarrow \mathrm{H}_{\mathrm{ads}} & \text { Equation } 6.5 \\
\text { Tafel step: } 2 \mathrm{H}_{\mathrm{ads}} \rightarrow \mathrm{H}_{2}+2^{*} & \text { Equation } 6.6 \\
\text { Heyrovsky step: } \mathrm{H}_{\mathrm{ads}}+\mathrm{H}^{+}+\mathrm{e}^{-}=\mathrm{H}_{2} & \text { Equation 6.7 }
\end{array}
$$

where * represents an available site on the electrode surface and $\mathrm{H}_{\mathrm{ads}}$ is an adsorbed hydrogen atom. It is apparent that both mechanisms depend on the adsorption of hydrogen and thus the rate of HER will depend on the Tafel or Heyrovsky step. DFT modeling of Mg with Sn alloying additions has shown that $\mathrm{Sn}$ produces a positive adsorption energy for nearest neighbor $\mathrm{H}_{\mathrm{ads}}$ which repels $\mathrm{H}_{\mathrm{ads}}$ away from $\mathrm{Sn}$ atoms [5]. This prevents the recombination of $\mathrm{H}_{\mathrm{ads}}$ on the surface near Sn atoms and thus decreases the rate of HER on the electrode surface. Increasing the fraction of Sn on the Mg surface will therefor decrease that cathodic kinetics by decreasing favorable Mg sites for hydrogen evolution. TEM and XPS studies by Yang and co-workers [2,3] on solid solution $\mathrm{Mg}-2 \mathrm{Sn}$ and $\mathrm{Mg}-5 \mathrm{Sn}$ alloys have shown evidence that the corrosion film surface of $\mathrm{Mg}-2 \mathrm{Sn}$ and $\mathrm{Mg}-5 \mathrm{Sn}$ alloys is composed of a laminar inner layer and outer layer of plate like $\mathrm{Mg}(\mathrm{OH})_{2}$ and $\mathrm{MgO}$ with elemental Sn enrichment in the inner layer and on the $\mathrm{Mg}$ metal surface. The 
compactness of the outer layer increased with increasing Sn content which was attributed to decreased $\mathrm{H}_{2}$ evolution on the surface with increasing $\mathrm{Sn}$ concentration. These observations are in agreement with this work where the compactness of the black film formed on $\mathrm{Mg}-5 \mathrm{Sn}$ and $\mathrm{Mg}$ 10Sn alloys would certainly provide a better passive barrier film than the typically porous $\mathrm{Mg}(\mathrm{OH})_{2}$ film formed on $\mathrm{Mg}$ alloys during corrosion. Yang and co-workers also provided evidence that a small amount of a tin oxide formed on top of the inner corrosion layer. The authors concluded that the identity of the oxide was $\mathrm{SnO}_{2}$ however it is also possible that the oxide could be $\mathrm{SnO}$ as the difference in binding energy between the two oxides is $0.6 \mathrm{eV}$. They did not state if valence band spectrum were taken which would differentiate the two. $\mathrm{SnO}_{2}$ was not observed by the Raman spectroscopy results in this study (Figure 6.8) but instead, a species resembling that of $\mathrm{SnO}$ was observed. It be dehydrated $\mathrm{Sn}(\mathrm{OH})_{2}$ as the oxidation sequence of $\mathrm{Sn}$ is cited to be $\mathrm{Sn} \rightarrow$ $\mathrm{Sn}(\mathrm{OH})_{2} \rightarrow \mathrm{Sn}(\mathrm{OH})_{4} \rightarrow \mathrm{SnO}_{2}[2,14]$ in water. Dehydration could account for the slight Raman shift of the $\mathrm{SnO}$ standard compared to the peaks observed on $\mathrm{Mg}$-Sn alloys while the $\mathrm{SnO}_{2}$ standard did not resemble any of the observed Raman peaks. However, $\mathrm{SnO}$ is known to be blueish black in appearance while $\mathrm{Sn}(\mathrm{OH})_{2}$ is white [15] which would indicate $\mathrm{SnO}$ being the identity of the film when combined with the Raman results. In either case, $\mathrm{Sn}(\mathrm{OH})_{2}$ or $\mathrm{SnO}$ formation on the $\mathrm{Mg}$ surface would be beneficial to the corrosion resistance as both species are stable over a broad range of $\mathrm{pH}$ as shown in the predominance diagram in Figure 6.17. However, it is unclear how $\mathrm{Sn}$ is oxidizing at the potentials measured on the $\mathrm{Mg}$ surface. The OCP of $\mathrm{Mg}$-Sn alloys measured in this study lie below $-1.58 \mathrm{~V}_{\mathrm{SCE}}$ or $-1.34 \mathrm{~V}_{\mathrm{SHE}}$. For oxidation of $\mathrm{Sn}$ to occur, the thermodynamic potential for oxidation must be below the OCP of the Mg-Sn alloy. The standard oxidationreduction reactions and potentials for the sequence $\mathrm{Sn} \rightarrow \mathrm{Sn}(\mathrm{OH})_{2} \rightarrow \mathrm{Sn}(\mathrm{OH})_{4} \rightarrow \mathrm{SnO}_{2}$ are given by [16]: 


$$
\begin{array}{cr}
\mathrm{Sn}+2 \mathrm{H}_{2} \mathrm{O}=\mathrm{Sn}(\mathrm{OH})_{2}+2 \mathrm{H}^{+}+2 e^{-} ; \mathrm{E}=-0.091-0.0591 p \mathrm{H} & \text { Equation 6.8 } \\
\mathrm{Sn}(\mathrm{OH})_{2}+2 \mathrm{H}_{2} \mathrm{O}=\mathrm{Sn}(\mathrm{OH})_{4}+2 \mathrm{H}^{+}+2 e^{-} ; \mathrm{E}=+0.075-0.0591 p H & \text { Equation 6.9 } \\
\mathrm{Sn}(\mathrm{OH})_{4}=\mathrm{SnO}_{2}+2 \mathrm{H}_{2} \mathrm{O} & \text { Equation 6.10 }
\end{array}
$$

These oxidation-reduction potentials indicate that oxidation of Sn through this mechanism is not thermodynamically likely even at $\mathrm{pH}=10.25$ where the calculated oxidation-reduction potentials for Equation 6.8 and Equation 6.9 are $-0.937 \mathrm{~V}_{\mathrm{SCE}}$ and $-0.771 \mathrm{~V}_{\mathrm{SCE}}$ respectively. Even if the $\mathrm{Sn}$ enriched film was nano porous, the reduction in oxidation-reduction potential is only approximately $110 \mathrm{mV}$ for a $1 \mathrm{~nm}$ radius particle using the Gibbs-Thompson equation [17]:

$$
\Delta E=-\frac{2 \gamma \Omega}{n F r}
$$

where $\gamma$ is the surface energy of $\mathrm{Sn}, 0.650 \mathrm{~J} / \mathrm{m}^{2}[18], \Omega$ is the molar volume of $\mathrm{Sn}, 1.629 \times 10^{-5} \mathrm{~m}^{3}$, $\mathrm{n}$ is the number of electrons transferred, $\mathrm{F}$ is Faraday's constant, and $\mathrm{r}$ is the particle radius. Other effects which may lead to the electrochemical oxidation of Sn are complexation of the electrolyte and decrease in the metal-metal bond strength with an increase in wt $\% \mathrm{Sn}$ as predicted by the liquidus surface of the binary phase diagram in Figure 6.1 which may promote oxidation of $\mathrm{Sn}$ when alloyed.

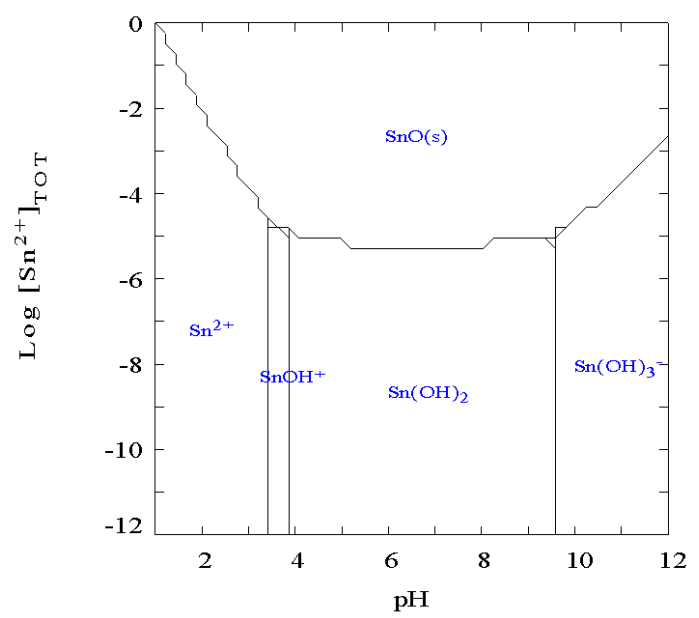

Figure 6.17. Predominance diagram for $\mathrm{Sn}^{2+}$ calculated using the MEDUSA software package. 


\subsubsection{Performance of Mg-Sn Alloys for Sacrificial Protection of AZ31B-H24}

Zero resistance ammeter testing of bulk Mg-Sn alloys with AZ31B showed excellent protection of AZ31B compared to couples with CP Mg or WE43. This is likely due to the combined effects of increased passivity and decreased cathodic kinetics of Mg-Sn alloys which is in contrast to traditional sacrificial cathodic protection [19]. Chapter 4 quantified the average fraction of selfcorrosion of the anodes in the couple. The self-corrosion fraction is determined by:

$$
\frac{I_{d}^{A}-I_{T}^{A}}{I_{d}^{A}} \times 100 \%
$$

Equation 6.12

where $I_{d}^{A}$ is the dissolution rate of the anode in a galvanic couple measured by mass loss and $I_{T}^{A}$ is the total anodic current measured by the potentiostat i.e. the galvanic couple current. This equation implies that the rate of persistent hydrogen evolution on the surface due to the NDE is large when the self-corrosion fraction is large. In this study, the average self-corrosion fraction for $\mathrm{Mg}-\mathrm{Sn}$ couples in this study was found to be $77 \%, 70 \%$, and $77 \%$, respectively, for $\mathrm{Mg}-1 \mathrm{Sn}, \mathrm{Mg}-5 \mathrm{Sn}$, and Mg-10Sn. These values are similar to the self-corrosion fraction of coupled WE43 (75\%) which showed better sacrificial performance than $\mathrm{CP} \mathrm{Mg}$ (93\%). Thus, sacrificial cathodic protection will be the best when this parameter is minimized. This is rationalized by accounting for the total cathodic current in the electrochemical system. The cathodic protection of metals is improved as cathodic polarization is increased due to decreases in the residual anodic reaction rate on the protected metal. If there is a persistent cathodic reaction on the anode surface, as in the case of $\mathrm{Mg}$ alloys, then the cathodic polarization of the cathode will be reduced from its theoretical value in the absence of any cathodic reaction on the anode and dissolution will remain high as observed on AZ31B. The improved performance in sacrificial cathodic protection of $\mathrm{Mg}-\mathrm{Sn}$ alloys in comparison to WE43 is attributed to the slow intrinsic cathodic kinetics on this alloy and low 
anodically enhanced cathodic activity of $\mathrm{Mg}-\mathrm{Sn}$ alloys despite a similar value for fraction selfcorrosion.

\subsubsection{Effect of Polarity Reversal on Sacrificial Cathodic Protection}

The Mg-10Sn alloy displayed the lowest corrosion rate and highest passivity of the $\mathrm{Mg}-\mathrm{Sn}$ alloys tested in this investigation. However, polarity reversal was observed for a brief period of time when coupled to AZ31B while polarity reversal was not observed for $\mathrm{Mg}-1 \mathrm{Sn}$ or $\mathrm{Mg}-5 \mathrm{Sn}$. This suggests that the optimal composition of $\mathrm{Mg}-\mathrm{Sn}$ lies between 5-10 wt\% $\mathrm{Sn}$ in order to prevent polarity reversal from occurring with AZ31B while producing the best coupled corrosion rates. Polarity reversal may not be of concern in the long-term protection of AZ31B beyond 24 hours if the dissolution of Mg-10Sn and AZ31B is better than that of other Mg-Sn alloys but this is not clear at this time. This would also depend on the thickness of a Mg-Sn alloys film on AZ31B surfaces and the ability to provide sacrificial protection as a thin film.

ZRA testing of Mg-Sn alloys thin films deposited on AZ31B were ineffective based on multiple observations. First, some portion of the film was oxidized and there was little Sn in the film but was sequestered in small magnesium oxide particles. Sacrificial protection cannot occur if the film is already oxidized as no cathodic current can be supplied to base AZ31B. This is evident in the optical images in Figure 6.15 where heavy corrosion damage is observed on both coated and non-coated surfaces. For the deposited metallic film to be effective, it would likely have to be much thicker on the order of several micrometers vs. the $225 \mathrm{~nm}$ film produced in this study. Thus, longer deposition times are needed to produce such a coating. However, even a $10 \mu \mathrm{m}$ film would not survive very long as the approximate dissolution rate of coupled $\mathrm{Mg}-\mathrm{Sn}$ alloys is $320 \mu \mathrm{m} / \mathrm{year}$ (12 mpy). With respect to the oxidization of the film during deposition, an alternate deposition technique where the deposition pressure is lower than that used in this experiment could be helpful 
to reduce the concentration of oxygen in the chamber in addition to purging the chamber with a heavy gas such as Argon to remove more oxygen from the chamber. However, this does not guarantee that the film won't oxidize when exposed to the ambient air when removing from the vacuum chamber. As the coating produced in this experiment provides little protection, the ZRA behavior is similar to that of AZ31B coupled to AZ31B where polarity reversal is governed by the small differences in microstructure.

\subsubsection{Future Prospects of Mg-Sn Metallic Coatings for Sacrificial Cathodic Protection of Mg-based Alloys}

This chapter has demonstrated that sacrificial cathodic protection of AZ31B-H24 can be improved through the use of Mg-Sn based anodes. However, the implementation and practical application of $\mathrm{Mg}-\mathrm{Sn}$ sacrificial anodes may lie in as the pigment in an organic primer system. The primer would be able to provide an improved barrier to corrosion while metallic $\mathrm{Mg}$-Sn alloy pigments would be able to provide coupled cathodic protection to scratches and defects. To date, only pure Mg-rich primers have been studied for use on $\mathrm{Mg}$ [20-22] but Mg-Sn alloys present an opportunity to improvement of the protection offered by Mg-rich primers. 


\subsection{Conclusions}

1. The corrosion rate of solid solution $\mathrm{Mg}-\mathrm{Sn}$ alloys was shown to decrease greatly with increased Sn content. This is likely due to enrichment of $\mathrm{Sn}$ and formation of a $\mathrm{SnO}$ or $\mathrm{Sn}(\mathrm{OH})_{2}$ on the corroding surface which showed increased passivity and decreased cathodic kinetics.

2. The anodically enhanced cathodic kinetics of $\mathrm{Mg}$-Sn alloys was small in comparison to HP $\mathrm{Mg}$ due to the low HER exchange current density of Sn and increased fraction of Sn on the surface. The change in cathodic kinetics was the least for $\mathrm{Mg}-10 \mathrm{Sn}$ due to formation of a partially passive thin film compared to $\mathrm{Mg}-5 \mathrm{Sn}$ and $\mathrm{Mg}-1 \mathrm{Sn}$ which experienced film breakdown and filiform corrosion.

3. Mg-Sn alloys have shown improved sacrificial cathodic protection of Mg alloy AZ31B compared to CP Mg and WE43 anode materials due decreased cathodic kinetics of Mg-Sn alloys and low intrinsic corrosion rate. The anodic Tafel slope of $\mathrm{Mg}$ increased with increasing Sn concentration which lead a more polarizable electrode. This increased polarizability is not desired for a sacrificial anode and led, in part, to polarity reversal AZ31B coupled to Mg-10Sn. However, the polarity switched back to Mg-10 being the anode after a brief period of time and was not detrimental to long term sacrificial performance.

4. Deposition of Mg-Sn alloys on AZ31B by pulsed laser deposition was ineffective due to oxidation of the film during the deposition process. As such, limited cathodic protection was supplied to non-coated AZ31B during zero resistance ammeter (ZRA) testing. Deposition of sacrificial Mg-Sn based coating may be improved using other deposition 
parameters or deposition techniques which produce micrometer scale films with low oxidation.

5. Metallic Mg-Sn based anode materials should be explored for use as a pigment in primer coatings for the theorized improvement of pure $\mathrm{Mg}$-rich particles in primer coatings on $\mathrm{Mg}$ alloys. 


\subsection{References}

[1] H.-Y. Ha, J.-Y. Kang, J. Yang, C.D. Yim, B.S. You, "Role of Sn in corrosion and passive behavior of extruded Mg-5 wt\%Sn alloy," Corros. Sci. 102 , 355-362, 2016.

[2] J. Yang, C.D. Yim, B.S. You, "Effects of $\mathrm{Sn}$ in $\alpha-\mathrm{Mg}$ matrix on properties of surface films of $\mathrm{Mg}-\mathrm{xSn}(\mathrm{x}=0,2,5 \mathrm{wt} \%)$ alloys: Effects of $\mathrm{Sn}$ on properties of surface films of $\mathrm{Mg}-\mathrm{Sn}$ alloys," Mater. Corros. 67 (5) , 531-541, 2016.

[3] J. Yang, C.D. Yim, B.S. You, "Characteristics of Surface Films Formed on Mg-Sn Alloys in $\mathrm{NaCl}$ Solution,” J. Electrochem. Soc. 163 (8) , C395-C401, 2016.

[4] S. Trasatti, "Work function, electronegativity, and electrochemical behaviour of metals," J. Electroanal. Chem. Interfacial Electrochem. 39 (1) , 163-184, 1972.

[5] K.R. Limmer, K.S. Williams, J.P. Labukas, J.W. Andzelm, "First Principles Modeling of Cathodic Reaction Thermodynamics in Dilute Magnesium Alloys," CORROSION. 73 (5), 506-517, 2017.

[6] R.L. Liu, S. Thomas, J.R. Scully, G. Williams, N. Birbilis, "An Experimental Survey of the Cathodic Activation of Metals Including $\mathrm{Mg}, \mathrm{Sc}, \mathrm{Gd}, \mathrm{La}, \mathrm{Al}, \mathrm{Sn}, \mathrm{Pb}$, and $\mathrm{Ge}$ in Dilute Chloride Solutions of Varying pH," CORROSION. 73 (5) , 494-505, 2017.

[7] A.A. Nayeb-Hashemi, J.B. Clark, Phase Diagram of Binary Magnesium Alloys, ASM International, Metals Park, Ohio, 1988.

[8] J.R. Scully, F. Presuel-Moreno, M. Goldman, R.G. Kelly, N. Tailleart, "User-selectable barrier, sacrificial anode, and active corrosion inhibiting properties of $\mathrm{Al}-\mathrm{Co}-\mathrm{Ce}$ alloys for coating applications," Corrosion. 64 (3) , 210-229, 2008.

[9] F. Presuel-Moreno, M.A. Jakab, N. Tailleart, M. Goldman, J.R. Scully, "Corrosion-resistant metallic coatings," Mater. Today. 11 (10) , 14-23, 2008.

[10] A.D. King, N. Birbilis, J.R. Scully, "Accurate Electrochemical Measurement of Magnesium Corrosion Rates; a Combined Impedance, Mass-Loss and Hydrogen Collection Study," Electrochimica Acta. 121 , 394-406, 2014.

[11] L.G. Bland, A.D. King, N. Birbilis, J.R. Scully, "Assessing the Corrosion of Commercially Pure Magnesium and Commercial AZ31B by Electrochemical Impedance, Mass-Loss, Hydrogen Collection, and Inductively Coupled Plasma Optical Emission Spectrometry Solution Analysis," CORROSION. 71 (2) , 128-145, 2015.

[12] G.L. Makar, J. Kruger, “Corrosion of magnesium," Int. Mater. Rev. 38 (3) , 138-153, 1993.

[13] Z.W. Seh, J. Kibsgaard, C.F. Dickens, I. Chorkendorff, J.K. Nørskov, T.F. Jaramillo, "Combining theory and experiment in electrocatalysis: Insights into materials design," Science. 355 (6321), eaad4998, 2017.

[14] P.E. Alvarez, S.B. Ribotta, M.E. Folquer, C.A. Gervasi, J.R. Vilche, "Potentiodynamic behaviour of tin in different buffer solutions," Corros. Sci. 44 (1) , 49-65, 2002.

[15] A.F. Wells, Structural inorganic chemistry, 5th ed, Clarendon Press ; Oxford University Press, Oxford [Oxfordshire] : New York, 1984.

[16] M. Pourbaix, Atlas of Electrochemical Equilibria in Aqueous Solutions, Pergamon Press, n.d.

[17] L. Tang, B. Han, K. Persson, C. Friesen, T. He, K. Sieradzki, G. Ceder, "Electrochemical Stability of Nanometer-Scale Pt Particles in Acidic Environments," J. Am. Chem. Soc. 132 (2) , 596-600, 2010.

[18] W.R. Tyson, "Surface energies of solid metals," Can. Metall. Q. 14 (4) , 307-314, 1975.

[19] D.A. Jones, Principles and Prevention of Corrosion, Pearson-Prentice Hall, 2005. 
[20] X. Lu, Y. Zuo, X. Zhao, S. Shen, "The Effects of Magnesium Particles in Mg-rich Primers Applied on AZ91D Magnesium Alloy," Int. J. Electrochem. Sci. 10 (11) , 9586-9604, 2015.

[21] X. Lu, Y. Zuo, X. Zhao, Y. Tang, "The improved performance of a Mg-rich epoxy coating on AZ91D magnesium alloy by silane pretreatment," Corros. Sci. 60 , 165-172, 2012.

[22] X. Lu, Y. Zuo, X. Zhao, Y. Tang, X. Feng, "The study of a Mg-rich epoxy primer for protection of AZ91D magnesium alloy," Corros. Sci. 53 (1) , 153-160, 2011. 


\section{Synthesis of Findings and Suggestions for Future Research}

\subsection{Synthesis of Findings}

This dissertation investigated critical factors governing $\mathrm{Mg}$ corrosion and how an understanding of these factors can be used to design and produce Mg-based sacrificial anodes for the cathodic protection of $\mathrm{Mg}$ alloy AZ31B-H24. It has been demonstrated that the corrosion performance of sacrificial anodes for AZ31B-H24 is improved by alloys which have the combination of a low exchange current density for the hydrogen evolution reaction (HER) and a low fraction of self-corrosion in a galvanic couple. Of the anodes studied in this dissertation, the ranking of sacrificial anodes follows $\mathrm{Mg}-5 \mathrm{Sn}>\mathrm{Mg}-1 \mathrm{Sn}>\mathrm{Mg}-10 \mathrm{Sn}>\mathrm{WE} 43>\mathrm{CP} \mathrm{Mg}$ where Mg5Sn produced the lowest dissolution rate of AZ31B-H24 when galvanically coupled. While $\mathrm{Mg}$ 10Sn possessed the highest corrosion resistance of the $\mathrm{Mg}$-Sn alloys produced in this dissertation, polarity reversal of the galvanic couple occurred which lead to AZ31B being anodically polarized for a brief period of time. This is related to the increasing polarizability with increasing wt $\% \mathrm{Sn}$ meaning that the galvanic couple potential becomes close to the OCP of AZ31B-H24. An ideal sacrificial anode should be non-polarizable in order to resist changes in galvanic couple potential and increase the level of cathodic polarization of the metal to be protected. The polarity reversal of Mg-10Sn was short lived as the cathodic kinetics decreased with time which decreased the corrosion potential of the alloy while outcompeting decreases in the anodic current density which would nominally increase the OCP.

The manifestation of the negative difference effect of Mg alloys was shown to be a strong function of noble element impurity enrichment on the dissolving $\mathrm{Mg}$ surface and formation of stable, protective dissolution films. The formation of a stable, protective dissolution film serves to reduce the fraction of anodically active sites where the HER can proceed. This was shown for HP 
$\mathrm{Mg}$ anodically dissolved in $0.1 \mathrm{M} \mathrm{Na}_{2} \mathrm{SO}_{4}$ where the $\mathrm{NDE}$ was reduced greatly due to a more stable dissolution film which reduced the number of available site on the $\mathrm{Mg}$ surface for further $\mathrm{Mg}$ dissolution and hydrogen evolution compared to the porous films typically observed during $\mathrm{Mg}$ dissolution in chlorides. Furthermore, the NDE was not present during Mg dissolution in $0.1 \mathrm{M}$ TRIS which restricted the formation of a dissolution film and did not allow for the enrichment of noble metals on the dissolving Mg surface due to TRIS's ability to chelate metal ions in solution and prevent replating. The manifestation of the NDE is therefor likely to be due to a film forming mechanism that enables capture of noble elements on dissolving Mg surfaces.

The inhibition of AZ31B-H24 via $\mathrm{La}^{3+}$ and $\mathrm{Gd}^{3+}$ ions in solution was limited. It was shown that the anodic and cathodic kinetics of AZ31B-H24 increased with increasing concentration of $\mathrm{La}^{3+}$ or $\mathrm{Gd}^{3+}$. As such, the use of La and Gd alloying additions to a multifunctional sacrificial $\mathrm{Mg}$ alloy is not advised but small additions as an alloying element may be beneficial. Moreover, the use of chemical stability diagrams to predict the dissolution trajectory of corroding $\mathrm{Mg}$ was successfully implemented which provides a foundation for use of these diagrams to predict other phenomena for $\mathrm{Mg}$ corrosion and explained the negative effects of high concentrations of inhibitors.

\subsection{Suggestions for Future Work}

The findings of this dissertation have led to a number of additional research questions and possibilities for development of sacrificial anode based cathodic protection of $\mathrm{Mg}$ alloys. The following is suggested:

- Investigate alternative deposition conditions/techniques for the production of metal coatings on AZ31B-H24. One such possibility is alloying of $\mathrm{Sn}$ on AZ31B-H24 surfaces via the combination of coating pure Sn on the surface followed by laser surface modification. 
- Investigate the use of Mg-Sn alloys for use as a pigment in organic primer coatings for $\mathrm{Mg}$ alloys.

- Investigate the galvanic couple behavior of $\mathrm{Mg}$-Sn anodes with different anode to cathode ratios.

- Perform further characterization of Mg-Sn alloys to determine a thermodynamically founded explanation for the oxidation of $\mathrm{Sn}$ in a $\mathrm{Mg}$ matrix.

- Investigate the anodic dissolution behavior of $\mathrm{Mg}-\mathrm{Sn}$ based alloys for further characterization and insight of the NDE.

- Characterize the NDE of $\mathrm{Mg}$ in the different solutions investigated in this dissertation through the use of the scanning vibrating electrode technique to resolve the spatial distribution of anodic and cathodic activity on dissolving $\mathrm{Mg}$ surfaces.

- Investigate use of other alloying additions in combination with $\mathrm{Sn}$ to $\mathrm{Mg}$ which reduce the cathodic kinetics such as Ge.

- Field exposures of Mg-Sn coated AZ31B-H24. Extend to atmospheric environments with $\mathrm{NaCl}, \mathrm{MgCl}_{2}$, and carbonates. 